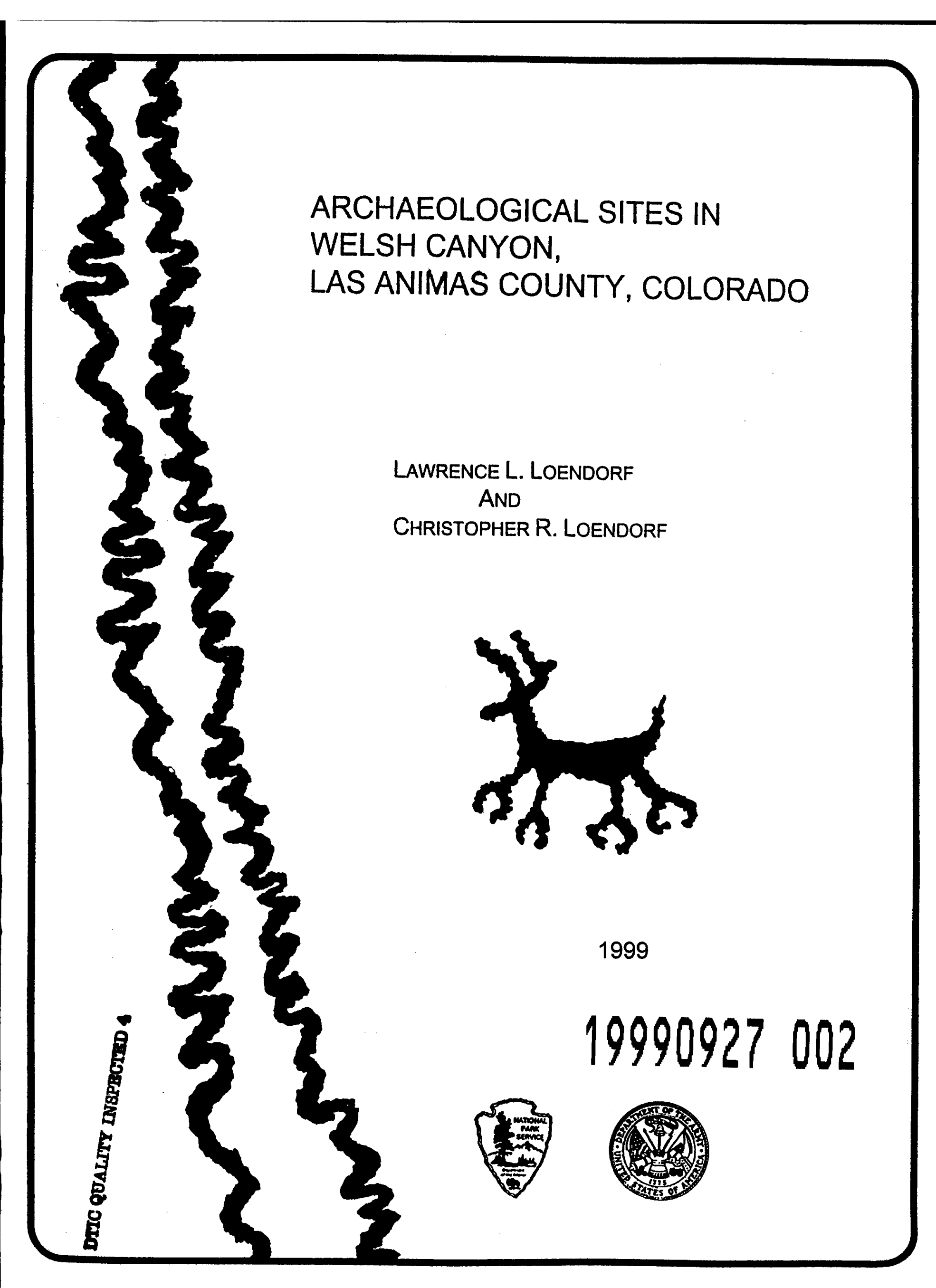




\title{
ARCHAEOLOGICAL SITES IN WELSH CANYON, LAS ANIMAS COUNTY, COLORADO
}

\author{
by \\ Lawrence L. Loendorf \\ and \\ Christopher R. Loendorf
}

1999

Project Administered through Midwest Archeological Center National Park Service

\author{
Prepared by \\ The Department of Sociology and Anthropology \\ New Mexico State University \\ Las Cruces, New Mexico
}

The project was prepared for and funded by the Directorate of Environmental Compliance and Management, Department of the Army, Fort Carson, Colorado. 


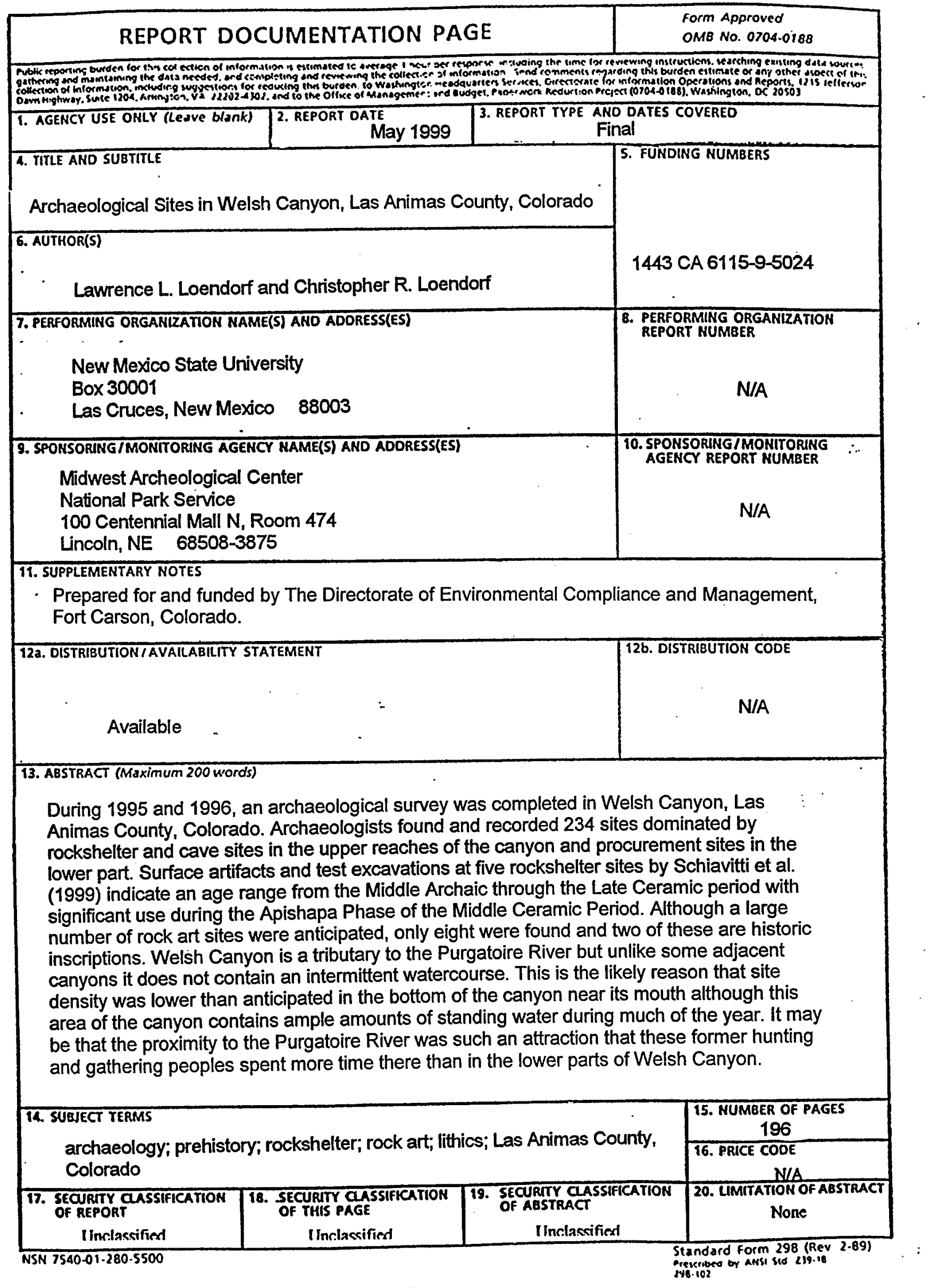


During 1995 and 1996, an archaeological survey was completed in Welsh Canyon, Las Animas County, Colorado. In this survey, archaeologists found and recorded 234 sites that are dominated by rock shelter and cave sites in the upper reaches of the canyon and quartzite procurement sites in the lower part of the canyon. Surface artifacts and subsequent test excavations at five rockshelter sites by Schiavitti et al. (1999) indicate an age range from the Middle Archaic through the Late Ceramic Period with significant use during the Apishapa Phase of the Middle Ceramic Period. Although a large number of rock art sites were anticipated, only eight were found and two of these are historic inscriptions. Welsh Canyon is a tributary to the Purgatoire River but unlike some adjacent canyons it does not contain an intermittent watercourse. This is the likely reason that site density was lower than anticipated in the bottom of the canyon near its mouth although this area of the canyon contains ample amounts of standing water during much of the year. It may be that the proximity to the Purgatoire River was such an attraction that these former hunting and gathering peoples spent more time there than in the lower parts of Welsh Canyon.

\section{Popular abstract}

During an archaeological survey in Welsh Canyon, Las Animas County, Colorado, 226 sites were discovered. Welsh Canyon, a tributary to the Purgatoire River, drains the upland prairie to the west and the Black Hill region to the north. Archaeological survey is the process where a group of archaeoligsts walk across the ground, spaced 20 meters apart, in search of any clues that indicate peoples were at the location in the past. The most common evidence in Welsh Canyon is fragments of stone that represent residue from the manufacture of stone tools but occasionally a few broken pieces of pottery are also found. Significant sites found in Welsh Canyon include several groups of rock shelters near the upper reaches of the canyon or along the rim in the lower canyon. The rock shelter sites are important because some contain soil deposits, intermixed with stone tools, other artifacts, the remains of house walls, and remnants of fires, and these are found in layers that can be excavated to learn the sequence and the length of time humans have used the region. Excavations in some of the Welsh Canyon rock shelters indicate intensive use during by hunters and gatherers in Apishapa Phase, 600 to 1200 years ago. 


\section{Acknowledgements}

A major archaeological survey in rough terrain can be a daunting adventure and Welsh Canyon is a rugged place that could make research very difficult. Thanks to the help of a good field crew, who are named in the body of the text of this report, it was possible to complete the project with minimal problems. The support of Tom Warren, Mary Barber and Steve Chomko from the Department of the Army, Directorate of Environmental Compliance and Management is appreciated. Melissa Connor coordinated the project for the National Park Service and her help is appreciated. Other individuals who either read or edited sections of this report include Vince Schiavitti, Mark Owens, Bonnie Newman, Marilyn Mueller, and Randy Korgel. We thank them for their help. The help and support offered by Renee Beltran in the Department of Sociology and Anthropology at New Mexico State University is essential to the success of all the projects at Pinon Canyon. Thank you, Renee.

For a variety of reasons, this report is past due. It is important to recognize, however, that the site forms, the major paperwork generated in archaeological survey were submitted on schedule. Work on the recommendations offered on those forms has already begun with test excavations at some of the important sites. Thus even though this report may be slow in completion, the sites have not been overlooked and that is the most important consideration. 


\section{WELSH CANYON SURVEY}

\section{PREFACE}

The archeological survey and evaluations reported in this manuscript are an important part of the Fort Carson Cultural Resources Management Program whose goal is to maintain the largest possible area for military training while protecting significant cultural and environmental resources. The current study is part of an integrated program that takes a long-term systematic approach to meeting identification, evaluation, and resource protection requirements mandated by the National Historic Preservation Act. While meeting legislated requirements, this project also provides a valuable contribution to our knowledge of the prehistory and resources of Las Animas County, Colorado. Under a cooperative agreement, New Mexico State University operating through the National Park Service, Midwest Archeological Center, provides assistance in meeting Fort Carson's cultural resources goals.

Fort Carson began cultural resources studies immediately following the purchase of the lands that became the Pinon Canyon Maneuver Site in 1983. The Cultural Resources Program takes a multidisciplinary approach, combining archeological theory and historical methods with geological, geomorphological, botanical, and statistical techniques and procedures in order to focus its efforts to locate, evaluate, and protect significant cultural properties. Professional studies and consultations with Native American tribes have resulted in the identification of National Register eligible sites and districts. The cultural resources of Fort Carson and the Pinon Canyon Maneuver Site represent all major prehistoric and historic cultural periods recognized in the Great Plains and Rocky Mountains. Sites of the Paleoindian, Archaic, Ceramic, and Protohistoric periods are present, as are sites from the Fur Trade era, $19^{\text {th }}$ century Hispanic and Euroamerican settlement, early $20^{\text {th }}$ century homesteading and ranching, and World War II and Cold War era military sites.

The Cultural Resources Management Program is in the Directorate of Environmental Compliance and Management (DECAM). The directorate is tasked with maintaining Fort Carson's compliance with federal, state, and local environmental laws and mandates. The DECAM holistic management philosophy maintains that all resources are interrelated. Because decisions affecting one resource will impact other resources, the decisions we make today will affect the condition of Department of Army lands and resources for future training, research, and recreation. Mission requirements, training resources, wildlife, range, soil, hydrology, air, and recreation influence cultural resources management decisions. Integrating compliance and resource protection concerns into a comprehensive planning process reduces the time and effort expended on the compliance process, minimizes conflicts between resource 
protection and use, allows flexibility in project design, minimizes costs, and maximizes resource protection.

Federal laws protect the resources on the Pinon Canyon Maneuver Site and Fort Carson. Theft and vandalism are federal crimes. Protective measures ensure that Army activity does not inadvertently impact significant cultural and paleontological sites. Fort Carson does not give out site location information nor are sites developed for public visitation. Similar resources are located in the Picketwire Canyonlands where public visits can be arranged through the U.S. Forest Service, Comanche National Grasslands in La Junta, Colorado.

Fort Carson endeavors to make results of the resource investigations available to the public and scientific communities. Technical reports on cultural resources are on file at the Fort Carson Curation Facility (Building 2420) and the Colorado State Historic Preservation Office and are available through the National Technical Information Service, Springfield VA. Non-technical reports on the prehistory, history and rock art of southeastern Colorado have been distributed to schools and public libraries in Colorado. Three video programs produced by Fort Carson are periodically shown on Public Broadcasting Stations. Fort Carson continues to demonstrate that military training and resource protection are mutually compatible goals.

Stephen A. Chomko

Cultural Resources Manager

Directorate of Environmental Compliance and Management Fort Carson, Colorado

April 1999 
INTRODUCTION

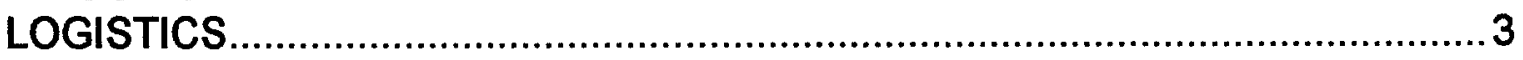

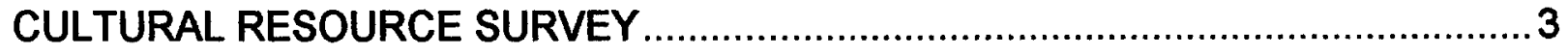

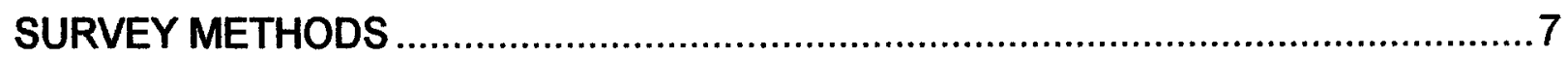

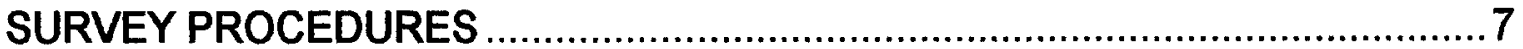

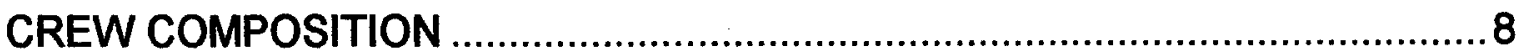

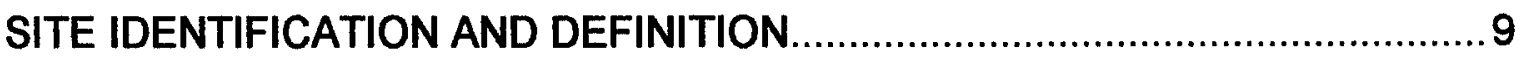

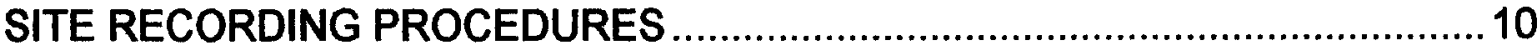

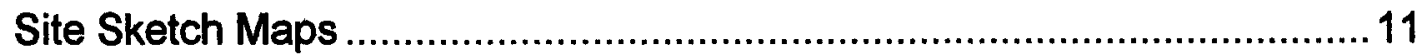

Management Data Form ..................................................................11

Prehistoric Components, Historic Components, or Rockart Supplemental

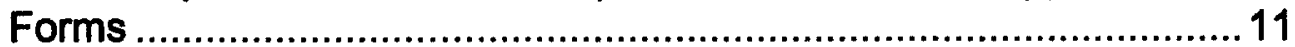

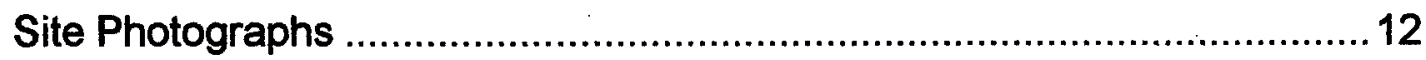

ARTIFACT RECORDING AND COLLECTION PROCEDURES ........................ 12

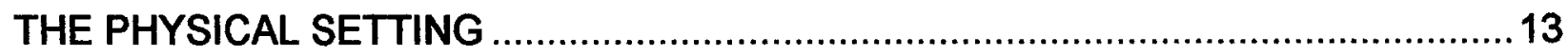

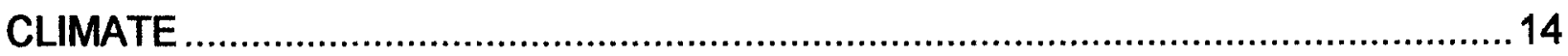

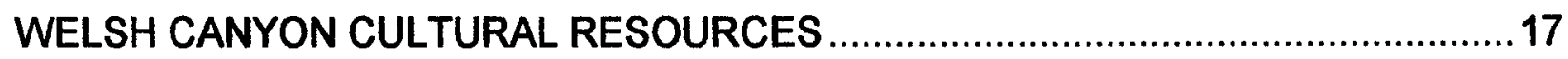

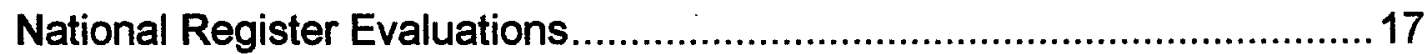

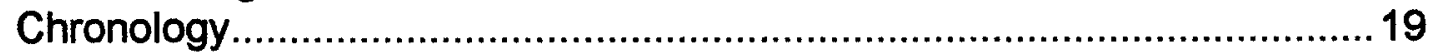

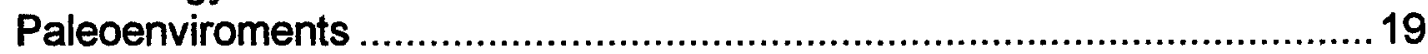

Settlement-Subsistence Systems.......................................................19

Exchange and Mobility .....................................................................20

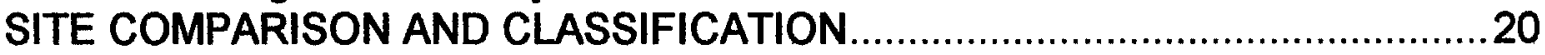

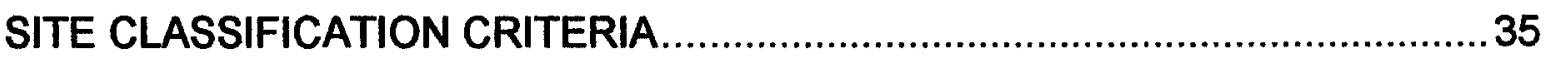

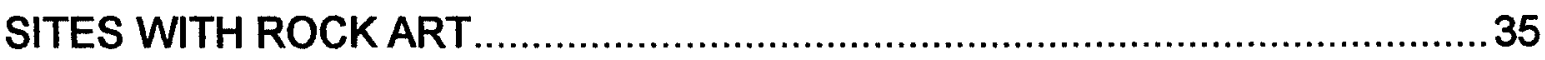

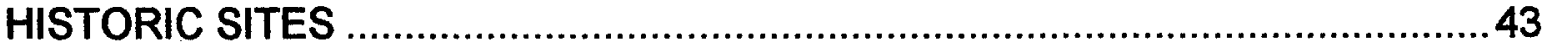

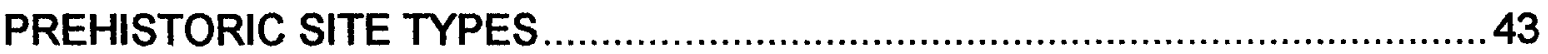

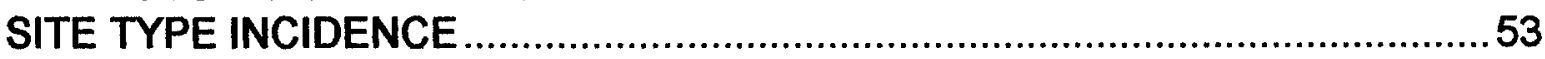

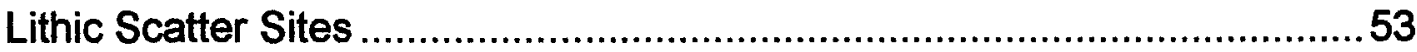

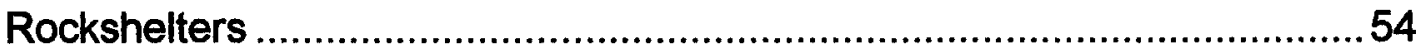

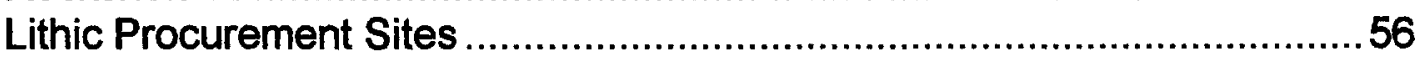

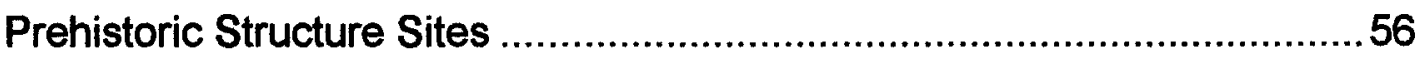

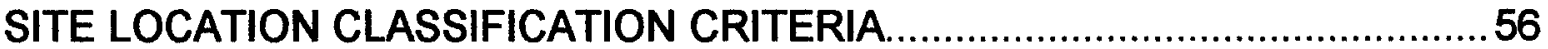

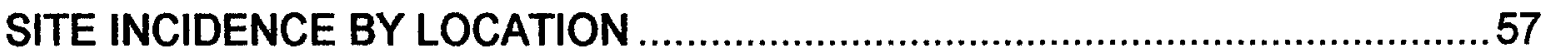

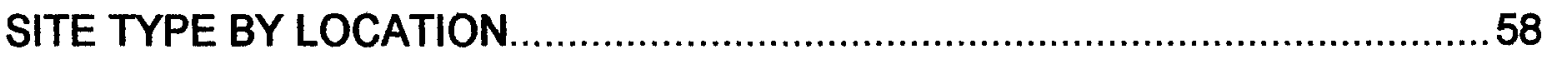

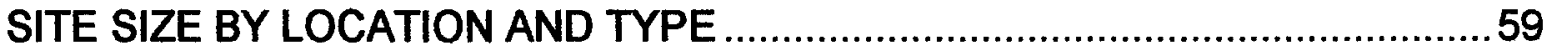


COLLECTED PREHISTORIC ARTIFACTS ….............................................62

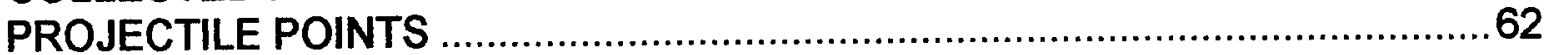

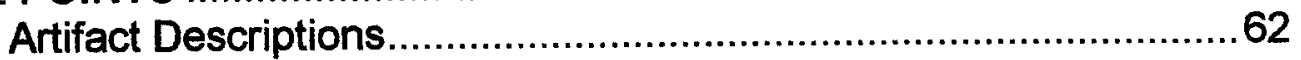

GROUNDSTONE76

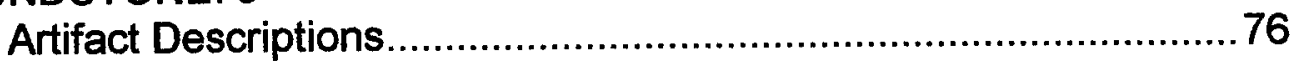

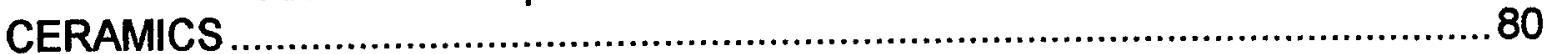

Artifact Descriptions ................................................................. 80

ARTIFACT AND FEATURE DISTRIBUTION BY SITE LOCATION AND TYPE ....82

Artifact and Feature Types.......................................................82

Artifact and Feature Distribution By Site Location .........................83

Artifact and Feature Distribution By Site Type............................. 84

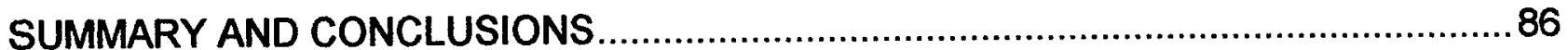

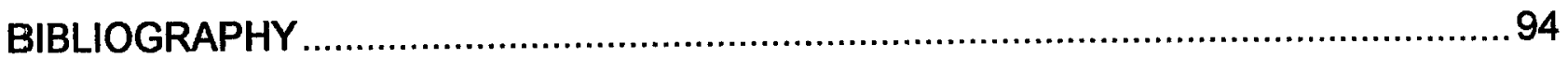

APPENDIX 


\section{LIST OF FIGURES}

FIGURE 1 Major Topographic Features of the Pinon Canyon Maneuver Site ........... 2

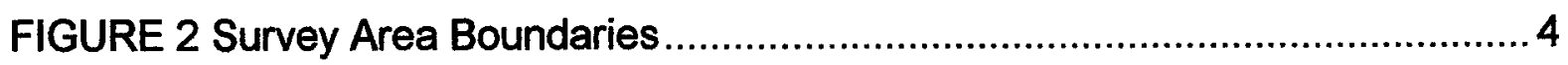

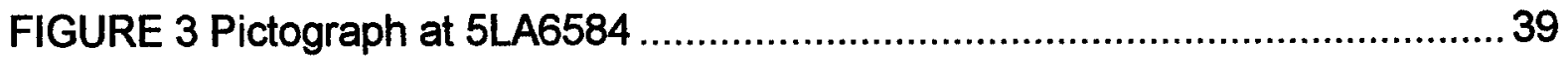

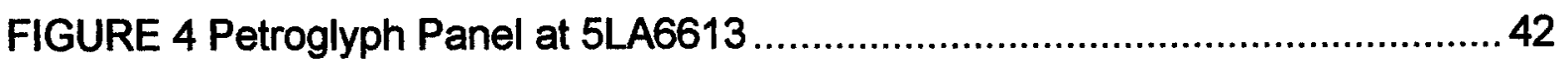

FIGURE 5 Sketch Map of Rock Shelter Site 5LA6598 ....................................... 45

FIGURE 6 Sketch Map of Rock Shelter with Stone Wall Site 5LA6603.................. 47

FIGURE 7 Sketch Map of Lithic Scatter Site 5LA6595 .........................................48

FIGURE 8 Sketch Map of Prehistoric Structure Site 5LA6799..............................51

FIGURE 9 Sketch Map of Lithic Procurement Site 5LA6888 …...........................52

FIGURE 10 Histogram of Site Are in Square Meters .......................................6

FIGURE 11 Boxplots of Site Size in Square Meters by Location ...........................60

FIGURE 12 Histogram of Site Area in Square Meters ......................................61

FIGURE 13 Age Range Estimates for Surface Collected Projectile Points ..............87

FIGURE 14 Midpoints of Projectile Points Age Range Estimates .......................... 88 


\section{LIST OF TABLES}

TABLE 1 Sites Identified in the 1995 - 1996 Survey of Welsh Canyon...................21

TABLE 2 Site Type by Location, 1995 - 1996 Welsh Canyon Survey Data ............ 54

TABLE 3 Artifact and Feature Distribution by Physiographic Zone.........................84

TABLE 4 Artifact and Feature Distribution by Site Type ...................................... 85 


\section{INTRODUCTION}

Welsh Canyon is a tributary canyon to the considerably larger canyon that confines the Purgatoire River in southeastern Colorado. Welsh Canyon enters the Purgatoire from the northwest, with dozens of separate arroyos in a fan-shape at its head and cutting into a single, deep canyon at its mouth. The portion of the canyon where it enters the Purgatoire River is on lands administered by the United States Forest Service, Comanche National Grasslands but the main canyon and its upper tributary arroyos are on lands administered by the Department of Army, Pinon Canyon Maneuver Site (PCMS) (Figure 1).

The Welsh Canyon cultural resource survey was completed in two field seasons. The first survey project was carried out between August 30, 1995 and October 13, 1995. Crew size varied during the project but two survey teams were maintained one supervised by Stephanie Crockett and the other by Bob Swain. Each crew generally completed survey on opposite sides of the canyon. Crewmembers included Anna Backer, Ann Phillips, Anita Schoen, Dennis Pry and Rusty Smith. A photographer, Hadley Harper, joined the project at its midpoint to photographically document the current condition of significant sites. A rock art recording specialist, Janet Lever, was employed for one ten day session but there was not a substantial amount of rock art found during the survey and part of her effort was devoted to other tasks.

We had two volunteers who assisted with the project. Jamie Schoen worked for the last ten-day session and because he is a trained archaeologist with prior experience in the PCMS his help was the equivalent of an experienced crew member. Another volunteer, Courtney Yilk, helped with rock art recording for four days. Although Courtney is an experienced rock art recording specialist, her assistance was less effective for the Welsh Canyon project because we found so few rock art sites. Rather than waste her effort, she traced petroglyphs found in previous research. Kerry Hackett who has prior experience in the PCMS managed the laboratory and office. Cooks were Elizabeth Fuller and Martha Marno.

Survey crews returned to the field to complete the survey of Welsh Canyon in a second session between May 15, 1996 and August 17, 1996. Crew size varied from session to session but throughout the project we maintained at least two survey teams. We initially started with three survey crews but discovered a greater need for a laboratory crew and thereafter maintained two primary field survey crews, one supervised by Chris Loendorf and the other by Randy Korgel. Crew members, at various times throughout the fieldwork, included Jane Arie, Anna Backer, Mike Flowers, Greg Johnson, Hadley Harper, Sherry Landis, Sylvia Marinas-Feliner, Judie McNew, Ann Owen, and Ann Phillips. 


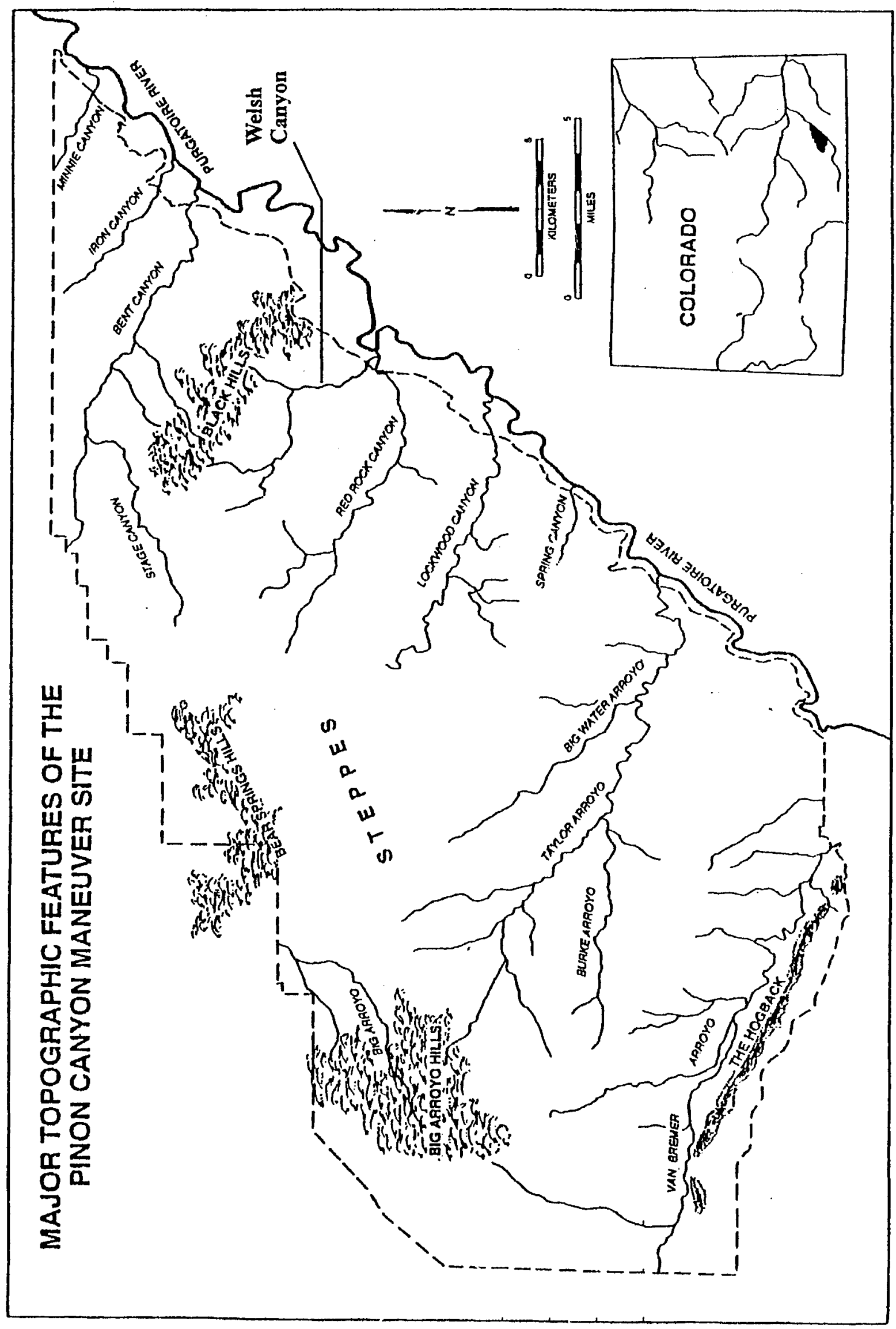

晜 
Hadley Harper again served as the project photographer and entered the field on several occasions to photographically document the current condition of significant sites that were located during the survey. Hadley also worked as a survey crewmember when the documentary photography was caught up. We had a single volunteer throughout the summer; John Gallegos came at the beginning and constructed the field showers and the water screen racks. He also kept up with camp maintenance, kept the water trailer filled, and traveled to town for various errands. During the last 40 field days, John served as an essential assistant to Sherry Landis, who had taken over the cooking chores. The initial cook, Nancy Nelson, left after the third 10-day session.

\section{LOGISTICS}

The 1995 research was directed from the Crowder Ranch facility. The former ranch house has become a very effective base for fieldwork and electricity, telephone service, and access to mail are especially helpful in operating a productive field project. The major problem with Crowder is the commute to Welsh Canyon that takes a full hour each direction.

Fortunately in the 1996 field season we were able to direct the project from the Red Rock's Research facility and this eliminated the problems with the long commute. Because this was the first use of the Red Rock Ranch for an archaeological project, initial days were spent building an outdoor shower and cleaning the facility. The Army was helpful in screening the porch to the bunkhouse so as to have a cool place to avoid the mosquitoes and gnats in the evening. As the fieldwork progressed, we constructed a water screening area and cleaned other outbuildings for storage and various uses. Two problems with Red Rocks are the lack of a telephone and the fluctuating electrical current which plays havoc with computers, but these are minor compared to the advantages of having the facility within a few kilometers of the survey area. Commute times were much more reasonable during the 1996 research.

Between June 26, 1996 and August 3, 1996, we shared the Red Rocks Research facility with a test excavation crew that ranged in size from 4 to 7 individuals. Because this crew ate with the survey personnel, it added to the workload of the cook and put extra stress on the camp facilities. At no point, however, did we feel the camp facilities were inadequate or over used.

\section{CULTURAL RESOURCE SURVEY}

The 1995 survey of Welsh Canyon started in the upper reaches of the large side canyons entering Welsh from the north (Figure 2). In this beginning effort we completed survey on the uplands between the tributary canyons, as well as within these canyons. 


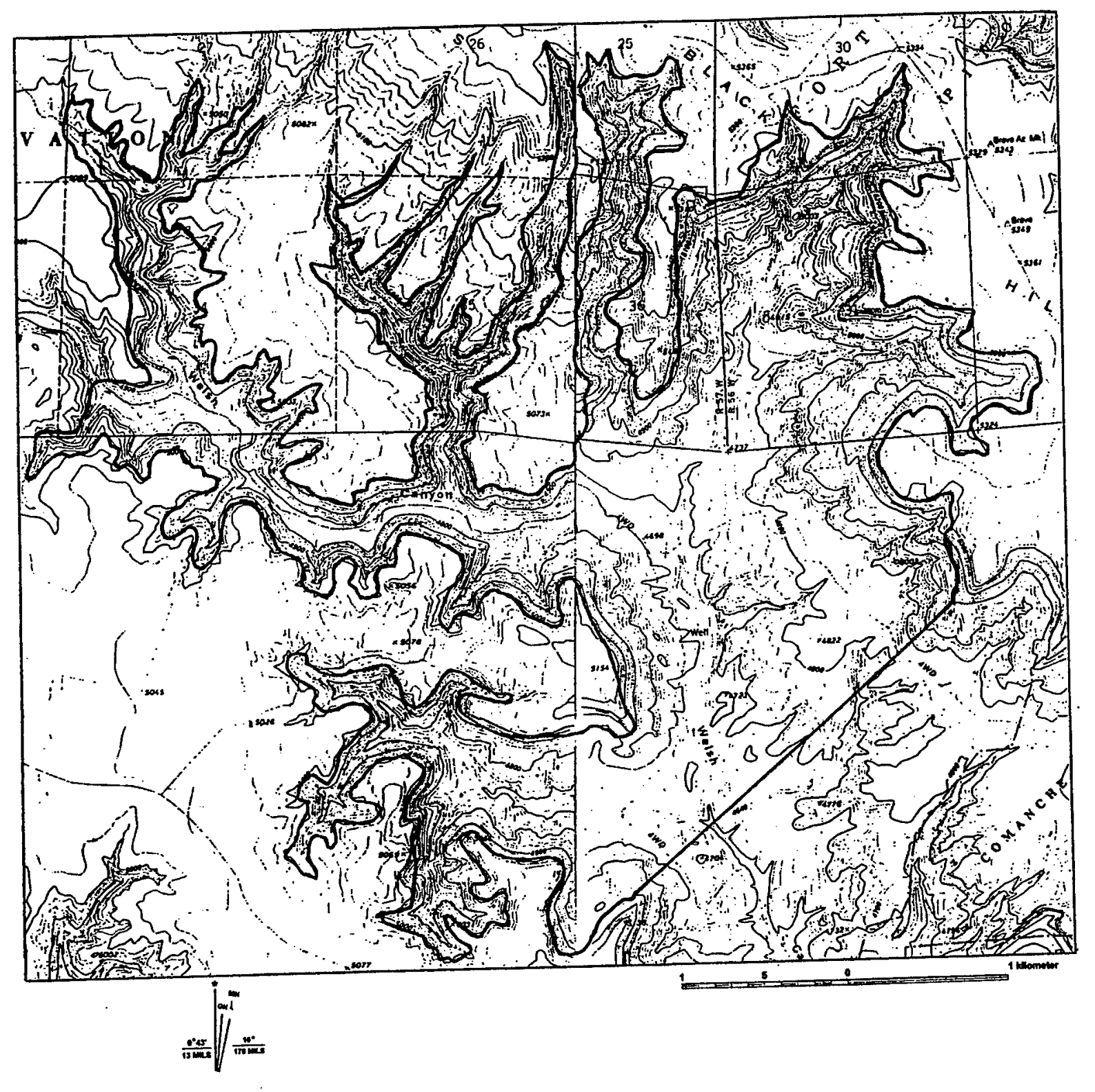

Figure 2. Survey Area Boundaries 
Although it was originally hoped to direct the survey in square units so the results could be compared to previous archaeological research in the PCMS, it soon was apparent the entire field season would be spent recording small lithic scatters on the finger ridges between the tributary canyons heads. The intent of the survey was to find sites in the canyons, which are potentially vulnerable to some Army training exercises. Small lowdensity lithic scatters on finger ridges where little deposition exists are of less concern, and the survey effort was therefore focused within the canyons, beginning in the upper end of Welsh Canyon where it meets the steppes.

In the first days, crewmembers became acquainted with the terrain and local logistical problems for survey. Lithic material types were identified and a system for counting and classifying these artifacts was developed. Proper completion of the site forms was discussed so that all crewmembers were operating on a uniform system (See Methods Section).

In the initial survey we encountered drift fences, the stone barriers used to control sheep and cattle that were constructed by former herders in the region. There are hundreds of kilometers of these features in the region and recording them would take a considerable effort with no worthwhile research questions to answer. Therefore we decided to record only a sample of the historic features by using GPS units to pinpoint locations accompanied by notes on the height and composition of the fence. These data are available in the field notes for anyone who is interested in drift fences.

Although rugged terrain complicated the survey, field personal attempted to maintain uniform and complete coverage at all times. Survey was conducted in all areas of Welsh Canyon with less than $75 \%$ grade, including the canyon walls proper, the floor of the canyon, and a 15 to 20 meter wide area along the perimeter of the rim. The canyon rim is stepped in many locations. It was not always possible to use it to define the upper boundary of the survey, but this problem notwithstanding, the surveyed areas were plotted on the USGS maps.

To evaluate the effectiveness of the 1995 survey, it is important to recognize that we were working in optimum conditions. The region received significant moisture in the spring and summer and ground cover was relatively lush, but in the autumn this growth was reduced and good ground surface examination was possible. The project director conducted major portions of the actual pedestrian search to locate sites and then directed the crews to the sites to record them. In this respect, the survey is as good as the project director's capabilities to recognize sites. This approach is also effective in that the crews learn about the kinds of archaeological features on the sites in the region. We were fortunate to locate rockshelters with low rock walls and rock wall house remains in the early days of the survey. By visiting these sites the crew became familiar with features like these and thereby improved their capabilities for finding these types of features and sites.

Although new personnel were employed in the 1996 survey, several of the previous season's workers returned and this helped with the continuity of the survey. In 
addition, several of the new crew had considerable prior experience in archaeological survey, including some with previous work in the PCMS. The 1996 survey started at the mid-canyon point where the project terminated the previous year. Although the crew had more extensive experience than most members of the 1995-survey team, we spent the initial field days acquainting all the crew members with the terrain and local logistical problems for survey. Lithic material types were discussed, as was the system for classifying lithic artifacts. Proper methods for completing the site forms were also discussed in order to insure that all crewmembers were operating within a uniform system.

Welsh Canyon widens toward the mouth to distances of roughly three to four kilometers. Within this wide floor area there are numerous small canyons, ridges, and buttes that created new and challenging survey problems. Significant parts of the canyon floor, constituting hundreds of acres, are open, exposed sandstone bedrock that is largely devoid of vegetation. Some of these surfaces contained remains of sites, but for the most part they were devoid of cultural material, which expedited the survey. Most sites identified in this area were located on small pockets of deposition that exist in scattered locations. On the other hand, the upland rim of Welsh Canyon undulates and meanders, jutting in and out, over most of its course. This presents large survey areas in locations where sites are more frequent.

Ground exposure during the 1996 field season was excellent. In the beginning of the project, the area was extremely dry and little vegetation had grown to hamper ground visibility. In the latter half of the project, it rained far more often than usual, but the survey had progressed to the point that many of the final days were devoted to revisiting survey areas and collecting additional information for sites found during the beginning of the summer. We are confident that very few sites were overlooked because of inadequate surface exposure.

The survey started in the canyon bottom with crews working up to the canyon rim and then back to the bottom during a day's work. As the survey progressed, we started to use the roads onto the canyon rims and complete survey along the upper contours of the canyons then we would go into the bottom and complete the survey along the lower reaches below where the work had been done from the top side. Primarily because we had good access, this system worked quite well.

The major problem encountered during the 1996 season was the heavy rainfall. This made the roads muddy and difficult to travel which complicated or prevented access to the canyon. Most days it was possible to get in at some point during the day, but there was a period during which access to Welsh Canyon was not possible. During this period, the crews worked on a survey unit established by Steve Chomko, DECAM Archaeologist, near the head of Red Rocks Canyon where access was possible on foot from the field station. Forms for the sites found during this research were completed and submitted with the forms for the Welsh Canyon research. 


\section{SURVEY METHODS}

In order to insure compatibility with previous research, the 1995 - 1996 survey of Welsh Canyon followed archaeological survey procedures and recording methods that have been established for the Pinon Canyon Maneuver site (Dean 1992). The intent of this investigation was to locate and record all significant historic and prehistoric cultural remains within the survey area. Most historic cultural resources within this area had already been recorded as part of another project (Carrillo et al. 1996), and only small historic sites that had not been previously identified were recorded as part of the present investigation. The presence of paleontology remains was noted, but these locations were not recorded in great detail. Military ordnance was not disturbed in any manner, and the locations of these items were only marked with pin flags and plotted on U.S.G.S. maps.

As a safety precaution, survey crews were issued hand held Motorola radios. The units provide contact with Pinon Canyon Range Control personnel in case of emergency. Unfortunately, the highly dissected terrain prevented radio contact throughout much of the survey area.

This section begins with a description of site survey procedures, and concludes with a discussion of the site recording methods that were employed in the 1995 - 1996 survey of Welsh Canyon.

\section{SURVEY PROCEDURES}

Ideally, parallel straight line transects aligned on compass bearings and spaced at regular intervals are used in archeological survey procedures. However, the terrain in some portions of Welsh Canyon does not allow the use of this survey method, and necessitates the use of a flexible strategy in order to maximize both efficiency and survey coverage. Steep slopes and vertical cliffs limit access to many areas of Welsh Canyon and these physiographic features prevent (without the use of climbing equipment) or complicate the use of linear survey transects organized on compass bearings.

For example, it is necessary to walk up or down the small meandering drainage systems with vertical sided sandstone walls in the bottom of Welsh Canyon, and because these drainages are not straight, survey transects walked within them also meander. The survey of these drainage systems was further complicated by the varying width, which forced transects together in narrow locations, while additional transects were necessary to uniformly cover small terraces in the drainage bottoms.

The field director allocated survey blocks to individual crews; crews completed a survey block before being assigned a new location, and each crew was responsible for a single area at any given time. The terrain in Welsh Canyon greatly complicates the 
partitioning of the survey area on the basis of arbitrary section lines; in many instances it is impossible or impractical to traverse section lines on foot for considerable distances. Therefore, survey blocks were generally defined on the basis of prominent geological features such as a large drainage. The use of conspicuous natural features to define survey blocks also facilitates coordination between survey crews such that areas are less likely to be missed.

As will be discussed further below, three person survey crews were generally employed because they result in the most efficient use of personnel. Each crew had a chief who was responsible for organizing survey transects that resulted in the most comprehensive and complete coverage possible. At all times, the intent was to maintain uniform spacing of 20 meters between survey transects. Crew chiefs were also responsible for maintaining contact between crew personnel so that they did not become separated.

Parallel linear survey transects aligned on compass bearings and spaced at 20 meter intervals were walked by foot in approximately level areas with less than 10 percent gradient. Twenty meter interval survey transects that followed the contour of the slope were walked along gradients of between roughly 10 degrees and 75 degrees. Vertical cliffs and slopes with a gradient of greater than 75 percent were not walked and were traversed only along access routes (i.e., usually game trails and small-eroded features).

Throughout the survey area, particular attention was given to any rock overhangs that may have been used as shelters, and the slopes below these features. Frequently, deposition within shelters obscured evidence of human use, and most artifacts were generally identified eroding down the slopes in front of shelters. Survey transects were walked along cliff faces and above cliffs.

Additional attention was also given to any rock faces or boulders with varnish. This was done because these locations are more likely to exhibit prehistoric rock art for two principle reasons. (1) Varnish accumulation is a slow depositional process. The presence of varnish on rock surfaces indicates that they have been stable for an extended period of time, and prehistoric human modification to the surface is more likely to be preserved. Unvarnished surfaces are more likely to be undergoing active erosion, thus destroying evidence for human modification if it was ever present. (2) The prehistoric makers of rock art may have favored varnished surfaces for their work because pecking through the dark outer surface exposes the lighter rock below, resulting in a highly visible figure.

\section{Crew Composition}

In order to minimize access logistics, sites were recorded as they were identified during the survey. The site recording procedures consist of three principle tasks which are; completing the sketch map, the State of Colorado Management Data form, and the State of Colorado Prehistoric Component, Historic Component, or Rock Art Panel 
Supplement forms. Three person survey crews therefore result in the most efficient use of personnel during site recording - for this reason survey crews generally consisted of a crew chief and two other members. Several additional tasks in the recording process include; photographically documenting the site and any features, obtaining Global Positioning System (GPS) coordinates for the site datum, and plotting the site on a 7.5 minute series U.S.G.S. topographic map. These additional tasks were completed by crewmembers as the primary procedures were finished.

Crew chiefs were responsible for delegating tasks during recording procedures, and checking for proper completion of these jobs. In order to alleviate monotony, recording tasks were generally rotated among crewmembers. However, crew chiefs were responsible for determining site locations in all instances, and they wrote the descriptive information for all large or complicated sites.

Site Identification and Definition

With the exception of certain items listed below, all cultural resources identified within the survey area were recorded as either an isolated find or a site. Evidence of human activities that were not recorded in detail include: contemporary transportation routes; trash associated with these routes (i.e., litter along modern roads); historic fence lines; pipelines; isolated metal windmills and stock tanks not associated with buildings or homestead locations; recent recreation camps or facilities.

When a prehistoric or historic artifact was identified during the survey a pin flag was placed next to it. The area around this artifact was then intensively examined for additional cultural material. Pin flags were placed next to artifacts (double pin flags were placed at any features, diagnostic artifacts, or unusual artifacts), working outward in all directions from the original cultural material that was identified. Site boundaries were based on the extent of the artifact scatters; natural boundaries such as drainages were also used to delimit separate sites. In cases were natural geographical divisions did not occur, large areas with less than 20 meter spacing between artifacts were not arbitrarily split into separate sites. The extent of all sites was determined even if the site extended outside of the survey area.

Pin flagging continued for $\mathbf{3 0}$ minutes or until the extent of the cultural material was identified (indicated by 20 -meter gaps that lacked artifacts); artifact counts were estimated for large sites. For expansive or particularly dense sites, flags were placed next to some artifacts throughout the site area, rather than flagging all the artifacts within a small area of the site-- pin flags were used to indicate clusters of artifacts at high density and/or large sites.

The location was considered an isolated find if fewer than 5 unmodified flakes or a single tool occurred in a 20 by 20 meter area that was surrounded by sterile terrain for a distance of more than $\mathbf{2 0}$ meters. Recording procedures for isolated finds consisted of completing a State of Colorado isolated find form, and plotting the location on a 
U.S.G.S. 7.5-minute series topographic map. Significant isolated artifacts were located by GPS, but we were not consistent in this effort.

Localities were considered to be prehistoric sites when more than 5 unmodified flakes or 1 or more tools with 1 or more flakes were identified within less than 20 meters of one another. If indications of subsurface deposits were present (e.g., heat altered stone eroding from a cut bank), areas were always recorded as sites regardless of surface evidence. All rock art localities were recorded as sites, whether or not artifacts were associated. Locations with architectural or non-architectural features were also recorded as sites regardless of surface artifact density. Historic sites or isolated finds were defined on the same artiract density criteria, as were the prehistoric localities.

\section{Site Recording Procedures}

After determining the distribution and general nature of the cultural materials at the site, a suitable location for the permanent site datum was chosen. Datums were generally placed on high locations with good visibility near the center of the artifact scatters, or were placed immediately in front of rock shelters. Site datums consisted of 45-centimeter lengths of steel reinforcing bar, which were pounded at least half way into the ground. Natural stones were piled around datums in locations where only exposed bedrock existed. An aluminum site tag with the temporary site number was then securely attached to the bar using stainless steel wire.

Temporary site numbers were assigned during each field season beginning with number 1 and sites were numbered sequentially afterward. For example, during the 1996 field season the first site identified was assigned PC 96 001, after which sites were numbered sequentially. The designator PC 96 was used to indicate the project name and survey year. A master list of temporary sites numbers was established at the beginning of the each season, and one person from each crew was responsible for signing out a sufficient block of site numbers for each day.

One crewmember then determined the approximate location of the datum using a Trimble Pathfinder Global Positioning System (GPS). Ideally, these units provide an initial accuracy to within an average of 100 meters. However, rugged terrain often blocked satellite reception that affected performance. More than 180 point readings were then collected for use in post-processing at the base station maintained at Fort Carson. Because the exact location of the base station is known, it is possible to correct for the error in the GPS readings in the rover files and correct for the error in the reading taken in the field. Using this method Trimble Pathfinders provide accuracy within a few meters for the exact position of the datum.

The location of the site was then plotted on a 7.5' U.S.G.S. topographic map, using the uncorrected GPS coordinates as a guide. Crew chiefs were instructed to plot the site in the location they thought it was, rather than blindly using the uncorrected GPS readings. The exact locations of the sites were plotted later when the postprocessed GPS coordinates were available. 


\section{Site Sketch Maps}

Scaled sketch maps were drawn in the field for all historic or prehistoric sites that were recorded. In order to facilitate drawing and measurement of dimensions, sketch maps were generally aligned based on the topography at the site (i.e., north was not always at the top). The first step in drawing the map consisted of establishing a baseline along the long axis of the site. Baselines that intersected the site datum were established either along an existing feature if one was present (e.g., along the center of a ridge), or based on a arbitrary compass alignment (usually magnetic north). For smaller sites a 50-meter tape was laid along the baseline, but it was necessary to pace baseline distances at larger sites. The site boundaries, any cultural features, diagnostic or unusual artifacts, and the approximate topographic features and vegetation were placed on the map by pacing right angle distances to the baseline.

Magnetic North was recorded on all maps, as well as an approximate scale, and key to any symbols used in the map. Smaller scale and more detailed plan views were generally drawn for cultural features. Both plan views and front-to-back cross-sections were drawn for rockshelter sites. Floor plans indicated any associated features (architectural and non-architectural), point provenience artifacts, prominent natural features, and the drip line for rockshelters.

\section{Management Data Form}

This form requires some site-specific data, and general information, which pertains to all sites in the survey area. One survey team member completed site specific questions on this form. Laboratory personnel filled out general questions that are applicable to all sites at a later date. This form also requests an assessment of National Register eligibility; these judgments were made exclusively by the Principle Investigator (Larry Loendorf), and were therefore also filled in at a later date.

\section{Prehistoric Component, Historic Component, or Rock Art Panel Supplement Forms}

These forms contain more detailed information regarding sites and the associated artifacts. Consequently they were generally completed by crew chiefs, especially at large or important sites. All information on these forms was filled out in the field. A lithic analysis was completed in the field for prehistoric sites (see below), and this information was recorded on the Prehistoric component form. The forms generated during a cultural resource survey represent the most significant part of the collected data. In the case of this survey the forms, sketch maps, and site photographs were submitted to the Army for review before being sent to the Colorado Historic Preservation Office. Individuals who have a legitimate reason to review the forms could gain access to them in either repository. 
Site Photographs

At least one site overview photograph was taken at each site that was identified during the survey using Canon cameras with data imprint backs. These cameras automatically record the date of each photograph in the lower right hand corner. Additional photographs were taken of any features. Sites were photographed using Kodak T-MAX black and white film. For sites with stone architecture or unusual features, the sites were revisited by Hadley Harper using $35 \mathrm{~mm}$ cameras to expose a series of photographs which document the current condition of standing walls and other sites that might be damaged easily by visitors. Both color slides and black and white shots were taken for documentation of the significant features and sites. Future visits to these sites by a photographer will provide an inventory of photographs that can be used to identify any disturbance to the site.

\section{ARTIFACT RECORDING AND COLLECTION PROCEDURES}

Non-diagnostic artifacts were analyzed in the field, and were not collected. Lithic data were recorded on the prehistoric component form; material types (e.g., quartzite, chert, basalt), flake types (i.e., primary, secondary, tertiary), core types (e.g., bipolar core, non-directional core), and tool types (e.g., end scraper, large corner-notched projectile point) were recorded.

Non-portable groundstone forms were filled out for any grinding features. The dimensions of portable groundstone artifacts (e.g., manos, metates) and a brief description were recorded on the prehistoric component form.

Raw material samples that encompassed the range of variation in appearance were collected from lithic procurement localities. Particular attention was given to the collection of chert samples. Nodules of stone that had not been flaked were collected when possible; however; this was not always possible and some worked nodules were collected.

All diagnostic or unusual prehistoric artifacts were collected including; projectile points, ceramics, bone artifacts, and obsidian artifacts. Collected historic artifacts include; ceramics or bottles that have maker's marks, cartridge casings, and unique items. The location of all collected artifacts was indicated on the site sketch map. Artifacts were placed in a bag labeled with the following information; site number, brief description of contents (e.g., corner notched projectile point), date, and collector's name. 


\section{THE PHYSICAL SETTING}

Welsh Canyon is a prominent tributary to Purgatoire Canyon entering the latter from the northwest. Welsh Canyon has several upper branches and in terms of size, it is one of the largest side-canyons entering from the west. It is about 9 kilometers in length, in straight-line distance measured on a map, but traversing the bottom with its bends and twists it is much longer. Welsh Canyon begins on the upland rolling prairie about 10 to 12 kilometers east of the Bear Spring Hills. The terrain known as the Black Hills are immediately to the northeast where they form part of the northern canyon rim for Welsh Canyon. Red Rock Canyon is situated in a parallel course to the southwest.

Welsh Canyon is relatively gradual at its upper reaches, but it continually deepens along its course to the deepest point near its mouth. Welsh Canyon and Red Rock Canyon join at their mouths, near the point where they both enter the Purgatoire Canyon. At this junction the canyons have a common point of land with an excellent view of all the surrounding lowlands including a significant stretch of the Purgatoire Canyon bottom. Although not named on the map this point is locally known as "Lookout Point", not to be confused with another similar point to the south that is referred to as "Highpoint". Both positions have excellent views of the region. Lookout Point is 5175 feet ( 1593 meters) in elevation and it is about 600 feet ( 185 meters) above the river below.

Welsh Canyon does not contain a permanent stream. Freshwater springs are located at the heads of several tributary canyons to Welsh on the northwestern edge of the project area; some of these flow throughout the year while others have more sporadic output. However, the main canyon bottom, the two large side drainages that enter from the north, and the major drainage that enters from the east all lack springs. Consequently, water catchments are an important factor in Welsh Canyon, and archaeological sites are generally concentrated in the vicinity of standing water pools. This is especially true in the lower reaches of the canyon where large, fan-shaped, expanses of exposed bedrock create precipitation catchment basins that drain into tinajas and other natural rock bottom basins to form reservoirs of standing water.

Very minor maintenance to direct water into these pools and to keep it protected for human consumption would have produced substantial amounts of water for hunting and gathering peoples. It is clear, however, that in periods of drought these localized water sources would not have been reliable. This is evidenced by the observation that almost all catchments were dry at the onset of the 1997 season, after a winter that was not extremely dry. As the season progressed and precipitation increased, even small catchments held water, and a number of larger pools, some of which approached a meter in depth, were present.

The exposed bedrock stratigraphy includes Permian and Triassic age red sandstones along the floor near the mouth of Welsh Canyon (Evanhoff 1997). White sandstone, alabaster, and multi-colored mudstones in Jurassic age deposits overlie these red sandstones. This group contains the Morrison Formation with dinosaur bones 
and tracks including the well-known set of allosaur and aptosaur tracks in the Purgatoire Canyon near the mouth of the Welsh Canyon. Cretaceous age shales and sandstone overlie the Morrison (Evanhoff 1997). This stratigraphic sequence indicates that the exposed bedrock in the canyon ranges through the past 200 million years.

The surface deposits in the Quaternary include scouring and filling and this serves as a significant factor in the preservation of archaeological resources in the PCMS (Schuldenrein 1985). Although there is some debate as to the actual dates of terrace formation in the side canyons to the Purgatoire (McFaul 1991:39), there is little question that these canyons have experienced numerous localized floods. These floods have moved major amounts of sediment toward the Purgatoire River and even though Welsh Canyon does not contain a permanent stream, sediments still flush downward during heavy rains. The upshot of this, for the archaeologist, is that rockshelters in relatively high and protected locations offer the best opportunity for recovery of intact cultural remains.

Juniper and cholla are the dominant vegetation in Welsh Canyon, but hundreds of smaller plants are found throughout the canyon. Large stands of grasses, collectively referred to as cheno-ams, are abundant in the canyon bottom near its mouth, along the mesa tops and out onto the rolling upland grass savannas that characterize the majority of the terrain in the PCMS. Pollen studies indicate that these plants were a major source of food prior to European contact. Archaeological sites on Van Bremer Arroyo and Burke Arroyo, at locations adjacent to the steppe southwest of Welsh Canyon, contain abundant evidence of cheno-am use (Loendorf, Borchert and Klinner 1996).

Cottonwood trees grow in the vicinity of the freshwater springs and in scattered locations along major drainages and in the main canyon where water must be within a meter or two of the surface. Many of the freshwater springs and other moist areas also support abundant berries like goose berries and skunk berries. Massive vines of wild grapes are often found intertwined in the cottonwood trees in these areas. Although they occur in relatively small numbers compared to the juniper, pinon pine are found in the Black Hills and on the higher mesa areas surrounding Welsh Canyon. It is not clear, from an archaeological perspective, how these nuts and berries played a role in the diets of the past inhabitants, but it is reasonable to assume they probably were important additions to the annual larder.

\section{CLIMATE}

During the summer, the Welsh Canyon region is often influenced by southwestern weather patterns that contain hot and dry air. Through July and August, these patterns contain frequent thunderstorms that come toward the PCMS from southwest of the Sangre de Cristo Mountains. These storms usually build in the afternoon and drop rain in a relatively localized area. Nearly every summer, violent summer thunderstorms also originate in the plains and come toward the PCMS from the northeast. These can include high winds and tornadoes and sometimes drop torrents of 
water in a short period of time. Winters are also subject to short and violent bursts of weather that bring blizzards from the north, but generally the winters are mild and dry. The Gulf of Mexico offers up moisture for spring, and autumn precipitation, but not on a predicable basis. Nonetheless, when the averages are calculated for the past half century, one learns that nearly three-quarters of the annual precipitation falls during March to April.

The climate in southeastern Colorado develops through the intersection of three major air masses: cold Arctic air that originates in the Arctic circle; mild Pacific air, with its origin along the west coast of North America; and tropical air that comes into the region from the Gulf of Mexico. The interaction of these air masses determines the temperatures and amounts of precipitation in the region (Bryson and Wendland 1967:274). Several models have been developed to show how one of these air masses may have dominated the others in past climatic regimes. Brown (1994:8) compiles the collected information from a model known as the Blytt-Sernander climatic classification. Developed for North America by Bryson, Baerris and Wendland (1970), and Wendland and Bryson (1974), this model relies, in part, upon radiocarbon age estimates from archaeological sites in the North American Plains. Using these dates in conjunction with pollen analysis, faunal distribution studies, and other paleoenvironmental data they postulate that significant environmental events took place through Holocene and that these events are linked to human use of certain regions.

As the last Pleistocene glaciers were melting, the Welsh Canyon region apparently experienced major torrents of water moving eastward from the Rocky Mountains. Evidence for this high water is found on Van Bremer Arroyo, a tributary to the Purgatoire River that is near the southern border of the PCMS. Using cation-ratio age estimate methods, the varnish on two rounded basalt cobbles and boulders on the high banks and benches along the arroyo was dated at 12,800 \pm 1150 and 12,000 \pm 550 B.C.(Loendorf 1989:148). A basalt dike, known locally as the Hogback, to the south of Van Bremer Arroyo, is believed to be the source of these boulders. Because they are found on the north bank of the arroyo, they were apparently deposited when glacial meltwater had sufficient carrying capacity to move them along the channel (Loendorf 1989:148). Climate during this time is thought to have been fairly cool and dry but apparently the region had good water supplies from the melting glaciers.

As time passed, however, and the glacier melt water dried up, the region entered a hot and dry climatic phase. Known originally through the research of Ernst Antevs (1955) as the altithermal, this period has also been identified as the climatic optimum, the hypsithermal, the thermal maximum and the xerothermic period (Brown 1994 quoting Story 1990:25). In the Blytt-Sernander model this hot and dry climatic period correlates with the Atlantic Period, beginning about 6500 B.C. The impact of this dry climatic phase on the PCMS is not known, but if the grasslands of the southern plains were drier, there would be an obvious affect on herd animals. This period correlates with the Early Archaic which is dated between 5500 and 3000 B.C. in the region. 
The Sub-Boreal climatic episode, hypothesized to start about 3100 B.C., is thought to have been influenced by colder Arctic air masses and as colder air pushed southward into the southeastern plains it came into contact with warm, moist Gulf air creating more precipitation for the region. The climatic episode is correlated with the Middle Archaic Period with dates of 3000 to 1000 B.C. Sometime between 1000 and 800 B.C. an episode known as the Sub-Atlantic begins and continues until about A.D.200. Correlating with the Late Archaic, this period is characterized by increased summer precipitation and more snowfall in the winters.

The Scandic climatic episode starts about A.D.200 and lasts until the beginning of the Neo-Atlantic at about M.D.900. Sometimes named the Little Climatic Optimum, the climate during this time is thought to have returned to the warmer and drier regimes. This period correlates with the Early Ceramic Period in the region and based on radiocarbon dated site assemblages, especially toward the end of this period, it is time of relatively intense habitation in the PCMS (Loendorf, Borchert and Klinner 1996). Perhaps this reflects movements of groups of people out of the drier plains into regions closer to the mountains. The Neo-Atlantic, from A.D.900 to 1200, is thought to have brought increased summer rainfall to the region, as much as two to three inches greater than the present in northern New Mexico (Brown 1994:10). The Sub-Atlantic, as well as part of the following Pacific episode, correlates with the Middle Ceramic Period. Even though the Pacific climate is thought to have been hot and dry in the north, an increase in precipitation is hypothesized for the southern Plains. This suggests it had less impact on cultures in the PCMS and the radiocarbon dated cultural deposits indicate the heavy use of the region, that started in the Early Ceramic Period continued throughout the Middle Ceramic.

At about A.D.1550, the Little Ice Age is thought to have influenced the climate in an episode known as the Neo-Boreal. This cool and moist period may have triggered movements of protohistoric tribes in search of a new means of livelihood. The Kiowa, for example, a tribe that would ultimately reside in the southern Plains to the east of the PCMS, are thought to have moved from one location to another in their northern homeland at about that period of time. This is also the time that many researchers hypothesize the movements of Apache tribes to the south from their northern homes (Gunnerson 1987; see Opler 1983:382 for contrasting ideas).

Using these data collectively, it is apparent that from mid-Holocene time forward, the Welsh Canyon region offered a relatively good setting for hunters and gatherers. While surrounding regions were experiencing droughts the moisture remained fairly constant in the Purgatoire River area and while the temperature dropped colder in the north, the PCMS was less affected by cold. The question as to whether the climate in the region was conducive to domesticated crop production remains unresolved, but the affect of climate on hunters and gatherers through the past 3000 years appears to be minimal. The only possible exception to this is the Scandic climatic episode which may have been sufficiently dry and warm to affect the regional resources available for hunting and gathering cultures. Certainly there were cycles with fluctuations in precipitation and periods of increased or decreased temperatures. These undoubtedly 
had deleterious affects on some animal and plant species, but the ability of hunters and gatherers to switch their livelihood to unaffected resources appears to have allowed them to persist in the region through the millennia.

\section{WELSH CANYON CULTURAL RESOURCES}

This section describes the types and settings of cultural resources that were identified during the 1995 - 1996 Welsh Canyon survey, and presents a preliminary quantitative examination of these data. Detailed descriptions of individual prehistoric sites and Historic sites are presented in Appendix I.

A total of 234 sites were identified during the survey. These sites varied substantially in size, and in the numbers and types of artifacts and features that were identified.

The quantitative analysis examines relationships between site type, physiographic setting, site area, features, and artifact types. This preliminary consideration of the distribution of prehistoric sites and artifacts in Welsh Canyon suggests that prehistoric people used all areas of the canyon, but the canyon rim appears to have been most intensively used for habitation. Data suggest that prehistoric cultural activities that occurred in Welsh Canyon include; habitation, food collection and processing, tool manufacture, raw material collection, and ritual activities.

Diagnostic artifacts such as projectile points were relatively rare throughout the prehistoric sequence in Welsh Canyon. Patterned tools of any type are uncommon at many sites, and the bulk of the evidence for prehistoric human use of the canyon consists of simple chipped stone artifacts. Although the majority of these artifacts lack macroscopic evidence for use-wear, many of them may have been used as expedient tools for brief periods.

The small proportion of sites from which diagnostic tools were collected and the generally low density of patterned tools and features complicate any quantitative comparisons of site assemblages. However, it is still possible to make a number of observations concerning the distribution of different artifact types and features by site type and location. Furthermore it is these data that are used to evaluate the sites and establish their significance. Before proceeding with any additional comparison or description, the following section is presented to present the criteria used to establish the significance of the sites.

\section{NATIONAL REGISTER EVALUATIONS}

A diverse group of regulations, plans and agreements are used in managing the cultural resources in the PCMS. In terms of evaluating archaeological sites, the most important of these is the Multiple Property National Register Nomination which includes 
documentation for the recorded sites and research objectives for additional site recording projects (DeVore nd ca. 1993). The procedures for a Multiple Property nomination are described in the 1966 National Historic Preservation Act (NHPA) as amended in 1980 and 1992. The Section 106 process in this regulation outlines the requirement for Federal agencies to locate and evaluate cultural resources before expending federal funds on any project that might adversely affect such resources. In 1973, Executive Order 11593 (included in the 1992 NEPA amendment as Section 110) placed additional emphasis on the location of cultural resources on Federal lands through systematic programs of survey and inventory. The intent is to locate and evaluate the cultural resources according to the criteria set forth for inclusion on the National Register of Historic Places.

The Welsh Canyon cultural resource survey was directed through these mandates. Each site recorded was evaluated using the National Register criteria and determined whether it: $(A)$ is associated with events that have made a significant contribution to the broad patterns of history; or $(B)$ is associated with the lives of significant persons; or (C) embodies the distinctive characteristics of a type, period, or construction method that represents the work of a master or that possesses high artistic value or that represents significant and distinguishable entity whose components may lack individual distinction; or (D) might yield, or be likely to yield, information important in prehistory or history. In research areas like the PCMS, cultural resources are dominated by prehistoric sites associated with ancient American Indian cultures and Criterion D is most frequently employed, however in the case of rock art, Criterion C can be useful for evaluating sites.

As noted above, any previously recorded cultural resources in the PCMS have been evaluated and described within a Multiple Resource nomination process. The parameters of the nomination were established through the Colorado Plains Prehistoric Context (Eighmy 1984), which describes the prehistoric setting, as it is currently understood, for the PCMS region. This document outlines a series of information gaps that might be filled by the discovery and study of new sites. Considerable emphasis is placed on the recovery of chronometric information to better understand any increases or decreases in the use of the region through time. Other important questions are related to the advent of horticulture and any associated changes in the lifestyle that might be associated with the transformation from nomadic hunter and gatherers to sedentary farmers.

More specifically, the prehistoric research domains for the PCMS are based on the information from the 2000 previously recorded archaeological sites. These sites are divided into two general broad lifestyles (DeVore n.d.:21) with one that is associated with the sites of Hunter Gatherers (8500 B.C. to A.D. 200) and the second that is related to the sites containing evidence of Sedentism and Incipient Horticulture along the Purgatoire River (A.D. 200 to A.D. 1541). Paleolndian and Archaic period sites are in the Hunter-Gatherer context while Ceramic period sites are in the Sedentism and 
Incipient Horticulture context. Four major research domains are established within these contexts -- prehistoric chronology, paleoenvironments, settlement-subsistence, and exchange and mobility (Andrefsky et al 1990). These four research domains present the basic framework within which all prehistoric research is conducted in the PCMS and they played an important role in the evaluation of the sites found during the Welsh Canyon survey.

\section{Chronology}

Prehistoric chronologies in the PCMS are based on numerical age estimates, primarily Carbon 14 dating methods, and relative age estimates, made by comparing the projectile points found on the sites to recognized and named types with established age criteria. Recognized prehistoric periods in the PCMS include Paleolndian (Plano), Early Archaic, Middle Archaic, Late Archaic, Early Ceramic, Middle Ceramic, Late Ceramic and Protohistoric periods. Because the Welsh Canyon survey was conducted in terrain that had not been extensively sampled in any previous survey efforts in the PCMS, we recognized the potential for the recovery of surface artifacts without any preference for one or the other of these time periods. Sites with surface artifacts that could be placed in typologies were evaluated more highly than those which did not produce such artifacts. Equally important were sites with evidence of charcoal or hearth remains that might be used for radiocarbon samples and establishing chronologies.

\section{Paleoenviroments}

It has been postulated that there are few sites associated with the Paleolndian and Early Archaic time periods in the PCMS because the post-Altithermal erosional processes have destroyed them (Schuldenrein 1985). However, more recent investigations by McFaul and Reider (1990) indicate there may be isolated settings where deposits of these ages were not washed away. Any site with the potential to recover information that was related to these early paleoclimatic events was recommended for inclusion on the National Register. Other sites, such as rockshelters with intact deposits, were also recognized as important for the recovery of faunal and floral materials that might offer clues to understanding past climatic regimes.

Settlement-Subsistence Systems

Settlement archaeology is conducted within a recognized theoretical framework in which the investigator examines the strategies used by humans to utilize various environmental and geographical regions. In these studies the geographical location of the site is plotted against the relevant environmental information of its setting. Sites are compared to their proximity to water, the view of surrounding terrain, the presence of floral and faunal resources and so forth. By examining these subsistence factors in relationship to the site location, the investigator hopes to identify patterns that are 
associated with the various time periods. In other words, the investigator hopes to answer questions like that regarding Archaic hunters and gatherers and their movements from one setting to another on a seasonal basis and what ways this pattern of transhumance may have changed with the advent of horticulture in the Ceramic period. The Welsh Canyon sites were evaluated according to their settings with emphasis placed on identifying sites with intact cultural deposits in all the possible microenvironments. Using this reasoning, for example, we recognized the importance of protecting examples of rockshelters with good cultural deposits in the canyon bottom as well as others along the canyon rim.

\section{Exchange and Mobility}

The exchange and trade of various raw materials and manufactured items presents the investigator with the opportunity to study the intertribal contacts and communication with other groups. Areas of exchange are also important avenues for the introduction of new ideas and the diffusion of non-material aspects of culture. Within the Hunter and Gatherer context of the PCMS, the raw materials used to manufacture chipped stone tools are extremely important and because it is possible to trace the locations of certain raw materials, they have important implications for avenues of exchange and mobility. In the Sedentism and Incipient Horticulture context, different types of ceramics can be useful in learning the areas of exchange and travel. Sites located in the Welsh Canyon survey were evaluated according to these criteria by recognizing the importance of those with any obsidian or other exotic stone material.

Ceramics are so rare in the PCMS that nearly any site that contains them is identified as significant.

All of the sites found in the Welsh Canyon survey were evaluated using the foregoing regulations, criteria, and research domains. Of the 234 sites recorded, 97 were recognized as significant and recommended for inclusion on the National Register (see Table 1). Individual site descriptions in Appendix One offer information as to reasoning used by the investigators when they evaluated each site.

\section{SITE COMPARISON AND CLASSIFICATION}

This section begins with a description of the criteria that were employed to classify Welsh Canyon's prehistoric sites. The following text discusses the incidence of these site types in the canyon. The four major physiographic zones that were used to classify the site settings are then described, after which site density in each of these zones is considered. Next, the patterning in site size by type and physiographic settings is considered. In the following section we evaluate the distribution of site types by physiographic zone. Site type and location are examined in relationship to the distribution of different artifact types and features. Finally, a summary and general observation is presented. 


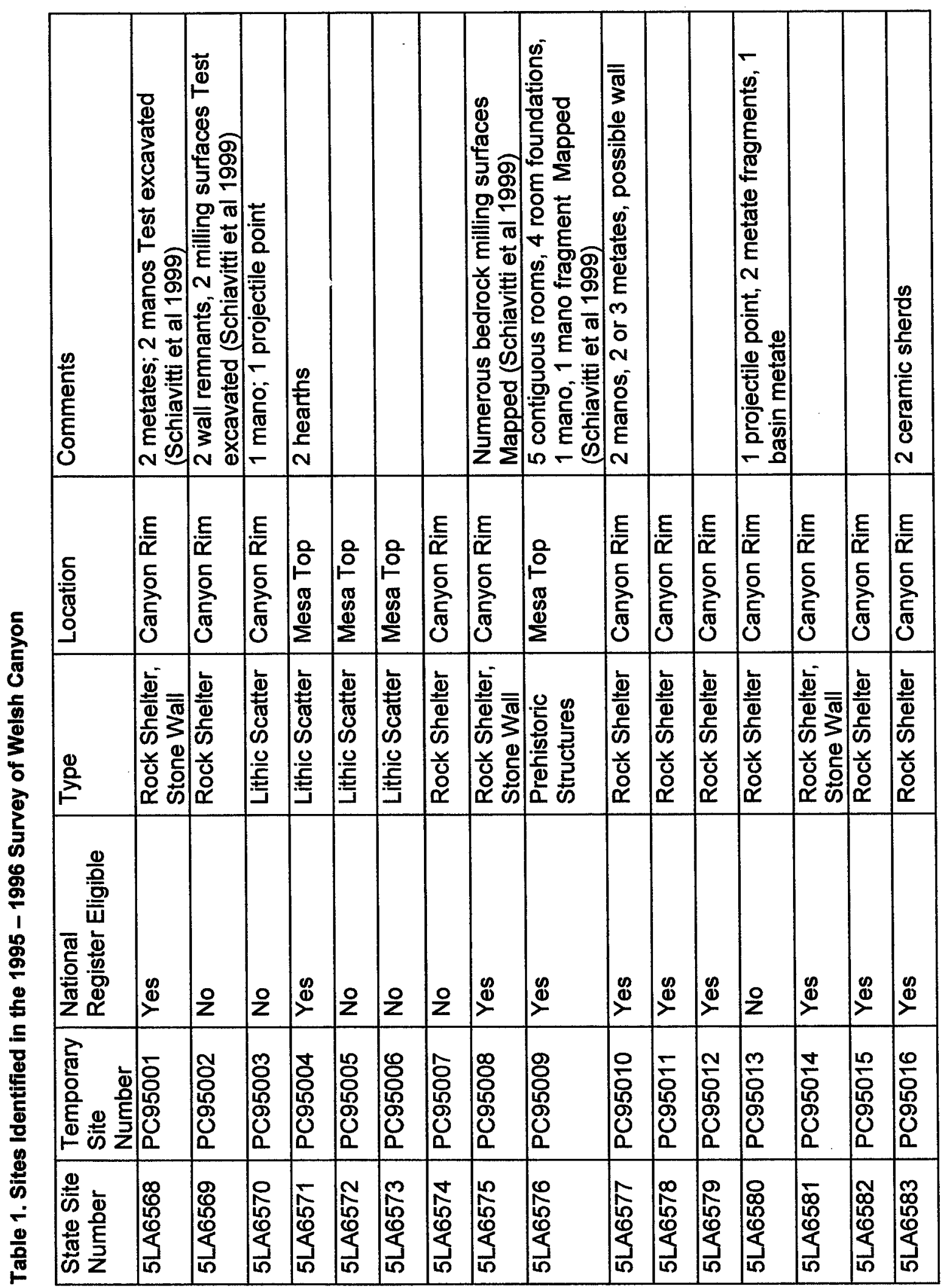




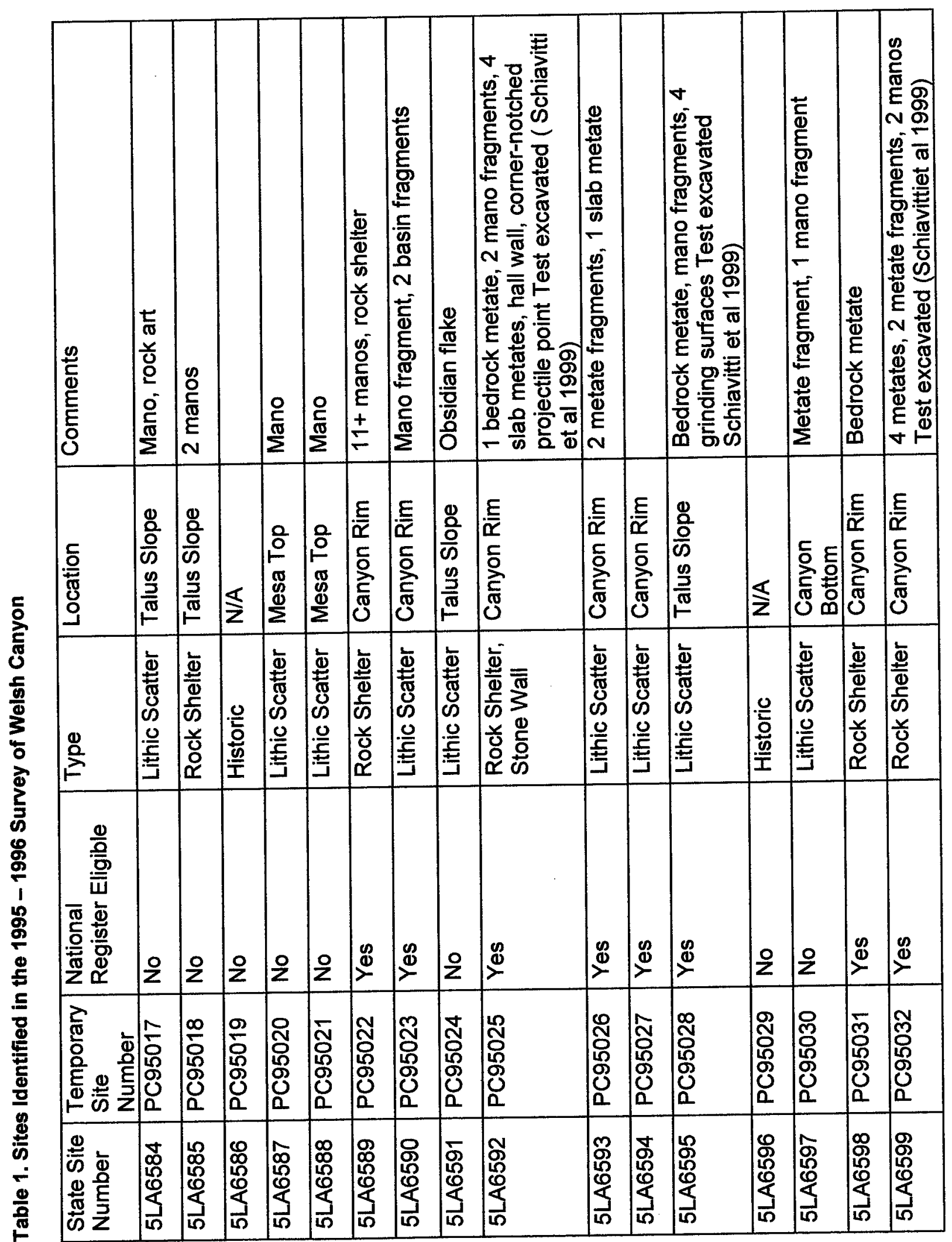




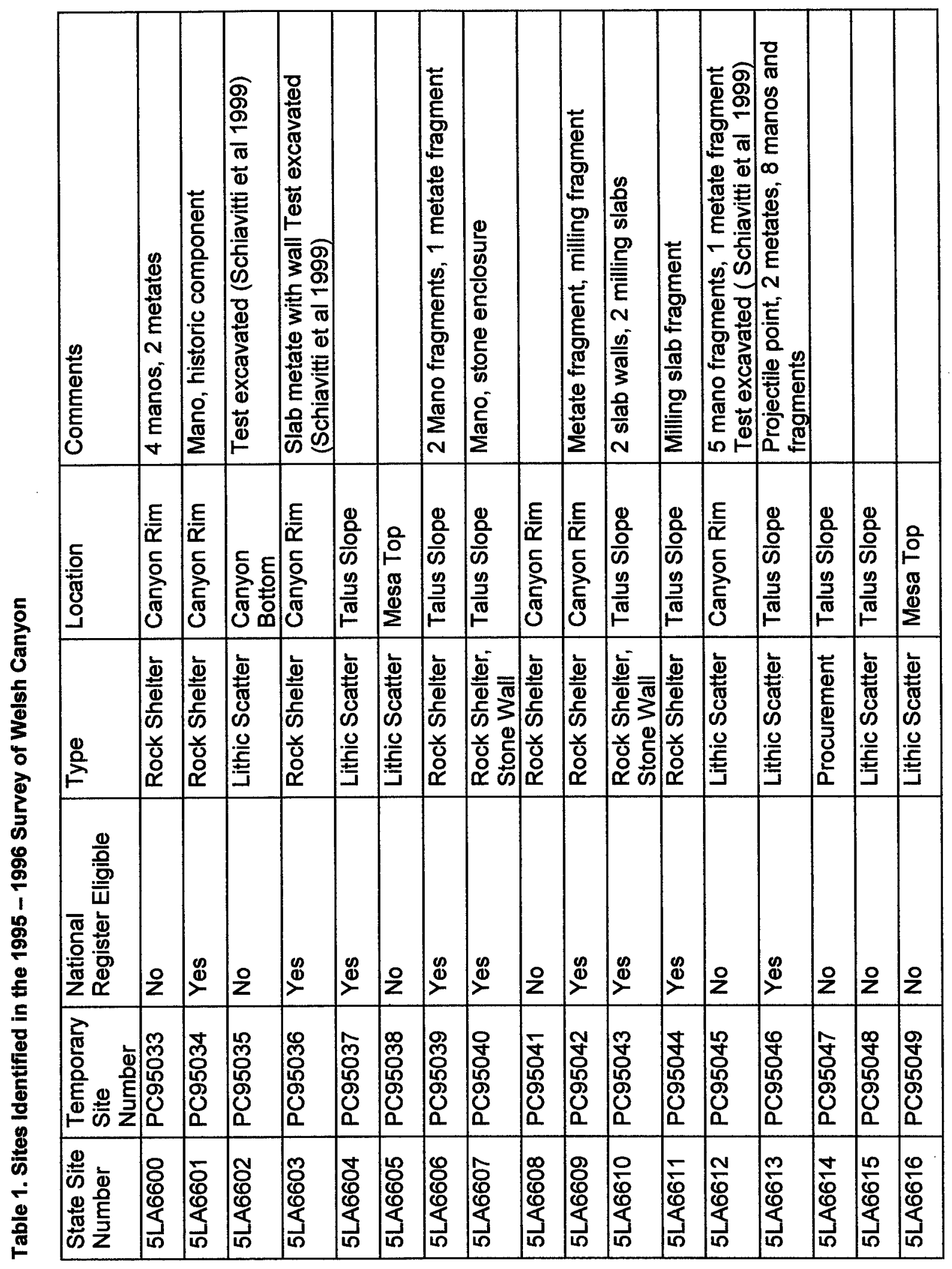




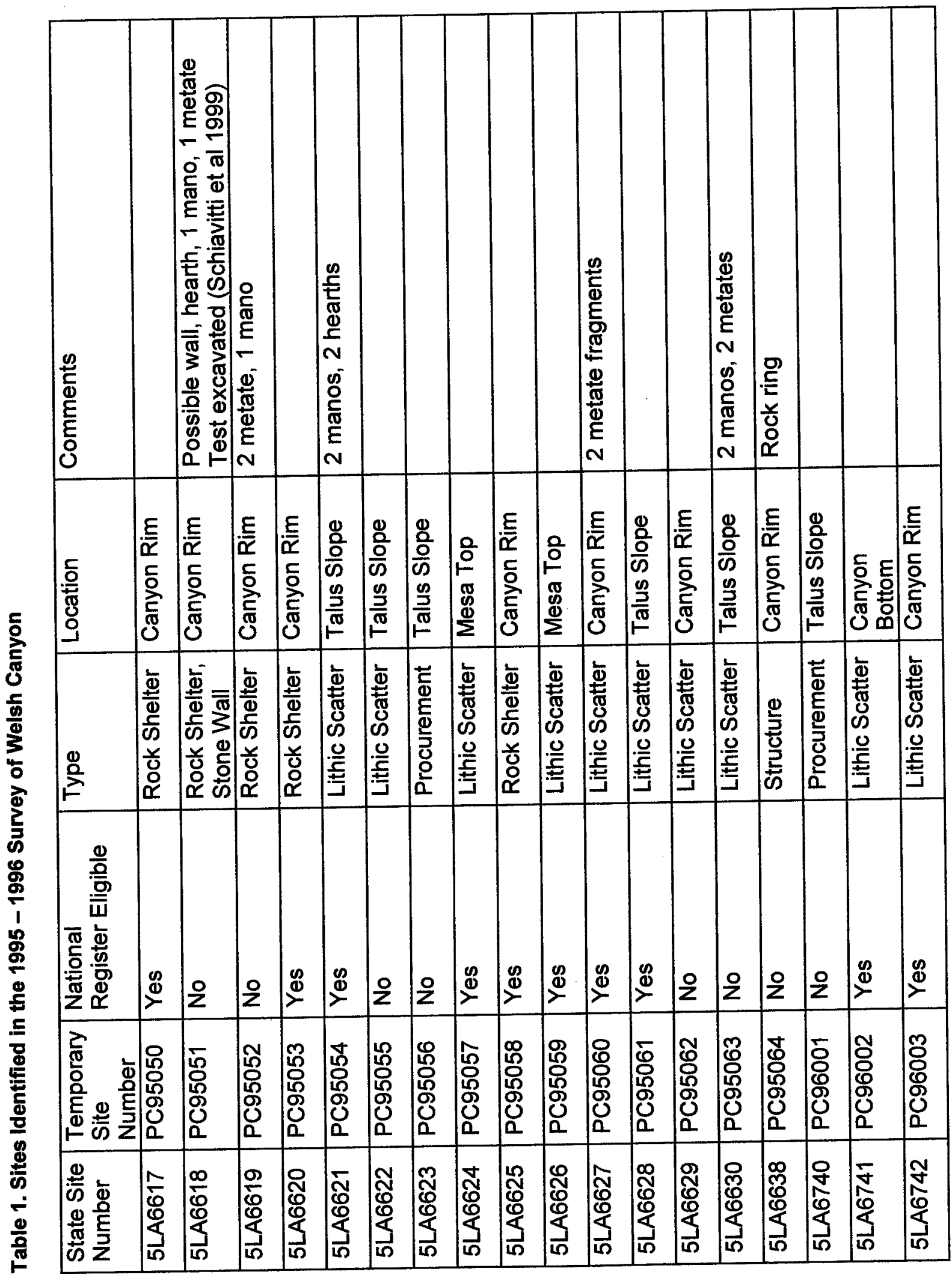




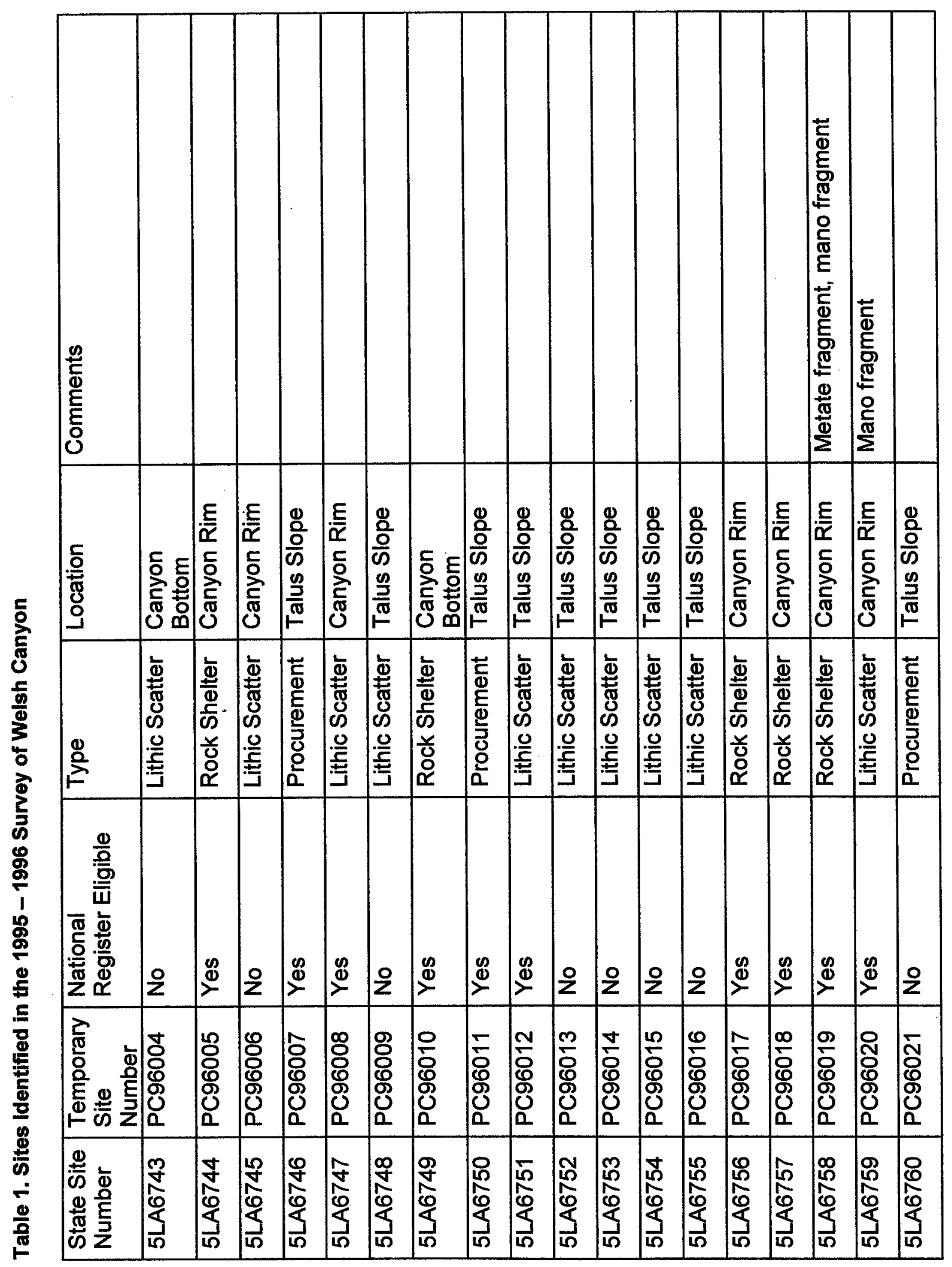




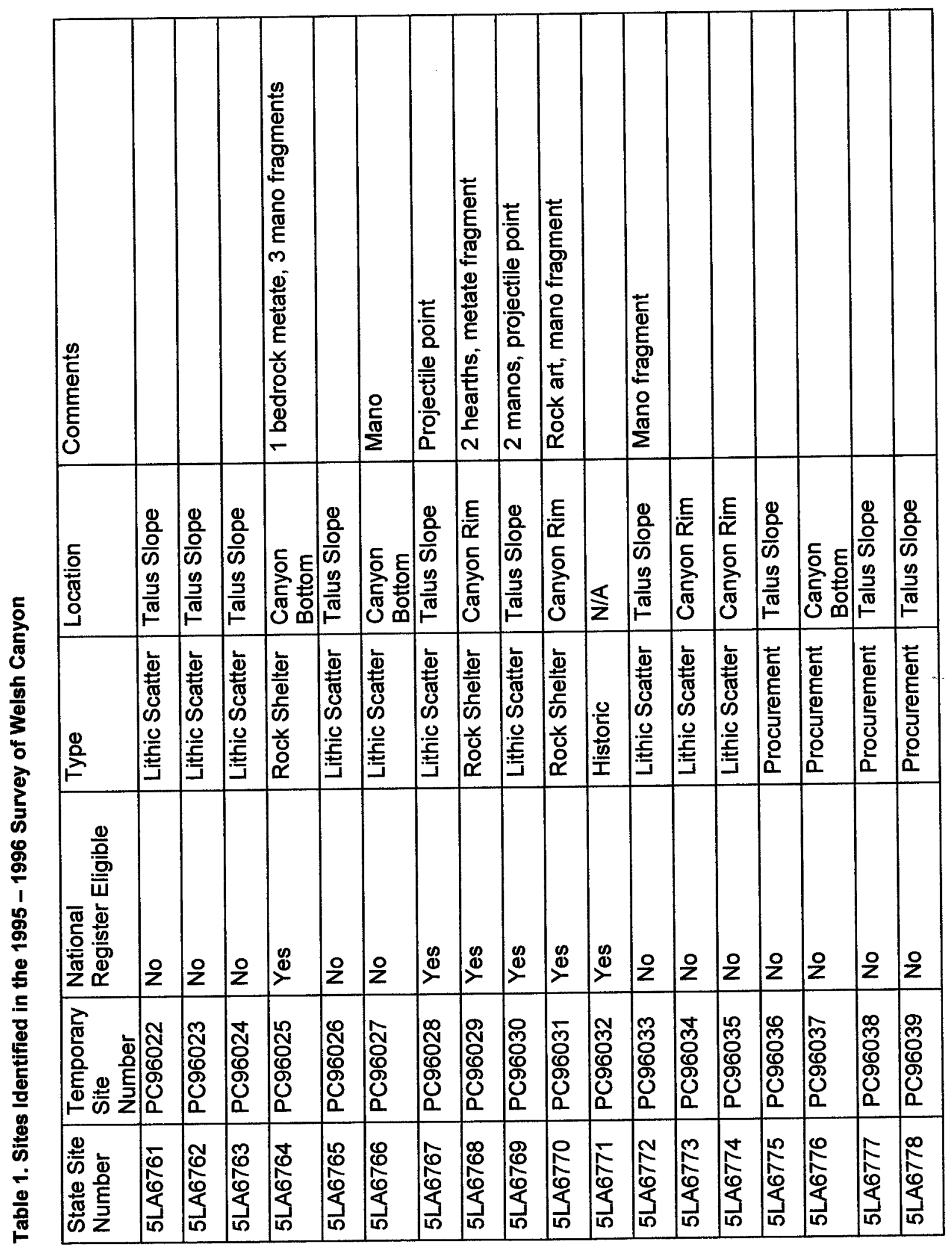




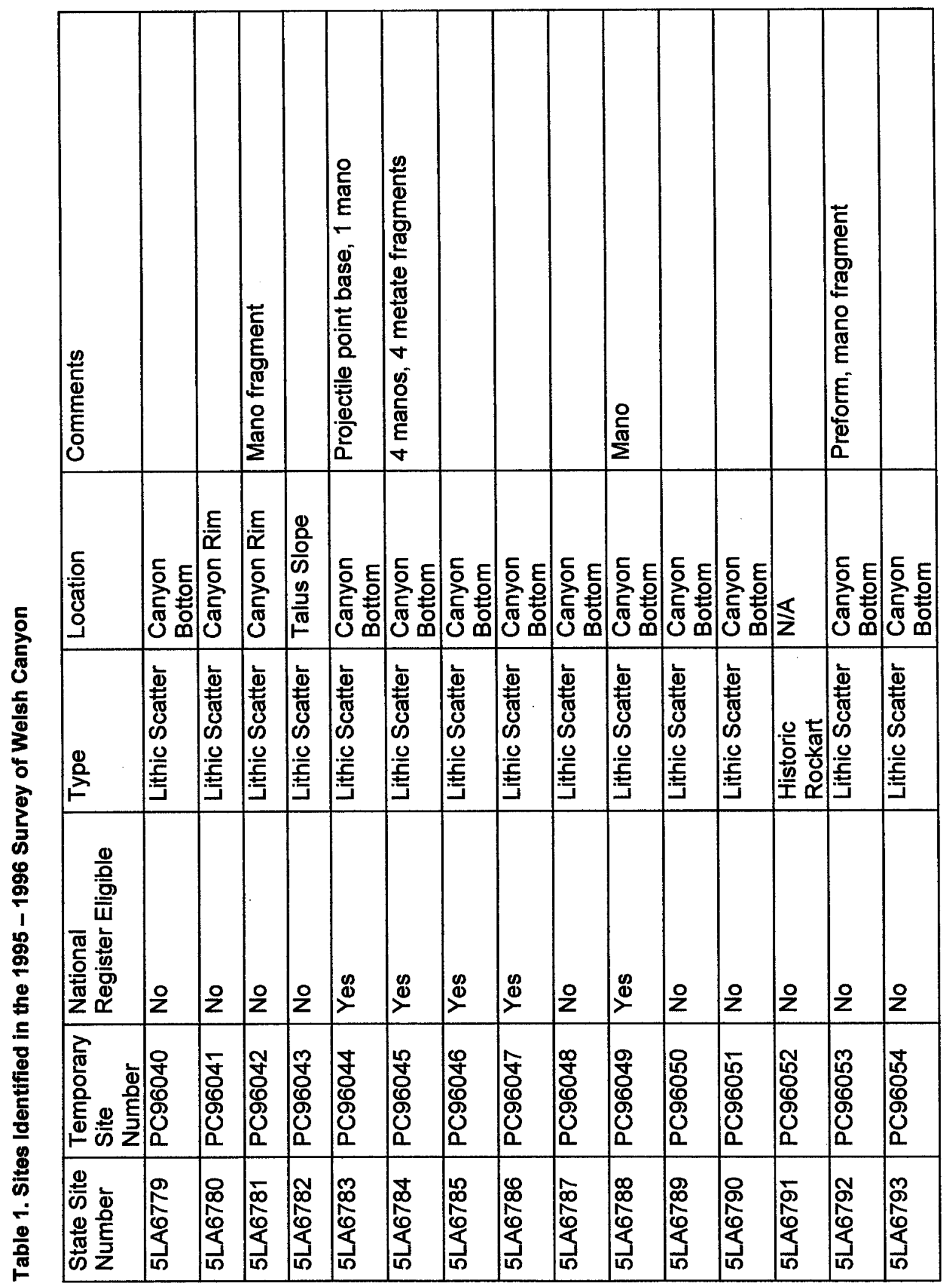




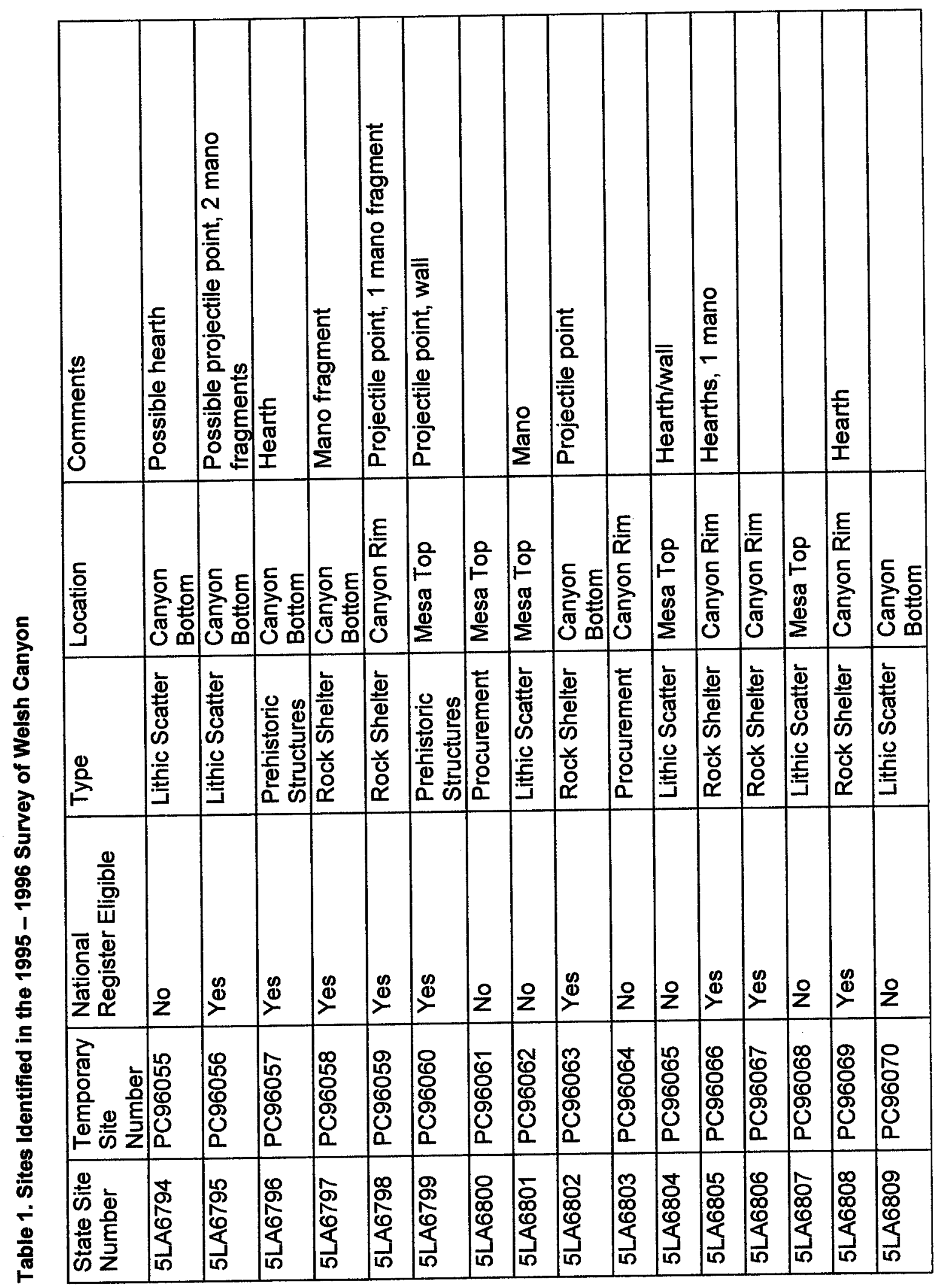




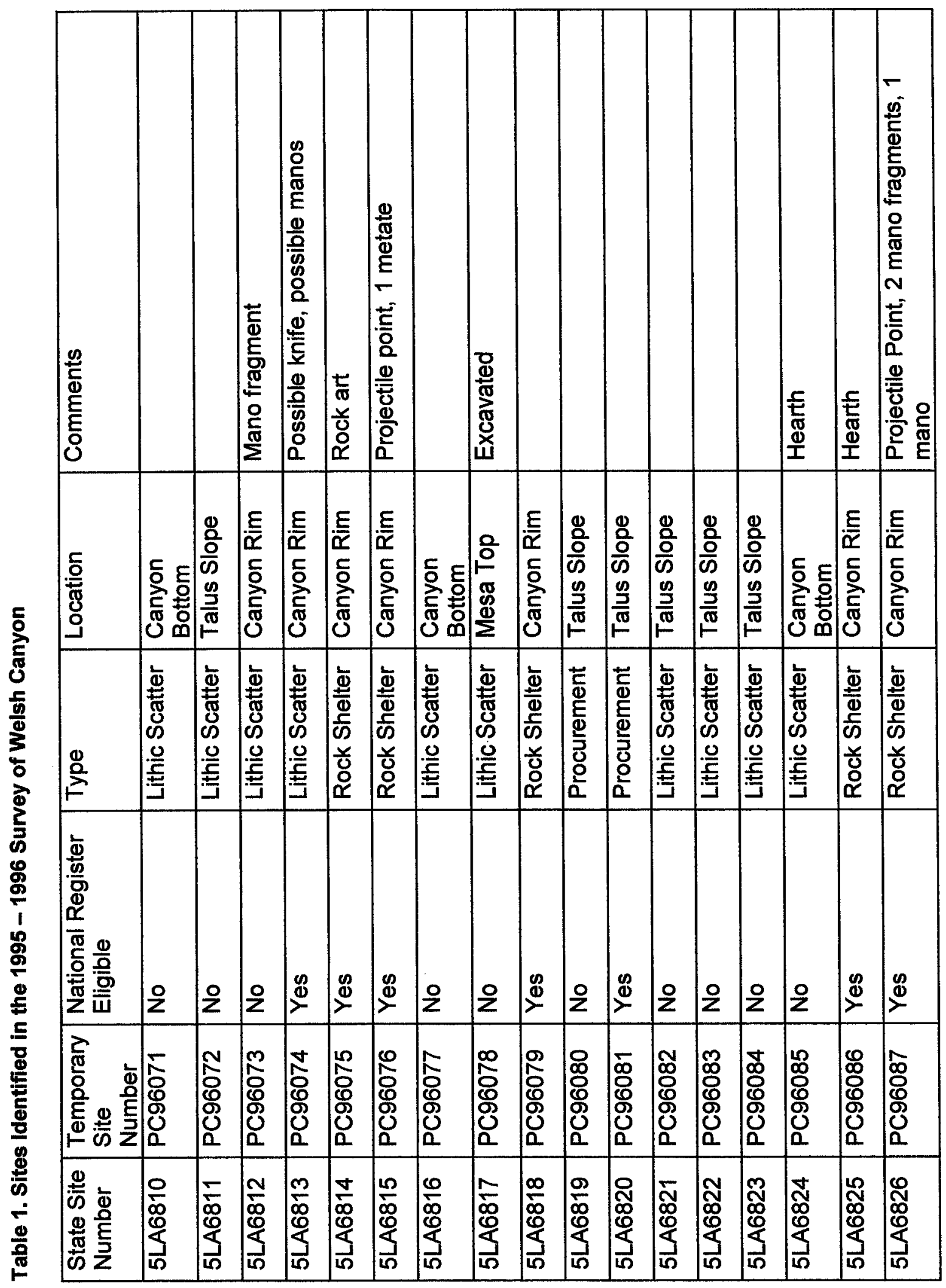




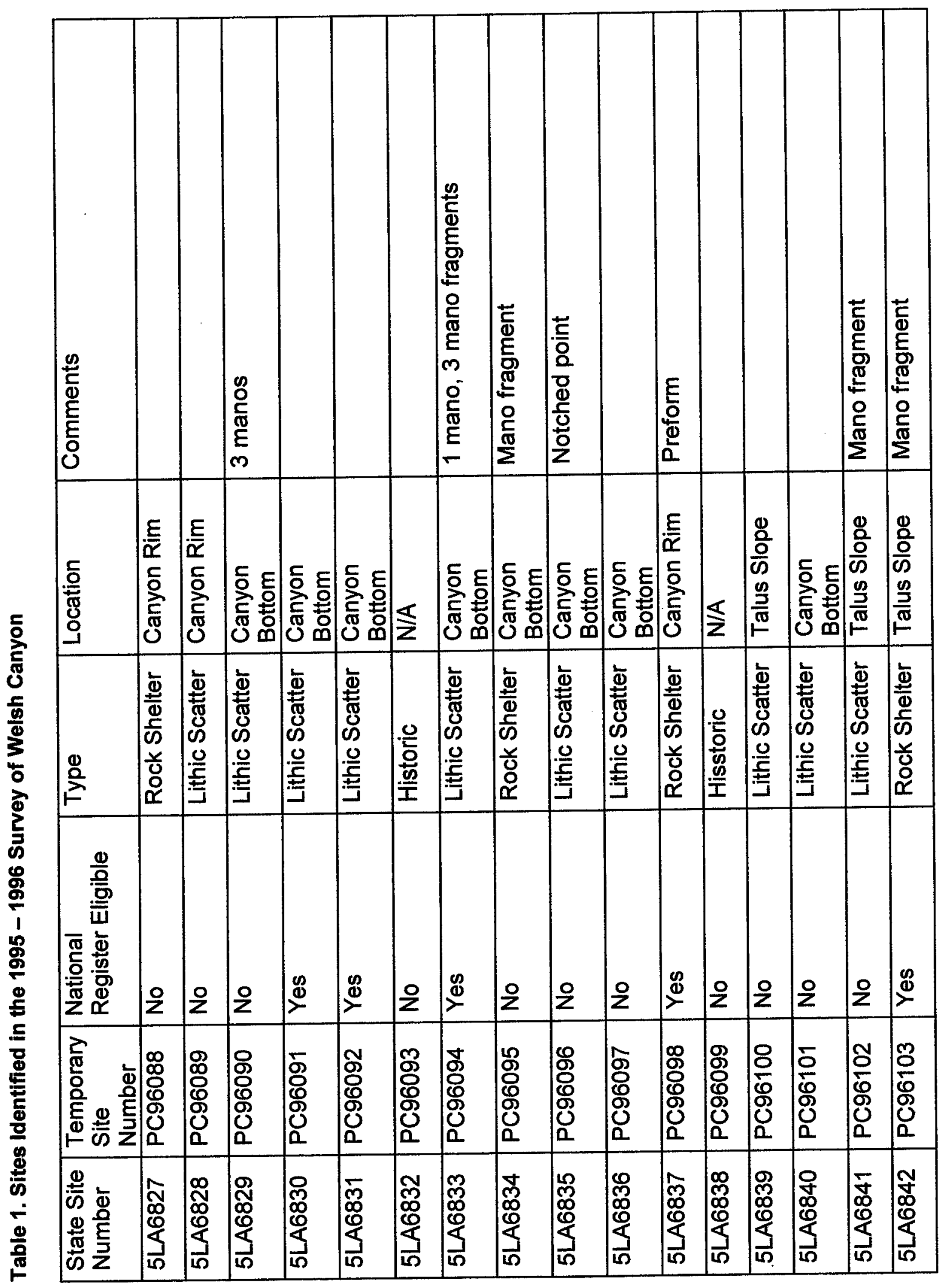




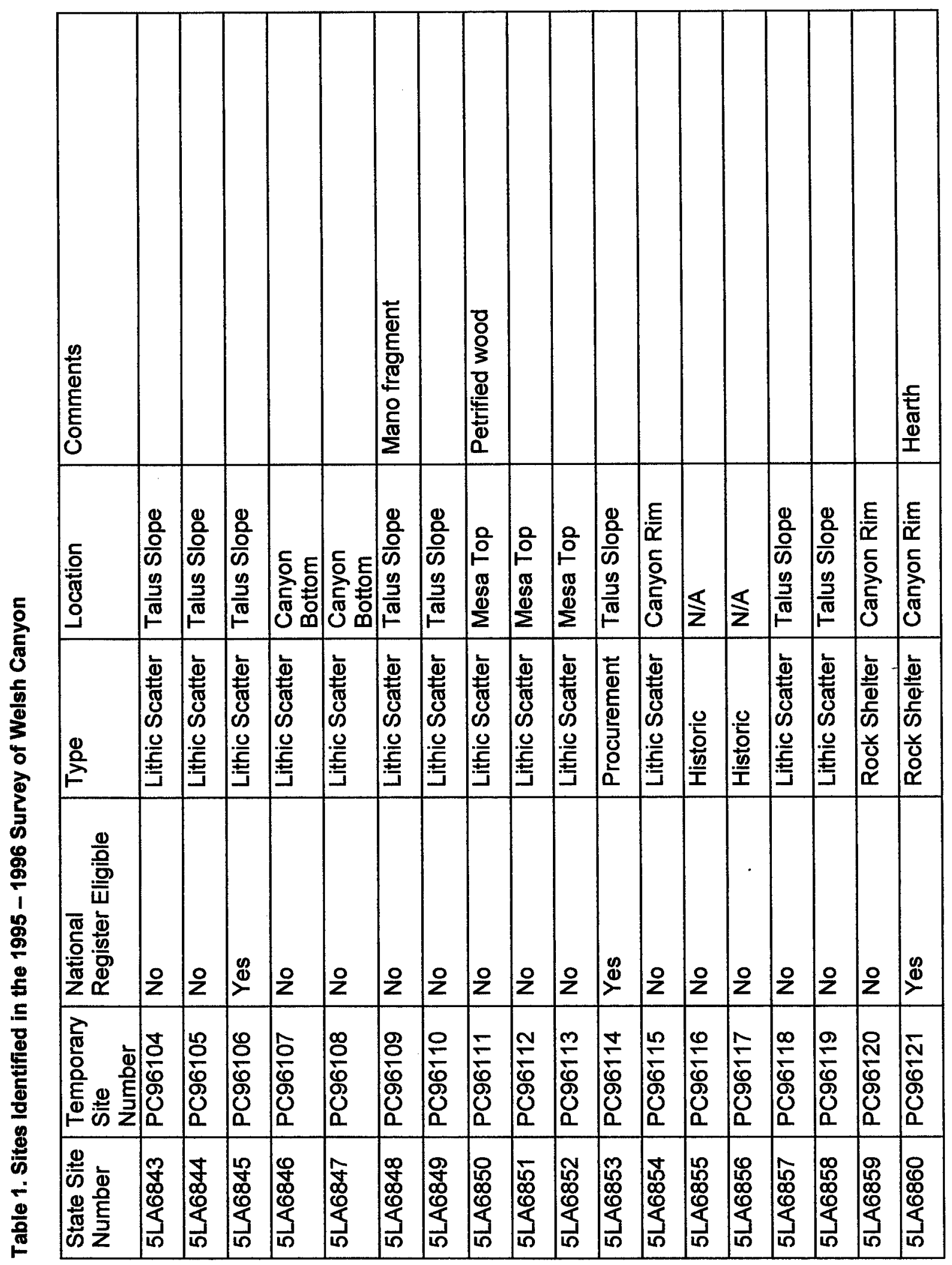




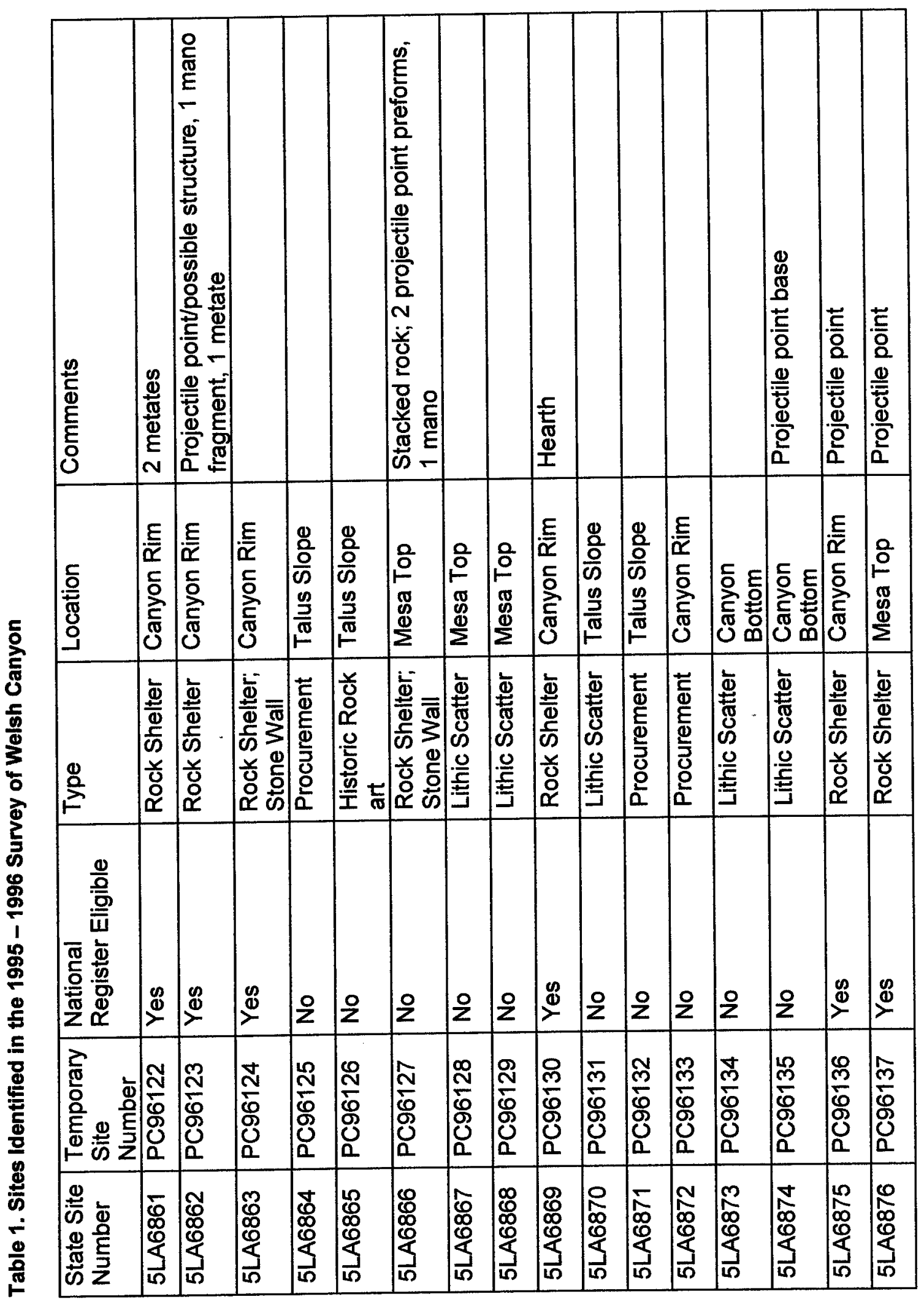




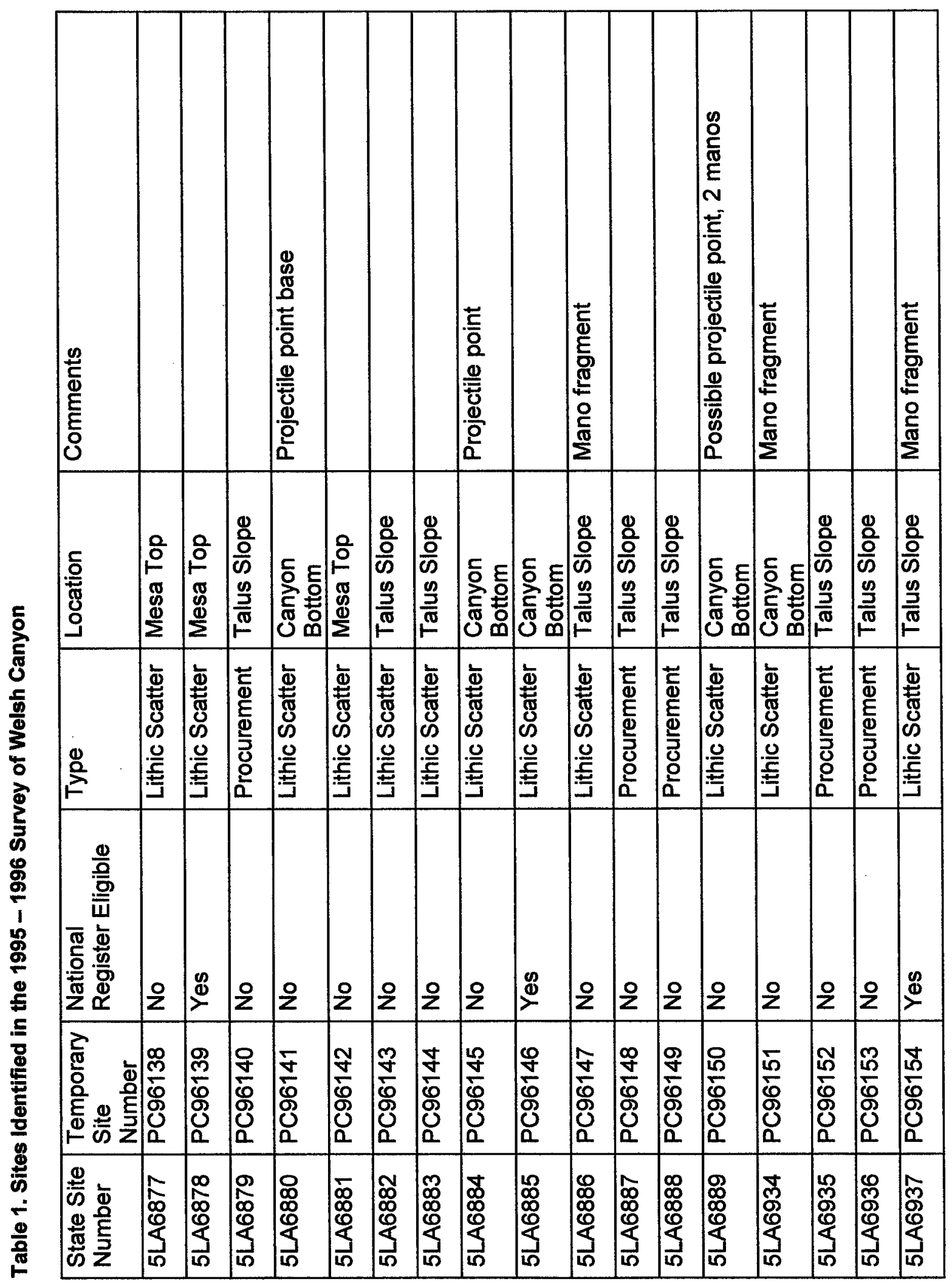




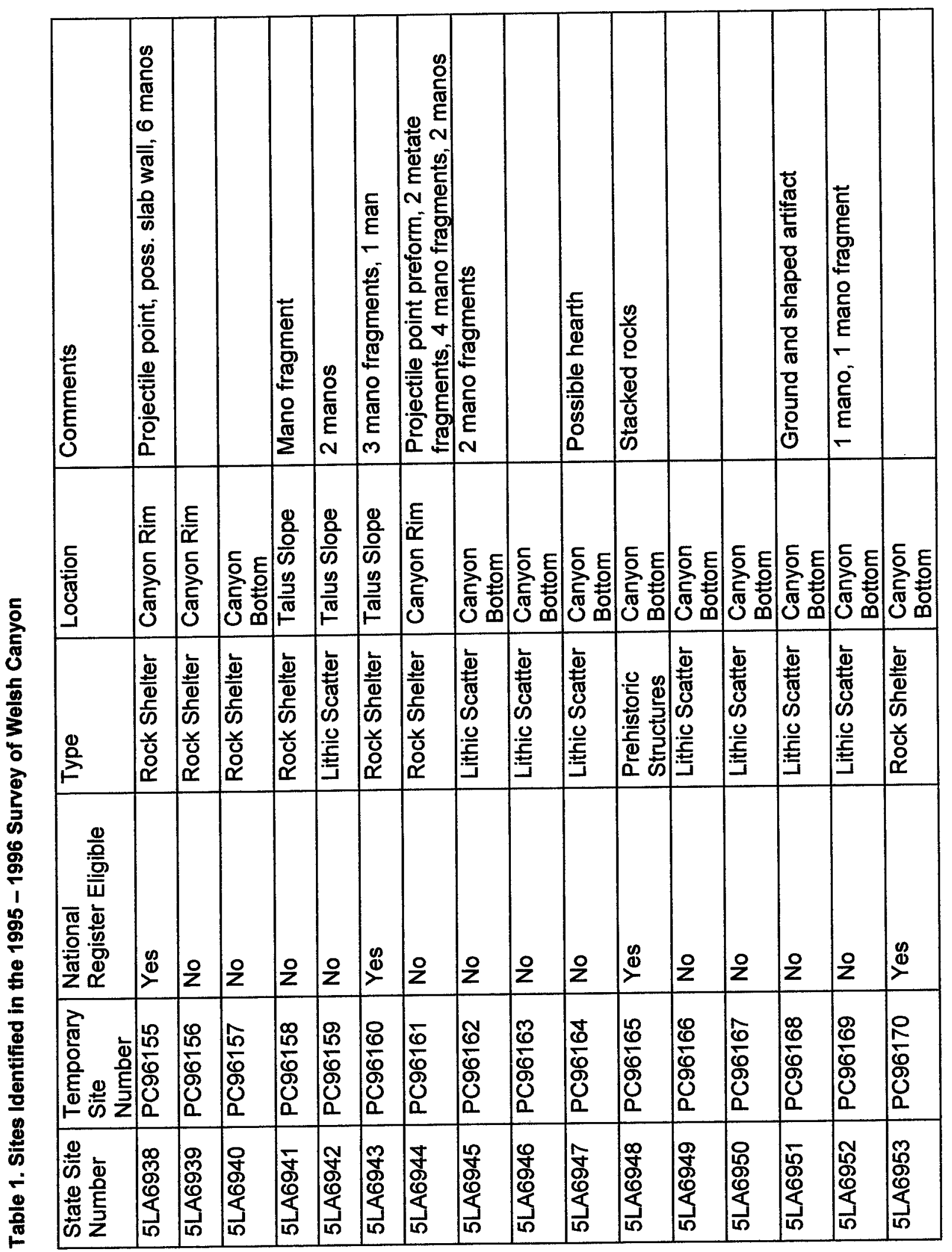




\section{SITE CLASSIFICATION CRITERIA}

This section describes five site types that were used to classify prehistoric cultural resources in Welsh Canyon, and examples of each type are presented. A number of different site types were identified in the 1995 - 1996 survey of Welsh Canyon including: lithic scatters, lithic procurement, rockshelters, rockshelters with stone walls, prehistoric structures, sites with rock art, and historic sites. Rock art was generally found at sites with other important features, usually rockshelters, and the sites are classed as rockshelters in the analysis. Because they represent a separate cultural period the historic sites are also excluded from quantitative considerations. Therefore sites with rock art and historic materials are described here, before the discussion of the other sites types.

\section{SITES WITH ROCK ART}

At the outset of the survey in Welsh Canyon the expectations were high for the discovery of new rock art sites. With the numerous pictograph and petroglyph sites in other side canyons to the Purgatoire River, like Van Bremer Arroyo, and the dozens of sites in the Purgatoire River bottom itself, survey personnel anticipated finding many new sites in Welsh Canyon. Individuals with prior experience in recording the rock art in the PCMS were employed in order to manage the anticipated large numbers of new sites. Unfortunately as the survey progressed into the canyon it became apparent that rock art was surprisingly rare in Welsh Canyon.

Rock art was found at only 8 sites ( 2 of these were historic initials) and none of these sites had a substantial number of rock art elements. Five of the sites with rock art were in rockshelters or closely associated with rockshelters and they are classed with this site type in the analysis. A single rock art panel was associated with a lithic scatter. The historic initial site (5LA6791) was in the lower reaches of the canyon bottom. This site includes JUAN, A. JONIO, COPuuts, CARPIO, and 101 incised and pecked into the sandstone surface. The 101 may be a reference to the famous Texas ranch brand, a fairly common historic motif in the region (Loendorf 1989), but these names and initials are not familiar. The second site with historic initials, 5LA6865, is located near the head of a side canyon to lower Welsh Canyon. The initials "X", "B", "O" and the number " 30 " are found incised into a sandstone boulder at the site. They are likely historic in origin, but none are recognizable. Native rock art sites include two with remains of pictographs and four with petroglyphs.

One of these is within the large rockshelter, 5LA6575 that also contains numerous bedrock metates. The petroglyphs include a panel of pecked figures which most closely resemble Archaic Pecked Representational Style (Loendorf 1989; Faris 1995) that dates between 3500 and 1500 B.P. Several quadrupeds, measuring as much as $21 \mathrm{~cm}$ across their maximum width, have ovoid bodies with short straight legs but no hooves or digitate feet. Their heads are simple oval 
blobs with straight ears or horns. These animals could represent any of a half dozen different quadrupeds. A pecked line that meanders through the panel has several loops and extensions. This panel is in a lightly varnished rock surface that makes it difficult to see. The relationship of this panel to the bedrock metates is not clear, but on another rock surface there a pecked line meanders through an area of bedrock metates.

This line may have been made at some time before or after the figures in the pecked panel, but it is directly associated with the metates as it meanders through the basins of several of them and along the sides of others. The longest extent of the line measures $180 \mathrm{~cm}$. At places there are horizontal branches connected to the line at right angles and these end in circles, loops, and other more elaborate meanders. These side branches, one as long as $50 \mathrm{~cm}$, appear to frame bedrock metates and divide the whole surface into quadrants. Some loops and connected circles, one measuring $26 \mathrm{~cm}$ in length, are found on this same surface but they are faint and hard to discern. The proximity of these petroglyphs to the bedrock metates suggests a direct relationship between the two, but the meaning or intent is unclear. It is possible the surface was originally covered with petroglyphs and then used for metates but judging from the degree of varnish cover it is more likely, the petroglyphs were made at the same time the metates were in use.

About $20 \%$ of the metates actually have pecking in them. This is expected, however, because the surfaces need to be roughened to make them function for grinding. There are also areas around the perimeter of some metates that are heavily pecked, perhaps as the areas for new metates. These examples indicate that the individuals who were involved in the menial task of grinding food were also responsible for pecking to roughen the surface and in many ways, the pecked lines around the metates look like the work of a person bored with the drudgery of grinding. If so, however, this "idle doodling" runs counter to current thoughts about the manufacture and use of petroglyphs.

A third panel of petroglyphs in 5LA6575 is unique in that it appears to use the dish-shaped metate form as the bodies of animals. These figures which measure $33 \mathrm{~cm}$ across their maximum are made on a vertical surface where the ovoid bodies and rounded heads were ground into the sandstone and then enhanced by incising short straight legs and ears or horns onto them. These surfaces may have never been used for grinding but the artists used the grinding technology to manufacture the form. In some ways these figures also suggest $a$ person bored with other tasks in the rockshelter.

The rock surface in 5 LA6575 also has historic initials, names, and dates. The dated graffiti includes J.B. Cordova, 4-7-1920; J.A. Cordova 4-7-1920; RMM, June 28, 1902; Roy Moygan (Moycan?), June 7, 1902; and J.K. Zwicker, Mar 29, 1909 The rame Juan Cordova is common on the rocks in the region and he is 
probably related to the Cordovas in 5LA6575. Perhaps Juan and his son, Juan (or Juan and his brother, Jesus) are the JA and JB of this site.

Site 5LA6575 also exhibits the linear grooves and incised lines known as tool grooves. These grooves were found at several dozen sites and they are discussed in separate section. Perhaps the most unique thing about the petroglyphs in 5LA6575 is the intermixing with the bedrock metates. According to the current understanding, metates are most commonly used for the grinding and processing of seeds into flour or mashing berries into a pulp. These are utilitarian purposes and they are not in agreement with the explanations for the manufacture and use of rock art as part of a ceremonial or supernatural complex. Understanding the association of these two seemingly disparate functions in this rockshelter is likely a key to interpreting the petroglyphs.

No artifacts were found in site 5LA6575. Metates used for grinding will only function with manos and it is extremely rare to find metates without manos in close association. The total absence of manos in 5LA6575 suggests the individuals who used the shelter for grinding removed their manos when they were finished. There are dozens of places to hide or cache manos in this rockshelter but if that is what happened, they are hidden so well they cannot be found. Archaeologists crawled into and searched every crevice, nook, and cranny in the shelter looking for manos but none were found. The talus washed out of the mouth of the rockshelter was carefully searched but no manos either complete or in broken fragments were found. Furthermore this talus was completely devoid of cultural remains or other habitation debris like chipped stone debitage, heat altered stones, charred earth, and animal bones. This is highly unusual for rockshelters in this region and it clearly indicates the individuals who were using the metates were not living in the rockshelter.

The absence of debris usually associated with habitation activities suggests the rockshelter was used for some other purpose and the rock art, using the accepted explanation for rock art, indicates the use may have been ceremonial. Perhaps the metates were used for grinding ceremonial products like pigment for paint or herbs for medicinal use but the fact that 60 metates are found in the shelter mitigates against such an explanation. Perhaps there were a dozen individuals doing the ceremonial grinding or the grinding in different individual metates was for different purposes but these explanations lack parsimony and become doubtful.

Site 5LA6584 is multi-component with an undated cultural material scatter and a protohistoric or historic rock art panel. The rock art is among one of the more interesting in the Maneuver Site in that it represents the horse riding Indian use of the region. Located near the junction of two upper canyon forks to Welsh Canyon, the painted figures are executed on the lower side of a large boulder where they have been protected from the elements (Figure 3). This is fortunate because the artists appear to have used a simple red mud mixture to put them on 
the rock surface. Those which are on the under side of the rock have preserved while those on the vertical surface, even though they are protected, have nearly faded from view. Originally there may have been more panels of the figures.

The relatively crude drawings include two human figures that are riding horses and chasing three other animals. Some see the animals being pursued as bison while others think they may be horses. Using historic Plains Indian paintings on other media like hides or ledger paper, either could be correct because it was common to depict scenes of hunts or examples of the horses obtained in raids. One of the riders may be holding a bow (Figure 3 ) and if this is the case, the rendition of a hunting scene is likely the more accurate assessment because hunters carry bows while horse thieves more frequently carry the medicine shields, or lances and staffs identifying their warrior societies.

The lower panel is probably an example of a similar scene, but the horse and rider is too faded to determine much about the depiction. There is a possibility that these images could be enhanced through computer imagery, the use of camera filters, or by employing ultra-violet or infrared light.

Although they are not commonplace, other scenes of horses and riders are known in the region. A group of figures at 5LA5569 in Taylor Arroyo, are executed in charcoal and riding horses much like the ones in the Welsh Canyon scene (Loendorf and Kuehn 1991:187-188, 207-208). The riders on these horses differ in that they are more stylized, but the horses themselves are similar forms with elongated necks and exaggerated straight ears. There is assurance that the authors of the figures at site 5LA6584 are mounted Plains Indians but a more direct tribal identification is not possible. Comanche, Ute, Cheyenne, and Kiowa are candidates and until more research is completed, it is not possible to differentiate among one or the other of these tribes as the artists.

An interesting aspect of the paintings is the use of mud in their manufacture. The reddish-brown colored mud appears to simply be a mixture of clayey earth and water that was applied by a hand or fingers to the rock surface. These mud-glyph drawings are at least 100 years old and they may be as old as 200 years. As such they are remarkable testimony to the preservation of rock paintings that are placed in situations where factors favor their conservation. Protected from wind and water erosion, these figures have remained for generations after their makers left them on the rock. It is unfortunate that we cannot bring back the great, grand children of the original artists to witness the legacy left by their forefathers. Hopefully now that they have been identified they will remain untouched and not suffer the destruction of so many other pictograph sites, especially those near towns and cities where unthinking clowns and reckless idiots destroy them for the fun of it. 


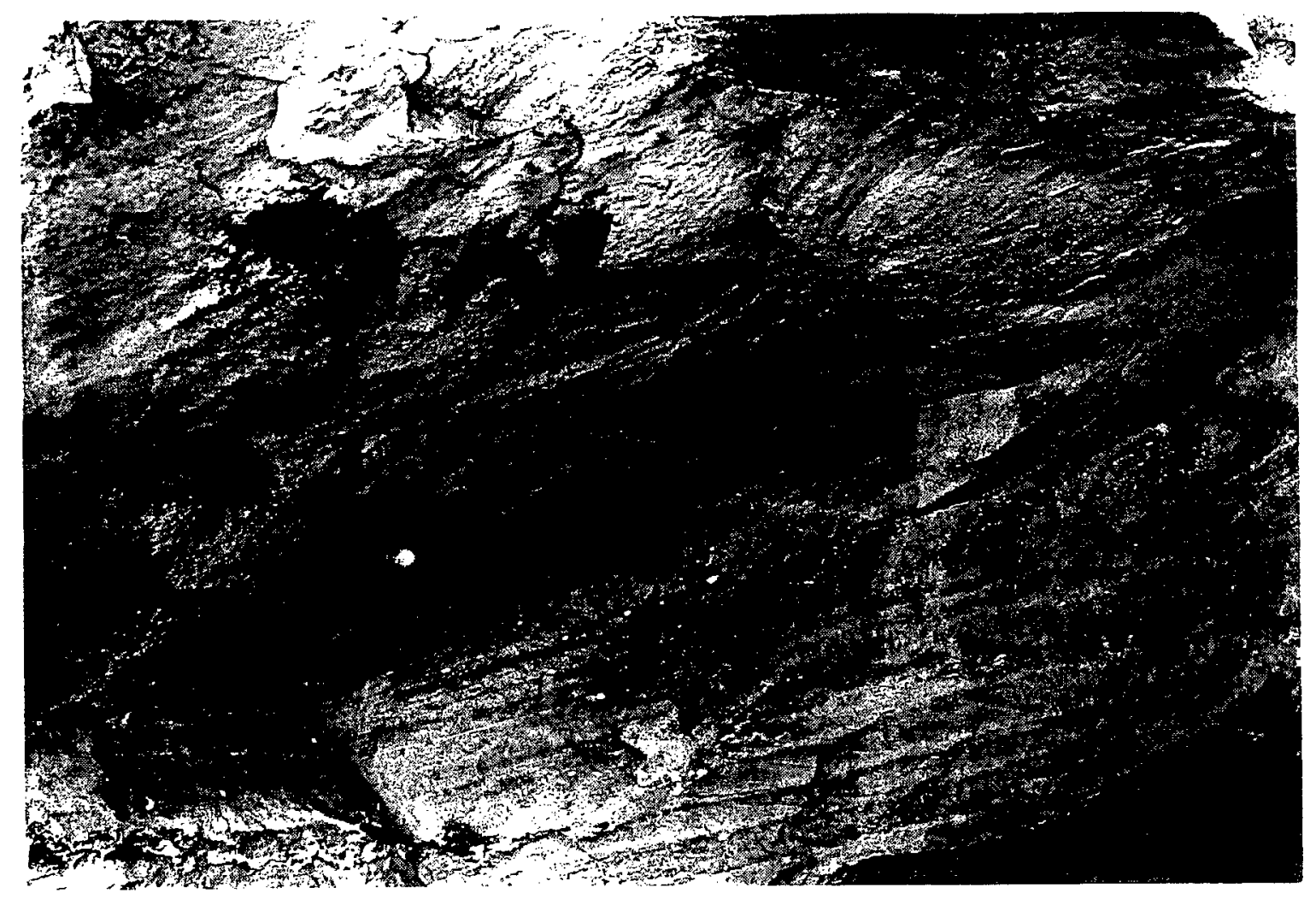

5LA6584 - Overview of pictographs.

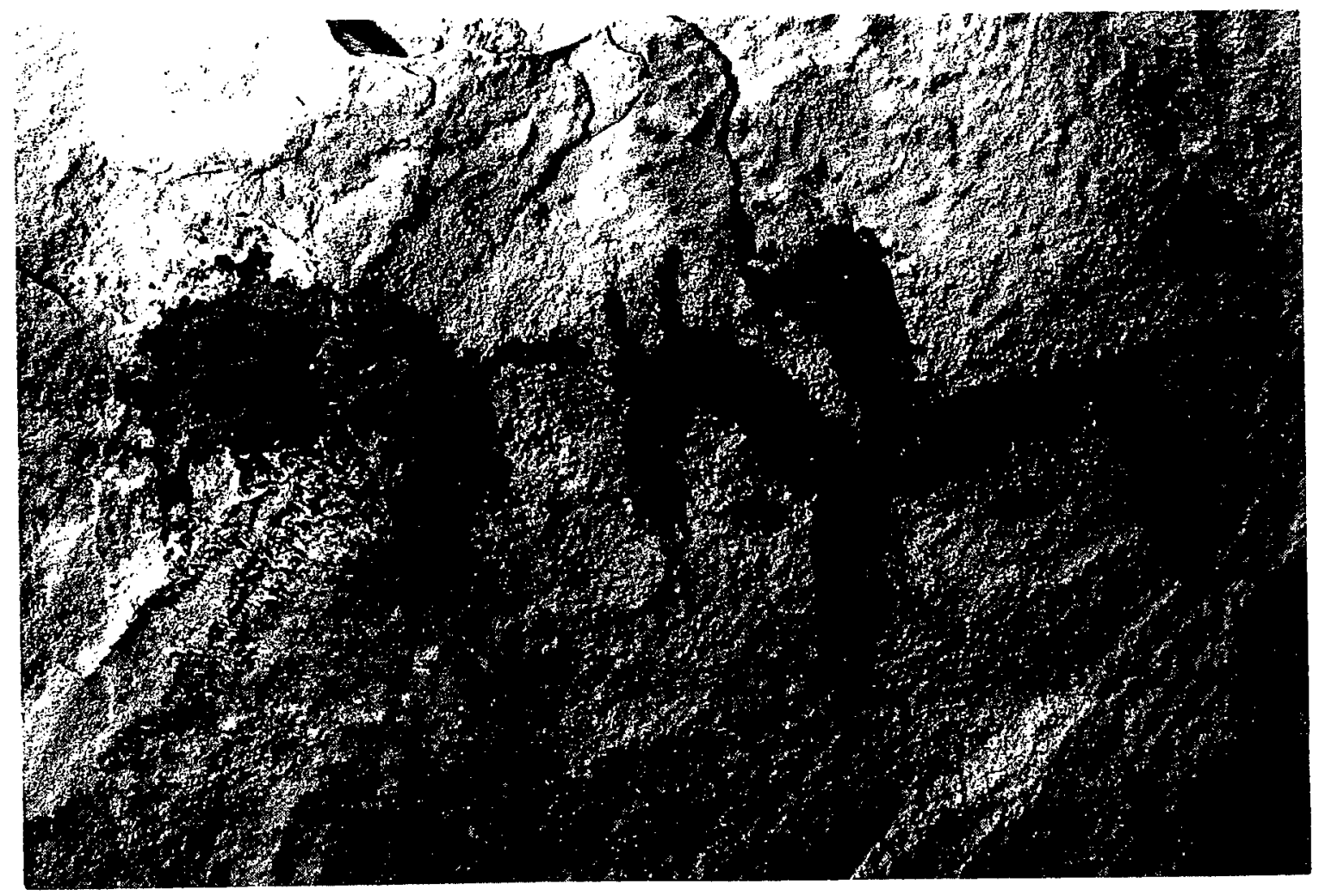

5LA6584 - Pictographs around northern top end of panel.

Figure 3. Pictographs at 5LA6584 
The rock art at site 5LA6589 includes historic and prehistoric components that are located near the head of a tributary canyon that enters from the north in the upper reaches of Welsh Canyon. The historic component is represented by a homestead and ranching operation while based on surface artifacts the prehistoric use was primarily during the Ceramic Period, although there may have been an Archaic use as well.

The rock art reflects the same time periods as the surface artifacts. An historic human figure with a large brimmed hat appears to represent a cowboy. A pecked circle and a pecked p-shaped figure in the same panel may also be historic or they could be abstract designs from an earlier period. A second panel of figures is clearly from the Ceramic Period. The remains of 9 to 10 quadrupeds are found on a vertical canyon wall that faces southwest on surface that is nearly 8 meters above the current ground level. This group of pecked quadrupeds includes examples with boat-shaped bodies and other with more rectangular body shapes. Heads display swept back horns that apparently represent bighorn sheep. The legs on the animals are short and straight in stiff poses that are most common in the Late Archaic and Early Ceramic Period. Comparable figures are found on the Zookeeper site (Loendorf 1992) and elsewhere in the Pinon Canyon region (Faris 1995) where they are part of the Pecked Representational Style (Loendorf 1989).

A pictograph at 5LA6599 is within a rockshelter that is associated lithic scatter. The site is situated near the floor of Welsh Canyon along the north wall about 6 meters above the drainage bottom. Surface artifacts at the site suggest multiple episodes of use during the Ceramic Period and test excavations into the site indicate this is apparently correct (Schiavitti et al1999).

The single remaining rock art is a pictograph of a quadruped that was painted in a black pigment. The eroded figure looks most like a horse but it could also be some other four-legged animal. No evidence for historic use of the rockshelter was recognized in the excavation but it is not uncommon to find historic rock art and no associated artifacts. In part this reflects the more careful curation of metal artifacts that were sufficiently important so that they were not readily lost. Metal artifacts, compared to stone ones, are also less easily altered and for this reason there is less detritus or residue in historic-age sites.

Black paint near the figure indicates there were once more figures in the small rockshelter. The site with its eroded figures serves as an example of the state of the rock art in Welsh Canyon. The sandstone surfaces are not well consolidated and erosion has apparently taken its toll on the rock art.

Site 5 LA6613 is situated along the southern Welsh Canyon rim where it overlooks the main canyon that is about 150 meters below. The multi-component site exhibits surface artifacts from both the Middle Archaic and the Historic 
Period. Fire features, manos, metates, edge-ground cobbles, flaking detritus, flake tools, and a large-notched dart point represent the older component. The historic artifacts include a tin coffee box, a side seam can, and an $8 \mathrm{~mm}$ cartridge case. These apparently represent a sheepherder or cow camp that was set in the protected area along the face of Welsh Canyon below the main areas of the prehistoric site. A freshwater spring adjacent to the site appears to have been a prime attraction to the location.

The rock art is located on the face of Welsh Canyon in areas where large blocks of rock talus create protected crevices and fissures. One of these fissures allows access to the top of the canyon rim about 12 meters above and one of the petroglyphs is situated near the lower entrance to this passage. It has a net-like or grid-like pattern of interconnected squares and rectangles within rounded perimeter. Slightly larger than 10 centimeters across, it looks like an oversized pretzel. A small pile of 20 to 30 rocks is situated immediately below the rock art and apparently related to it.

The second petroglyph is an undulating line that measures 80 centimeters across its maximum dimension (Figure 4). The line, which is oriented horizontally, has deep and complete u-shaped curves and bends in its contorted outline. It looks like a long snake without a head or tail.

Originally there may have been more petroglyphs at the site but erosion and surface rock fall have obliterated them. Both of the remaining petroglyphs are heavily covered with varnish and because the rock wall erodes so rapidly in this region it is probably fortunate that they have survived. The petroglyph designs at this site are typical of Archaic-age rock art sites elsewhere in the Pinon Canyon Maneuver Site. The Archaic-age projectile point denotes an associated use of the area and serves as secondary confirmation of the age of the petroglyphs.

The petroglyphs at 5LA6770 are found in a small rockshelter at the head of a tributary drainage to Welsh Canyon. Tool grooves are the most prominent features at this location but it is possible to identify remnants of pecked figures. Unfortunately the figures are so eroded and faint it is not possible to recognize any of their former design or style. 


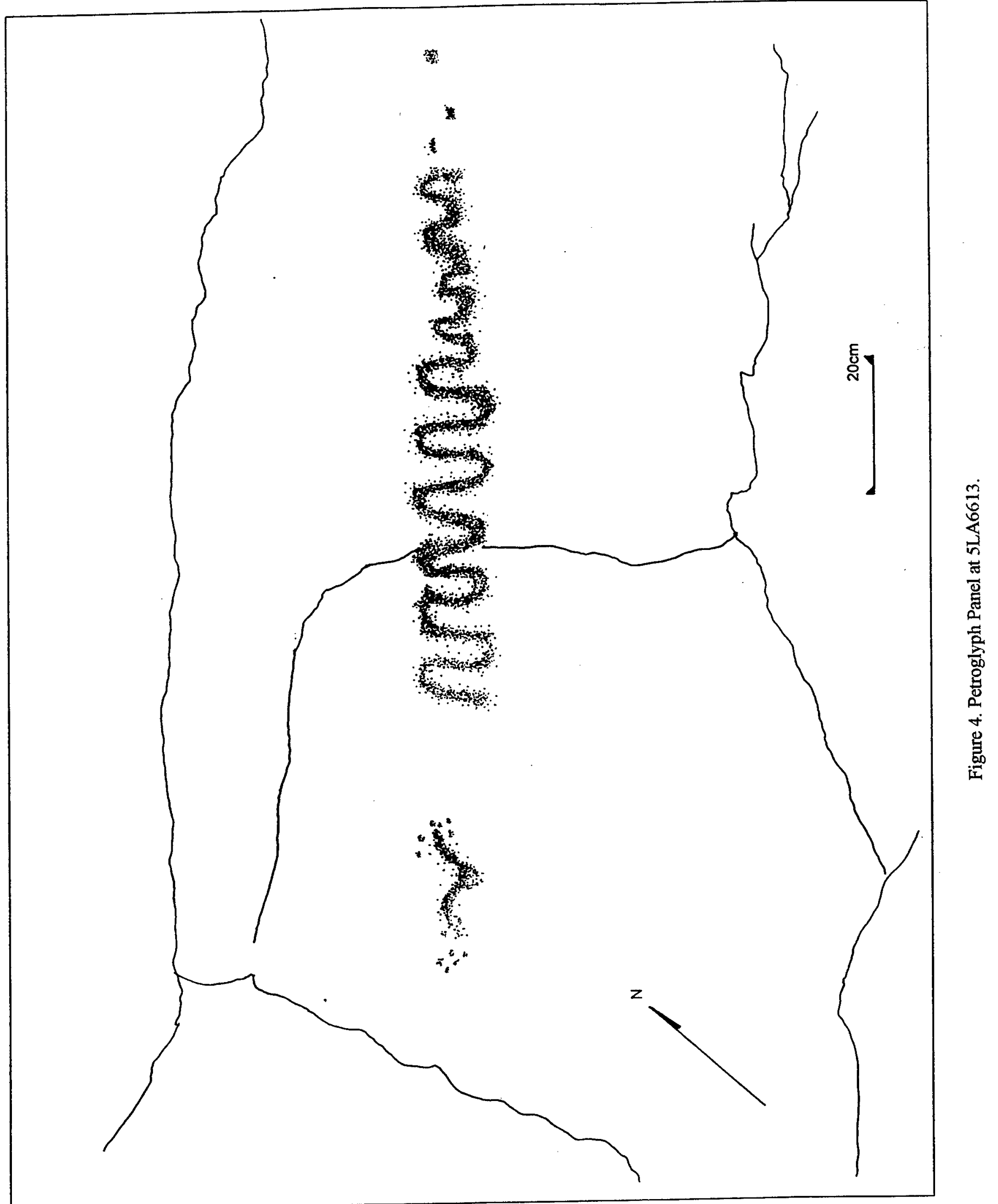




\section{HISTORIC SITES}

Historic sites are excluded from the quantitative analysis, and are only briefly described here. The historic sites include a dry-laid rock wall exposed in a cutbank, a corral, and a lambing pen with a rock enclosing wall and removable door. The single site with both prehistoric and historic features contains groundstone and chipped stone debris, bedrock metates and rock art as well as the remains of a former Euroamerican homestead and associated debris. The historic site inventory is skewed considerably because the standing structural remains were previously recorded and therefore not included in the survey. If these sites had not been previously recorded, they would have added eight to ten standing Euroamerican structures to the survey.

Site 5LA6602 is among the more interesting of the historic sites found in the survey. The historic debris at this site is found in a trench that apparently represents a breech in an earthen dam. Like other earthen check dams this one is at the mouth of a side tributary to an upper arm of Welsh Canyon where it is designed to catch and hold run-off from spring meltwaters and the intense thunderstorms, which frequent the region in the summer. Stored in the ponds behind these dams, the water was available for cattle, sheep and horses.

The curious thing about site 5LA6602 was a dry-laid stone wall that was evident in one side of the breech trench through the dam. Initially this was suspected to represent some sort of a floodgate, constructed to allow extra water out of the area behind the dam and into a lower pond. As learned during the test . excavations, however, the stone wall is more likely the remains of a dugout or some other historic building that was buried in the construction of the dam (Schiavitti et al1999).

\section{PREHISTORIC SITE TYPES}

Rockshelters, these sites have natural rock overhangs with associated artifact scatters or features such as basin shaped ground areas of bedrock commonly referred to as bedrock metates. The highest concentrations of artifacts were generally identified on the slopes below shelters, which is probably the result of both natural erosion down the slope, and a tendency for the shelter's prehistoric inhabitants to dispose of refuse immediately outside the rock overhangs. A wide range of different artifact types was identified at Welsh Canyon rock shelter sites. Archaic style projectile points as well as late prehistoric style points and ceramics were found in rock shelters suggesting that considerable time depth exists for human use of these natural refuges from the elements.

Site 5 LA6875 is a typical example of a rockshelter site. Three small northwest facing rock overhangs and an associated lithic artifact scatter are present at the site. The site measures 17 meters from north to south and 12 
meters east to west. The rockshelters are located at the base of a cliff, above the roughly 40-degree slope of a Welsh Canyon tributary drainage. The modern vegetation in the site area consists of juniper, prickly pear, yucca, cholla, grasses, cane-like stalk grass, moss, and Rhus trilobata.

Fill in the shelters consists predominantly of aeolian deposited brown silty sands, with a maximum deposition of 50 centimeters. Moderately intense water erosion has disturbed sediments at the site. Two of the rockshelters have little or no deposition on the interior and their base consists of exposed sandstone bedrock, consequently, no cultural material was observed inside them. The remaining rockshelter, however, has $50 \mathrm{~cm}$ or more of deposition; buried cultural deposits are probably present within this shelter.

Artifact density was relatively low at the site; however, the area is covered by comparatively dense vegetation and surface visibility at the time of the survey was poor. A corner-notched basalt projectile point was collected from the surface of fill that appears to have eroded from the rockshelters. Additional artifacts observed at the site include an argillite secondary flake, quartzite flakes, and shatter. The projectile point style suggests that this site was used for habitation and tool manufacture some time during the Late Archaic Period.

A second example of a rock shelter site is provided by 5LA6598 (Figure 5). This site consists of a south facing rock overhang approximately 50 feet from the bottom of Welsh Canyon, at an elevation of 4890 feet. The site measures 16 meters east to west and 9 meters from north to south. The vegetation at the site consists largely of scattered juniper trees. Other vegetation observed in the site area includes yucca, Rhus trilobata, prickly pear, bunch grass, cholla, snakeweed, and artemisia. Fill within the rock shelter consisted of aeolian deposited brown sandy silt.

A small number of macroscopically unmodified lithics and tools were identified within the shelter, and artifacts were scattered down the slope in front. Sixteen quartzite flakes, 3 chert flakes, and 1 hornfels flake were identified. One utilized flake and one biface fragment were also located. Two bedrock metates were found within the shelter; one-measured 20 by 14 centimeters with depth of 1-2 centimeters, dimensions of the second metate were 18 by 13 centimeters with a maximum depth of 0.7 centimeters.

Rockshelters with Stone Walls, these sites are similar to those in the first category except that dry laid stone walls were added along the front of the shelter. The upper portions of these walls that were visible on the surface were usually no more the two or three courses in height, but natural erosion and historic disturbances (especially use of the shelters by livestock in historic times) may have frequently reduced the number of standing courses. 


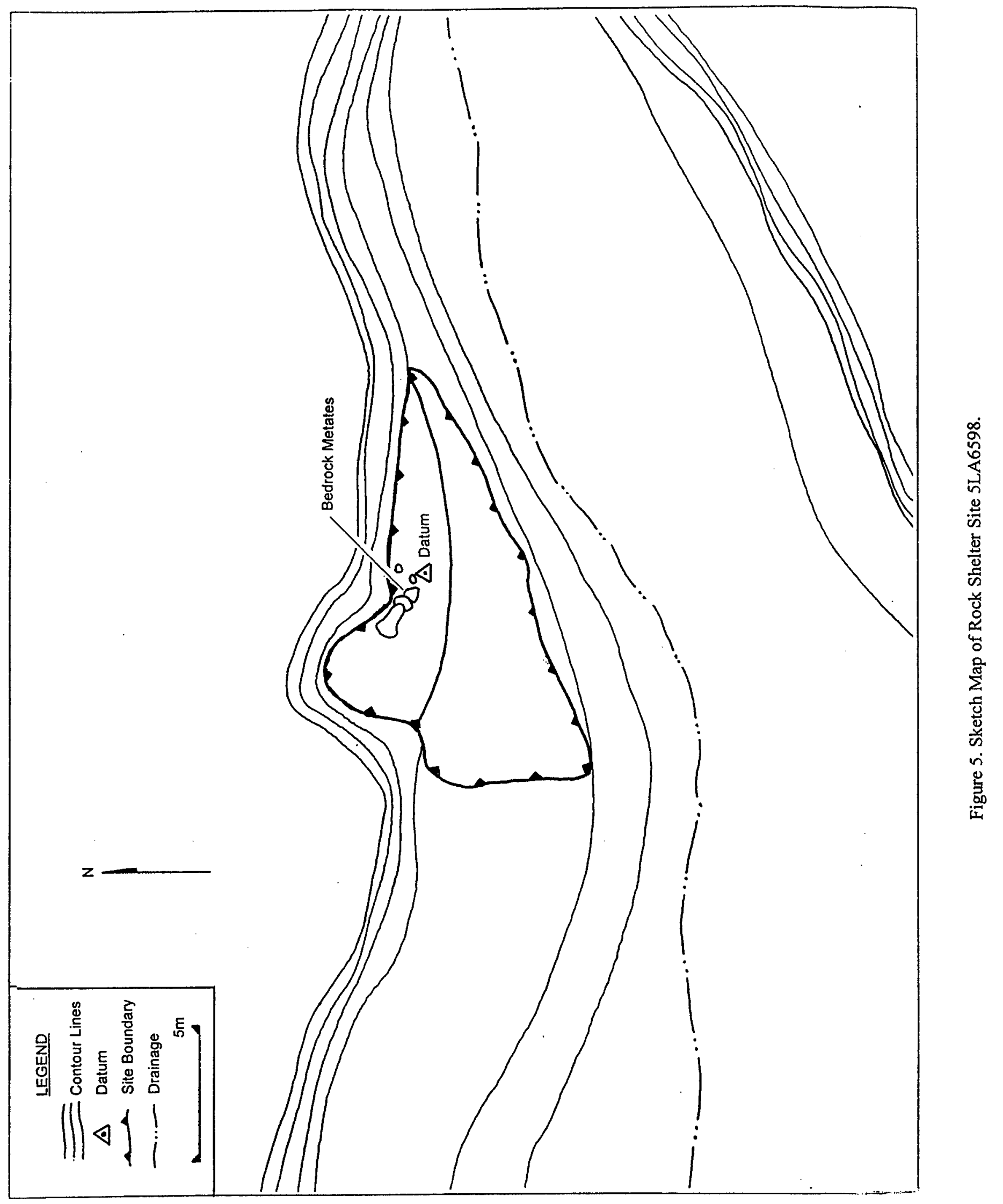


Site 5 LA6860 is an example of a typical rockshelter site with stone walls. This sites consists of two south-facing rock overhangs with evidence for prehistoric habitation that are located on the slope of a side drainage at an elevation of 5200 feet. The site covers an area of 92 meters east to west and 20 north to south. Vegetation at the site includes juniper, bee weed, grasses, cholla, prickly pear, and Rhus trilobata. Fill ranges up to 20 centimeters deep within the rockshelters, and consists largely of aeolian deposited light brown, silty sand. Disturbance to the site has resulted from animal burrows, and there has also been some water erosion.

The two rock overhangs are located within approximately 15 meters of each other. The first shelter is unusually large; this shelter is $\mathbf{3 0}$ meters wide with a maximum depth of 17 meters. Large piles of rock-fall are present at both ends of the shelter. Height at the tallest point is approximately 4.5 meters. Two probable hearths were identified toward one end of the shelter. Heat cracked rock is present on the surface and flaking debitage is scattered over the floor of the shelter.

A natural barrier of large boulders protects the interior of the shelter, and additional smaller rocks appear to have been stacked at one end. This exposed portion of wall has been extensively disturbed; most of the wall consists of a single irregular course, but two courses are present in isolated locations. It is possible that the wall continues below the current ground surface.

The second shelter measures approximately 28 meters from east to west and 10 meters deep, with a maximum height of 4 meters. No artifacts or features are found on the interior of the shelter, but they are scattered down slope in front.

A relatively high density of artifacts is scattered down the slope below the shelters. Ashy fill and heat altered stone are also scattered down the slope. A small bench, below the shelters, exhibits artifacts but it is unclear if they were deposited by slope wash or are associated with another activity area.

Over 100 flakes were identified within the site boundaries. These artifacts consisted largely of tertiary quartzite flakes, but primary and secondary flakes were also present. Most of the chert flakes were secondary, but all stages are also present. A single fine-grained basalt utilized flake was noted, and a second quartzite utilized flake was recorded. Several pieces of bone were found. Four of these appeared burned while another fragment, speculated to be a bird bone, was not burned. No temporally diagnostic artifacts were visible on the surface and no collections were made.

Site 5LA6603 provides an additional example of rockshelter with a stone wall (Figure 6). The site is located on the southeast-facing slope of an unnamed tributary to Welsh Canyon at the base of a cliff, at and elevation of 4887 feet. The 


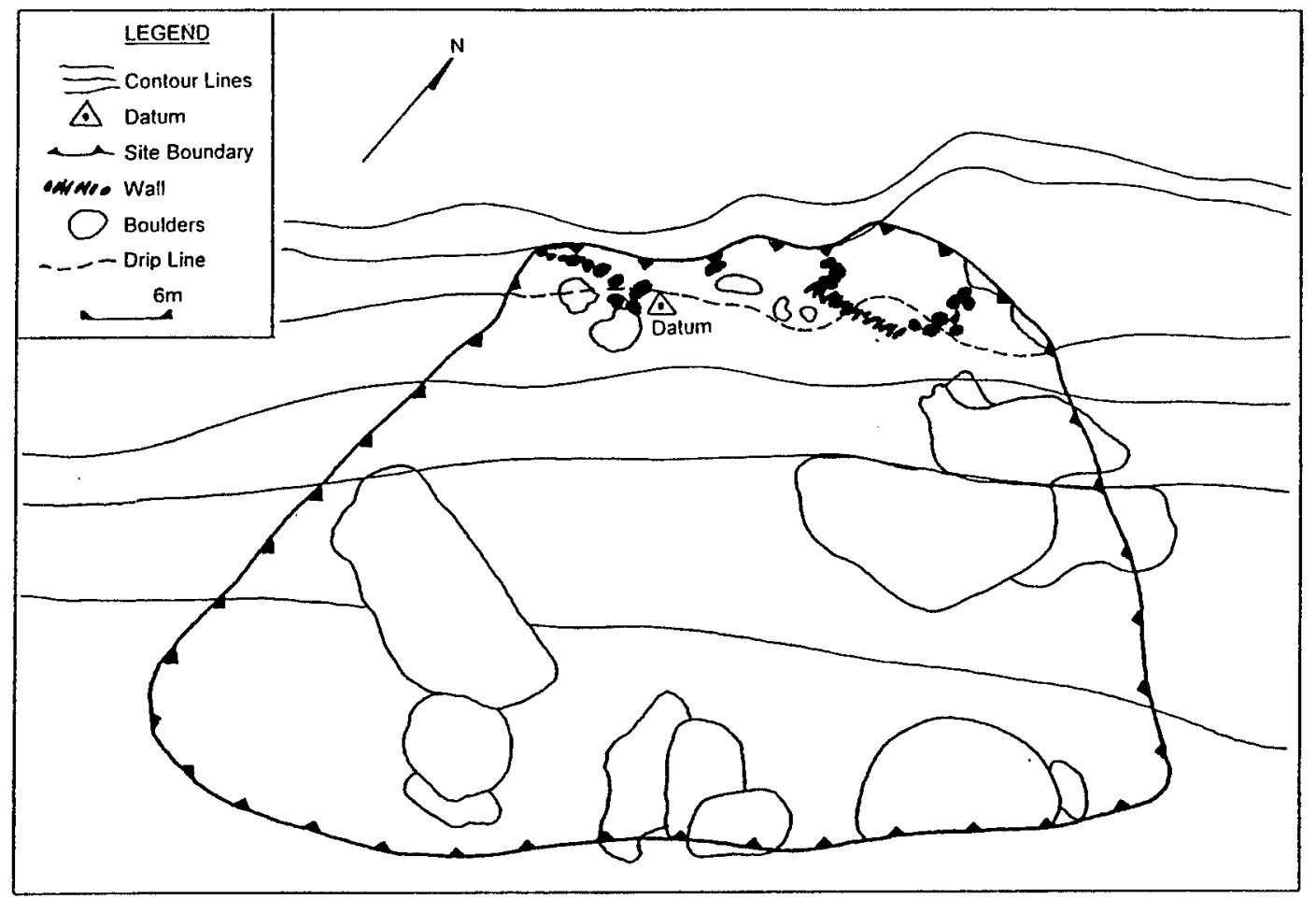

Figure 6. Sketch Map of Rock Shelter with stone Wall Site 5LA3303.

dimensions of the site are 30 meters by 29 meters. Vegetation observed at the site includes juniper, Rhus trilobata, sage, wolf berry, scrub oak, and mixed grasses. Fill within the shelter consists of aeolian deposited tan silty sand, and pediment gravels are present on the slope.

Two rockshelters with walls and an associated lithic scatter were recorded at the site. The walls are constructed of piled sandstone slabs with several upright slabs; they are both in a semicircular pattern and partially collapsed. A single slab metate was noted within the southern most shelter, where a deflated hearth and burned earth associated with heat altered stone were also noted. Lithic density is fairly high; the artifacts were largely quartzite flakes, but a quartzite core, a chert flake, an argillite flake, and 2 metate fragments were also recorded.

Lithic Scatter, this category consists of localities that exhibited prehistoric artifacts but lacked preserved surface evidence for habitation structures. Artifacts in these scatters consisted largely of unmodified chipped stone flakes, but a variety of other artifacts were sometimes found. A partial list artifact types found at lithic scatters is as follows: patterned chipped stone tools including projectile points and other bifaces, unifaces, scrapers, cores; groundstone artifacts including manos and metates were also sometimes identified.

Site 5LA6595 is a typical lithic scatter that was identified on the south facing slope of an intermittent drainage which flows northeast into the Mary Doyle 
fork of Welsh Canyon (Figure 7). The lithics are located at the base of a sandstone cliff along a bend in the drainage, at an elevation of 1494 meters. Lithics are scattered over an area that measures 24 meters north to south and 50 meters east to west.

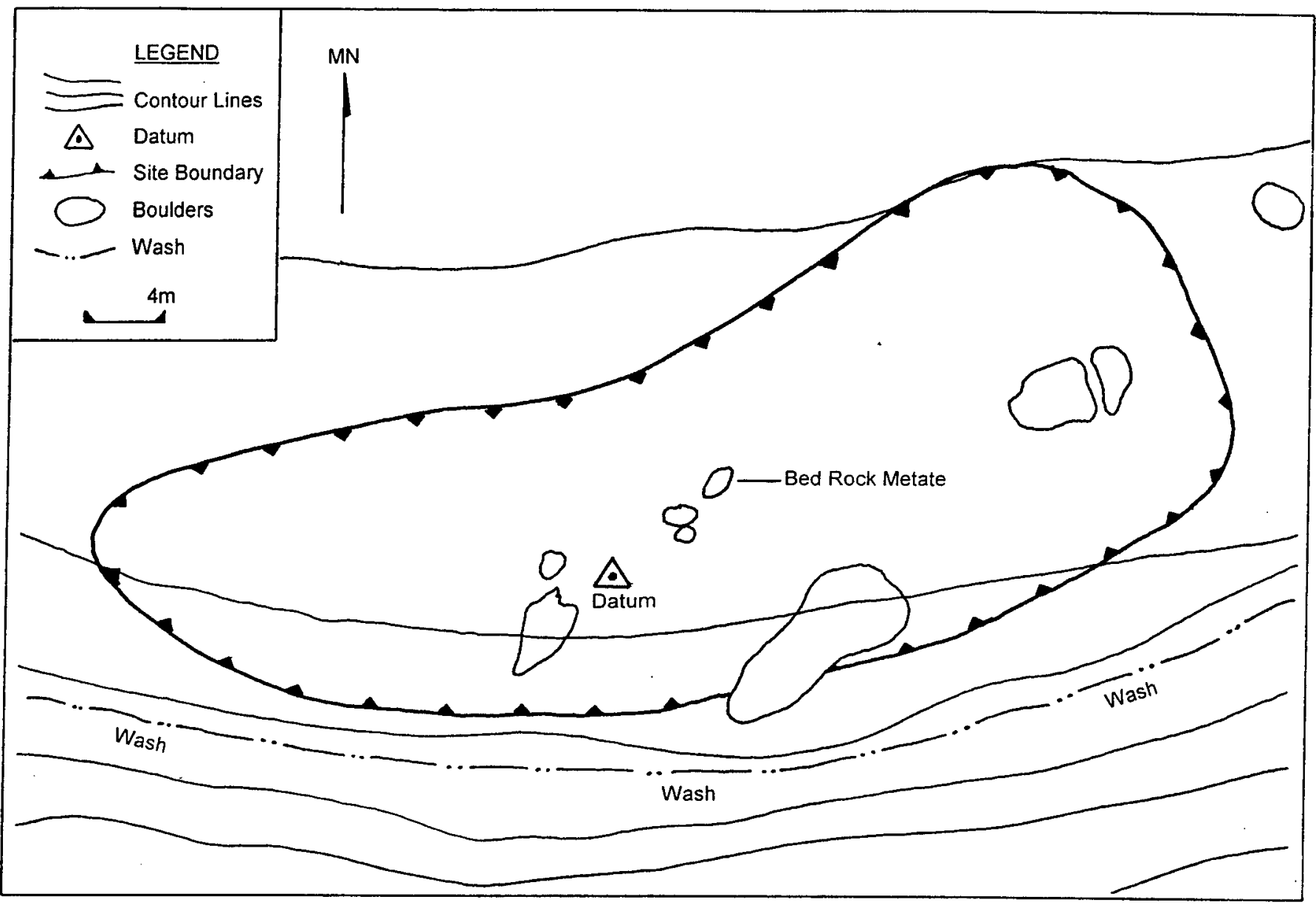

Figure 7. Sketch Map of Lithic Scatter Site 5LA6595.

The predominant vegetation in the area is currently juniper, which is typical of the vegetation at sites throughout much of the survey area. Other vegetation observed on the site includes; cholla, prickly pear, sage, chenopodia, blue gramma, mullein, Rhus trilobata, mixed grasses, and low forbs. Cottonwood trees currently occur a short distance up the drainage, indicating the presence of shallow water. The natural fill in the location consists of tan to gray silty sand with sandstone outcrops and pediment gravels. With the exception of the canyon bottoms, little soil development exists throughout the survey area. 
Evidence for plant or other food processing was observed on the site; a large area with heat-altered stone, ash, and burned soil was identified. These types of features are commonly referred to as middens, and were only occasionally identified at lithic scatters. Rodent burrows in the burned area have exposed more than 70 centimeters of ashy fill, suggesting a fairly substantial period of use. Additional evidence for food processing includes a number of groundstone artifacts at the site.

Cultural materials identified at the site consisted largely of lithics; a dense scatter of these artifacts occurs in the site area. The lithic artifacts recorded at the site consisted of 66 quartzite flakes, 9 chert flakes, and 1 argillite flake. Most of the flakes were macroscopically unmodified, but several utilized and retouched flakes were also noted; no patterned tools were identified. There also were 2 sandstone mano fragments and 1 sandstone metate fragment. A boulder metate with four grinding surfaces was also identified. A single small ceramic sherd was found on the site. Several burned bone fragments were also found; these items may be associated with the prehistoric use of the site area.

Site 5LA6626 provides a second lithic scatter example. This site is located on top of a narrow unnamed mesa between the Black Hills and Welsh Canyon at an elevation of 5040 feet. The lithics are scattered over an area of 80 meters by 140 meters. The vegetation observed in the site area was sparse and consisted of juniper, oak, mixed grasses, small forbs, buckwheat, prickly pear, pinon, and snakeweed. Deposition in the site area consisted of light brown sandy loam.

Lithic density is variable across the site, and several small areas with high artifact density were recorded. A possible deflated hearth ( 1 by 1-meter) with groundstone fragments was identified. Several slab metate fragments were observed around this hearth, and other fragments were scattered around the site.

Lithic materials identified include 81 quartzite flakes, 4 chert flakes, and a quartzite core. Tools found at the site consist of 3 retouched quartzite flakes, a chert biface, a argillite biface, and 4 quartzite core tools. Eight groundstone fragments and 4 basin metate fragments also were noted.

Prehistoric Structures, these open sites have one or more dry laid stone structures. Prehistoric stone structures consisted of roughly circular to oval courses of stacked rocks. The structures occurred both singly and in groups.

Site 5LA6799 is an example of an open site with stone structures (Figure 8). This small site includes; the partially disturbed remains of a circular rock structure, a semi-circular wall, the remains of two additional rock walls, and an associated lithic scatter. The site is located on a narrow sandstone ridge with vertical sides, at an elevation of 4720 feet. The site extends 74 meters by 30 meters. Vegetation observed in the site area includes; native grasses, pin 
cushion cactus, juniper, mountain mahogany, and yucca. Deposition consists of reddish brown sandy loam, with a maximum depth of only 10 centimeters.

The stone structures are all in fairly good condition although the west side of the circular feature is missing. This feature measures about 3 meters in diameter, and probably severed as a foundation or windbreak for a wooden structure. A second feature, roughly 15 meters from the first, consists of a section of stone wall in a semi-circular shape that extends for about 15 meters. This may be a portion of another much larger structure, or may be a protecting wall for the first. A concentration of lithics was recorded between these two features. A pair of additional rock alignments was identified to the southeast of these features. The first is located 20 meters from the semi-circular feature, and consists of a wall that is two courses wide. The other rock alignment, is about 7.5 meters to the southeast. These two walls extend across a narrow portion of the ridge, and may have served defensive purposes.

A variety of chipped stone artifacts were recorded at this site. The most common lithic material by far was quartzite, but a small number of chert and argillite flakes were also recorded. The site assemblage included cores, a variety of different flake types, and a back-hafted knife.

Site 5LA6948 is a second example of a prehistoric structure site. The site consists of a circular series of rocks located on top of an isolated sandstone outcrop above a small terrace adjacent to the bottom of Welsh Canyon. Ten additional stones are scattered in the vicinity of the structure; these rocks may have been displaced from the structure. Vegetation on the site includes juniper and native grasses. Little deposition exists in the site area, with a maximum depth of only 10 centimeters within the feature. Animal activity, wind and water have heavily disturbed the site.

The site is located immediately north of lithic scatter 5LA6783 and the two sites may be associated. A single quartzite flake that was in the rock structure was the only artifact observed on top of the outcrop.

Procurement Sites, are locations where the primary activity appears to have been the collection of lithic raw materials. These sites were distinguished from other lithic scatters by a lack of diversity in raw materials (i.e., procurement sites had almost exclusively one material type), and the presence of unworked nodules of lithic materials. Procurement sites also lacked of evidence for other domestic activities (e.g., manos or other grinding implements were not present). 


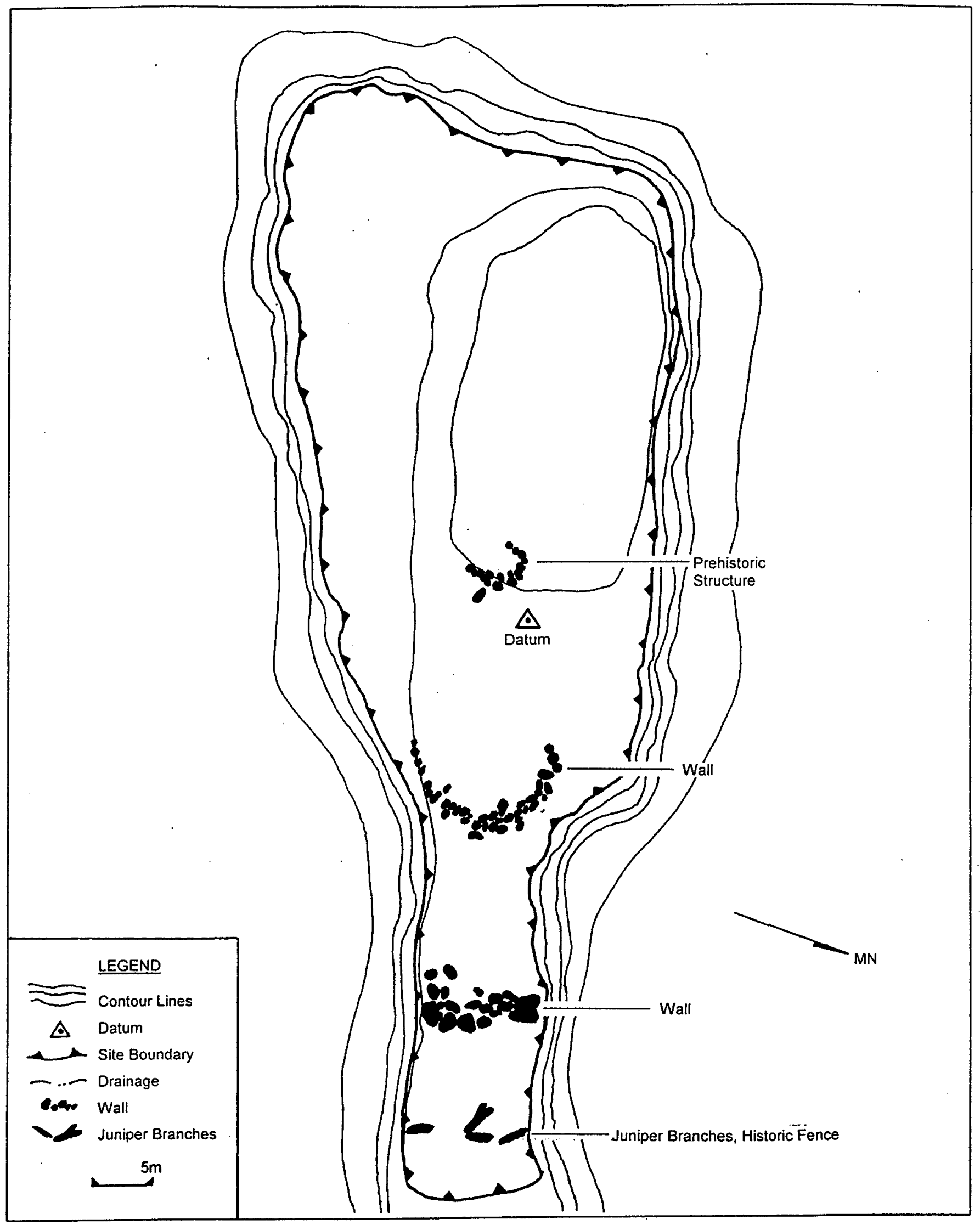

Figure 8. Sketch Map of Prehistoric Structure Site 5LA6799. 
A typical example of procurement sites is provided by 5LA6888 (Figure 9). This lithic procurement site is located on a terrace near the bottom of a tributary to Welsh Canyon, at an elevation of 4900 feet. It measures $75 \mathrm{~m}$ northeast southwest by $55 \mathrm{~m}$ northwest by southeast. The $30 \mathrm{~cm}$ deep soil is light brown silty sand with a good mix of pebbles. Juniper, yucca, grasses and prickly pear are the main plants on the site.

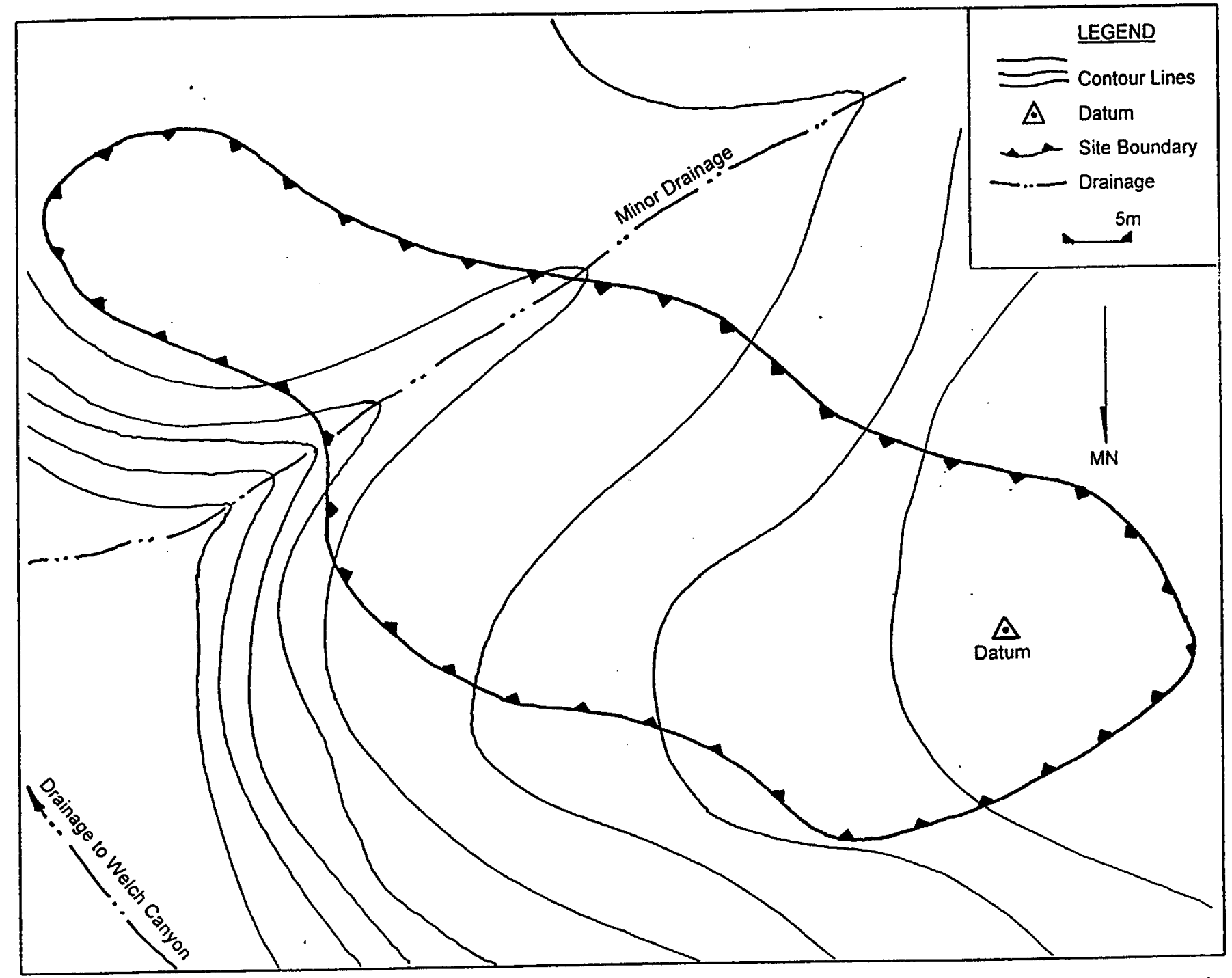

Figure 9. Sketch Map of Lithic Procurement Site 5LA6888. 
This site is located at one of a series of limestone outcrops containing chert nodules that occurs on small ridges in Welsh Canyon. This chert source contains more whiter and light green nodules than nearby chert outcrops, but all these sources have a roughly similar range of variation in appearance. A chert sample was collected. Most of the material at the site consists of shattered nodules, but some breakage appears to have resulted from cultural activities. Unmistakable flakes have been produced and remain at the site. Isolated chert fragments are scattered in the deposits between other procurement sites in the area. A single quartzite flake was also noted on 5LA6888.

Site 5LA6776 provides a second example of a procurement site. This small lithic procurement area measures only 18 meters by 13 meters, and occurs at an elevation of 4825 feet. Vegetation in the site area consists of juniper, yucca, prickly pear, mountain mahogany, spiderwort and mixed bunch grasses. The fill at the site consisted of light yellow sand with shattered quartzite nodule inclusions.

The site consists of a quartzite outcrop on a bench above the bottom of Welsh Canyon. Tested cobbles and flakes in all stages of reduction were found in the area of this outcrop. The quartzite is gray, somewhat fine grained, but appears to be fairly low quality (i.e., it has high fracture toughness and numerous inclusions as well as other imperfections).

\section{SITE TYPE INCIDENCE}

This section discusses the prevalence of the five types of sites that are defined above. These site types are not exhaustive, but represent the most common types of prehistoric cultural resources that were identified in Welsh Canyon.

\section{Lithic Scatter Sites}

Lithic scatters were the most common prehistoric site identified in the project area (Table 2). Chipped stone artifact scatters account for almost 56 percent of the 226 prehistoric sites that were identified in the 1995-1996 survey of Welsh Canyon. The prevalence of chipped stone artifact scatters results, in part, from the fact that these artifacts were produced throughout the prehistoric record of the PCMS, thus lithic scatters without diagnostic artifacts could date to any period within the sequence. Chipped stone artifacts are also one of the most durable items of prehistoric cultural material, and are thus most likely to be preserved at any sites. 
Table 2. Site Type by Location, 1995 - 1996 Welsh Canyon Survey Data.

\begin{tabular}{|l|cccc|c|}
\hline Site Type & $\begin{array}{c}\text { Canyon } \\
\text { Bottom }\end{array}$ & $\begin{array}{c}\text { Canyon } \\
\text { Rim }\end{array}$ & $\begin{array}{c}\text { Mesa } \\
\text { Top }\end{array}$ & $\begin{array}{c}\text { Talus } \\
\text { Slope }\end{array}$ & Grand Total \\
\hline Lithic Scatter & 46 & 18 & 21 & 43 & $127(56 \%)$ \\
Prehistoric Structure & 2 & 2 & 2 & 0 & $6(3 \%)$ \\
Procurement & 1 & 2 & 1 & 19 & $23(10 \%)$ \\
Rockshelter & 7 & 44 & 1 & 6 & $58(26 \%)$ \\
Rockshelter with Wall & 0 & 9 & 1 & 2 & $12(5 \%)$ \\
\hline Grand Total & $55(24 \%)$ & $75(33 \%)$ & $26(12 \%)$ & $70(31 \%)$ & 226 \\
\hline
\end{tabular}

Rockshelters

Rockshelters were the next most common site type with a combined total of 70 sites or 31 percent of the identified sites. Only 12 (5 percent) of these shelters had evidence for dry laid stone walls. Many walls built in shelters appear to have been very expedient features, suggesting that they may have simply resulted from moving aside roof fall in the center of shelters to clear the area for habitation. However, data presented below suggest that shelters with walls were more intensively utilized for habitation, and that the walls were intentionally made in most instances. These features may have been used to provide wind breaks. They also may have served defensive purposes in some cases; although none of the walls were of sufficient height to provide an effective barrier, even a low stone wall can provide useful protection against projectiles. It is also possible in some instances that the stones were employed to help support enclosures of wood or other organic materials, although little empirical evidence to support this possibility was identified during the survey.

Tool grooves were found in eight sites classed as rockshelter sites, although one set of the grooves are in a rockshelter and another in an exposed location at site 5LA6589. The identifying name "tool groove" is assigned by archaeologists to the short vertical grooves that are cut into stone surfaces. These grooves come in two definite shapes. One is a v-shaped groove that is relatively narrow, shallow and shorter than its counterpart which is a bananashaped groove that is wider, deeper, and longer. Tool grooves are almost always found in sets of parallel rows or parallel rows that have other grooves intersecting and crossing them. This latter characteristic has led a group of researchers to suggest the figures resemble ancient writing systems from Asian or European intruders to North America. A common group suggested is the Celtic cultures of ancient Ireland who are suggested to have left Ogam script on the walls of southeastern Colorado (McGlone and Leonard 1986; McGlone et al 1993). 
Individual tool grooves range in size from 5 to $8 \mathrm{~cm}$ in width and 14 to $28 \mathrm{~cm}$ in length for the banana shaped ones. This variety often has depths to 3 and $4 \mathrm{~cm}$. The v-shaped varieties are almost uniformly smaller with widths from 2 to $3 \mathrm{~cm}$ and lengths in the 8 to $10 \mathrm{~cm}$. Depths are often less than $1 \mathrm{~cm}$.

A large number of the grooves were found at site 5 LA6589 where 47 are found at one location and 9 at another location. Site 5LA6592 has 40 grooves in one location and 11 at another. Site 5LA6575 has 21 at one location and 9 at another. Site 5LA6744 has 11 at one location and sets of 5, 4, and 2 at another location. Site 5LA6770 has 9 grooves in a single location. Site 5LA6594 exhibits 4 grooves in one location, site 5LA6585 has 3 in one location and site 5LA6593 has only a single groove.

Six of the 8 sites are associated with ground stone tools including 5 sites with bedrock metates and these 5 latter sites are the ones with the largest numbers of tool grooves. Projectile points were found at only 4 of the sites. If one assumes the task of grinding was associated with women, these data suggest the grooves may be the products of some task associated with women.

There is debate about the origin and function of tool grooves. The controversy as to whether they represent Ogam script aside, there is no wellsupported explanation for prehistoric uses. Feyhl (1980) describes experiments where he made antler and bone tools to learn if the grooves could be duplicated. He learned that in using the rock as a sanding block to remove the tine of an elk antler, forming a bent handle for a scraping tool, the result was a banana shaped groove much like those in the archaeological sites. Feyhl also learned that sharpening tools like antler tine awls he produced the v-shaped variety of grooves. These experiments clearly suggest the grooves are related to the manufacture of bone and antler tools.

The sharpening of bone awls was probably a fairly constant task and it does not seem unreasonable to suggest it was women who undertook this task. If this is correct, it might explain the high correlation between grinding tools and $v$-shaped tool grooves. On the other hand, the manufacture of scraper handles could have been either a male or female task making the association with grinding tools more problematic. Perhaps the scrapers were made entirely from long bones and used as tools without stone tips or scraper inserts. This kind of hide scraping tool, sometimes with a serrated edge, was relatively common among historic tribes. Assuming this kind of tool would dull easily, the banana shaped grooves may be the product of efforts to sharpen them.

A final note regarding tool grooves is in order. In examining their distribution, they appear to be at rockshelter sites in the upper reaches of Welsh Canyon. Rockshelters in the bottom or near the mouth of Welsh Canyon do not exhibit tool grooves. Curiously these rockshelters do exhibit large numbers of ground stone tools and a moderate number of bedrock metates. Apparently 
women were grinding seeds and manufacturing ground products in both the upper reaches and the mouths of the canyons. One suggestion is that there is a difference in the density of the stone because the grooves are often found in soft sandstone. But the sandstone is equally as soft at the head of Welsh Canyon as it is at the mouth. This distribution information suggests the grooves were more important for some function associated with the uplands or the heads of the canyons.

\section{Lithic Procurement Sites}

Only 23 (10 percent) of the sites were classified as locations where the primary activity consisted of the procurement of lithic raw materials. It appears that the collection of lithic raw materials also occurred at some of the sites that were classified as lithic scatters, but only those sites where the primary activity consisted of the collection of raw materials were classified as procurement sites.

\section{Prehistoric Structure Sites}

The remaining six sites ( 3 percent) had one or more dry laid masonry structures, and in all instances these features were associated with scatters of lithic artifacts. Several possibilities could account for the rarity of this site type. First, erosion and other natural processes such as bioturbation (especially cattle) could have disturbed evidence for these features. Second, this site type may be . associated with a brief period of the archaeological sequence. Third, these features may have been special purpose facilities that were only rarely manufactured. Fourth, the use of this type of feature may have been restricted largely to seasons in which the prehistoric inhabitants of the region did not intensively utilize Welsh Canyon.

\section{SITE LOCATION CLASSIFICATION CRITERIA}

This section discusses the primary physiographic zones in which prehistoric sites were identified in Welsh Canyon. Sites were classified into one of four micro environmental zones, which are:

(1) Canyon Rim: a micro-environment that we defined as the rim of the canyon and the slope below for thirty meters, as well as the upper edge within thirty meters. The edges support some juniper and other plants, but they are also more rocky and open than areas slightly more distant from the rim.

(2) Canyon Bottom: a micro-environment that we defined as on the floor of the canyon more than thirty meters from the sloping walls or sides. Riparian vegetation is found in some of the watered areas of these lower settings while 
others are open exposed bedrock. In general, however, these settings offer better potential for water than the upland rims or mesa tops.

(3) Mesa Top; a micro-environment that we defined as the area along the top of the canyons at a distance greater than thirty meters from the canyon edge. These environments along Welsh Canyon support moderate to dense stands of juniper with intermixed pine trees and wide variety of lesser plants.

(4) Talus Slope; a micro-environment that we defined as the area on the sloping canyon walls that includes thirty meters of the bottom and the sloping sides to thirty meters below the rim. These slopes support some sparse stands of juniper. At places there are flat areas that are usually behind or around large talus boulders and these offer some potential for camping. Raw materials for chipped stone tools are eroding out of these slopes in Welsh Canyon.

\section{SITE INCIDENCE BY LOCATION}

Almost equal numbers of sites were identified in Canyon Rim locations ( $n=75,33$ percent) and on Talus Slopes ( $n=70,31$ percent); almost 65 percent of all sites were found in these two locations (Table 2). Several possibilities could account for prevalence of prehistoric sites along the canyon rim and talus slopes. First, most of these locations provide an excellent view of the canyon floor, and visibility is generally greater than in the canyon bottom or on the mesa tops surrounding the canyon, which are covered with comparatively dense vegetation. Second, locations along the edge of the canyon provide the most direct access to resources in both the bottom of the canyon and the surrounding uplands. Support for this possibility is provided by the observation that inhabited rock shelters along the rim were almost invariably in locations where there was good access to both the bottom of the canyon and the adjacent uplands. At the same time, large and deep shelters, well suited for habitation, but lacking any evidence for human activities were present below and/or above vertical cliffs that blocked access to the uplands and/or lowlands. Third, these areas may have been better defensive locations.

Slightly fewer sites were identified in the Canyon Bottom ( $n=55,24$ percent); however, as will be discussed further below canyon bottom sites were on average somewhat larger than were sites in other locations. In addition, greater natural deposition also occurs in some canyon bottom locations (especially on the terraces along the main drainage), and this may have obscured or destroyed some sites.

Only 26 (12 percent) of the sites were found on Mesa Tops. However, the survey area was restricted to Welsh Canyon, and consequently few mesa top locations were examined in this study. 


\section{SITE TYPE BY LOCATION}

This section evaluates variation in frequency of site types among physiographic zones. All site types except rockshelters with walls and prehistoric structures were found in all four physiographic settings. The limited distribution of these two site types may, in part, be a result of their small sample sizes. Although sites of different types were recorded in most settings, the frequency of different types varies substantially among locations.

Rock overhangs with evidence of human use are most common along the canyon rim; 53 sites or 76 percent of all rockshelters were found in canyon rim settings, and these sites comprise 71 percent of all canyon rim sites. Several possibilities may account for the greater incidence of rockshelters on the canyon rim. First, in most locations the caprock along the rim is comparatively resistant to erosion; consequently, erosion has removed less resilient deposits immediately below the caprock and created numerous overhangs of sufficient depth to provide good shelter. Second, as previously discussed, canyon rim settings may have been favored for habitation. Third, much of the sandstone in the canyon bottom is highly friable, and although numerous rock overhangs that would provide effective shelter are present in these formations, the highly erosive nature of these areas may have removed or obscured evidence for human use.

Procurement sites occur largely on talus slopes, and 19 sites or 82 percent of the procurement sites were recorded on this setting. The tendency for procurement sites to occur along talus slopes probably results from the distribution of primary deposits of lithic raw materials. Although secondary deposits of knappable stone are scattered throughout much of the canyon, primary deposits of some lithic raw materials such as chert most commonly outcrop along the talus slopes on the edges of Welsh Canyon. In addition, although the prehistoric inhabitants of Welsh Canyon probably utilized some lithic raw materials throughout much of the canyon only sites where this was the primary activity were classified as procurement sites. Talus slopes are generally poorly suited for habitation (i.e., most talus slope areas have steep grades and loose rocks), consequently the primary activity on talus slopes was more commonly lithic procurement.

Lithic scatters were found throughout Welsh Canyon. This site type was almost equally distributed between canyon bottom ( $n=45,35$ percent), and talus slopes $(n=43,34$ percent). The remaining lithic scatters were split between the canyon rim ( $n=18,14$ percent), and mesa tops $(n=21,16$ percent). Lithic scatters were the most common site type in the canyon bottom ( $n=45,82$ percent), mesa tops ( $n=21,81$ percent), and on talus slopes ( $n=43,61$ percent). The prevalence of lithic scatters in the most different locations and the lack of strong patterning in their distribution suggest that wide range of different activities occurred at these sites. 
Although only six sites with prehistoric structures were recorded, they were evenly divided between the canyon bottom ( $n=2,33$ percent), canyon rim $(n=2,33$ percent), and mesa top settings ( $n=2,33$ percent). The uniform distribution of this site type among all locations except talus slopes suggests that these sites were not associated with specialized resource collection activities.

In summary, with the exception of the canyon rim, lithic scatters were the most common site type identified in all physiographic zones of Welsh Canyon. Rockshelters were most common on the canyon rim, and this area has more natural rock overhangs than other physiographic settings. This suggests that rock overhangs were generally preferred for habitation where they were available, and open areas were used in locations where suitable rockshelters were not present. Not surprisingly, procurement sites were concentrated in areas (talus slopes) where primary sources of lithic raw materials were available. Prehistoric structures were uncommon but were evenly distributed between all locations except talus slopes.

\section{SITE SIZE BY LOCATION AND TYPE}

Figure 10 is a histogram of site size in square meters. The distribution is skewed right, discontinuous, and distinct modes are not apparent in the data. Almost half of the sites (49 percent) were less than 1500 square meters and all but 2 of the sites were less than 50,000 square meters in area.

Figure 11 presents boxplots of site size in square meters by location. Sites in all locations exhibit a considerable range of variation in size. Canyon bottom sites were on average larger than were sites in other areas, and canyon rim were on average the smallest. The generally larger size of canyon bottom sites probably results from the homogeneous terrain in many areas of the canyon bottom (i.e., comparatively large flats without drainages were present in some locations), and artifact scatters in settings that lacked geographical divisions were classified as single sites. It is possible that some of the large canyon bottom sites represent multiple over-lapping occupations of the same area. Support for this possibility is provided by the observation that artifact density generally varied across sites and concentration of lithics that may represent individual occupations were generally present at larger sites.

Figure 12 presents boxplots of site size in square meters by type (prehistoric structure sites are not included because of the small sample size). Rockshelters and lithic scatters have the greatest range of variation in size, but these were also the most common site types. Rockshelters were on average smaller than lithic scatters, which may result from a stronger tendency for reuse of exactly the same location- rockshelters may have been focal points for habitation that resulted in the concentration of artifacts in these locations. 


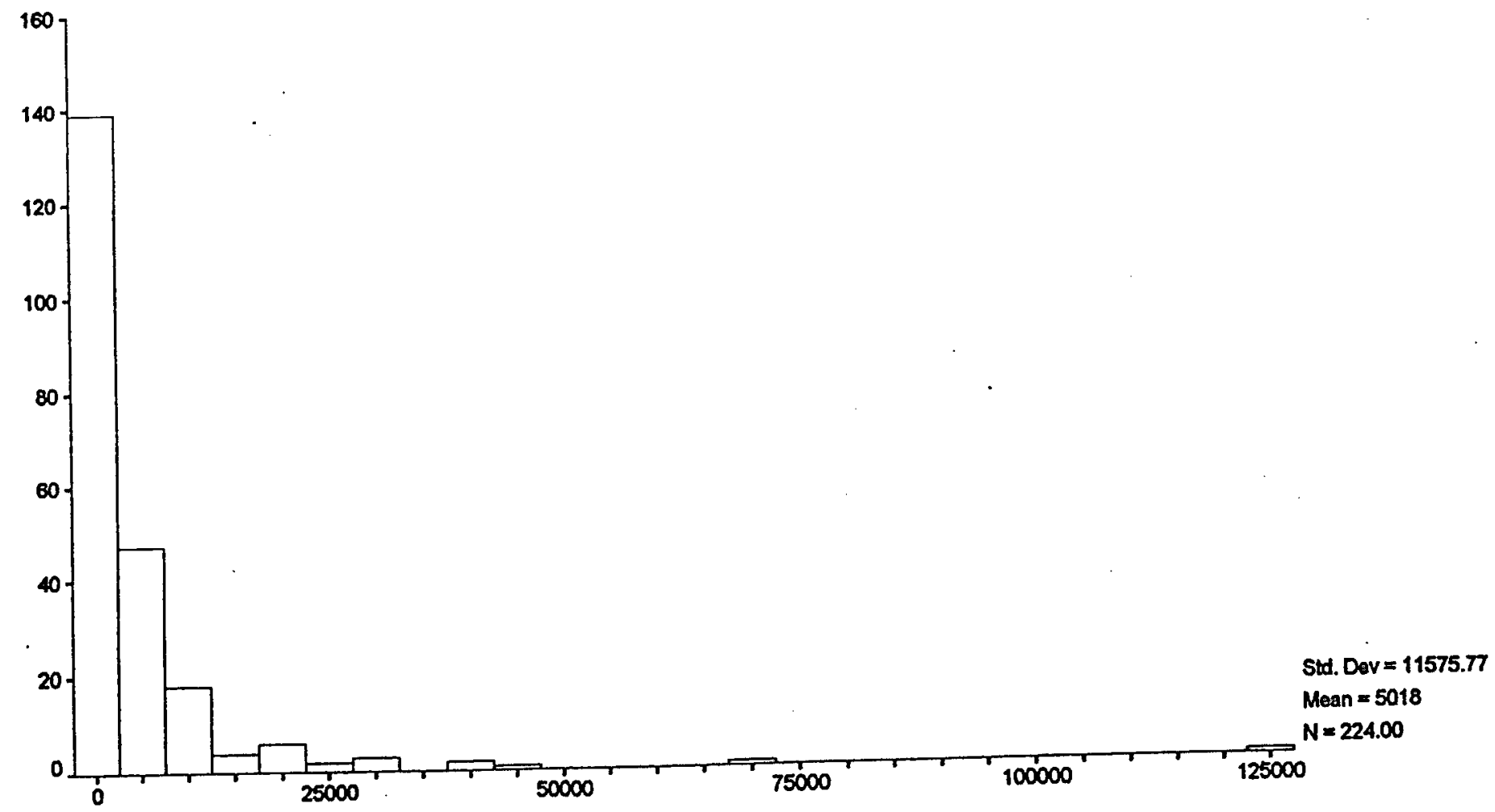

Figure 10. Site Area in Square Meters.

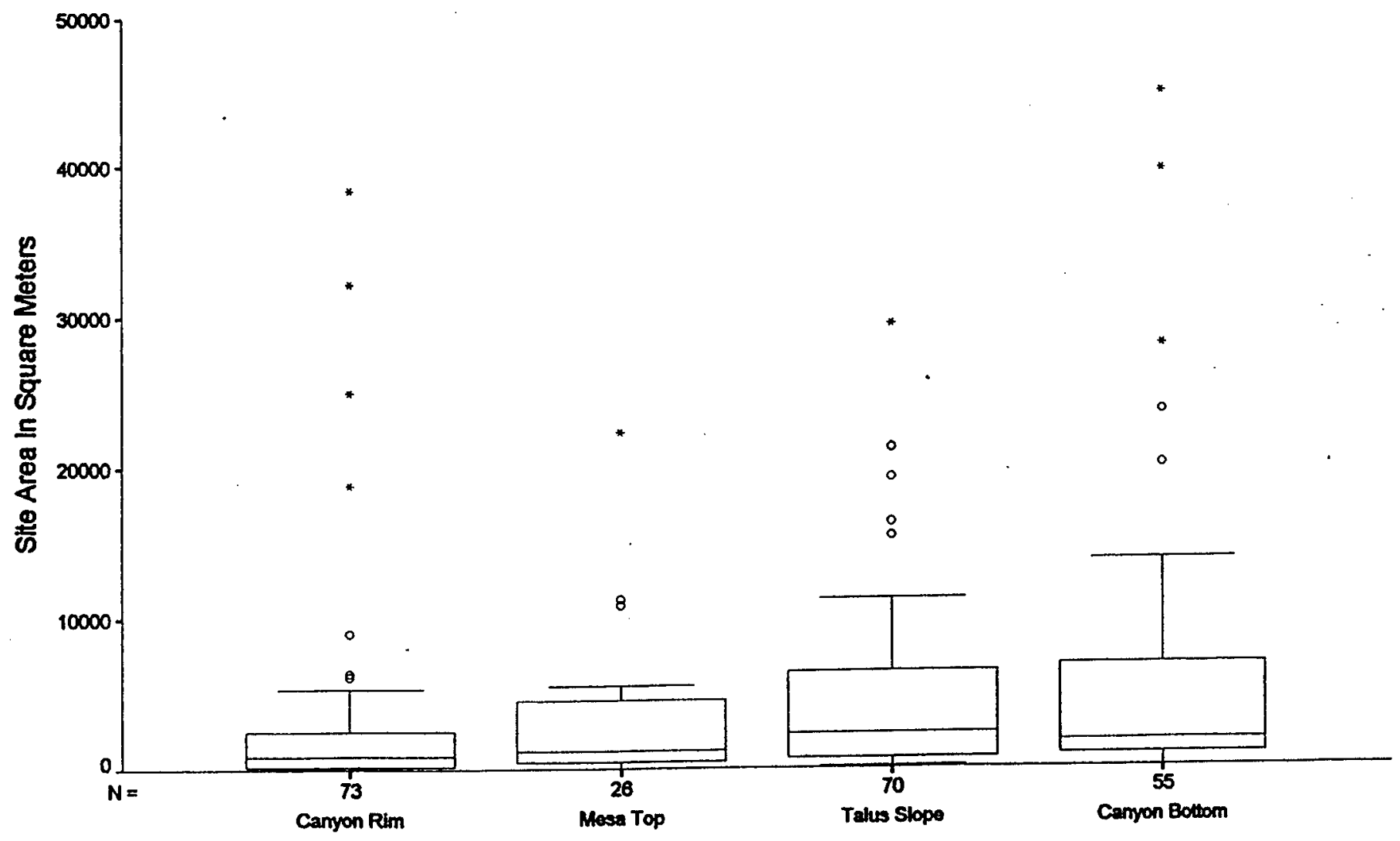

Figure 11. Site Size in Square Meters, By Location (Two Extreme Outliers not Shown) 


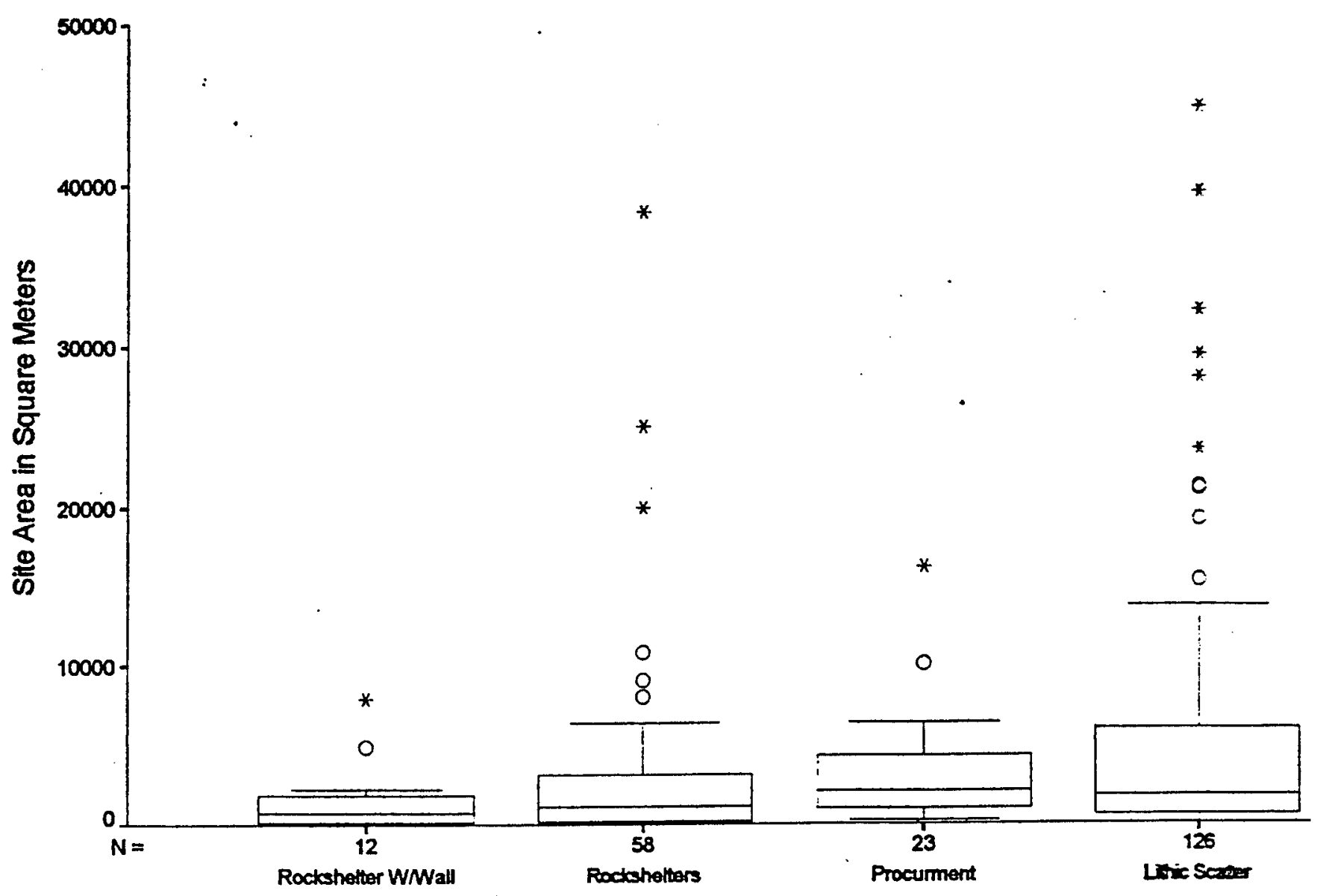

Figure 12. Site Size in Square Meters, by Type (Two extreme Outliers not Shown)

Natural water catchments in the sandstone bedrock at the bottom of Welsh Canyon appear to have been focal points for habitation and we noted that cultural material scatters were associated with all of the larger water catchments in the canyon bottom. However, many of the water catchments in the canyon bottom occur in areas of relatively uniform terrain. On one occasion people who lived on one side of the water may have used it and on another occasion people who lived on a different side may have used it. This would account for the large size of the lithic scatter sites. In other words the size of the sites is not a good indicator of the number of individuals at a site. 


\section{COLLECTED PREHISTORIC ARTIFACTS}

This section describes diagnostic and other unusual artifacts that were collected during the 1995 - 1996 survey of Welsh canyon. Collected prehistoric artifacts consist largely of projectile points, but unusual groundstone artifacts and several other atypical artifacts are also described in this chapter. Artifacts that were collected from the surface of sites that had test excavations are described in the report on the test excavations (Schiavitti 1997). Because the sites selected for test excavations were important ones, these include a significant number of the projectile points collected from the surface in 1995.

\section{PROJECTILE POINTS}

A total of 35 variously complete hafted bifaces or projectile points were collected during the 1995 - 1996 Welsh canyon survey. This section contains descriptive information regarding these artifacts, and when it is possible the projectile points are categorized according the system developed by Anderson (1989:111-315) for classification of projectile points from the PCMS, hereafter referred to as the Anderson typology.

The Anderson typology is by no means perfect. Lacking good comparative information the Anderson often relies on information from sites that are far afield from the PCMS. Furthermore the lessons learned by projectile point chronologists suggest the types may not always hold true through time. In part this reflects the lack of good typologies elsewhere and the absence of rules for classifying projectile points into types, but it also indicates there are some serious problems with the use of projectile points as time indicators, especially for any refined chronology research. None the less projectile points are all that one has from the surface of many sites and they need to continue to be studied to learn if there are distinct types in the PCMS that can be relied upon as temporally diagnositc artifacts.

\section{Artifact Descriptions}

\section{LA4414.0.1}

\section{Description:}

Large partial corner-notched argillite projectile point; tip missing, bi-convex cross-section, straight blade edges, very weakly barbed shoulders, slightly expanding stem, rounded tang, slightly concave base. This well made point (it is fully flaked on both faces) is most similar to category $P 21$ in the Anderson typology, for which an age estimate of between 1000 B.C. to A.D. 700 is suggested. The point most likely dates to the Late Archaic period. 
Metric Attributes:

Point Length* $\quad<44 \mathrm{~mm}$

Point Width $\quad 27 \mathrm{~mm}$

Thickness $\quad 6 \mathrm{~mm}$

Blade Length* $<34 \mathrm{~mm}$

Stem Width $\quad 15 \mathrm{~mm}$

Base Width $19 \mathrm{~mm}$

* Indicates partial measurement of broken attribute
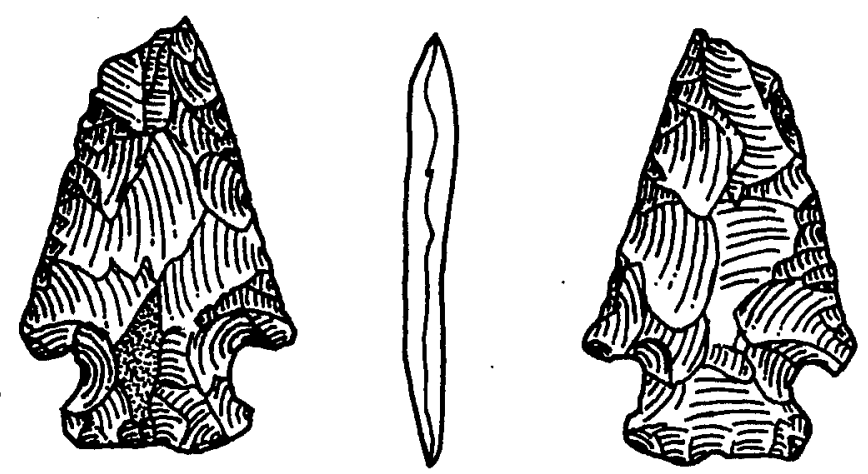

\section{LA4938.0.1}

Description:

Small nearly complete stemmed basalt projectile point; tip missing, bi-convex cross-section, slightly concave edges, weakly barbed shoulders, straight stem, rounded tangs, concave base. The tip of the artifact appears to have been reworked. This projectile point is most similar to category P 54 in the Anderson typology; an age estimate of between A.D. 750 and A.D. 1400 is suggested.

Metric Attributes:

Point Length* $\quad<21 \mathrm{~mm}$

Point Width $13 \mathrm{~mm}$

Thickness $\quad 4 \mathrm{~mm}$

Blade Length* ${ }^{*}<14 \mathrm{~mm}$

Stem Width $\quad 7 \mathrm{~mm}$

Base Width* $\quad<7 \mathrm{~mm}$
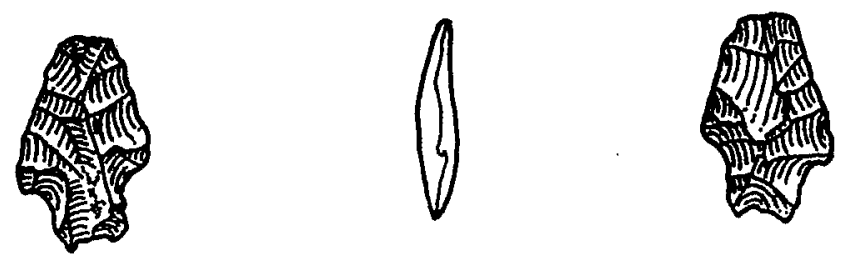

*Indicates partial measurement of broken attribute

\section{LA4938.0.2}

\section{Description:}

Large complete triangular chert projectile point preform; tip sharp, planoconvex cross-section, slightly convex edges, no shoulders, no stem, no tangs, straight base. A potlid fracture is present on one face, suggesting that the artifact was heat-treated. The artifact appears to be a projectile point preform that was discarded during manufacture, probably because a hinge fracture and the potlid fracture precluded further thinning of the tip. This artifact is most similar to category P 49 in the Anderson typology; and age estimate of between A.D. 800 to A.D. 1750 is suggested.

Metric Attributes:

$\begin{array}{lr}\text { Point Length } & 33 \mathrm{~mm} \\ \text { Point Width } & 19 \mathrm{~mm} \\ \text { Thickness } & 6 \mathrm{~mm} \\ \text { Blade Length } & 34 \mathrm{~mm} \\ \text { Stem Width } & 19 \mathrm{~mm} \\ \text { Base Width } & 19 \mathrm{~mm}\end{array}$
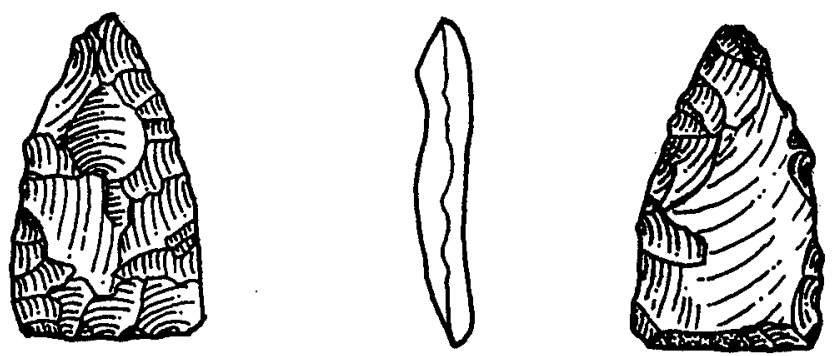
5LA4938.0.3

Description:

Small nearly complete corner-notched projectile point (one shoulder missing); tip very sharp, plano-convex cross-section, slightly convex edges, barbed shoulders, expanding stem, rounded tangs, convex base. This projectile point is most similar to category P 62 in the Anderson typology, for which an age estimate of between A.D. 500 and A.D. 1400 is suggested.

Metric Attributes:

Point Length $\quad 21 \mathrm{~mm}$

Point Width $14 \mathrm{~mm}$

Thickness $\quad 3 \mathrm{~mm}$

Blade Length $\quad 17 \mathrm{~mm}$

Stem Width $6 \mathrm{~mm}$

Base Width $\quad 9 \mathrm{~mm}$
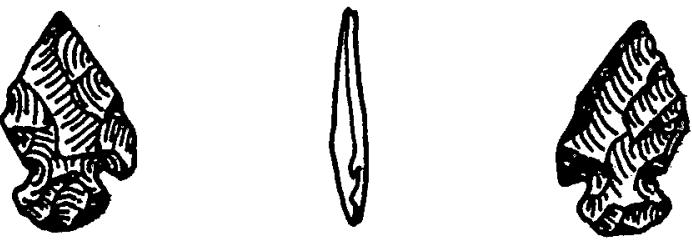

\section{LA6568.0.1}

Description:

Small quartzite projectile point preform; tip very sharp, bi-convex to planoconvex cross-section, straight edges, no shoulders, no stem, rounded tang, convex base. This artifact appears to be a point preform that was discarded during manufacture due to several step fractures. The biface is most similar to category P 48, for which an age estimate of A.D. 500 to A.D. 1400 is suggested.

Metric Attributes:

Point Length

Point Width

$23 \mathrm{~mm}$

Thickness

$13 \mathrm{~mm}$

$4 \mathrm{~mm}$

$\begin{array}{ll}\text { Blade Length } & 23 \mathrm{~mm} \\ \text { Stem Width } & \text { N/A } \\ \text { Base Width } & 13 \mathrm{~mm}\end{array}$

5LA6570.0.1

Description:

Small complete side-notched chalcedony projectile points; tip sharp, biconvex cross-section, straight blade edges, slightly expanding flange stem, pointed tang, concave base. One edge of the blade may be have been intentionally serrated, but is possibly only irregular. This artifact is most similar to category P 83, for which an age estimate A.D. 750 to A.D. 1650 or later is suggested.

Metric Attributes:

Point Length

Point Width

Thickness

$21 \mathrm{~mm}$

Blade Length

Stem Width

$13 \mathrm{~mm}$

$4 \mathrm{~mm}$

Base Width

$14 \mathrm{~mm}$

$7 \mathrm{~mm}$

$13 \mathrm{~mm}$
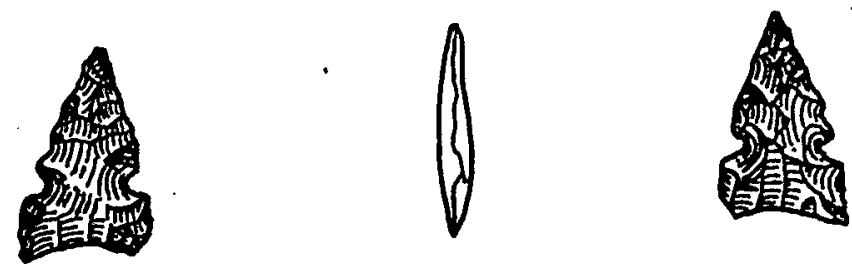


\section{LA6576.0.1}

Description:

Irregular quartzite biface, probably an early stage projectile point preform; tip dull, plano-convex cross-section, convex blade edges, no shoulder, no stem, rounded tang, convex base. This artifact is most similar to category $P 48$, for which an age estimate of A.D. 500 to A.D. 1400 is suggested.

Metric Attributes:

Point Length

$32 \mathrm{~mm}$

Blade Length

$29 \mathrm{~mm}$

Point Width

$18 \mathrm{~mm}$

Stem Width

N/A

Thickness

$7 \mathrm{~mm}$

Base Width

$18 \mathrm{~mm}$

5LA6580.0.1

Description:

Large reworked corner-notched quartzite projectile point base; tip missing, indeterminate blade edges, abrupt shoulders, expanding stem, rounded tang, slightly convex base. This artifact is most similar to category $P 42$, for which an age estimate of A.D. 600 to A.D. 1600 is suggested.

Metric Attributes:

Point Length* $\quad<23 \mathrm{~mm}$

Point Width $22 \mathrm{~mm}$

Thickness $\quad 5 \mathrm{~mm}$

Blade Length* $<15 \mathrm{~mm}$

Stem Width

Base Width
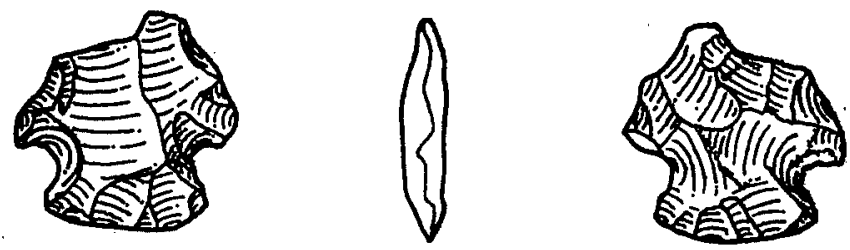

*Indicates partial measurement of

broken attributes

\section{LA6589.0.1}

\section{Description:}

Small complete side-notched argillite projectile point, tip sharp, plano-convex cross-section, convex to straight blade edges, abrupt shoulders, straight flange stem, pointed tang, straight base. The point is poorly made and highly irregular, suggesting that it may never have been used. This artifact is most similar to category P 83, with an age estimate A.D. 750 to A.D. 1650 or later. Metric Attributes:

Point Length

Point Width $\quad 11 \mathrm{~mm}$

Thickness $\quad 3 \mathrm{~mm}$

Blade Length $12 \mathrm{~mm}$

Stem Width $\quad 9 \mathrm{~mm}$

Base Width $\quad 11 \mathrm{~mm}$
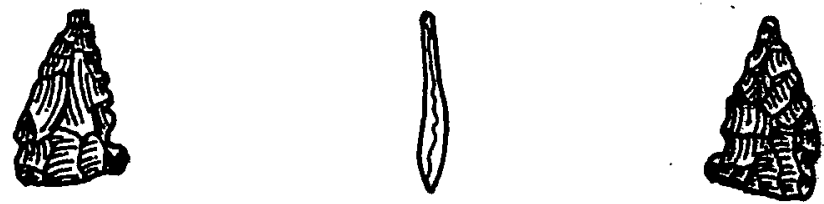

\section{LA6589.0.2}

Description:

Small corner-notched chert projectile point base; tip missing, bi-convex crosssection, straight edges, weakly barbed shoulders, expanding stem, rounded 
tang, concave base. This artifact is most similar to category P 59 in the Anderson typology, with an age estimate of A.D. 500 to A.D. 1200, although they may have persisted until A.D. 1450.

Metric Attributes:

Point Length* ${ }^{\star}<19 \mathrm{~mm}$

Point Width $\quad 16 \mathrm{~mm}$

Thickness $\quad 3 \mathrm{~mm}$

Blade Length ${ }^{*}<13 \mathrm{~mm}$

Stem Width $\quad 6 \mathrm{~mm}$

Base Width $\quad 8 \mathrm{~mm}$
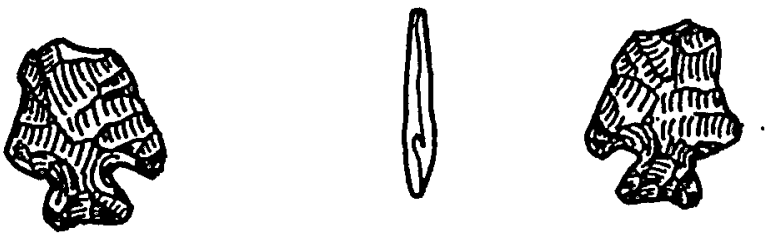

*Indicates partial measurement of

broken attributes

\section{LA6592.0.1}

Description:

Large complete corner-notched quartzite projectile point, tip sharp, bi-convex cross-section, slightly convex blade edges, rounded shoulders, slightly expanding stem, rounded tang, straight base. This well made projectile point is most similar to category $P 32$, for which an age estimate of between 500 B.C. to A.D. 1000 is offered.

Metric Attributes:

Point Length

Thickness

$35 \mathrm{~mm}$
$5 \mathrm{~mm}$ Blade Length $27 \mathrm{~mm}$

Point Width
Base Width

$16 \mathrm{~mm}$

$14 \mathrm{~mm}$

\section{LA6613.0.1}

Description:

Complete corner-notched basalt projectile point; tip sharp, bi-convex crosssection, slightly convex blade edges, abrupt shoulders, slightly expanding stem, pointed tang, straight base. This artifact is most similar to category $P$ 33 , for which an age estimate of 500 B.C. to A.D. 900 is suggested. Metric Attributes:

Point Length

Point Width $\quad 23 \mathrm{~mm}$

Thickness $\quad 6 \mathrm{~mm}$

Blade Length $29 \mathrm{~mm}$

Stem Width $17 \mathrm{~mm}$

Base Width $20 \mathrm{~mm}$

\section{LA6741.0.1}
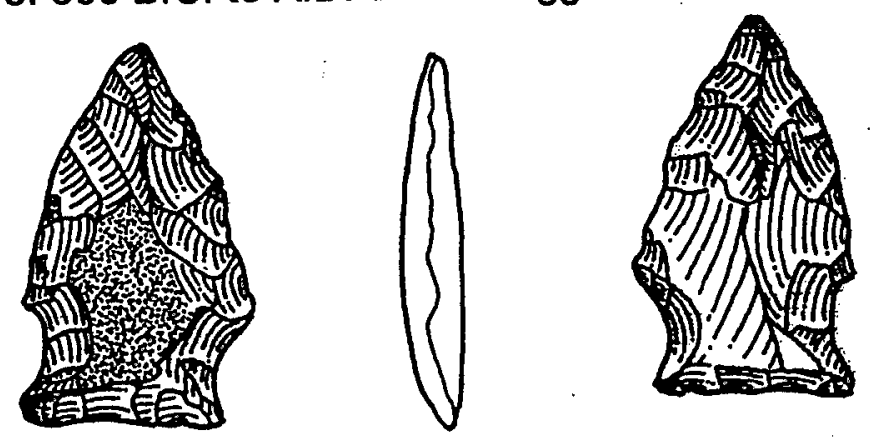

Description:

Large corner-notched quartzite projectile point base (one ear also missing); tip missing, plano-convex cross-section, slightly convex blade edges, weakly barbed shoulders, very slightly expanding stem, pointed tang, straight base. This projectile point is most similar to category P 26 in the Anderson typology, for which an age estimate of 1000 B.C. to A.D. 500 is suggested. 
Metric Attributes:

Point Length* $\quad<25 \mathrm{~mm}$

Point Width $\quad 26 \mathrm{~mm}$

Thickness $\quad 5 \mathrm{~mm}$

Blade Length* $\quad<23 \mathrm{~mm}$

Stem Width $\quad 13 \mathrm{~mm}$

Base Width* $<13 \mathrm{~mm}$

*Indicates partial measurement of
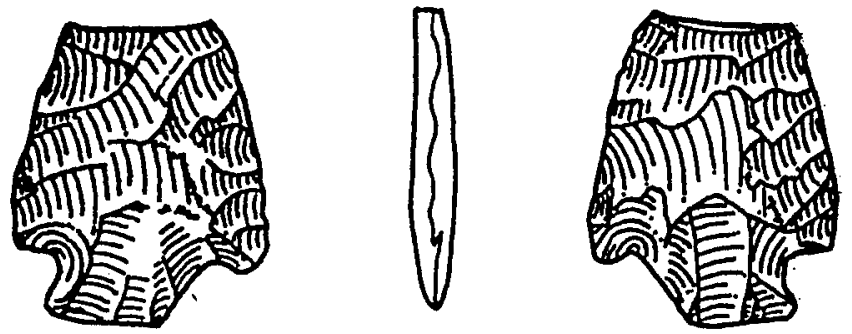

broken attributes

\section{LA6743.0.1}

\section{Description:}

Gray argillite corner notched projectile point base, tip missing, bi-convex crosssection, straight edges, weakly barbed tang, expanding stem, rounded tang, straight base. The point has light patination and is fully flaked on both faces. The artifact is similar to categories $P 26$ and $P$ 32, but appears to be most similar to $P$ 32. A numerical age estimate of between 500 B.C. to A.D. 1000 is suggested for this style.

Metric Attributes:

$\begin{array}{lr}\text { Point Length* }^{*} & <26 \mathrm{~mm} \\ \text { Point Width } & 20 \mathrm{~mm} \\ \text { Thickness } & 5 \mathrm{~mm} \\ \text { Blade Length* } & <17 \mathrm{~mm} \\ \text { Stem Width } & 11 \mathrm{~mm} \\ \text { Base Width* } & <12 \mathrm{~mm}\end{array}$
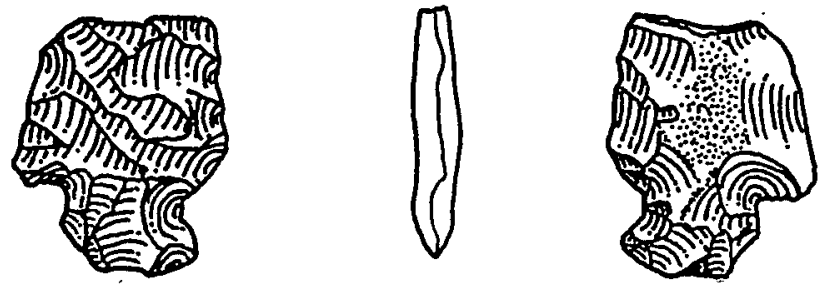

*Indicates partial measurement of broken attribute

\section{LA6767.0.1}

\section{Description:}

Large basalt projectile point base, tip missing, bi-convex cross-section, straight to slightly convex edges, sloping shoulders, slightly expanding stem, rounded tang, slightly concave base. The point is very crudely made with steep edge angles and step fractures that prevent further thinning. The surface of the artifact has light patination, but the break at the tip is unpatinated suggesting a more recent fracture. The point is most similar to category $P 18$ of the Anderson typology, for which an age estimate of 3000 B.C. to 500 B.C. is assigned.

Metric Attributes:

Point Length* $\quad<51 \mathrm{~mm}$

Point Width $20 \mathrm{~mm}$

Thickness $\quad 8 \mathrm{~mm}$

Blade Length* $\quad<28 \mathrm{~mm}$

Stem Width $\quad 17 \mathrm{~mm}$

Base Width $\quad 19 \mathrm{~mm}$

* Indicates partial measurement of broken attribute

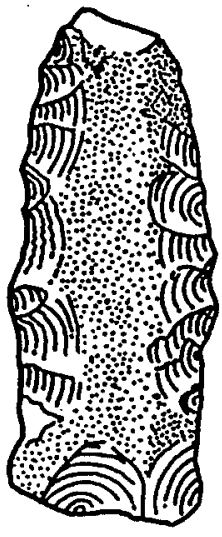

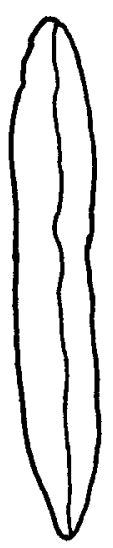

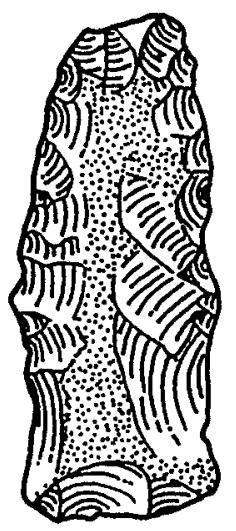




\section{LA6771.0.1}

Description:

Large stemmed basalt projectile point, dull point, plano-convex cross-section, convex edges, rounded shoulders, straight stem, rounded tang, straight base. The point has use-wear (crushing, nibbing) on both edges (the wear is heavier on one edge), the tip, and the artifact appears to be a broken point that was reused for cutting/slicing or scraping activities. The base point is fractured but was reworked, and the artifact was probably originally corner notched. The artifact is best classified as category P 29 in the Anderson typology, for which a numerical age estimate of between 500 B.C. and A.D. 600 is suggested.

Metric Attributes:

Point Length

Point Width

Thickness

Blade Length

Stem Width

Base Width

Weight

$30 \mathrm{~mm}$
$23 \mathrm{~mm}$
$6 \mathrm{~mm}$
$20 \mathrm{~mm}$
$11 \mathrm{~mm}$
$13 \mathrm{~mm}$
$4.9 \mathrm{~g}$
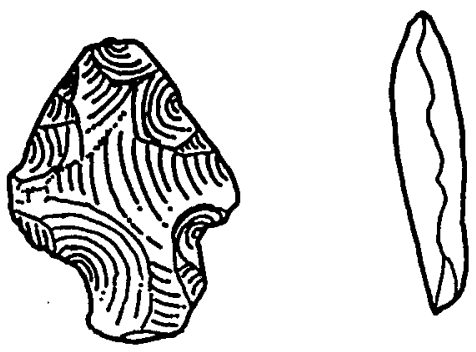

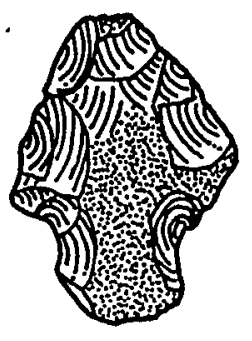

\section{LA6783.0.1}

Description:

Quartzite projectile point base; tip missing, bi-convex cross-section,

indeterminate edges, indeterminate shoulder, expanding stem, pointed tang, straight base. The point fragment appears to be the base of a large corner notched projectile point that broke near the top of the notches, but it is too fragmentary to classify.

\section{Metric Attributes:}

Point Length*

Point Width*

Thickness*

Weight*

* Indicates partial measurement of broken attribute

$<17 \mathrm{~mm}$

$\begin{array}{ll}\text { Blade Length } & \text { unknown } \\ \text { Stem Width } & 11 \mathrm{~mm} \\ \text { Base Width } & 17 \mathrm{~mm}\end{array}$

<10 $\mathrm{mm}$

$<4 \mathrm{~mm}$

Base Width

$17 \mathrm{~mm}$

\section{LA6798.0.1}

\section{Description:}

Complete small corner notched chalcedony projectile point, very sharp point tip, plano-convex cross-section, straight edges, abrupt to rounded shoulders, expanding stem, pointed tang, straight base. The point is crudely made, and the dorsal surface of the flake from which it was made is minimally retouched. The point is considerably smaller, but has very similar notching to the hafted knife 5LA6799.0.1 which was found on the ridge immediately above 5LA6798. This artifact is most similar to category $P 66$ of the Anderson typology, for which an age estimate of between A.D. 800 - A.D. 1450 is assigned. 
Metric Attributes:

Point Length

Point Width

Thickness

$22 \mathrm{~mm}$

$11 \mathrm{~mm}$

Blade Length

$3 \mathrm{~mm}$

Stem Width

$18 \mathrm{~mm}$

Base Width

$7 \mathrm{~mm}$

$9 \mathrm{~mm}$
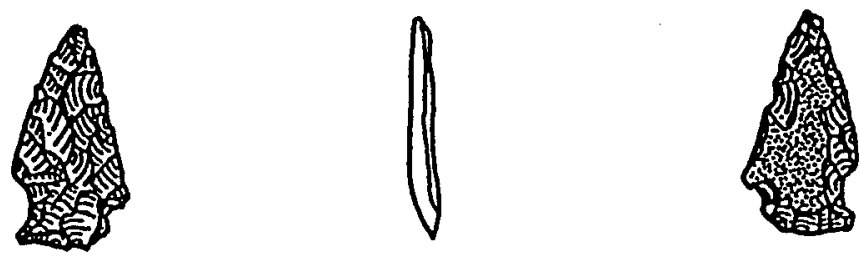

5LA6799.0.1

Description:

Large back hafted quartz:e biface, tip sharp, bi-convex cross-section, straight to slightly convex edges, abrupt shoulders, expanding stem, rounded tangs, straight base. This artifact has heavy use-wear (nibbing) along both edges on both faces. This suggests that the artifact was a hafted knife rather than a projectile point. The biface has unusual notches with one rounder deeper notch and a more shallow and straight notch. The notches are very similar to a small late prehistoric projectile point (5LA6798.0.1) that was collected from a rock shelter immediately below 5LA6799. The artifact is roughly similar to some archaic projectile point styles in the Anderson typology (e.g., P 10, P 40), but the similar notching of 5LA6798.0.1 and 5LA6799.0.1 and the fact that they occurred in close proximity to one another suggests that 5LA6799.0.1 is also a late prehistoric artifact.

Metric Attributes:

Point Length

Point Width

Thickness

Blade Length

Stem Width

Base Width

Weight

$51 \mathrm{~mm}$
$25 \mathrm{~mm}$
$6 \mathrm{~mm}$
$38 \mathrm{~mm}$
$15 \mathrm{~mm}$
$23 \mathrm{~mm}$
$10 \mathrm{~g}$
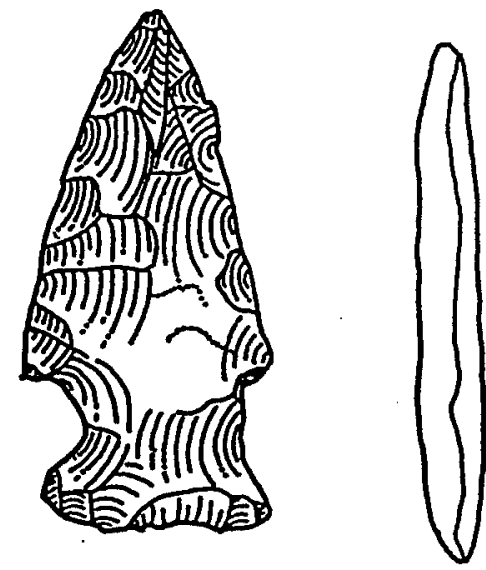

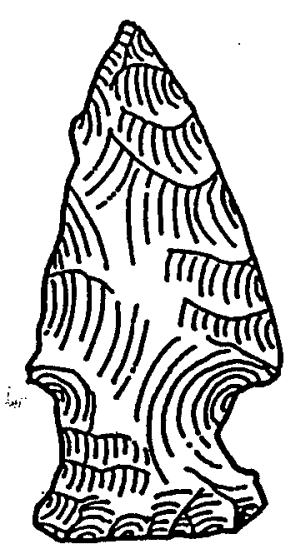

5LA6802.0.1

Description:

Complete small side notched quartzite projectile point, sharp tip, bi-convex crosssection, slightly convex edges, abrupt shoulders, contracting flange stem, point tang, concave base. The point is very well made especially considering that it is quartzite. The point is most similar to category $P 83$ in the Anderson typology, for which an age estimate of between A.D. 750 to A.D. 1650 or later is suggested (Anderson 1989:220). 
Metric Attributes:

Point Length

$20 \mathrm{~mm}$

Point Width

$13 \mathrm{~mm}$

Thickness

$5 \mathrm{~mm}$

Blade Length*

$<26 \mathrm{~mm}$

Stem Width

$8 \mathrm{~mm}$

Base Width*

$12 \mathrm{~mm}$

Weight*

$<3 \mathrm{~g}$
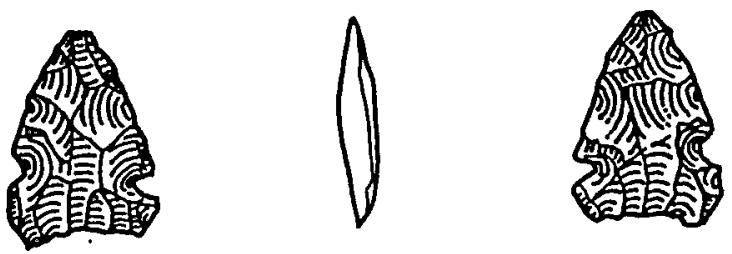

\section{LA6815.0.1}

Description:

Reworked stemmed jasper (chert) projectile point base; tip dull (reworked); biconvex cross-section; convex blade edges; abrupt shoulders; contracting stem; rounded tang; convex base. The point is heavily patinated, but substantially more recent flake scars have exposed the lighter underlying stone. This suggests that the age estimate for the point may predate the lithic scatter from which it was collected. The artifact is most similar to $P 43$ in the Anderson point typology, for which an age estimate of between 3000 B.C. to 500 B.C., but in some areas their use may have persisted as late as A.D. 1000.

Metric Attributes:

Point Length ${ }^{\star} \quad<28 \mathrm{~mm}$

Point Width $\quad 20 \mathrm{~mm}$

Thickness $\quad 5 \mathrm{~mm}$

Blade Length* $\quad<20 \mathrm{~mm}$

Stem Width $\quad 8 \mathrm{~mm}$

Base Width $\quad 6 \mathrm{~mm}$

Weight $^{*}<4 \mathrm{~g}$

*Indicates partial measurement of
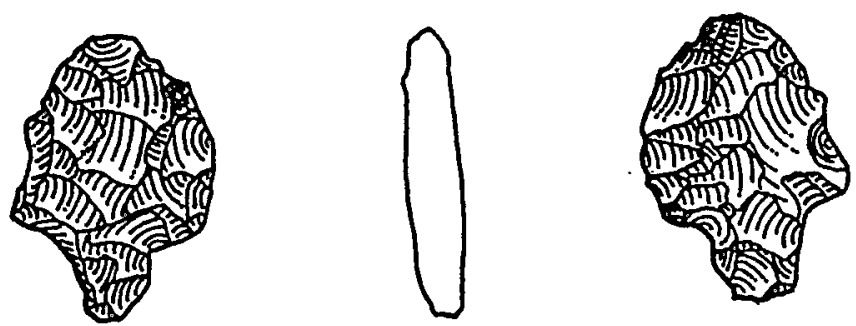

broken attribute

\section{LA6826.0.1}

Description:

Corner notched quartzite projectile point, tip dull, bi-convex cross-section, straight blade edges, weakly barbed shoulders, slightly expanding stem, rounded tang, convex base. Material type is difficult to determine and may be argillite. The point is most similar to category $P 26$, but is possibly better classified in category $P 42$. The numerical age estimate suggested for $P 26$ is between 1000 B.C. to A.D. 500, but may persist as late as A.D. 1400.

Metric Attributes:

Point Length $\quad 33 \mathrm{~mm}$

Point Width $22 \mathrm{~mm}$

Thickness $\quad 5 \mathrm{~mm}$

Blade Length $25 \mathrm{~mm}$

Stem Width $\quad 15 \mathrm{~mm}$

Base Width $\quad 18 \mathrm{~mm}$

Weight

$3.8 \mathrm{~g}$
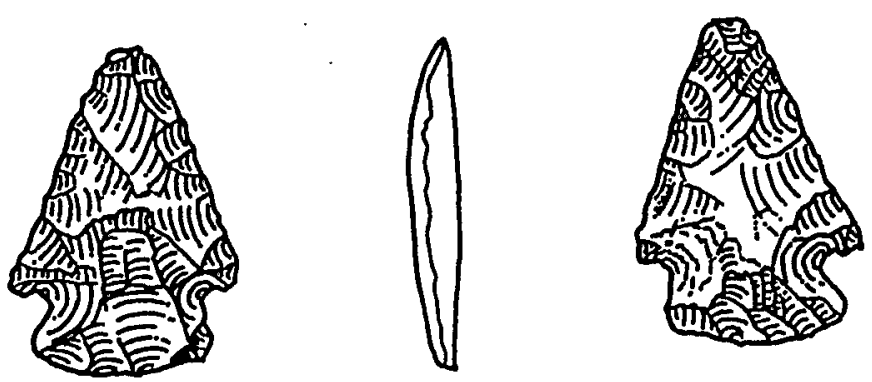


\section{LA6831.0.1}

Description:

Chert projectile point base; tip missing, bi-convex cross-section, indeterminate edges, indeterminate shoulder, indeterminate stem, rounded tang, slightly convex base. This point fragment appears to be the base from a large projectile point, but it is too fragmentary to classify.

Metric Attributes:

Point Length* $<10 \mathrm{~mm}$

Point Width* $\quad<17 \mathrm{~mm}$

Thickness* $\quad<3 \mathrm{~mm}$

Blade Length unknown

Stem Width unknown Base Width $17 \mathrm{~mm}$

Weight $^{*} \quad<1.1 \mathrm{~g}$

*Indicates partial measurement of broken attribute

\section{$\underline{5 L A 6835.0 .1}$}

Description:

Nearly complete (one shoulder may be broken) small corner notched chert projectile point, tip sharp, bi-convex cross-section, straight edges, abrupt shoulders, slightly expanding stem, pointed tang, straight base. This is probably a point base that was reworked; generally the base of points is thinned last because this creates ridges that are perpendicular to the blade edges and these scars terminate flakes removed from the blade edges, but this artifact has flake scars that originate from the blade edge and terminate on scars that originate on the base-thinning on the blade edges was completed after basal thinning, suggesting that the point was reworked. Also, the point is thickest at the base (which does not appear to be substantially reworked). The point is most similar to P 66 of the Anderson typology, for which an age estimate of A.D. 800 to A.D. 1450 is suggested.

Metric Attributes:

Point Length

Point Width

Thickness

Blade Length

Stem Width

Base Width

Weight

$$
\begin{array}{r}
20 \mathrm{~mm} \\
12 \mathrm{~mm} \\
5 \mathrm{~mm} \\
15 \mathrm{~mm} \\
8 \mathrm{~mm} \\
10 \mathrm{~mm} \\
1.2 \mathrm{~g}
\end{array}
$$
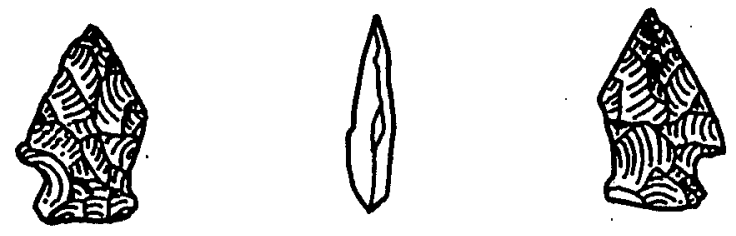

5LA6862.0.1

Description:

Crude sided notched argillite projectile point with the tip missing; very sharp tip?,

bi-convex cross-section, slightly concave edges, straight flange stem, rounded tang, convex base. This projectile point is very irregular, and consequently is difficult to classify. The length and weight suggest that it is and archaic style, but the stem width is narrow for a large point. The point may be a type $P 68$ in the Anderson typology, for which an age estimate of A.D. 800 to A.D. 1350 is suggested. 
Metric Attributes:

Point Length ${ }^{*} \quad<36 \mathrm{~mm}$

Point Width $\quad 13 \mathrm{~mm}$

Thickness $\quad 5 \mathrm{~mm}$

Blade Length* $\quad<26 \mathrm{~mm}$

Stem Width $\quad 8 \mathrm{~mm}$

Base Width* $12 \mathrm{~mm}$

Weight $^{\star}$

$<3 \mathrm{~g}$
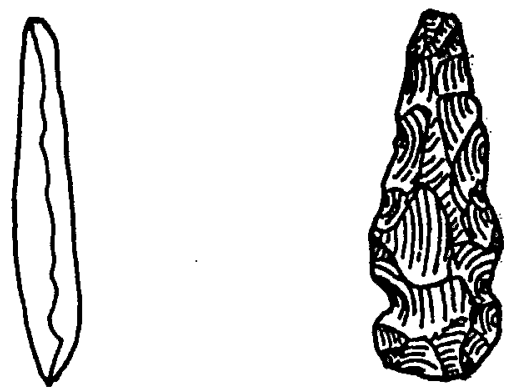

*Indicates pártial measurement of

broken attribute

\section{LA6866.0.1}

\section{Description:}

Nearly completed small chert projectile point preform, very sharp tip, bi-convex cross-section, convex to straight edges, rounded shoulder? slightly expanding stem?, indeterminate tang, indeterminate base. This projectile point appears to be in the final stages of completion and probably broke during notching (only part of one notch is present, and the base is not finished). The point is difficult to classify, and may have been intended to be either side or corner notched. The artifact appears to be a late prehistoric style and may be either type P 66 (A.D. 800 to A.D. 1450) or P 83 (A.D. 759 to A.D. 1650 or later) in the Anderson typology.

Metric Attributes:

Point Length

$22 \mathrm{~mm}$

Point Width

Thickness

$13 \mathrm{~mm}$

Blade Length

Stem Width*

Base Width*

$3 \mathrm{~mm}$

Weight

$17 \mathrm{~mm}$

$8 \mathrm{~mm}$

$9 \mathrm{~mm}$
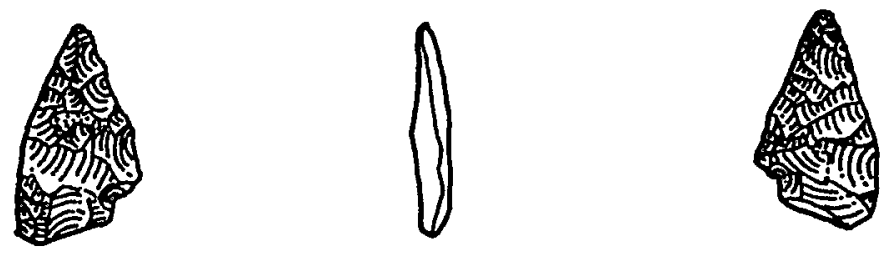

*Indicates partial measurement of broken attribute

\section{LA6875.0.1}

\section{Description:}

Small unbroken corner notched basalt projectile point, sharp tip, plano-convex cross-section, straight to slightly convex edges, barbed shoulders, very slightly expanding stem, pointed tangs, slightly convex base. This point is poorly thinned resulting in the plano-convex cross-section. This artifact is similar to categories $P 52, P 58$, and $P 62$ of the Anderson typology. The point is most similar to $P 58$ for which a numerical age estimate of between A.D. 400 to A.D. 1400 is suggested, but most points of this style fall between A.D. 600 and A.D. 1200. 
Metric Attributes:

Point Length $\quad 28 \mathrm{~mm}$

Point Width $19 \mathrm{~mm}$

Thickness $\quad 4 \mathrm{~mm}$

Blade Length $21 \mathrm{~mm}$

Stem Width $9 \mathrm{~mm}$

Base Width $12 \mathrm{~mm}$
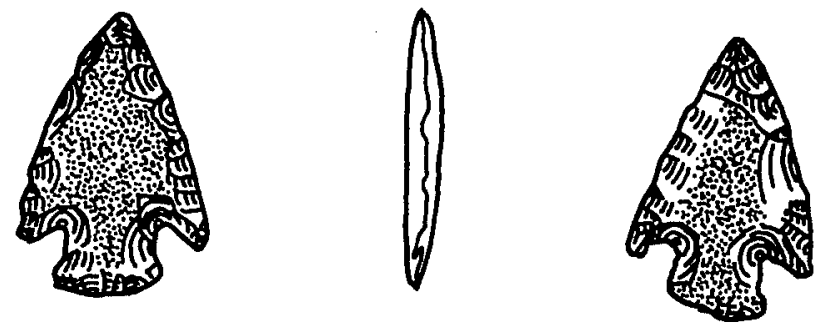

\section{LA6876.0.1}

Description:

Large quartzite probably corner notched projectile point mid-section; tip missing, bi-convex cross-section, convex blade edges, indeterminate shoulder shape, indeterminate stem shape, indeterminate tang shape, indeterminate base shape. This well made biface is broken through the notches and at the tip. The artifact has long flake scars $(20 \mathrm{~mm})$ that appear to have been removed by soft hammer percussion. The tool has nibbing along both edges, which suggests that it was reused for cutting/slicing after breakage. The artifact is a dart point that appears to be an archaic style but is difficult to classify and may fall in categories $P 12$ (3000 B.C. to A.D. 500), P 21 (1000 B.C. to A.D. $500 / 1000$ ), or P 26 (1000 B.C. to A.D. 500) of the Anderson typology.

Metric Attributes:

Point Length* $\quad<28 \mathrm{~mm}$

Point Width $26 \mathrm{~mm}$

Thickness $\quad 5 \mathrm{~mm}$

Stem Width $15 \mathrm{~mm}$

Base Width* ${ }^{*}<16 \mathrm{~mm}$

Blade Length* $\quad<26 \mathrm{~mm}$

Weight*

$<5.2 \mathrm{~g}$

* Indicates partial measurement of broken attribute

\section{$\underline{5 L A 6880.0 .1}$}

Description:

Chalcedony projectile point base; tip missing, bi-convex cross-section, indeterminate edges, indeterminate shoulder, expanding stem, rounded tang, straight base. The point fragment appears to be the base of a large corner notched projectile point, but it is too fragmentary to classify.

Metric Attributes:

$\begin{array}{llll}\text { Point Length* }^{*} & <11 \mathrm{~mm} & \text { Stem Width } & 14 \mathrm{~mm} \\ \text { Point Width }^{*} & <16 \mathrm{~mm} & \text { Base Width } & 17 \mathrm{~mm} \\ \text { Thickness }^{*} & <5 \mathrm{~mm} & \text { Weight }^{*} & <1.8 \mathrm{~g}\end{array}$

Blade Length unknown

* Indicates partial measurement of broken attribute

\section{LA6884.0.1}

Description:

Small side notched chert projectile point base; tip missing, bi-convex crosssection, blade edges convex, abrupt shoulders, straight flange stem, pointed tang, convex base. This projectile point is very irregular and may have broken during manufacture and never been completed. The point is closest to 
category P 83 in the Anderson typology, for which a date of between A.D. 750 to A.D. 1650 or later is suggested.

Metric Attributes:

$\begin{array}{lrlr}\text { Point Length } & <22 \mathrm{~mm} & \text { Stem Width } & 8 \mathrm{~mm} \\ \text { Point Width } & 12 \mathrm{~mm} & \text { Base Width }^{*} & <10 \mathrm{~mm} \\ \text { Thickness } & 5 \mathrm{~mm} & \text { Weight }^{*} & <1.5 \mathrm{~g}\end{array}$

Blade Length* ${ }^{*}<10 \mathrm{~mm}$

* Indicates partial measurement of broken attribute

\section{LA6889.0.1}

\section{Description:}

Retouched chert flake, probably a broken projectile point preform; tip dull, planoconvex cross-section, straight edges, no stem, rounded tang, concave base.

The artifact is split longitudinally, and is most probably a small late prehistoric point preform that was broken during manufacture. It is not possible to classify this artifact in the Anderson typology.

Metric Attributes:

Point Length

Point Width* $\quad<11 \mathrm{~mm}$

Thickness $\quad 3 \mathrm{~mm}$

Blade Length $22 \mathrm{~mm}$

$\begin{array}{ll}\text { Stem Width } & \text { N/A } \\ \text { Base Width* } & <11 \mathrm{~mm} \\ \text { Weight }^{*} & <1.5 \mathrm{~g}\end{array}$

* Indicates partial measurement of broken attribute

\section{LA6938.0.1}

\section{Description:}

Large nearly complete corner notched jasper (chert) projectile point with the tip and one shoulder missing, tip rounded?, bi-convex cross-section, convex blade edges, weakly barbed shoulders, slightly expanding stem, rounded tang, slightly convex base. The point is missing one shoulder, and has some light nibbing along both edges that suggests it may have been reused for cutting/slicing. The point is most similar to category $P 26$. The numerical age estimate suggested for P 26 is between 1000 B.C. to A.D. 500, though they may persist as late as A.D. 1400.

Metric Attributes:

$\begin{array}{lr}\text { Point Length* } & 35 \mathrm{~mm} \\ \text { Point Width } & 22 \mathrm{~mm} \\ \text { Thickness } & 6 \mathrm{~mm} \\ \text { Blade Length } & 31 \mathrm{~mm} \\ \text { Stem Width } & 11 \mathrm{~mm} \\ \text { Base Width* }^{*} & <11 \mathrm{~mm} \\ \text { Weight }^{*} & <5.1 \mathrm{~g}\end{array}$
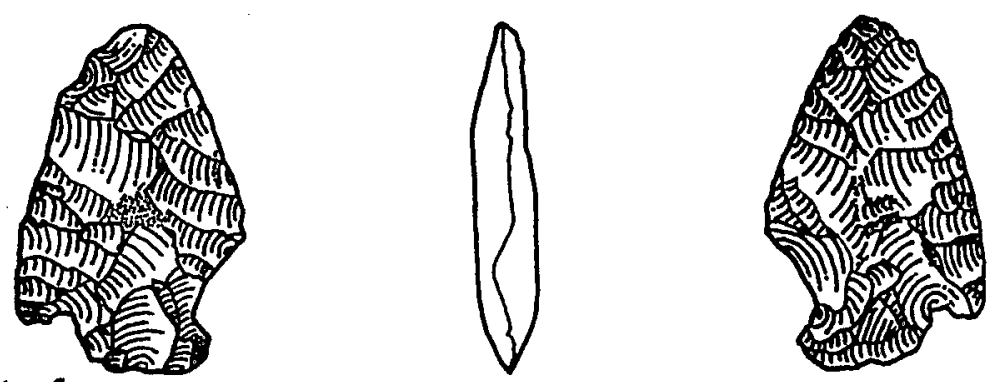

*Indicates partial measurement of broken attribute 


\section{LA6938.0.2}

\section{Description:}

Small unusual retouched chert flake that is probably a projectile point preform; dull tip?, bi-planar cross-section, straight edges, rounded shoulders?, rounded tang?, rounded base?. This artifact is possibly the base of a large projectile point; however, the artifact is too thin and is more likely a chert flake that was only thinned along one edge and then discarded. It is not possible to classify the artifact in the Anderson typology, but it is probably a late prehistoric type.

Metric Attributes:

Point Length

Point Width

Thickness

Blade Length
$25 \mathrm{~mm}$

$12 \mathrm{~mm}$

$3 \mathrm{~mm}$

$17 \mathrm{~mm}$

$\begin{array}{ll}\text { Stem Width } & 7 \mathrm{~mm} \\ \text { Base Width } & 8 \mathrm{~mm} \\ \text { Weight } & 1.9 \mathrm{~g}\end{array}$

\section{LA7160.0.1}

\section{Description:}

Corner notched chert projectile point base; tip missing, bi-convex cross-section, straight edges, indeterminate shoulder, expanding stem, rounded tang, straight base. This point fragment is well made and is fully flaked on both faces with pressure flake scars extending as long as $12 \mathrm{~mm}$. The point is difficult to classify but appears to be most similar to category $P 35$ of the Anderson typology, with an age estimate of between 1000 B.C. to A.D. 1200. Metric Attributes:

Point Length* $\quad<26 \mathrm{~mm}$

Point Width $\quad 19 \mathrm{~mm}$

Thickness $\quad 4 \mathrm{~mm}$

Blade Length* $\quad<20 \mathrm{~mm}$

Stem Width $\quad 10 \mathrm{~mm}$

Base Width* $\quad<10 \mathrm{~mm}$
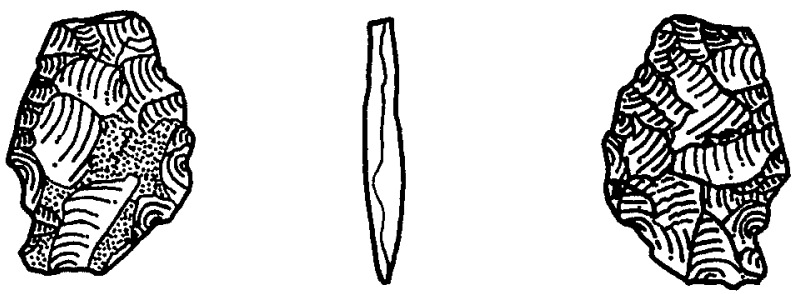

*Indicates partial measurement of broken attribute

\section{$\underline{5 L A 7163.0 .1}$}

\section{Description:}

Quartzite projectile point base; tip missing, bi-convex cross-section, indeterminate edges, indeterminate shoulder, expanding stem, pointed tang, slightly concave base. This artifact may be the base of a large corner notched projectile point, but it is too fragmentary to classify.

Metric Attributes:

$\begin{array}{llll}\text { Point Length }^{*} & <10 \mathrm{~mm} & \text { Stem Width } & 13 \mathrm{~mm} \\ \text { Point Width }^{*} & <20 \mathrm{~mm} & \text { Base Width }^{*} & 19 \mathrm{~mm} \\ \text { Thickness }^{*} & <4 \mathrm{~mm} & \text { Weight }^{*} & <1.5 \mathrm{~g}\end{array}$

Blade Length unknown

* Indicates partial measurement of broken attribute 


\section{GROUNDSTONE}

Although hundreds of groundstone artifacts were identified during field investigations, and described on the field forms, only a few unusual ground artifacts that were collected are described in this section.

\section{Artifact Descriptions}

\section{$\underline{5 L A 4938.0 .4}$}

Description:

Complete sandstone edge-ground mano. The elongated triangular- shaped rock

has one edge that is smoothed and polished from heavy grinding activity.

One face of the mano exhibits a light polish and it may have been used for light grinding. Both ends of the mano have been battered, and the battering is also apparent on one face, perhaps a product of shaping the tool. A red stain on two faces of the tool may be red ochre or it may represent some other substance, but it appears to be in the granular structure of the rock (under a silica covering) and it does not look like it got there through natural means. Metric Attributes: Length $14 \mathrm{~cm}$ Width $6.5 \mathrm{~cm}$ Thickness $5.5 \mathrm{~cm}$

\section{LA6592.0.2}

\section{Description:}

Complete sandstone shaft abrader. Both faces of this artifact have shallow (1

$\mathrm{mm}$ ) longitudinal rounded grooves. The edges of the artifact have been shaped by grinding.

Metric Attributes: Length $10 \mathrm{~cm}$ Width $3.5 \mathrm{~cm}$ Thickness $2 \mathrm{~cm}$
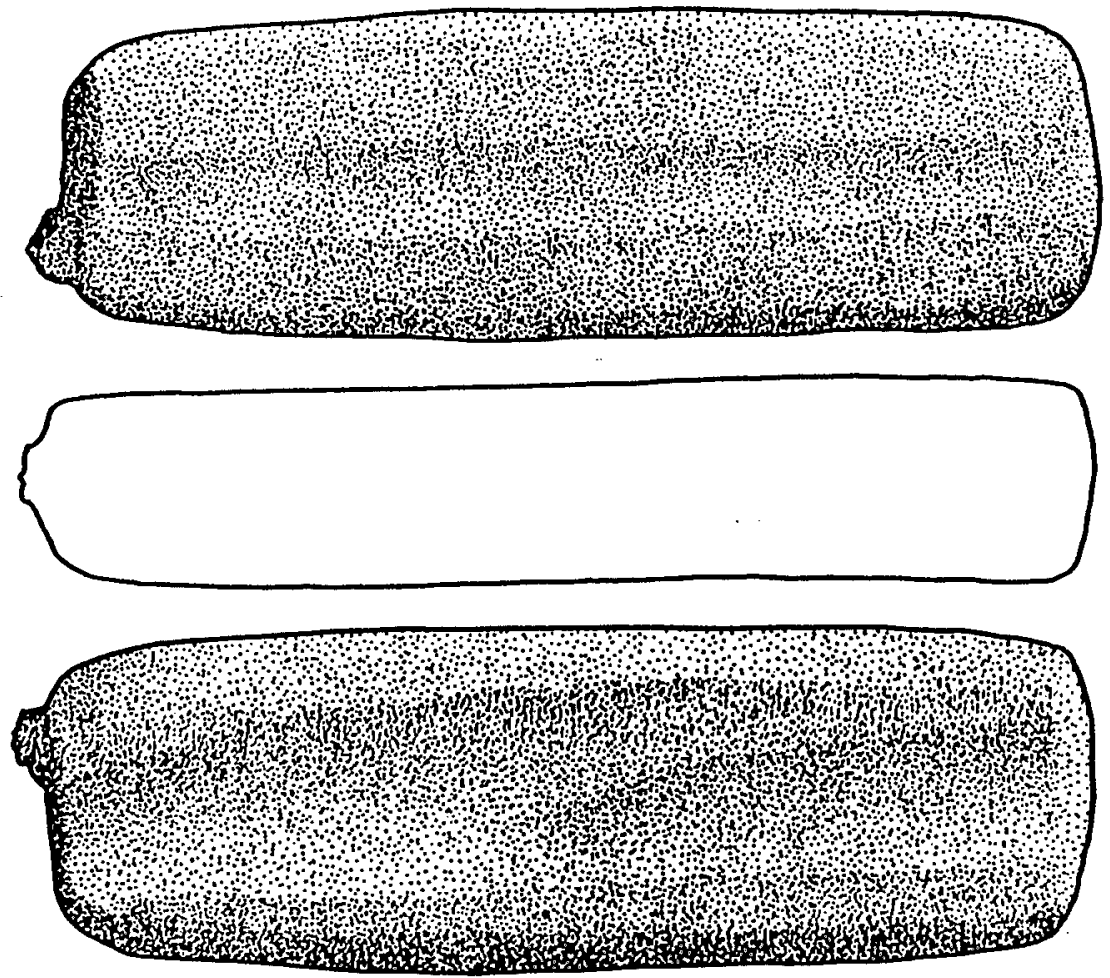


\section{LA6592.0.3}

Description:

Complete sandstone shaft abrader. Both faces of this artifact have shallow (1 $\mathrm{mm}$ ) longitudinal rounded grooves. The edges of the artifact have been shaped by grinding. This artifact is smaller, but otherwise very similar to artifact number 5LA6592.0.2 Metric Attributes:

$\begin{array}{ll}\text { Length } & 8.5 \mathrm{~cm} \\ \text { Width } & 3.5 \mathrm{~cm} \\ \text { Thickness } & 2.0 \mathrm{~cm}\end{array}$
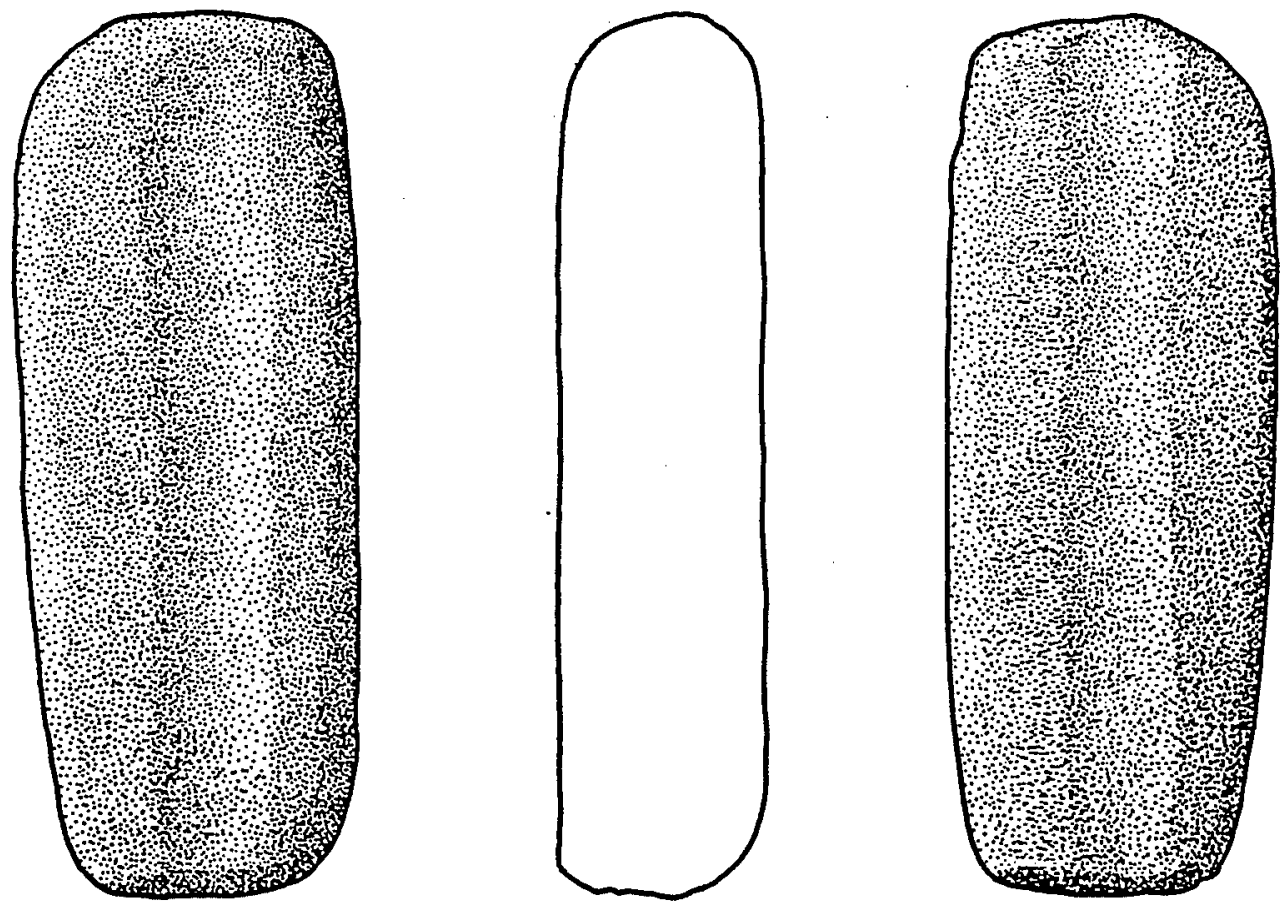

\section{LA6606.0.1}

Description:

Complete one hand basalt mano. One edge has been heavily battered, and several flakes have been removed. Both faces were used for grinding, but the grinding was more intense on one face that exhibits a light polish. Metric Attributes:

Length

$16.0 \mathrm{~cm}$

Thickness

$$
4.5 \mathrm{~cm}
$$

$8.5 \mathrm{~cm}$ 


\section{LA6862.0.2}

Description:

Sandstone slab with grinding on both faces. Both faces of this slab have been ground, but the grinding is heavier on one face the center of which is fairly highly polished. Some type of grayish black residue is present of both faces. The residue is heaviest on the face with the most intensive grinding. The residue appears to be associated with the use of the artifact, and is possibly some type of organic material. Other small flecks of a brown material, likely rodent excrement, are also present one the face with the heavy grinding. Metric Attributes: Length $29 \mathrm{~cm}$ Width $21 \mathrm{~cm}$ Weight $1971 \mathrm{~g}$ Thickness $1.5 \mathrm{~cm}$

\section{LA6889.0.2}

Description:

Complete one hand edge ground mano. Ground beveled ridges are present on both edges of the mano. Both faces have been ground, but one face has heavier grinding and exhibits a light polish.

Metric Attributes: Length $15 \mathrm{~cm}$ Width $7.8 \mathrm{~cm}$ Weight $728 \mathrm{~g}$ Thickness $4 \mathrm{~cm}$
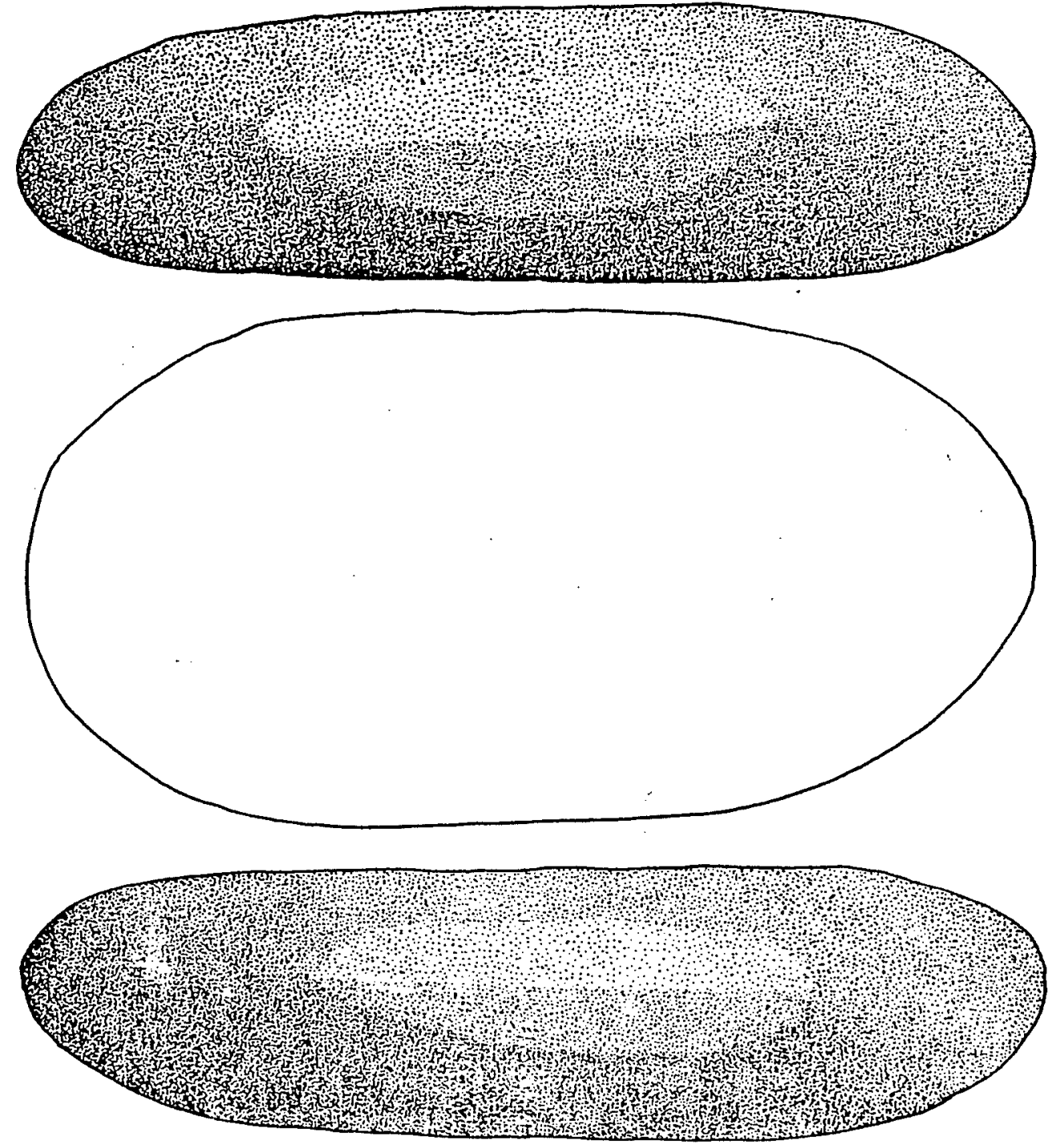


\section{LA6951.0.1}

Description:

Small incised and ground fragment of siltstone or kaolinite. Both surfaces of the artifact are covered with fine striations that appear to be the result of shaping the artifact. One edge was shaped by grooving and snapping, one edge is ground, and the two edges are broken. The size and shape of the artifact suggest that it is a fragment of a pendant.

Metric Attributes:

Length $26 \mathrm{~mm}$ Width $16 \mathrm{~mm}$ Weight $3.1 \mathrm{~g}$ Thickness $5 \mathrm{~mm}$

PC 95 IF 17

Description:

Shaft straightener with crossed grooves and ridge. This unusual artifact has two grooves that are perpendicular to each other. The two grooves are approximately the same width $(13-15 \mathrm{~mm})$, but the groove on the short axis of the artifact is deeper $(5 \mathrm{~mm})$ than the groove along the long axis $(3 \mathrm{~mm})$. Both grooves have heavy polishing on their interiors. The ridge is raised 2 $\mathrm{mm}$ above the surrounding surface of the artifact. All surfaces of the artifact have been shaped by grinding. The artifact appears to have been exposed to heat, and the heating was most intense on the upper surface. The artifact appears to have been heated and used when hot to straighten shafts (probably sections of reed).

Metric Attributes:

Length $11.1 \mathrm{~cm}$ Width $7.3 \mathrm{~cm}$ Thickness $3.5 \mathrm{~cm}$ Weight $622.0 \mathrm{~g}$
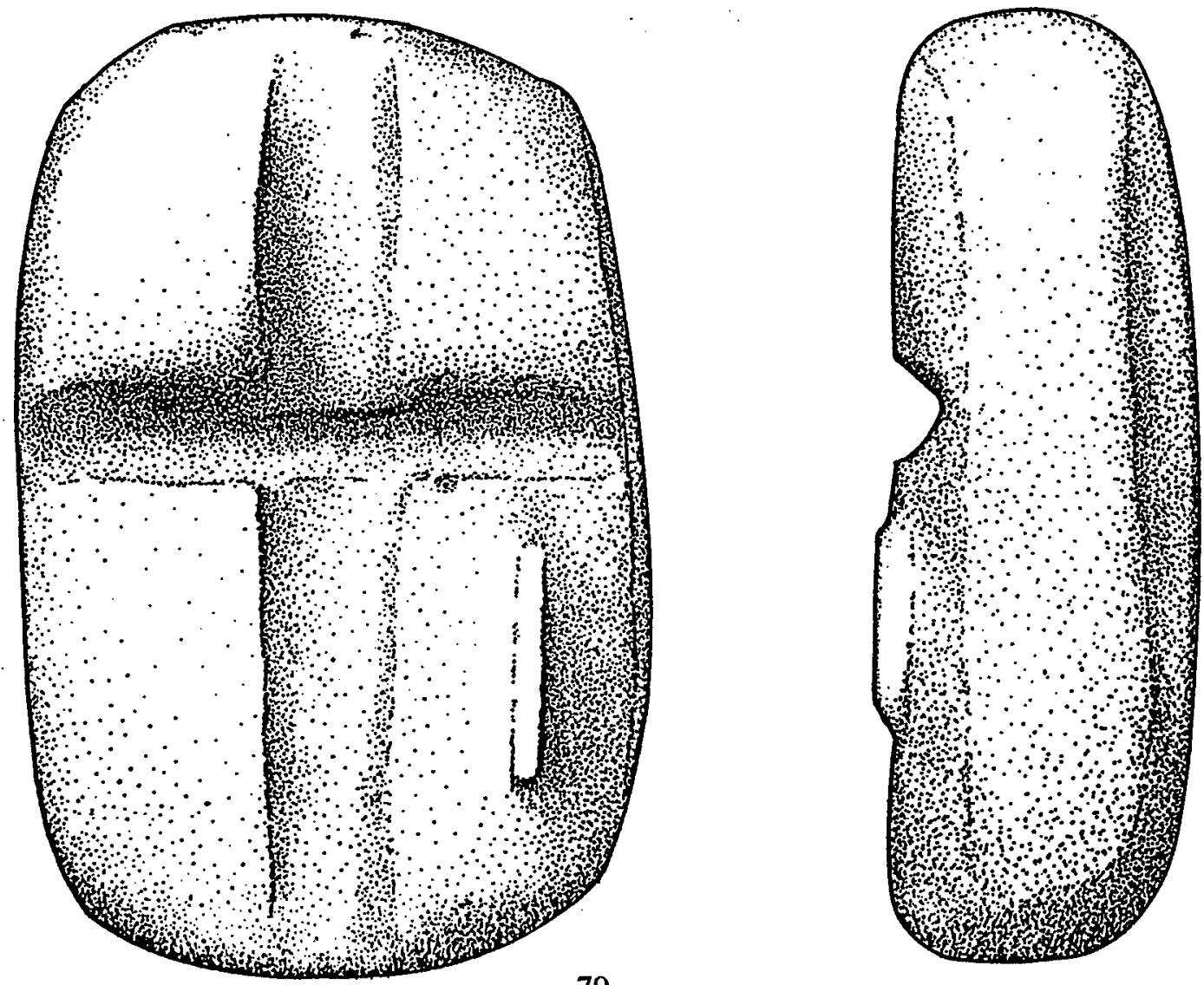


\section{CERAMICS}

A total of only 7 sherds were collected from 5 sites. This section contains descriptive information regarding these artifacts, and the sherds are classified according to the system developed by Hummer (1989:316-377) for ceramics from the PCMS.

Artifact Descriptions

5LA6583.0.1

Description:

Obliterated cordmarked body sherd (broken into two pieces); black paste, no carbon streak, compact texture, reddish brown exterior, black interior, coarse volcanic ash temper visible on interior. This artifact may be classified as Cordmarked Category 4 in the Hummer typology, for which and age estimate of between A.D. 1000 to A.D. 1450 is suggested.

Metric Attributes:

$\begin{array}{lr}\text { Length } & 38 \mathrm{~mm} \\ \text { Width } & 25 \mathrm{~mm} \\ \text { Thickness } & 5 \mathrm{~mm}\end{array}$

\section{LA6595.0.1}

Description:

Cordmarked body sherd; black paste, no carbon streak, compact texture, black
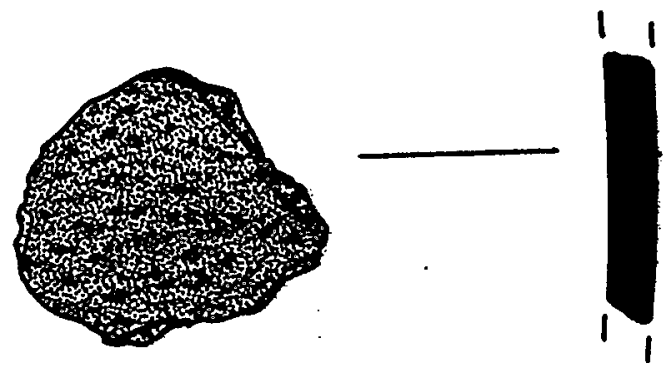

exterior, black interior, coarse angular quartz temper. This artifact is possibly

a Cordmarked Category 4 in the Hummer typology, for which and age estimate of between A.D. 1000 to A.D. 1450 is suggested.

Metric Attributes:

Length

$27 \mathrm{~mm}$

Width

$26 \mathrm{~mm}$

Thickness

$9 \mathrm{~mm}$

\section{LA6756.0.1}

Description:

Cordmarked body sherd; grayish white paste, no carbon streak, compact texture, white exterior, light grayish white interior, coarse angular temper visible on interior. This sherd is most similar to Cordmarked Category 3 in the Hummer typology, for which and age estimate of between A.D. 600 to A.D. 1000 is suggested.

Metric Attributes:

Length $\quad 17 \mathrm{~mm}$

Width $17 \mathrm{~mm}$

Thickness

$6 \mathrm{~mm}$ 


\section{LA6798.0.2}

\section{Description:}

Obliterated corrugated body sherd; gray paste with carbon streak, grayish white interior and exterior, fine angular quartz temper, friable texture, moderate polish on the ridges between cordmarks, slight polish on interior, indeterminate construction technique. This sherd appears to be a Polished Category 2 in the Hummer typology, for which an age estimate of between A.D. 1000 and A.D. 1400 is tentatively suggested.

Metric Attributes:

$\begin{array}{lr}\text { Length: } & 17 \mathrm{~mm} \\ \text { Width: } & 15 \mathrm{~mm} \\ \text { Thickness } & 4 \mathrm{~mm} \\ \text { Weight: } & 1.4 \mathrm{~g}\end{array}$

\section{LA6798.0.3}

Description:

Cordmarked body sherd; indeterminate construction technique, gray carbon streak, compact texture, light reddish brown exterior, brown interior, fine temper, light polish is present in the ridges between cordmarks on the exterior, no polish on interior. This sherd is most similar to Cordmarked Category 4 in the Hummer typology, for which and age estimate of between A.D. 1000 to A.D. 1450 is suggested.

Metric Attributes:

$\begin{array}{llll}\text { Length } & 20 \mathrm{~mm} & \text { Thickness } & 5 \mathrm{~mm} \\ \text { Width } & 16 \mathrm{~mm} & \text { Weight } & 2.1 \mathrm{~g}\end{array}$

\section{LA6837.0.1}

\section{Description:}

Cordmarked body sherd; gray paste, carbon streak, compact texture, tan exterior, light gray interior, fine angular temper. Cordmarks made with cordwrapped paddle and are criss-crossed at oblique angles. The cordmarks are approximately $2.1 \mathrm{~mm}$ wide, $0.6 \mathrm{~mm}$ deep, and $25 \mathrm{~mm}$ long. This sherd may be classified as a Cordmarked Category 4 in the Hummer typology, for which an age estimate of between A.D. 1000 to A.D. 1450 is suggested.

Metric Attributes:

Length:

Width:

Thickness
$44 \mathrm{~mm}$

$32 \mathrm{~mm}$

$5 \mathrm{~mm}$
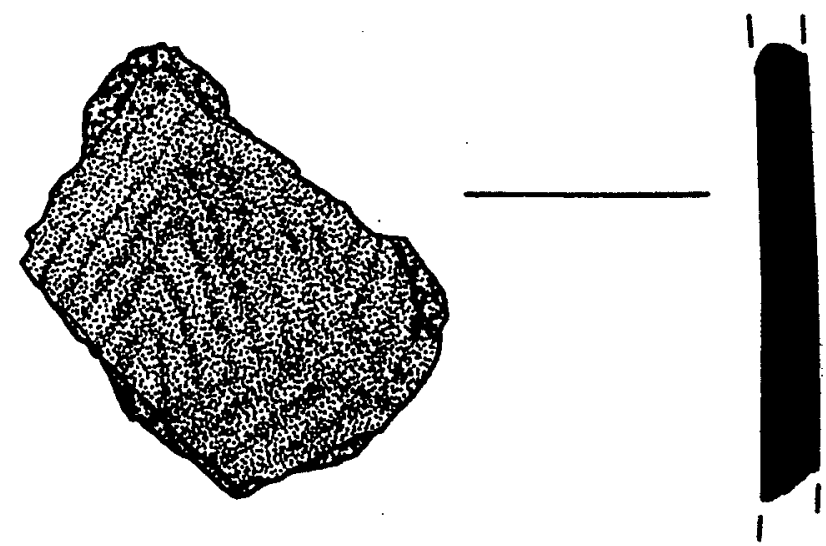


\section{DISTRIBUTION OF ARTIFACTS AND FEATURES BY SITE LOCATION AND TYPE}

This section begins with a discussion of the artifact and feature types employed in this analysis. The distribution of these artifact types and features by site location and type are then considered.

\section{Artifact and Feature Types}

Four different artifact types are considered in this analysis. Additional discussion of the prehistoric artifact types can be found in the preceding section. These types were selected because they are common, and because they may be related to different types of activities.

Both fragmentary and complete grinding implements that appear to have been used in a hand held fashion were classified as manos. These artifacts were generally tabular water worn cobbles of abrasive stone (much of this material may have been transported from the Purgatoire River), and were probably generally used for grinding against a stationary surface (i.e., metates). Some manos exhibited battering along their margins, which may have resulted from intentional shaping, and/or accidental battering against metate edges. It is also possible (especially for broken manos) that some battering resulted from the use of these artifacts as hammerstones.

Mano counts observed at sites ranged between 0 and 11 , with an average of 0.6 manos. Manos were one of the most common tool types identified, and were found at 28 percent of the prehistoric sites in Welsh Canyon.

Both ground surfaces on bedrock and ground surfaces on portable stone slabs were classified as metates. Ongoing research in the PCMS has suggested that the basin shaped ground areas in rockshelters may have been used to dehydrate foodstuffs (personal communication Steve Chomko), and it is possible that the metates include examples that were employed for different tasks.

The number of metates observed at sites ranged between 0 and approximately 60 , with an average of 0.6 metates per site. Metates were identified at only 35 sites, or 16 percent of the total.

Small bifacially retouched stone tools that we believe were hafted are classified as projectile points. Partially worked pieces that appear to have been projectile point preforms were also classified as projectile points. This variable includes both larger points that may have been used on atlatl darts, and smaller points that were probably hafted on arrow shafts. 
Projectile point counts observed at sites ranged between 0 and 3 , with an average of only 0.2 points. Projectile points were collected from 35 sites, or 16 percent of the total.

Localized areas that exhibited evidence of in situ burning (i.e., heat altered stone, charcoal, ash, soil discoloration, or other evidence of oxidization) were classified as hearths. Heat altered stone and ash were not classified as hearths unless this material was associated with in situ burning.

Hearth counts ranged between 0 and 2, with an average of only 0.07 hearths. These features were recorded at only 14 sites, or 7 percent of the total. However, heat altered stone and ash were relatively common at sites (especially on slopes below rockshelters) and it likely that hearths were substantially more common than is indicated by the survey data. In most instances it is probable that erosion or deposition obscured surface indications for these features.

Ceramic artifacts identified during the survey consist exclusively of unslipped body sherds from vessels. Sherd counts observed at sites ranged between 0 and 2 . Ceramics were found at only 5 sites, or only 2.2 percent of the total. Several observations suggest that the use of ceramic vessels may have been somewhat more common than is suggested by the survey data. First, it appears that broken vessels were not simply discarded at sites, and fragments of vessels continued to be used until they reached a very small size. For example, two very small sherds were identified at rockshleter site 5LA6798, but these two sherds were from separate vessels and an intensive search of the area failed to identify any additional sherds from these vessels. Second, ceramic sherds are very difficult to identify during survey because of their small size (collected sherds are usually less than 3 centimeters in maximum dimension). Natural tabular sandstone of approximately the same color and thickness as the sherds is present in many locations and this background material complicates the identification of sherds on the ground surface.

\section{Artifact and Feature Distribution by Site Location}

Artifacts of all types and hearths occurred most commonly at canyon rim sites, but each artifact and feature type except ceramics were found in all four physiographic zones (Table 3). The greater incidence of these artifact types at canyon rim sites suggests more intensive occupation occurred in this setting, and further supports the possibility that this location was preferred for habitation.

Manos occurred at relatively uniform rates throughout Welsh Canyon. Manos were found at roughly the same rate for canyon rim sites (33 percent had manos), canyon bottom (29 percent had manos), and talus slope sites (28 percent had manos). Manos were somewhat less common at mesa top sites and were found at 19 percent of these sites. The uniform distribution of these artifacts 
Table 3. Artifact and Feature Distribution by Physiographic Zone.

\begin{tabular}{|l|ccccc|}
\hline Physiographic Setting & $\begin{array}{c}\text { Mano } \\
\text { Present }\end{array}$ & $\begin{array}{c}\text { Metate } \\
\text { Present }\end{array}$ & $\begin{array}{c}\text { Projectile } \\
\text { Point } \\
\text { Present }\end{array}$ & $\begin{array}{c}\text { Hearth } \\
\text { Present }\end{array}$ & $\begin{array}{c}\text { Ceramics } \\
\text { Present }\end{array}$ \\
\hline Canyon Rim & $25(33 \%)$ & $24(32 \%)$ & $18(24 \%)$ & $8(11 \%)$ & $4(5 \%)$ \\
Canyon Bottom & $16(29 \%)$ & $4(7 \%)$ & $10(18 \%)$ & $4(7 \%)$ & 0 \\
Talus Slope & $18(28 \%)$ & $5(7 \%)$ & $3(4 \%)$ & $1(2 \%)$ & $1(1 \%)$ \\
Mesa Top & $5(19 \%)$ & $2(8 \%)$ & $4(15 \%)$ & $1(4 \%)$ & 0 \\
\hline
\end{tabular}

(Percent of Sites in each setting with artifact or feature)

suggests that they were associated with activities that were performed throughout Welsh Canyon.

Metates were largely recorded in canyon rim locations, and 24 (67 percent) of the sites with metates were in canyon rim areas. As will be discussed further below, metates were more common at rockshelter sites and the higher incidence of this site type in canyon rim settings may be related to the concentration of metates in this area.

Although lithic scatters were by far the most common site type identified on talus slopes, projectile points were least common at these sites and were found at only 3 ( 4 percent) of the 70 sites identified in this location. This paucity of completed chipped stone artifacts at talus slope lithic scatters suggests that many of these sites also represent locations where lithic raw materials were collected, with subsequent processing being completed in other locations.

The sample of ceramics identified during the survey is insufficient for meaningful quantitative comparisons. It is interesting to note that four of the five sites with sherds occurred in canyon rim settings, which is consistent with the suggestion that this area experienced more intensive occupation.

Artifact and Feature Distribution by Site Type

With the exception of ceramics, the different artifact and feature types considered in this analysis were found at all site categories (Table 4). Lithic procurement sites are not included in this discussion because by definition they lack these artifacts and features. The widespread distribution of different artifact and feature types suggests that none of the site types considered (with the exception of procurement sites) was associated exclusively with a single type of activity. However, the incidence of artifact and feature types does vary by site type. 
Table 4. Artifact and Feature Distribution by Site Type.

\begin{tabular}{|l|ccccc|}
\hline Site Type & Mano Present & $\begin{array}{c}\text { Metate } \\
\text { Present }\end{array}$ & $\begin{array}{c}\text { Projectile } \\
\text { Point Present }\end{array}$ & $\begin{array}{c}\text { Hearth } \\
\text { Present }\end{array}$ & $\begin{array}{c}\text { Ceramics } \\
\text { Present }\end{array}$ \\
\hline Rockshelter & $22(38 \%)$ & $16(28 \%)$ & $13(22 \%)$ & $6(10 \%)$ & $4(7 \%)$ \\
Rockshelter with Wall & $6(42 \%)$ & $7(58)$ & $4(33 \%)$ & $2(17 \%)$ & 0 \\
Artifact Scatter & $36(28 \%)$ & $10(8 \%)$ & $14(11 \%)$ & $5(4 \%)$ & $1(0.7 \%)$ \\
Prehistoric Structure & $2(33 \%)$ & $2(33)$ & $4(67 \%)$ & $1(17 \%)$ & 0 \\
\hline
\end{tabular}

(Percent of Sites with artifact or feature)

Architectural features including walls built in rockshelters and structures in open areas occur at sites that have evidence for more intensive habitation. Metates, manos, projectile points and hearths were more common at rockshelters with walls than they were at rockshelters that lacked these features. This suggests that walled rockshelters were more intensively utilized. Metates, manos, projectile points and hearths were also more common at open sites with prehistoric structures than they were at lithic scatters that lacked structures. 


\section{SUMMARY AND CONCLUSIONS}

A total of 226 prehistoric sites were recorded during the 1995 - 1996 archaeological survey of Welsh Canyon . A variety of different site, feature, and artifact types were identified during the project. Diagnostic artifacts were rare surface finds throughout the survey area, complicating the evaluation of research issues that are related to diachronic factors. Consequently, this discussion focuses on description of the most frequently identified cultural resources. In addition, suggestions are offered for why some other cultural resources (rock art in particular) that commonly occur in other portions of the PCMS were rare in Welsh Canyon.

The four major research domains outlined in the Multiple Propety National Register Nomination include Chronology, Paleoenvironments, Settlement Subsistence studies, and Exchange and Mobility studies. From the perspective of site chronology, very few surprises were encountered in the survey. Twenty-nine projectile points were sufficiently complete to classify according to the criteria in the Anderson typology and using the tentative dates established for these point types, it is evident that the Welsh Canyon sites are dominated by Early Ceramic to Middle Ceramic age projectile points. Twenty-one $(72.4 \%)$ of the classifiable points have an age estimate that overlaps A.D. 900 , a period of time that falls between the end of the Early Ceramic and the beginning of the Middle Ceramic. A group of ten projectile points have age estimates within the Late Archaic to Early or Middle Ceramic periods while only two are potentially as old as the Middle Archaic (Figure 13).

Fairly similar results are produced with other statistics. Using the means and medians for the individual ranges of the projectile point dates produces a frequency distribution with an upper age of A.D. 1275 and a lower age of 1750 B.C. Three or four clusters are evident in this distribution. One between A.D. 850 and A.D. 1275 includes 17 of the projectile point age estimates; this group has a mean age of A.D. 1088. A second group of five projectile point dates is between A.D. 50 and A.D. 250 with a mean age of A.D. 170. A third group of four projectile points have median age estimates between 150 B.C. and 250 B.C. with and average of $225 \mathrm{~B}$.C. Finally three of the projectile points have median age estimates between 1750 B.C. and 1250 B.C. with an average age of 4750 B.C. The strongest of these groups, with the greatest number of cases, is the one at A.D. 1088. It quite clearly reflects the intensive use of Welsh Canyon at the end of the Early Ceramic period and into the beginning of the Middle Ceramic period (Figure 14).

The projectile points from the sites that were subsequently test excavated, support similar conclusions and as reported in Schiavitti (1999) the radiocarbon dates from these sites are in several clusters, which correspond fairly closely with those from the projectile point estimates. Collectively these data suggest that 


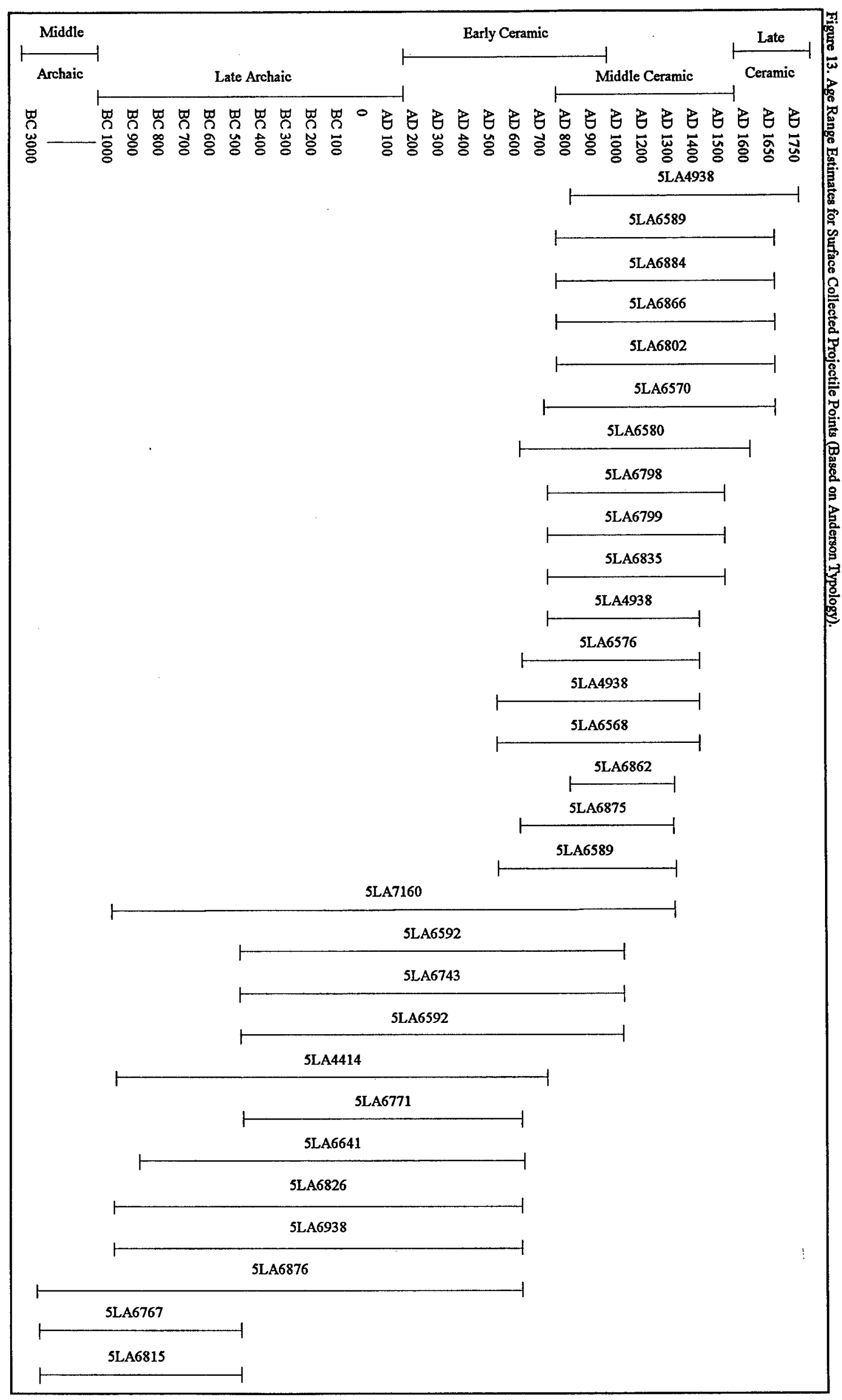




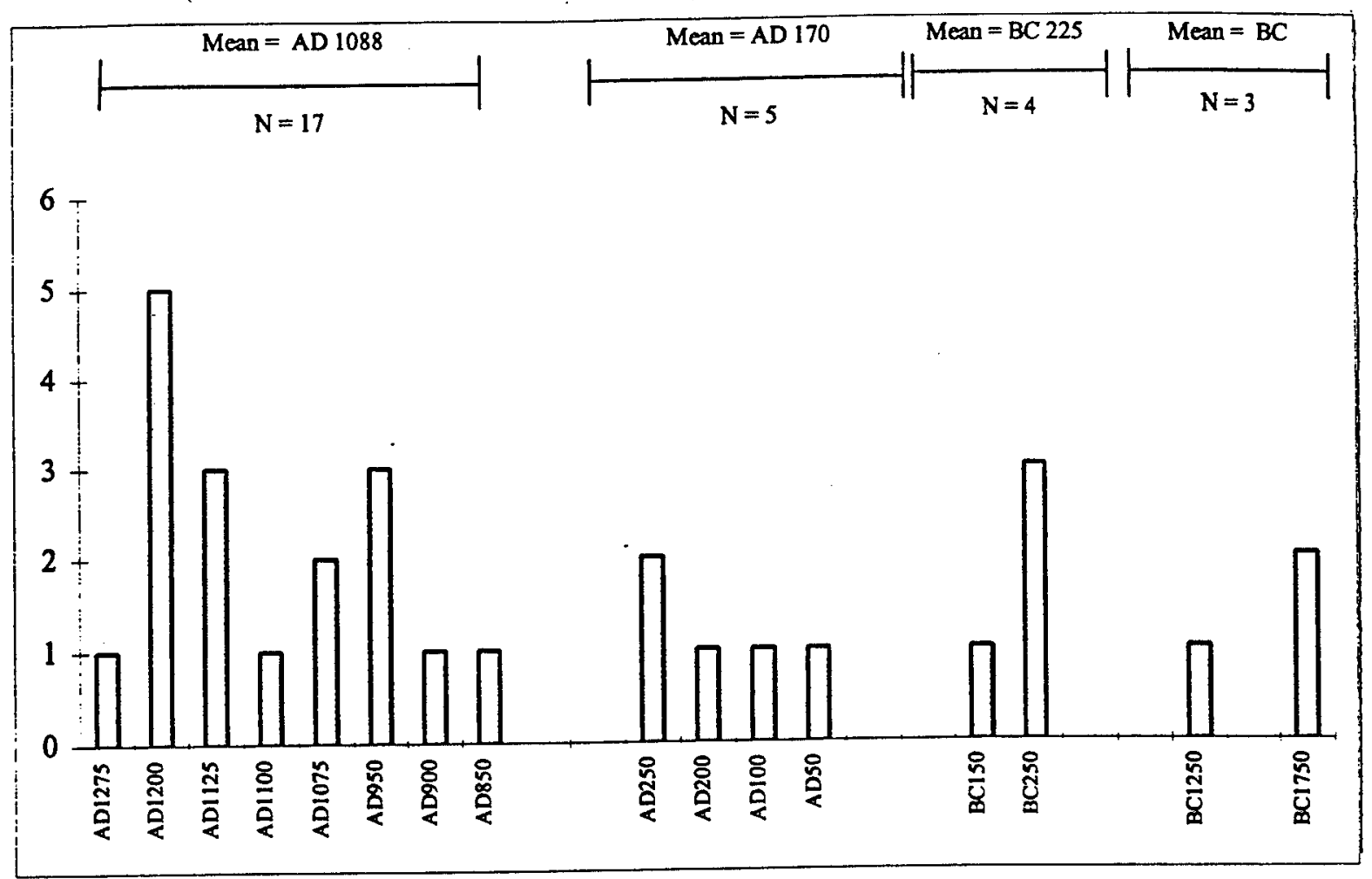

Figure 14. Mid-points of Projectile Points Age Range Estimates

Welsh Canyon received significant use during the Late Archaic period with increasing use into the Early Ceramic period and this use apparently culminated in the Middle Ceramic period.

The rock art in Welsh Canyon includes one definite historic age group of horses and riders and a second possible horse. Representing nearly a third of the sites found, these more recent age sites may reflect a more short term preservation of the soft sandstone that will erode from view in the next few centuries.

Nonetheless they are important reminders of the use of the side canyons to the Purgatoire River by the mounted historic tribes who practiced horse raiding into the settlements of New Mexico. Rockshelters in adjacent side canyons like 5LA5255, 5LA5563 and 5LA5569 have this same overtone of protohistoric rock art. They apparently reflect the use of these canyons by horse riding groups who may have been trying to keep their camping locations hidden and secretive.

Finally as a note for future studies of chronology, it is noteworthy that the rock art at site 5LA6613, is almost certainly Archaic in age and this is the same age as the surface artifacts on the site adjacent to the figures. The same association could be made for Ceramic age rock art and associated artifacts or 
features at sites 5LA6575 and 5LA6589. Although there are many obvious problems with the use of associated surface artifacts to assign an age to rock art they are still an important variable that is too frequently overlooked by archaeologists who are interested in the age of rock art. The accurate association between the age of surface artifacts and the age of the rock art in the nearly half of the sites found in this survey is worthy of note. It suggests that if large data sets were developed it might be possible to find patterns where associated diagnostic surface artifacts would aid in determining the age of the rock art.

Data to study Paleoenvironments are difficult to recover in archaeological survey projects. In the PCMS, however, Schuldenrein has hypothesized postAltithermal erosional activities that apparently eliminated all the old sites. In this regard it is important to note that neither Paleolndian nor Early Archaic projectile points were recovered from the surfaces of the sites. This tends to support the Schuldenrein model and if this hypothesis were correct, we would only expect to find projectile points older than the Altithermal in upland settings where they are in isolated pockets of undisturbed sediments. The locations of 5LA6767 and $5 \mathrm{LA6815}$, the two sites with projectile points of potentially Middle Archaic age are important in regard to this same hypothesis. Site 5LA6767 is located on a ridge at an elevation of 5100 feet $(1569 \mathrm{~m})$. It is along the upper side of a side canyon to Welsh Canyon and site 5LA6815, a rockshelter in the upper reaches of Red Rocks Canyon, is located at 4900 feet $(1047 \mathrm{~m})$. The former of these sites is high enough on the ridge to protect it from serious erosion and the other in a rockshelter receives some natural protection from the shelter walls. Both sites are in positions where they are better protected from erosional forces than if they were located in lower canyon bottom settings and following the Schuldenrein model their preservation appears to be a product of their location.

It is also worth noting that portions of the climatic model generated by Bryson et al (1970) have a relatively close correspondence to the projectile point dates. The Scandic episode (approximately A.D. 200 to A.D. 900) is sometimes referred to as the Little Climatic Optimum because conditions are believed to have returned to drought and heat similar to the earlier Altithermal times. The break in the projectile point dates during this period may reflect a lack of suitable resources in the region and the fact that there were not as many people living in Welsh Canyon. Likewise, during the following Neo-Atlantic episode (A.D. 900 to A.D. 1200) and the ensuing Pacific episode (A.D. 1200 to A.D. 1450) the climate is believed to have been wetter and cooler, especially in the southern Plains and northeastern New Mexico. The large number of dated projectile points from this time period appears to be reflecting this improved climate. It is important to remember that these climatic changes were not universal and that during NeoAtlantic and Pacific times it may have been drier and hotter in regions to the north of the PCMS. Therefore the increase in the number of dated sites from these times may indicate immigrating peoples to Welsh Canyon. If this is true, it 
is a time that there should be evidence for innovation and change in the cultural record.

Settlement and subsistence studies can be completed using the information from archaeological survey projects. In this project we learned that lithic scatters were the most common site type identified in all physiographic zones of Welsh Canyon, except the canyon rim where rock shelters predominated. The canyon rim has numerous natural rock overhangs, and it is probable that these features were preferred for habitation when available. Not surprisingly, procurement sites were concentrated on talus slopes where primary sources of lithic raw materials were more commonly available. Prehistoric structure sites were uncommon but were evenly distributed between all locations except talus slopes.

Patterning in the survey data from Welsh Canyon suggests that its prehistoric inhabitants used all areas of the canyon. Prehistoric cultural resources were found throughout the canyon, and artifact and feature types were not exclusively restricted to physiographic zones. However, the distribution of artifacts and features does suggest that canyon rim locations were preferred for habitation-- manos, metates, projectile points, ceramics, and hearths were most common at canyon rim sites. Prehistoric occupation of the canyon rim appears to have been focused on rockshelters in areas that provided access to both the surrounding uplands and the canyon bottom. This sort of pattern is common among hunting and gathering groups around the world where they maximize their camp locations in relationship to the greatest diversity of resources. In this case they selected the canyon rim because it offered access to resources in the canyon bottom as well as the upland mesa and prairie regions.

The greater abundance of cultural remains at sites along the canyon rims may also reflect the seasonal movements the hunters and gatherers. If they moved from the Purgatoire River bottom to the uplands at some point during the year they had to return and this means they traverse the canyon rims twice a year while they stop at destination points only once per year. Although we can assume the same campsites were selected year after year, these kinds of movements increase the number of campsites in transitional ecozones.

Regardless of whether they stop twice at the same site or stop at a new camping location, the longer period of time spent on the canyon rims means there is greater opportunity for loss of artifacts, which as archaeologists we recover today.

Although comparatively large numbers of sites were identified on talus slopes these sites were mainly lithic scatters, and procurement sites were most commonly found on talus slopes. In addition, talus slope sites had a very low proportion of patterned tools such as projectile points. This suggests that the collection and initial processing of lithic raw materials was the most frequent 
activity in these areas. However, the presence of metates, manos, and a variety of site types suggest that a range of activities occurred in this setting.

Canyon bottom sites were generally larger than those in other areas, which in part may reflect the comparatively large flats, with good areas for habitation. These are also more likely to be destination sites in annual subsistence strategies. Very large sites probably represent multiple over-lapping occupations of the same area. Support for this possibility is provided by the observation that artifact density generally varied across sites, and concentrations of lithics, which may represent individual occupations, were generally present at larger sites.

In archaeological survey projects the questions of exchange and mobility studies are undertaken through the analysis of material types and unique artifact categories. A single unique artifact (PC 95IF17) found as an isolate on a ridge to the north of Welsh Canyon provides some of the more interesting information regarding the exchange and mobility of the former residents of the PCMS. This artifact, a shaft straightener made of a dense stone, is almost certainly evidence of contact between the Plains border to the Southwest and the PCMS. Very similar artifacts are found in the pueblos to the east of the Rio Grande in New Mexico such as the former pueblo at Pecos where shaft straightening tools were found that are almost exact duplicates of the one from Pinon Canyon (Kidder 1932).

Unfortunately the artifact was recovered as an isolate and we therefore have no other artifacts to help establish its age. However, because these artifacts are most common a Pecos during protohistoric and early historic times, we might guess that it was traded during an exchange between the New Mexico villages and the PCMS hunters and gatherers. Because it likely fits the post-horse era, it may also have been part of extensive raiding and warfare that took place in the protohistoric and historic periods at Pinon Canyon. This shaft straightener fits in time with the horse and riders in the rock paintings.

Obsidian source information indicates that most of the obsidian comes from sources in the Jemez Mountains to the south and west of Welsh Canyon. Itinerant traders may have traded this obsidian into the Welsh Canyon region and it is not possible to rule out travel to the Jemez sources to procure the obsidian. A more reasonable explanation, however, is that it represents travel to a trade center like the Pecos pueblo where it was available for exchange. One of the samples originally identified as from an unknown source has affinities with Colorado Mountain sources and in this respect it may be a more local material, but it still indicates interaction of some kind with the mountains to the west of the PCMS.

Perhaps the most interesting obsidian comes from a source near Malad, Idaho that is in the extreme southeast corner of the state and more than 1000 
kilometers from the PCMS. This source is well known because a Paleolndian biface and associated Clovis projectile points are made of obsidian from Malad (Frison 1991:41). This obsidian source is also used throughout the prehistoric period into historic times and it is far more likely that it reached the PCMS at a time other than the Paleolndian period. As noted above, there is strong evidence to believe that the early sequences in the PCMS are gone because of erosion and with an absence of Paleolndian projectile points, it is highly unlikely that a fragment of obsidian might still remain. It is possible that a more recent stone toolmaker found an ancient fragment somewhere else and re-used it. A more logical explanation would put the source of obsidian during the historic period when there was regular exchange in horses from the Comanche on the southern Plains to the Ute and Shoshone in Idaho and Wyoming.

Obsidian from northern sources undoubtedly reached the southern Plains during this time period. Unfortunately the fragment from the PCMS is from an isolated location and not associated with any other diagnostic tools. As such, it can only be used to suggest contact between two distant regions.

Although the thematic category of ideology was not included in the National Register data, it is especially appropriate for Pinon Canyon because the region is so rich in rock art sites. Recent studies suggest that rock art played an important role in the vision seeking process of various western Indian groups (Loendorf 1989). It also may have had significant meaning for territorial boundary marking and in either instance its distribution and content might offer important information for studying ideology. The paucity of rock art in Welsh Canyon may, in part, be the result of natural erosion that could have removed prehistoric modifications to rock surfaces, especially in the canyon bottom where highly friable sandstone predominate. However, numerous varnished surfaces occur in the canyon, and rock art should have been preserved on these surfaces if it was present. This suggests that other factors must also be responsible for the low incidence of rock art, and several possibilities can be offered. These hypotheses are not all mutually exclusive and it is possible more than one of them occurred.

The first hypothesis suggests that the manufacture of rock art may have largely occurred during particular seasons, and intensive prehistoric use of Welsh Canyon may not have coincided with these seasons. For example, it is possible that rock art was largely made during the winter months, and prehistoric people may have not occupied Welsh Canyon at this time of year. Shoshonean groups believed that rock art was manufactured in the winter:

Rock drawings are supposed to represent spirits and have been made in the winter by these spirits themselves. Each spirit draws its picture. Indians have told me that in the spring and summer they have discovered new drawings on the rockface, apparently pecked by the spirits since their last visit [Hultkrantz 1987:49]. 
This sort of explanation is common for the rock art of hunters and gatherers on the Plains. If Welsh Canyon was not utilized during the winter season or if the spirits that made the rock art did not enter Welsh Canyon during the appropriate season, it may account for the absence of rock art.

Second, prehistoric people may have simply considered Welsh Canyon to be an inappropriate location for the manufacture of rock art. Recent research has suggested that rock art was concentrated in certain locales because of the belief that these areas were powerful locations (Hultkrantz 1987; Whitley 1992), and it is possible that the prehistoric people may not have considered Welsh Canyon to be a power place. Obviously this explanation is related to the previous one but could be expanded to suggest, for example, that the general absence of permanent water in Welsh Canyon makes it a poor place for spirits to live. This possibility is given some support by the observation that the rock art identified during the survey occurred almost exclusively toward the northeastern end of the canyon where there are more permanent water sources.

The third possibility suggests that the manufacture of rock art was associated with particular activities that were not performed in Welsh Canyon or were of less importance. For example, some rock art researchers have suggested that rock art was made, in part, as a form of territorial marker (Hartley and Vawser 1996; Olsen 1994). This type of boundary marking is inherently most likely to be placed along the margins of territories. It is possible that Welsh Canyon did not occur in a boundary area between cultural groups, and consequently rock art was not concentrated in the canyon.

Fourth, it is possible that a cultural group whose traditions did not include rock art manufacture used the area. This possibility is not considered likely because some rock art is present in Welsh Canyon, and the widespread occurrence of rock art throughout the general region suggests that it was a common practice. 


\section{BIBLIOGRAPHY}

Anderson, J.L.

1985 Projectile Points. In, A Chronological Framework of the Pinon Canyon Maneuver Site, Las Animas County, Colorado ed. C. Lintz, U.S Army Fort Carson Pinon Canyon Cultural Resources Project, Contribution No. 2, Center for Archaeological Research, University of Denver, Colorado.

1989 Chronological Framework. In, Temporal Assessment of Diagnostic Materials from the Pinon Canyon Maneuver Site: Towards the Development of a Cultural Chronology for Southeastern Colorado, ed. C. Lintz and J. Anderson, Colorado Archaeological Society Memoir, No. 4.

Brown, Kenneth $\mathrm{L}$

1994 A Cultural Resource Inventory of Corps of Engineers Properties below John Martin Dam, Bent County Colorado. Office of Contract Archaeology, University of New Mexico, Albuquerque.

Bryson, R.A., D.A. Barreis and W.M. Wendland

1970 The Character of Late-Glacial Climatic Changes. In Pleistocene and Recent Environments of the Central Great Plains. Ed. Wakefield Dort, Jr. and J. Knox Jones, Jr. University Press of Kansas, Lawrence.

Carrillo, R.F., C. Chambellan, and T.J. Lennon

1996 A Summary Report of a Historical Archaeology Sruvey Conducted at the Pinon Canyon Maneuver Site, Las Animas County, Colorado, During the Summer of 1993. Western Cultural Resource Management, Inc. Boulder. Submitted to the National Park Service, Rocky Mountain Regional Office, Interagency Archeological Services, Denver.

Dean, J.C.

1992 Guidelines to Required Procedures for Archaeological Field and Laboratory Work at Pinon Canyon Maneuver Site, Las Animas County, Colorado. Department of Anthropology, University of North Dakota, Grand Forks, North Dakota. Submitted to the National Park Service, Rocky Mountain Regional Office, Interagency Archeological Services, Denver.

DeVore, Steve

[ca 1993] Prehistoric Contexts: Hunters and Gatherers along the Purgatoire River (8500 B.C. -A.D. 200) in National Register of Historic Places: Multiple Property Documentation Form. Submitted to the National Park Service, Rocky Mountain Regional Office, Interagency Archeological Services, Denver. 
Eighmy, Jeffrey L.

1984 Colorado Plains Prehistoric Context: For the Management of Prehistoric

Resources of the Colorado Plains. Office of Archaeology and Historic

Preservation, Colorado Historical Society, Denver.

Evanhoff, Emmett

1997 Preliminary Mapping and Report on the Surficial Geology and Paleontologic Resources of the Pinon Canyon Maneuver Site, Las Animas County, Colorado.

On file, U.S. Army, Directorate of Environmental Compliance and Management, Fort Carson, CO.

Faris, Peter

1995 Petroglyph Chronology in Southeast Colorado. Southwestern Lore 61(1)7-35.

Feyhl, Kenneth

1980 Tool Grooves: A Challenge. Archaeology in Montana 21(1):1-32.

Frison, George

1991 Prehistoric Hunters of the High Plains. Second Edition, Academic Press, New York.

Gunnerson, J.H.

1987 Archaeology of the High Plains. Cultural Resources Series, N. 19, Bureau of Land Management, Colorado.

Hartley, Ralph and Anne M. Wooley Vawser

1996 Spatial Behavior and Learning in the Prehistoric Environment of the Colorado River Drainage, Southeastern Utah. Rock-Art ed. C Chippendale and P.S.C Tacon. Cambridge University Press.

Hultkrantz, Ake

1987 Native Religions of North America: the Poser of Visions and Fertility. Harper, San Francisco.

Kidder, Alfred

1932 The Artifacts at Pecos. Publications for the Phillips Academy, Yale University Press, New Haven.

Loendorf, L.

1989 Nine Rock Art Sites in the Pinon Canyon Maneuver Site, Southeastern Colorado. Contribution No. 248, Department of Anthropology, University of North Dakota, Grand Forks.

1992 The Zookeeper Petroglyph Site, 5LA5993. Southwestern Lore 58(1)17-28. 
Loendorf, L.L and D. D. Kuehn

19911989 Rock Art Research, Pinon Canyon Maneuver Site, Southeastern Colorado. Contribution N. 258, Department of Anthropology, University of North Dakota, Grand Forks.

Loendorf, L.L., J. L. Borchert and D. G. Klinner

1996 Archeological Investigations at Ceramic Stage Sites in the Pinon Canyon Maneuver Site. Contribution No. 308, Department of Anthropology, University of North Dakota, Grand Forks.

McFaul, M.

1991 Geoarchaeological Interpretation of Alluvial Sedimentation. In 1989 Rock Art Research, Pinon Canyon Maneuver Site, Southeastern Colorado by L.L. Loendorf and D.D. Kuehn, pp. 25-40. Department of Anthropology, University of North Dakota, Grand Forks.

McFaul, M. And R. Reider

1990 Environmental Setting: Physical Environment and Geoarchaeological Investigations. In An Introduction to the Archaeology of Pinon Canyon, Southeastern Colorado. ed. William Andrefsky Jr.,pp. II-1 to II-13 and III-1 to III30, Volume One. Larson-Tibesar Associates, Laramie, WY. Submitted to the National Park Service, Rocky Mountain Regional Office, Interagency Archeological Services, Denver.

McGlone, William R., and Phillip Leonard 1986 Ancient Celtic America. Panaorama West Books, Fresno, Ca.

McGlone William, Ted Barker and Phillip Leonard

1993 Petroglyphs of Southeast Colorado and the Oklahoma Panhandle. Mithras, Inc. Press. Kamas, Utah.

Olsen, Nancy

1994 Bandelier National Monument Rock Art Documentation Study; 1988-1994.

Typescript report Pp. 24. In the possession of the author and on file with Bandelier National Monument.

Opler, Morris

1983 The Apachean Culture Pattern and Its Origin. In Southwest, edited by Alfonso Ortiz, pp. 368-392. Handbook of North American Indians, Vol. 10, Smithsonian Institution, Washington, D.C. 
Schuldenrein, Joseph (assembler)

1985 Geomorphological and Geoarcheological Investigations at the U.S. Army Fort Carson-Pinon Canyon Maneuver Site, Las Animas County, Colorado.

Glbet/Commonwealth Inc. Jackson, Submitted to the National Park Service, Rocky Mountain Regional Office, Interagency Archeological Services, Denver.

Schiavitti, Vincent, Lawrence Loendorf and Erica Hill

1999 Archaeological Investigations at Eleven Sites of Welsh Canyon in the Pinon Canyon Maneuver Site, Las Animas County, Colorado. On file with Directorate of Environmental Compliance and Management, Fort Carson, Colorado.

Wendland and Bryson

1974 Dating Climatic Episodes of the Holocene. Quaternary Research 4:9-24.

Whitley, David

1992 Shamanism and Rock Art in Far Western North America. Cambridge Archaeological Journal 2(1):89-113. 


\section{APPENDIX : \\ SITE DESCRIPTIONS BY SITE NUMBER \\ ARCHAEOLOGICAL SITES IN WELSH CANYON LAS ANIMAS COUNTY, COLORADO}

\section{Prepared by:}

The Department of Sociology and Anthropology

New Mexico State university

Las Cruces, New Mexico 
Appendix One

Site descriptions by site number

1995 Field Season sites

\section{LA6568:}

Site is located on a finger ridge within the main fork of Welsh Canyon where it faces south on an E/W trending finger. The elevation is $4900^{\prime}(1494 \mathrm{~m})$ in a pinon/juniper environment. Other vegetation includes cholla, chenopodia, bunch grass, prickly pear, and low forbs.

The site dimensions are $52 \mathrm{~m} \mathrm{~N} / \mathrm{S} \times 55 \mathrm{~m} \mathrm{E} / \mathrm{W}$. The site includes one rock shelter, three shallow overhangs, and a moderate to dense lithic scatter. There is a low sandstone semi-circular stone wall, which encloses two of the overhangs, and two other semi-circular stone enclosures. Artifacts found include; a boulder metate with multiple grinding surfaces, several ground stone fragments, and a good sized lithic scatter, of mostly reduction flakes.

The site has had some disturbance due to water erosion and animal burrowing, but because of its buried condition and the good condition of the stone enclosures, the site has the potential to contribute further information to the prehistoric record of the area.

ROCK SHELTER:

Aspect (180 degrees) Permanent water 1060m

Grinding Surfaces

Lithics

5LA6569:

The site is located on a west-facing slope near the head of Welsh Canyon at an elevation of 5280' $(1609 \mathrm{~m})$ in a pinon/juniper environment. Other vegetation in the area includes grasses, prickly pear, sage, chenopodia, and low forbs. The soil is sandy loam.

The site dimensions are $37 \mathrm{~m} \times 23 \mathrm{~m}$. The site consists of two small rock shelters on a steep west-facing slope. Dark soil down slope has apparently eroded from the northern rock shelter, as it is associated with a scatter of heat-cracked stones and other lithic debris. Both rock shelters have wall remnants.

Artifacts found include a boulder milling stone with two milling surfaces, a milling slick on a tabular clast outside of shelter \# 2, and a lithic scatter down slope from the northern shelter. There was a total of 31 quartzite flakes counted on the site. Because of the potential of the cultural deposits, the site is likely to provide information on the prehistoric record of the area. 
ROCK SHELTERS (2):

Aspect (270 degrees) Permanent Water $2136 \mathrm{~m}$

Grinding surfaces

Wall remnant

Lithics

\section{LA6570:}

The site is located on the west facing side of a N/S trending drainage into the main fork of Welsh Canyon. It is at the base of the uppermost rimrock outcrop, near the cliff edge. The elevation is 4950' (1509 m) in a pinon/juniper environment. Other vegetation in the area include, cholla, Rhus trilobata, grasses, sage, and chenopodia.

The site is a rock shelter, lithic scatter, and processing area. The site dimensions are $18.5 \mathrm{~m} \mathrm{~N} / \mathrm{S} \times 15.5 \mathrm{~m} \mathrm{EN}$. A tall but shallow rock overhang is found at the site, with a light lithic scatter, and ground stone implements. The artifacts were light with only one ground stone fragment found and 10 flakes in the lithic scatter, of various materials, quartzite, hornfels, and chert.

Due to wind and water erosion, little soil remains on the site. Because of the paucity of artifacts, the site is not likely to yield further information. Further work is not recommended.

\section{ROCK SHELTER:}

Aspect (252 degrees) Permanent Water $1160 \mathrm{~m}$

Lithics

\section{LA6571:}

The site is located on a slightly rolling, shallow southwest facing slope on top of the mesa near the head of Welsh Canyon. The elevation is $5320^{\prime}(1621 \mathrm{~m})$ in a mostly juniper environment. Other vegetation in the area includes cholla, prickly pear, yucca, showy barley, and grasses. The soil is medium tan, fine-grained sand.

The site is a surface lithic scatter with two deflated hearths. Its dimensions are 50 $\mathrm{m} \times 23 \mathrm{~m}$. The site is in a dense stand of juniper, which may conceal more artifacts and intact features. The site can best be described as washed by alluvial run off, with moderate to heavy disturbance. The artifacts found include 12 chert and quartzite flakes, and the heat cracked stones associated with the deflated hearths.

\section{LA6572:}

The site is located on a finger ridge mesa top, which is bisected along the EM by two unnamed intermittent tributaries of Welsh Canyon. The elevation is $5300^{\prime}(1615 \mathrm{~m})$ and the environment is pinon/juniper forest. Other vegetation on the site consists of, cholla, prickly pear, bunch grass, and low forbs. Vegetation on the site is very sparse. The soil is shallow to bedrock. 
The site is a lithic scatter on the surface of the mesa top. It measures $25 \mathrm{~m} \times 20 \mathrm{~m}$. The lithic material, in all stages of reduction, includes quartzite and chert with one fragment of FCR. There were 18 lithic items noted on the site. Soil depth on the site is very shallow. Due to the paucity of artifacts, features, and shallow soil deposition, the site lacks the potential to reveal further information.

\section{LA6573:}

The site is on top of a finger ridge formed by two parallel N/S trending intermittent tributaries of Welsh Canyon. The elevation is $5310^{\prime}(1618.5 \mathrm{~m})$ and the environment is pinon/juniper, with other vegetation in the area being, yucca, prickly pear, bunch grass, and low forbs. Vegetation on the site is very sparse. The soil is shallow to bedrock.

The site consists of a small lithic scatter and a deflated hearth with light charcoal staining and FCR. It measures $25 \mathrm{~m} \mathrm{E} / \mathrm{W} \times 23 \mathrm{~m} \mathrm{~N} / \mathrm{S}$. The lithic materials include 10 flakes of chert and quartzite with a small concentration of FCR. Due to the paucity of artifacts, lack of intact features, and shallow soil depth the site lacks potential for further research.

\section{LA6574:}

The site is located on the slope of an intermittent tributary flowing south into Welsh Canyon. It is on the upper rim rock outcrop at an elevation of $5250^{\prime}(1600 \mathrm{~m})$. The vegetative community is pinon/juniper, with the site situated in a thick stand of juniper. Other vegetation in the area is cholla, prickly pear, bunch grass, and low forbs. The soil is shallow to bedrock.

The site consists of a rock shelter, with a possible heavily deflated rock wall and a sparse lithic scatter. The site measures $8 \mathrm{~m} \times 7.5 \mathrm{~m}$. in the shelter the soil is deflated, exposing the pediment gravels and a $10-12 \mathrm{~cm}$ thick layer of shale.

Four fragments of chipped stone of chert and quartzite were exposed in the erosion. There was a single coarse layer of sandstone slabs, that could possibly have once been a wall but it is badly deflated. Due to the paucity of artifacts, the bedrock nature of the shelter and no possibility of buried features, the information potential of this site has been exhausted.

ROCK SHELTER:

Aspect (70 degrees) Permanent Water $2208 \mathrm{~m}$

Wall remnant

Lithics 


\section{LA6575:}

The site is located at the head of a small steep-sided canyon, which is a tributary of Welsh Canyon. The elevation is 4960' $(1511 \mathrm{~m})$ in a pinon/juniper vegetative zone. The vegetation found on the site is Rhus trilobata, wild grape, cholla, current, chenopodia, mullein, grasses, and nightshade. The soil is loamy sand, depth unknown.

The site is a large rock shelter measuring $23 \mathrm{~m} \times 9 \mathrm{~m}$. Large roof fall blocks form an irregular tilted floor, with many cracks and cavities. The rock surfaces contain (ca. 60) milling surfaces of varying shapes and depths. There are pecked and incised petroglyphs, historical graffiti, and modern graffiti. No artifacts were observed on the surface within the shelter; however, they may be hidden within the cavities between and beneath roof fall blocks. Identifiable elements in the petroglyph panels include lines with branches to circles, linked circles, a set of tracks and some small lines. Some rock art is superimposed over grinding slicks and tool grooves. There is historic graffiti dating 1902-1920 and modern graffiti superimposed on prehistoric milling surfaces, although this is at a minimum.

ROCK SHELTER:

Aspect (270') Permanent Water $2328 \mathrm{~m}$

Grinding Surfaces

Rock Art

\section{LA6576:}

The site is located on a rolling terrace mesa top, along the eastern edge of Welsh Canyon at an elevation of $4990^{\prime}(1521 \mathrm{~m})$. The vegetative environment is a juniper forest/grassland transition with juniper, grasses, snakeweed, prickly pear, yucca, cholla, and low forbs. The soil is a light brown sandy loam.

The site contains 5 areas. Area 1 is a room block with 5 contiguous rooms. Area 2 contains a 4-room ring and a lithic scatter. Area 3 is a rock ring. Area 4 contains a 4room structure with a milling slab. Area 5 is a possible rock ring.

Artifacts found on the site include a large number of lithics. There were 66 lithics of various types found, including a quartzite biface, an obsidian projectile point, and a chert scraper. The materials used include quartzite, basalt, chert, siltstone, and obsidian. Two sandstone milling slab fragments were also found. The structures in this site are part of an apparently aceramic cultural tradition which is poorly understood in this region.

\section{LA6577:}

The site is located on a south facing rimrock of an ENW trending drainage of Welsh Canyon where it is situated within and below a rock shelter/alcove. The elevation is 4950' $(1509 \mathrm{~m})$ and the vegetative environment is pinon/juniper. Vegetation on the site includes juniper, cholla, prickly pear, Rhus Trilobata, blue gramma, bunch grass, and low forbs. The soil is light brown fine-grained silty sand. 
The site consists of a rock shelter with a semi-circular ring of small boulders, which are possibly the remains of a wall. The site measures $13.5 \mathrm{~m} \times 8 \mathrm{~m}$. Within the shelter there appears to be $20-30 \mathrm{~cm}$ of deposition due to rodent activity. There is a lithic scatter along the slope below the shelter. Among the artifacts found was a bedrock metate, with a basin and an ephemeral grinding surface. There were 2 slab metates with a single grinding surface and a mano fragment found. The lithics found were reduction flakes of chert and quartzite.

ROCK SHELTER:

Aspect (180 degrees) Permanent Water $1180 \mathrm{~m}$

Grinding Surfaces

Wall remnant

Lithics

\section{LA6578:}

The site is located on the west facing slope of a N/S trending tributary of Welsh Canyon where it is situated at the base of a west facing sandstone rimrock outcrop. The site elevation is $5040^{\prime}(1536 \mathrm{~m})$. The site vegetative community is pinon/juniper with other vegetation on the site being, rabbit brush, fern, Rhus trilobata, mullein, blue gramma, prickly pear, cholla, and low forbs. The soil is light brown silty sand.

The site consists of two small rock shelters situated within two rock alcoves. The site measures $40 \mathrm{~m} \times 30 \mathrm{~m}$. There is a sparse lithic scatter and an area of charcoal staining in the south end of the site. The rock shelters have good soil deposition.

Artifacts found within the rock shelters include 13 flakes, 4 of which were informal tools. There were 3 metate fragments, 1 complete slab metate, and 1 mano also found inside the shelters. Because of the soil deposition, charcoal staining, and lithics present the site has a potential to yield further research data.

ROCK SHELTER:

Aspect (300 degrees and 210 degrees) mean $255^{\circ}$

Permanent Water $1260 \mathrm{~m}$

Grinding Surfaces

Lithics

\section{LA6579:}

The site is located in a N/S trending drainage feeding into the western most extension of Welsh Canyon. It is in the east facing rim rock at an elevation of 5000' (1524 $\mathrm{m})$. Vegetation includes Rhus trilobata, rabbit brush, blue gramma, prickly pear, cholla, barley, bunch grass, and low forbs in addition to juniper. The soil is light brown silty sand. 
The site consists of 2 rock shelters, a lithic scatter, and charcoal staining. The site measures $16 \mathrm{~m} \mathrm{~N} / \mathrm{S} \times 18.5 \mathrm{~m} \mathrm{EM}$. Much of the exposed cultural material is located down slope from the shelters. There is an amorphous charcoal stain $(1 \mathrm{~m} \times 1.5 \mathrm{~m})$ with an upturned metate in the center. There is good soil deposition on the site.

Artifacts found include a sparse lithic scatter with 5 quartzite flakes. In addition 2 block metates were found; both with the grinding surfaces turned upside down. Because of the soil deposition, charcoal staining, and artifacts found the site has a potential for further research.

ROCK SHELTER:

Aspect $\left(100^{\circ}\right)$ Permanent Water $1608 \mathrm{~m}$

Grinding Surfaces

Lithics

Charcoal

\section{LA6580:}

The site is located down slope of a N/S trending intermittent drainage of Welsh Canyon. It is in the west facing rimrock at an elevation is 5000' (1524 m). Vegetation on the site includes juniper, pinon, chenopodia, rabbit brush, cholla, prickly pear, bunch grass, and low forbs. The soil is light brown silty sand.

The site is a small rock shelter in a shallow overhang with a sparse lithic scatter. The site measures $22 \mathrm{~m} \times 26 \mathrm{~m}$. There is very little soil deposition on the site, which is badly eroded and deflated. Artifacts found on the site include 17 quartzite flakes, 2 small metate fragments, 1 metate fragment $(20 \times 20 \times 5 \mathrm{~cm}$.) and a mano $(10 \times 8 \times 3 \mathrm{~cm}$. $)$. Due to the paucity of artifacts and the lack of soil deposition the site is not likely to yield any further research data.

ROCK SHELTER:

Aspect (270 degrees) Permanent Water $1584 \mathrm{~m}$

Grinding Surfaces

Lithics

Ground stone

\section{LA6581:}

The site is located in an E/NE facing rim rock in a tributary canyon of Welsh Canyon at an elevation of 5270' (1606 m). Vegetation on the site includes juniper, mixed grasses, rice grass, prickly pear, chenopodia, showy buckwheat, and low forbs. The soil is medium brown loamy sand.

The site is a rock shelter with a small low rock wall at the mouth of the shelter. This wall is partially collapsed. The site measures $7.5 \mathrm{~m} \mathrm{~N} / \mathrm{S} \times 6.5 \mathrm{~m} \mathrm{E} / \mathrm{W}$. There were no other 
features on the site besides the rock wall. There is a pack rat midden in the back area of the shelter and a roof fall has occurred. There is good soil deposition in the shelter where only 2 artifacts were found, a white orthoquartzite flake and a gray orthoquartzite bifacially flaked tool. Because of the soil deposition there is a possibility for further data recovery; however, due to the paucity of artifacts this site is not a priority.

\section{ROCK SHELTER:}

Aspect ( 80 degrees) Permanent Water

$2136 \mathrm{~m}$

Lithics

Wall remnant

\section{LA6582:}

The site is located on a moderately steep slope just below the edge of the mesa, forming the rim of Welsh Canyon at an elevation of $5260^{\prime}(1603 \mathrm{~m})$. Vegetation on the site include dense juniper and more sparse stands of mixed grasses, yucca, prickly pear, chenopodia, showy buckwheat, barrel cactus, and low forbs. The soil is grayish brown, loamy sand.

The site is a rock shelter, sparse lithic scatter and a portion of a historic juniper fence. The site measures $19 \mathrm{~m} \mathrm{~N} / \mathrm{S} \times 11 \mathrm{~m} \mathrm{EM}$. There is only a small intact matrix inside the rock shelter with the lithic scatter on the northeast slope down from the shelter. The historical fence consists of six iron axe cut juniper branches that had been placed in front of the shelter.

Artifacts found in the lithics scatter include 12 pieces of orthoquartzite debitage, a crude orthoquartzite biface, and 2 ground stone fragments. There are 6 iron axe cut juniper branches left over from a historical fence across the front of the shelter.

Because of the intact floor area inside the shelter and the lithic scatter there is a possibility for further research.

ROCK SHELTER:

Aspect (112 degrees) Permanent Water $2112 \mathrm{~m}$

Lithics

\section{LA6583:}

The site is located on a small east facing, sloping bench just below the rim of Welsh Canyon at an elevation of 5240' (1597 m). The site is located in moderate stands of juniper. Other vegetation on the site includes mixed grasses, yucca, barrel cactus, prickly pear, snakeweed, rabbit brush, chenopodia, and low forbs. The soil is tan to grey loamy sand.

The site is a rock shelter with lithic debitage and ceramic sherds. The site measures $15 \mathrm{~m} \times 5 \mathrm{~m}$. There is an ephemeral drainage running through the site. The soil depth is 
unknown. Artifacts found on the site include 2 lithic flakes of quartzite, a slab metate and a metate fragment, and 2 ceramic sherds. The ceramic is of an unknown type. It is black on the interior and light brown on the exterior. There are possible vegetal or fiber markings on the exterior and it is very fragile. Because the soil depth is unknown and there are ceramic sherds present the site has a potential for further research.

\section{ROCK SHELTER:}

Aspect (95 degrees) Permanent Water $2064 \mathrm{~m}$

Grinding Surfaces

Lithics

Ceramics

\section{LA6584:}

The site is located at the confluence of the two main forks of the head of Welsh Canyon. It site is at the base of the mesa top, bisected by these drainages at an elevation of $4870^{\prime}(1484 \mathrm{~m})$. The site is located in a juniper environment, with other vegetation including cholla, prickly pear, cheat grass, rabbit brush, sage and mixed grasses.

The site is sparse lithic scatter with one ground stone mano and a painted rock art panel. It measures $75 \mathrm{~m} \mathrm{~N} / \mathrm{S} \times 145 \mathrm{~m} \mathrm{E/W}$. The soil found on the site is fine-grained silty sand, and there is good deposition $(10-30 \mathrm{~cm})$. In addition to the painted rock art panel, the lithic scatter included 10 flakes of grey quartzite debitage and a broken sandstone mano.

The rock art includes horse riders chasing bison left by Indian artists in the protohistoric or historic periods. The surface debris, on the other hand, likely represents something quite different in age. It is difficult to find areas where the site might retain intact deposits but they may exist.

\section{LA6585:}

The site is located beneath a large free standing sandstone remnant, along the west wall of Welsh Canyon at an elevation of $4880^{\prime}(1487 \mathrm{~m})$. Its setting is within vegetative environment is juniper with other vegetation including cholla, grasses, sunflower, and low forbs.

The site is a small east facing rock shelter and a light lithic scatter. The site measures $15 \mathrm{~m} \mathrm{~N} / \mathrm{S} \times 13 \mathrm{~m}$ E/W. A large sandstone slab of bedrock $(90 \times 40 \times 10 \mathrm{~cm})$ sits in the center of the shelter. The lithic scatter extends down the slope to the south. The artifacts found included 4 flakes of quartzite debitage, 2 broken and heavily pecked manos, and 3 " $v$ " shaped tool grooves worked into the sandstone bedrock slab. Fire cracked rock was found in front of the shelter. 
ROCK SHELTER:

Aspect (90 degrees) Permanent Water $945 \mathrm{~m}$

Grinding Surfaces

Lithics and Groundstone

\section{LA6586:}

This site is a historical corral measuring $10 \mathrm{~m} \mathrm{~N} / \mathrm{S} \times 6 \mathrm{~m} \mathrm{E} / \mathrm{W}$ at an elevation of $5000^{\prime}(1524 \mathrm{~m})$. Vegetation on the site is dominated by juniper. The corral is set against a steep rock face approximately $3 \mathrm{~m}$ high on the east side, and used living juniper trees for the S/E and N/W posts. A third living juniper midway $(3 \mathrm{~m})$ from the S/w post is used to support larger branches. One post of the SM has been set. A tree branch on the SM has been used to block off a passage between the S/E post and the wall. Smaller branches, now partially collapsed, are used for the north wall. Both barbed wire and bailing wire were used on the south wall or gate and more branches were laid across the south opening. No other cultural features were found on the site.

\section{LA6587:}

The site is located on a small terraced mesa between two major tributary canyons near the head of Welsh Canyon at an elevation of 5010' $(1527 \mathrm{~m})$. A juniper forest dominates the vegetation with other plants including mixed grasses, snakeweed, prickly pear, cholla, and low forbs. The soil is a tan to light brown sandy loam.

The site is a scatter of chipped stone and ground stone artifacts on top of a small, steep-sided mesa between two canyons. The mesa is terraced, with most of the artifacts on the flat top, and a few on the first bench down from the mesa top. The site measures $60 \mathrm{~m} \mathrm{~N} / \mathrm{S} \times 45 \mathrm{~m} \mathrm{E} / \mathrm{W}$. The artifacts found are chert and quartzite debitage (10 flakes), one formal mano and some fragments of milling slabs. There were no other features found.

\section{LA6588:}

The site is located on a small sloping bench, on a southeast-facing slope, of an unnamed tributary of Welsh Canyon at an elevation of 5010' $(1527 \mathrm{~m})$. The site is located in a juniper forest with other vegetation including grasses, prickly pear, snakeweed, cholla, and low forbs. The soil is brown sandy loam.

The site is a small lithic scatter, probably redeposited from higher elevation. The site measures $7.5 \mathrm{~m}$ N/E-S/W $\times 4 \mathrm{~m}$ N/W-S/E. Five reduction flakes, 1 core, and 1 complete quartzite mano were noted on the site

\section{LA6589:}

The site is located on an unnamed bench, in an unnamed tributary of Welsh Canyon at an elevation of 4980'-5040'. It is in a pinon/juniper vegetative environment with 
prickly pear, cholla, rabbit brush, gramma, Indian rice grass, needle and thread grass, mixed grasses, and low forbs. The soil is colluvial silty loam.

The site is large, measuring $160 \mathrm{~m}$ by $240 \mathrm{~m}$, with multi component features. The prehistoric component features of the site are 2 small rock shelters with a large amount of ground stone debris present. There is a lithic scatter and petroglyphs in several locations and there are over 15 complete or fragmentary metates and 6 manos within close proximity to the rock shelters. The rock shelter contains intact deposits. There are petroglyph panels in 2 locations, which include both abstract geometric designs and quadrupeds; however, the panels are eroded and difficult to decipher.

A series of approximately 47 grooves cut into the sandstone bedrock at one location. These kinds of marks have been associated with stone tool sharpening or bone tool manufacture. The majority of them are on the back wall of a SW facing overhang where several are also cut into the floor of the same overhang. The marks are often deep $(2 \mathrm{~cm}$.) and vary in length from $8-22 \mathrm{~cm}$. The majority run up and down although there are 3 that run sideways or at a sharp angle.

Cut grooves are found at another location on the site in a large bedrock outcrop. The grooves are much like those in the rock shelter, except they are in a more exposed location facing east. There are 4 grooves located together and 5 grooves cut lower in the sandstone bedrock. The 4 together are located ca. $1.6 \mathrm{~m}$ above ground surface. They range from $3-10 \mathrm{~cm}$ in length, $1-2.5 \mathrm{~cm}$ in width, and $1-2.5$ in depth. The 2 lower grooves are located $90 \mathrm{~cm}$ above ground surface and are $5 \mathrm{~cm}$ to $20 \mathrm{~cm}$ long, $1-2 \mathrm{~cm}$ wide, and $1-2$ $\mathrm{cm}$ deep. One of the grooves connects to a small $(5 \times 5 \times 1.5 \mathrm{~cm})$ hole. It is not clear if this hole is cultural or not.

A rock art panel with 2 geometric figures that have been pecked, a human figure with a large cowboy/Navajo top hat, that appears to have been scratched in and a letter "P" that has been pecked. The panel is large $(5.8 \mathrm{~m} \times 2.45 \mathrm{~m})$ and the figures are spread out across the panel. One geometric figure $(13 \times 13 \mathrm{~cm})$ resembles an "O" or circle with a line through it. The figure is not perfectly round. It is located approximately. $1.35 \mathrm{~cm}$ above the ground surface. A second figures is a small, pecked geometric design that measures $10 \times 15 \mathrm{~cm}$ and is located $1.3 \mathrm{~cm}$ above the ground surface. A third figure is a scratched human form wearing a hat. The feet appear to be facing opposite the head. No arms are visible. The figure is located approximately $.95-1.45 \mathrm{~m}$ above the ground surface. At the back of the right foot may be a spur.

The pecked letter " $P$ " is located approximately. $59-75 \mathrm{~cm}$ above the bedrock surface.

Another rock art panel is located on a high, south/southwest-facing outcrop of sandstone. There are six obvious figures and there may have been at least three more but have since deteriorated. Three of the more obvious figures and three of the possible figures are four-legged animals with swept back horns. There are three smaller figures above the previously mentioned. They too are facing east. No obvious horns can be seen 
from this angle. All of the figures have been pecked. Age and cultural affiliation are unknown but the figures are likely within the Ceramic period.

Two small rock shelters on the site contain lithic debitage, bifaces, a core, manos and 15 metate fragments. One complete mano is lying underneath the overhang of the northern most rock shelter. This rock shelter, eroding out of a tan/light brown sandstone outcrop, measures $5.4 \mathrm{~m}$ wide, $1.6 \mathrm{~m}$ deep at its deepest point and $1.3 \mathrm{~m}$ high. There is one core inside the shelter. The southern most of the two rock shelters, separated from the other by a large boulder, is not as deep as its counter part. This rock shelter measures 3.3 $\mathrm{m}$ wide, $1.5 \mathrm{~m}$ deep at its deepest point and $1.3 \mathrm{~m}$ high.

The artifacts found in association with these prehistoric features include: $22+$ sandstone metate fragments in various sizes, $11+$ sandstone manos, and a lithic reduction scatter of cherts, hornfels, chalcedony, and quartzite (over 100+ flakes). Also was found 2 projectile points and a burnishing stone.

The historic component is an early to mid 20th century ranching/homesteading activity. The site was used in animal control with fences and a metal and concrete water tank. Two artificial terraces with stacked but unmortared walls are still partially intact and there is a small square stacked rock foundation with a cut juniper branch that may have been a support beam. The artifacts found in association with these historical features include: crockery, china, mortar, glass fragments (purple, green, brown, and clear). Also found on the site were cans, nails, wire, shell casing, milled lumber, axe cut juniper, a stove door, wagon springs, bolts, and a large metal water tank.

\section{ROCK SHELTER:}

Aspect (135 degrees) Permanent Water $1342 \mathrm{~m}$

Grinding Surfaces

Lithics

Ground stone

Rock Art

\section{LA6590:}

The site is located on a southeast facing slope of an unnamed canyon, which leads to Welsh Canyon at an elevation of 5000' (1524). The primary vegetation is juniper with chenopodia, gramma, Indian rice grass, rabbit brush, prickly pear, mixed grasses, and shrubbery. The soil is brown colluvial silt and brown residual silt.

The site contains several small rock shelters, but they do not exhibit any surface evidence of occupation but they do contain an undetermined amount of intact soil deposition. The site measures $32 \mathrm{~m} \times 21 \mathrm{~m}$. The site contains lithic tools, debitage, one basin metate fragment, and one piece of ground stone. The site is located on a slope and has undoubtedly undergone wind and water erosion. There is no evidence of hearths, charcoal, FCR or structures on the surface. Artifacts found on the site include: 38 quartzite 
reduction flakes, 5 chert reduction flakes, 2 hornfels reduction flakes, a quartzite biface, 2 quartzite retouched flakes, a quartzite core, 2 sandstone basin metate fragments, a bifacial sandstone mano fragment, and an obsidian biface fragment which was collected.

\section{LA6591:}

The site is located on a southwest sloping bench, at the head of an unnamed tributary of Welsh Canyon at an elevation of $5210^{\prime}(1588 \mathrm{~m})$. It is located in a juniper forest/grassland area with mixed grasses, prickly pear, cholla, snakeweed, scrub oak, and low forbs in addition to the juniper. The soil is light brown sandy loam.

The site consists of a sparse prehistoric lithic scatter and a historic camp site. It measures $52 \mathrm{~m} \times 45 \mathrm{~m}$. The lithic scatter consists of 4 reduction flakes of quartzite, hornfels, chert and a biface of grey banded quartzite. There were no other prehistoric artifacts, no features, stains, or FCR. The historic component consists of an artifact scatter with a stone feature. The artifacts are mass produced trash items that represent a recent use.

\section{LA6592:}

The site is located at the base of the lowest rimrock outcrop on the Mary Doyle tributary to Welsh Canyon. where it is beneath two rock overhangs and down the slope of a northeast facing ridge line. Major vegetation on the site is juniper with lesser stands of cholla, prickly pear, rabbit brush, Rhus trilobata, mixed grasses, and low forbs. The soil consists of silty sand with boulder outcrops and pediment gravels.

The site contains a rock shelter and lithic scatter in an area that measures $42.5 \mathrm{~m}$ $\mathrm{N} / \mathrm{S} \times 27 \mathrm{~m} \mathrm{EM}$. The artifacts on site include a bedrock metate with 5 grinding surfaces and 11 tool grooves. Along the NW wall of the shelter there are 40 additional tool grooves along a vertical surface. At the opening of the shelter are the remnants of a semi circular enclosure with two partially buried upright slabs. Five slab/block metates and two mano fragments comprise the remainder of the ground stone noted on the site.

Lithic debris was recorded within and down slope from the shelters. Debitage consists of quartzite and cherts in various stages of reduction. Tools collected include two sandstone abraders, from a ledge along the back wall of the shelter, and one corner notched projectile point. The total quantity of lithic debitage recorded was 44 flakes of various materials including quartzite, chert, chalcedony, argillite, and silicified shale.

ROCK SHELTER:

Aspect (20 degrees) Permanent Water $1020 \mathrm{~m}$

Grinding Surfaces

Lithics

Ground stone 


\section{LA6593:}

The site is located on the northwest facing side of a NE/SW trending drainage flowing into Mary Doyle Canyon at an elevation of $4910^{\prime}(1497 \mathrm{~m})$. In addition to juniper the other vegetation on the site includes winterberry, showy buckwheat, chenopodia, cholla, prickly pear, and mixed grasses. The soil is silty light brown sand with boulder outcrops and pediment gravels.

The rock shelter is a small $(5.3 \times 4 \mathrm{~m})$ overhang $(2.4 \mathrm{~m}$ high), with two metate fragments, one retouched flake, and one vertical tool groove. The site measures $5.3 \mathrm{~m}$ $E / W \times 7.6 \mathrm{~m} \mathrm{~N} / \mathrm{S}$. The remains of a semi circular stone wall partially enclose the northeastern portion of the shelter opening. The shelter has good $(5-30 \mathrm{~cm})$ intact soil deposition.

\section{LA6594:}

The site is located at the base of the lowest rimrock outcrop of an unnamed tributary, of the Mary Doyle section of Welsh Canyon. Its elevation is 4900, (1494 m). The site is situated in a pinon/juniper vegetative zone with other vegetation in the area including rabbit brush, chenopodia, prickly pear, and mixed bunch grasses. The soil is light brown sand with boulder outcrops and pediment gravels.

The site consists of a rock shelter and lithic scatter that are apparently prehistoric in use, and a single course stone enclosure, with a rock shelter that is historic in age. The site measures $27 \mathrm{~m} \mathrm{~N} / \mathrm{S} \times 31 \mathrm{~m} \mathrm{E} / \mathrm{W}$. Features on the site consist of one single course stone wall enclosure and one large boulder with four tool grooves and carved graffiti on the surface. The stone wall appears to be historic, possibly ranching related and associated with the initials carved near it.

The depositional environment within the shelter is extensive, more than $30 \mathrm{~cm}$ deep but the angle of the slope below the shelter is such that potential for buried cultural remains is low. Testing within the shelter could reveal more cultural features and remains. A single course stone wall/semi circular enclosure built between the south wall of the shelter and the large boulder with ground surfaces located within the shelter. The low wall forms a small enclosure on the south end of the shelter. There are no associated historic artifacts other than the initials "WH" carved into the large boulder.

The prehistoric artifacts on the site include lithics in varied stages of reduction and ground stone manos and metates. There were 20 quartzite reduction flakes, 2 quartzite cores, 2 chert reduction flakes, 1 chert flake tool, and 1 siltstone flake.

Because of the extensive depositional remains found within the shelter the potential, for retrieval of information remains high. 
ROCK SHELTER:

Aspect (84 degrees) Permanent Water $820 \mathrm{~m}$

Grinding Surfaces

Lithics

Ground stone

\section{LA6595:}

The site is located on the south facing slope of an intermittent drainage flowing northeast into the Mary Doyle fork of Welsh Canyon where it is situated at the base of a sandstone cliff, trending east to west. The site is located at a hairpin bend in this unnamed drainage at an elevation is $4900^{\prime}$ (1494). Juniper is the dominant vegetation but the site area includes cholla, prickly pear, sage, chenopodia, blue gramma, mullein, Rhus trilobata, mixed grasses, and low forbs. A slight distance up the drainage there is large stands of cottonwoods. The soil is tan to gray silty sand with sandstone outcrops and pediment gravels

The site is a cultural material scatter, food or plant processing locality, with a large burned soil area and rock midden. The site measures $24 \mathrm{~m} \mathrm{~N} / \mathrm{S} \times 50 \mathrm{~m}$ ENW. It consists of one large burned earth stain, FCR, lithics scatter, burned bone, and a large midden area. The burned bone consists of 3 large well worn teeth (possibly elk molars). The lithic debris on site is dense with numerous flaked tools but no formal tools found. Fire cracked rocks are dense across the midden area with the maximum density being 30 fist sized or larger pieces per meter. Rodent burrows have exposed a midden depth of $70 \mathrm{~cm}+$ and cultural remains continue to be exposed. Ground stone is also dominant on site with one boulder metate and several mano fragments noted. The boulder metate exhibits four grinding surfaces.

Among the lithic artifacts noted were 66 quartzite flakes, 9 chert flakes, and 1 silicified shale flake. Most of the flakes were shatter, with some utilized and retouched flakes, but there were no formal tools noted on the site. There were 2 sandstone mano fragments and 1 sandstone metate fragment. A single fragmented ceramic sherd was found on the site.

\section{LA6596:}

The site is located on the valley floor between canyon wall, at the mouth of an unnamed tributary, of Mary Doyle branch of Welsh Canyon at an elevation of 4900' (1494 $\mathrm{m})$. Soil depth is between 50 to $75 \mathrm{~cm}$ in a site of primarily juniper vegetation.

The site measuring $25 \mathrm{~m} \times 10 \mathrm{~m}$, contains a historic lamb pen. The pen is constructed from deadfall juniper posts set with dry laid tiers of sandstone slabs between them. The gate is corrugated metal, which slid up to let the lambs in and out. No other artifacts were noted on the site. 


\section{LA6597:}

The site is located on a terrace above a small unnamed side tributary drainage of Welsh Canyon where it is on a slightly sloping, southern facing bench. Large sandstone boulders are scattered to the north behind the site. Its elevation is $4987^{\prime}(1520 \mathrm{~m})$. The site is on the border between juniper forest/savanna. Other vegetation growing in the area consists of bunch grass, hedgehog cactus, yucca, gramma grass, prickly pear, cholla, barrel cactus, and mixed grasses. Soils are brown silty sand with large rock outcrops.

The site consists of a small dense concentration of lithic debitage, a mano fragment, and a metate fragment. The site measurements are $75 \mathrm{~m} \mathrm{EN} \times 25 \mathrm{~m} \mathrm{~N} / \mathrm{S}$. The majority of the debitage is made from quartzite but there were no patterned tools. No charcoal or stain was obvious but 4-6 pieces of scattered FCR were noted. The site is located on a mild slope near the edge of a mesa finger. No rock shelters are in the vicinity. Forty three quartzite reduction flakes, 3 chert flakes, a hornfels flake, a sandstone mano fragment, and a sandstone metate fragment were noted on the site.

\section{LA6598:}

The site is located in a south facing rock shelter, in a small unnamed drainage, approximately 50 feet above the floor of Welsh Canyon. It is at an elevation of 4890' (1490 $\mathrm{m})$. Sparse stands of juniper dominate the site with yucca, Rhus trilobata, prickly pear, bunch grass, cholla, snakeweed, and artemisia. The soil is brown sandy silt.

The site is a small south-facing rock shelter, which contains a small amount of lithic debitage and tools. The site measures $16 \mathrm{~m} \mathrm{EN} \times 9 \mathrm{~m} \mathrm{~N} / \mathrm{S}$. There are 2 bedrock metates beneath the overhang measuring $20 \times 14 \mathrm{~cm}$, by $1-2 \mathrm{~cm}$ deep and $18 \times 13 \mathrm{~cm}$ and by .7 $\mathrm{cm}$ deep. Sixteen quartzite flakes, 3 chert flakes, and 1 hornfels flake were found including one utilized flake and one biface fragment.

\section{ROCK SHELTER:}

Aspect (180 degrees) Permanent Water $1885 \mathrm{~m}$

Grinding Surfaces

Lithics

\section{LA6599:}

The site is located 120' above the floor of Welsh Canyon above a southwest facing bench, which tapers off to a horizontal field that measures $35 \mathrm{~m} \times 200 \mathrm{~m}$. The site elevation is $4880^{\prime}(1487 \mathrm{~m})$. The site environment is juniper scrub and cottonwood riparian. Vegetation on the site includes cholla, snakeweed, prickly pear, artemisia, bunch grass, and barrel cactus. Soils include brown sandy loams.

The site complex consists of one rock shelter, with artifacts on the surface and two pictographs, a small stacked rock wall remnant, and a large lithic scatter. The site measures $250 \mathrm{~m} \mathrm{E} / \mathrm{W} \times 100 \mathrm{~m}$ N/S. Manos, basin metates, groundstone fragments, and scattered FCR are found within the lithic scatter. Several small and apparently unoccupied 
rock shelters are located in the same sandstone formation as the occupied rock shelter. The majority of the lithic debitage lies in the canyon bottom where there is good soil deposition.

The rock art panel consists of a quadruped and a possible human painted in a black pigment. The quadruped is placed over the smoothest portion of the panel. The stacked rock wall is 3 to 4 courses high and stacked on a small bedrock outcrop. It is orientated true N/S. The debitage consists of 4 sandstone metate fragments, 3 quartzite metate fragments, 2 whole quartzite manos, 1 chert point base and 1 quartzite projectile point-midsection corner. Other reduction flakes found include 28 quartzite flakes, 5 chert flakes, and 1 hornfels. This site contains diagnostic lithics and intact deposits, which may yield more temporally and functionally diagnostic artifacts, and potentially cultural affiliation.

ROCK SHELTERS: (2)

Aspect (180 degrees and 220 degrees) Permanent Water $2593 \mathrm{~m}$

Grinding Surfaces

Lithics

Rock Art

\section{LA6600:}

The site is located on a gentle slope to small ephemeral drainages among some sandstone outcrops with naturally occurring niches. Its elevation is $4880^{\prime}(1487 \mathrm{~m})$. Vegetation on the site includes mixed grasses, mixed forbs, scrub oak, cholla, prickly pear, and snakeweed. The soil is mixed sands.

Groundstone artifacts were noted as abundant on the site. Fragments of 8 milling slabs were found with 2 well-formed basin metates. Four manos and an edge ground cobble were also noted in the surface debris. Chipped stone artifacts included chert and quartzite bifaces and cores. The lack of deposition at this site makes it a poor candidate for further research.

ROCK SHELTER:

Aspect (180 degrees) S Permanent Water $2440 \mathrm{~m}$

Grinding Surfaces

Lithics

\section{LA6601:}

The site is on a steep, rocky slope above a small drainage tributary of Welsh Canyon at an elevation of 4860' (1481 m). Vegetation includes juniper and cholla, prickly pear, mixed grasses, rice grass, scrub oak, low forbs, mullein, and snakeweed. Soils are yellow sand. 
The site is a shallow rock shelter in a sandstone outcrop with groundstone and chipped stone lithics. It measures $150 \mathrm{~m} \times 125 \mathrm{~m}$. and contains lithic debitage and groundstone fragments. Down slope from the rock shelter there is a large, sparsely concentrated lithic scatter, with at least one mano present. The debitage found on the site includes 40 quartzite reduction flakes/angular debris, 2 quartzite hammerstones, 3 quartzite bifaces, 4 chert reduction flakes, 1 bifacially ground mano, and a flaked sandstone chopper.

ROCK SHELTER:

Aspect (160 degrees) Permanent Water $2440 \mathrm{~m}$

Lithics

Groundstone

\section{LA6602:}

The site is located on the valley floor, at the confluence of a northeast flowing tributary and the Mary Doyle branch of Welsh Canyon at an elevation of 4500' (1372 m). Juniper dominates the site with cholla, sunflower, chenopodia, and mixed grasses in lesser stands. The soil is fine grained tan silty sand, with pediment gravels interspersed.

The site has two components a prehistoric lithic scatter/campsite and a historical wall. The prehistoric component consists of a sparse lithic scatter and FCR. The lithic debitage includes 4 quartzite flakes and a core, 2 silicified shale flakes, a piece of chert shatter, and 10 FCR. The FCR was discovered eroding out of the cutbank of a historic stock pond. The site has received heavy disturbance due to the intrusion of two stock ponds and an earthen/stone dam. Due to the paucity of artifacts and intact cultural features the potential for further information from the prehistoric component of this site is low.

The historic component consists of two stock ponds and one dam that has been breached, exposing a multi-course stone wall and rubble structure. The existing dam is an earthen structure approximately $2 \mathrm{~m}$ high $\times 75 \mathrm{~m}$ long. This larger portion of the dam appears to have been made with mechanical earth moving equipment and is backed up by a low rubble pile and two spill-way ditches on the north side of the dam. The stock ponds appear to have intruded upon an existing prehistoric component on the valley floor. Also, associated with this site there is a multi-course stone wall extending from the valley floor to the rim rock on the west side of the drainage; a remnant also exists on the east side.

\section{LA6603:}

The site is located on the southeast facing slope of an unnamed tributary to Welsh Canyon at the base of the lowest rimrock ledge and down slope to the drainage bottom. The site elevation is 4887' (1490 m). The vegetative environment is juniper scrub land with other vegetation including Rhus trilobata, sage, wolf berry, scrub oak, and mixed grasses. Soil is tan silty sand with outcropping boulders and pediment gravels. 
The site exhibits two prehistoric rock shelters, with walls and a lithic scatter, situated the base of and below the lowest sandstone outcrop. The site measures $30 \mathrm{mx}$ $29 \mathrm{~m}$. The walls are constructed of piled sandstone slabs and several upright slabs and they are partially collapsed in a semicircular pattern. One slab metate was noted within the southern most shelter where a deflated hearth and a burned earth and FCR feature were also noted.

The lithic scatter is fairly dense with 67 pieces of quartzite reduction flakes and one quartzite core. There was also one flake each of chert, argillite, and siltstone and 2 pieces of metate fragment. Because the stone enclosures exhibit distinctive characteristics of the Middle Ceramic style architecture and the floors of the shelters exhibit a high degree of soil deposition, there is the potential for intact cultural remains.

ROCK SHELTER:

Aspect (130 degrees) Permanent Water $1647 \mathrm{~m}$

Wall Remnant

Lithics

\section{LA6604:}

The site is located on a low gently sloping terrace formed at the confluence of Welsh Canyon and an unnamed tributary in a juniper forest. Other vegetation on the site includes scrub oak, Rhus trilobata, blue gramma, prickly pear, sage, yucca, rabbit brush, mixed grasses, and low forbs. The soil is tan silty sand with occasional gravels and sandstone boulders.

The site consists of a prehistoric campsite and lithic scatter in an area that measures $28 \mathrm{~m} \times 30 \mathrm{~m}$. In addition to the lithic scatter, the site contains two deflated hearths and a deflated midden which is washing down slope into an intermittent drainage. Both hearths are also exposed in the cut bank of this drainage, at the south edge of the site. The soil deposition is good $(30 \mathrm{~cm}+)$. The lithic debris is dense across the site with over 75 quartzite reduction flakes, 22 chert reduction flakes, 9 argillite flakes and 1 basalt. Due to the potential for intact buried cultural material this site may yield further information through excavation.

\section{LA6605:}

The site is located on the gentle northeastern sloping finger ridge formed by two unnamed ephemeral drainages, that empty into Welsh Canyon. It is at an elevation of $4913^{\prime}(1498 \mathrm{~m})$ in a juniper forest with other vegetation including yucca, prickly pear, low forbs, and bunch grass. The juniper and mixed clump grass area lies between the top-most rimrock outcrop and a lower shelf of outcropping sandstone bedrock, above the valley floor. Soil is tan silty sand with pediment gravels and sandstone escarpments.

The site consists of a prehistoric lithic scatter in an area $27 \mathrm{~m} \times 23 \mathrm{~m}$. The surface of the site is composed of boulders with intermixed pediment gravels, which contain the 
scatter of primarily quartzite lithics. Several intermittent sections of historic drift fence lie along the outcropping of sandstone bedrock escarpment. The site is extremely eroded by sheet wash and is unlikely to yield any important information. The lithic material found includes 9 quartzite reduction flakes, a core, a retouched flake, and a biface. There was also one chert flake found.

\section{LA6606:}

The site is located on the north facing wall of Welsh Canyon, at the lowest rim rock outcrop and down slope to the canyon floor. Numerous boulders outcrop at the front of the shelter. The main vegetation is juniper with other low shrubs. Cottonwood, mixed bunch grasses, shrubbery, showy buckwheat, prickly pear, cholla, sage, and chenopodia are also found at the site. Soils are a very fine grained, dark tan, silty sand with pediment gravels intermixed.

The site contains a prehistoric rock shelter and lithic scatter. The site measures 45 $\mathrm{m} \times 50 \mathrm{~m}$. Artifacts on the site consist of a moderate scatter of lithics down slope from the shelter and at the base of the slope. The artifact assemblage exhibits a predominance of gray quartzite in various stages of reduction. Also noted on the site were one sandstone metate fragment and two mano fragments. One edge ground pecked and flaked cobble was collected from the base of the slope below the shelter. One broom handle fragment was noted within the shelter with no other recent disturbance.

The lithic artifacts found on the site include 14 quartzite reduction flakes, a quartzite core, a quartzite edge ground and pecked cobble, a pecked and ground sandstone mano fragment, and a sandstone slab metate fragment. Due to the extent of soil deposition within the shelter and below the slope in front of the shelter, this site offers potential for further information relevant to the prehistory of the area.

\section{ROCK SHELTER:}

Aspect (360 degrees) Permanent Water $1845 \mathrm{~m}$

Lithics

Groundstone

\section{LA6607:}

The site is located on a shallow sloping bench on the north side of an intermittent stream channel within Welsh Canyon. Its elevation is $4760^{\prime}$ (1451). Vegetation found on the site include juniper, scrub oak, mixed grasses, yucca elata, prickly pear, cholla, snakeweed, mullein, thistle, and saltbush. The main soils are brown silty sand.

The site is a lithic procurement area associated with a small rock shelter. It measures $110 \mathrm{~m}$ E/W $\times 72 \mathrm{~m} \mathrm{~N} / \mathrm{S}$. A small wall remnant across the mouth of the shelter is almost unrecognizable as a cultural feature. The lithic scatter is dense and lithic procurement appears to be the predominant activity represented at the site. There are over $60+$ large quartzite reduction flakes of various quartzites, $10+$ chert reduction flakes and 
1 unofficial mano. The number of artifacts described here represent only those artifact found within 2 transects.

\section{ROCK SHELTER:}

Aspect (200 degrees) Permanent Water $3141 \mathrm{~m}$

Lithics and Groundstone

\section{LA6608:}

The site is located above the second terrace of an unnamed tributary to Welsh Canyon in a juniper and grassland area at an elevation of 4980' (1518 m). Other vegetation on the site includes mixed grasses, snakeweed, cholla, prickly pear, chenopodia, and gramma. Soils are tan residual silty sand.

A rock shelter with a small lithic scatter that measures $16 \mathrm{~m} \times 9 \mathrm{~m}$. is found on the site. The rock shelter faces southeast with a few artifacts on the slope out front. The lithic debitage is represented by 10 quartzite reduction flakes and 1 tested cobble. There is also 3 pieces of FCR found on the slope out front. The site has been affected by erosion, deflation and rodent disturbance. The soil deposition is unknown.

\section{ROCK SHELTER:}

Aspect (120 degrees) Permanent Water $1480 \mathrm{~m}$

Lithics

\section{LA6609:}

The site is located on a southeast facing slope of an unnamed tributary of Welsh Canyon at an elevation of $4820^{\prime}(1469 \mathrm{M})$. It is in a juniper environment with mixed grasses, small forbs, cholla, snakeweed, and prickly pear. The soil is light tan silty sand.

The site contains a rock shelter, $15 \mathrm{~m} \mathrm{EN} \times 14 \mathrm{~m} \mathrm{~N} / \mathrm{S}$, with a lithic scatter. Roof fall material is pulverized into a dust like powder on the rock shelter floor. Twenty one artifacts were observed but many could be buried within the powdery dust. The slope in front of the shelter is very steep and rocky. There is a packrat midden at the western end of the shelter with most of the artifacts located at the eastern end. Lithic debitage includes 15 quartzite reduction flakes, 2 quartzite cores, a sandstone milling slab, an unknown groundstone fragment, and 2 pieces of FCR. The depth of the deposition is unknown. The shelter is in an extremely friable condition and with the adjacent steep slope, artifacts have moved down the slope.

ROCK SHELTER:

Aspect (141 degrees) Permanent Water $2745 \mathrm{~m}$

Lithics

Groundstone 


\section{LA6610:}

The site is located in a narrow tributary of Welsh Canyon at an elevation of $5040^{\prime}$ $(1536 \mathrm{~m})$. Vegetation on the site, in addition to juniper, includes mixed grasses, chenopodia, snakeweed, and prickly pear. Soils are brown eolian silts and tan residual silty sands. The site contains a rock shelter, $17 \mathrm{~m} \times 7 \mathrm{~m}$, with a lithic scatter. Dark soil at the mouth of the shelter could represent a midden stain. Within the shelter, a semi-intact wall of vertical sandstone slabs was observed. This wall, along with another partially collapsed slab wall, appears to divide the shelter into 3 distinct areas. Most of the artifacts appear on the slope at the mouth of the shelter. Two pieces of groundstone are located near the collapsed wall. Soil depth is unknown. Surface lithic debitage includes 22 quartzite reduction flakes, 4 chert reduction flakes, 2 pieces of sandstone milling slab and 4 pieces of FCR.

ROCK SHELTER:

Aspect (125 degrees) Permanent Water $1922 \mathrm{~m}$

Wall Remnant

Lithics

Groundstone

\section{LA6611:}

The site is located at the base of a south/southeast facing sandstone outcrop in a narrow tributary of Welsh Canyon at an elevation of 5000' (1524 m). Juniper dominates the site with mixed grasses, chenopodia, mountain mahogany, mullein, and scrub oak. The soil is tan residual sand in the shelter and brown colluvial silt down slope.

The site contains a rock shelter and lithic scatter, which are confined in an area 9 $\mathrm{m} \mathrm{N} / \mathrm{S} \times 16 \mathrm{~m} \mathrm{EN}$. The rock shelter has a maximum height of $4 \mathrm{~m}$. Major roof fall at the SW end of the shelter has resulted in a $2 \mathrm{~m}$ tall pile of blocks, slabs, and debris at that end. The flat shelter floor has grass growing in at least $20 \mathrm{~cm}$ of fill. Most of the visible artifacts are on the slope in front of the shelter. Lithic debitage include 17 quartzite reduction flakes, and 1 quartzite milling slab fragment. Other debitage includes 1 chert reduction flake.

ROCK SHELTER:

Aspect (145 degrees) Permanent Water $1922 \mathrm{~m}$

Lithics

Groundstone

\section{LA6612:}

The site is located on the top of a rounded ridge overlooking Welsh Canyon to the north and an unnamed tributary to the northeast. The site environment is pinon/juniper with other vegetation including mixed grasses, Rhus trilobata, rabbit brush, yucca prickly pear, and sunflower. The main soil is a fine grained yellow sand with pediment gravels intermixed. 
The site is a prehistoric lithic scatter and campsite. The site that measures $240 \mathrm{~m}$ $\times 100 \mathrm{~m}$. The site consists of a large dense lithic scatter of primarily quartzite. Two projectile points were collected, one triangular and one triangular with a concave base. Both appear to be Archaic age artifacts. Three features were noted on the site. Feature 1 is a circular area of burned earth and stones. Feature 2 is a large midden area of burned earth, stone, and lithics. A trowel test of this feature shows a depth greater than $20 \mathrm{~cm}$. Feature 3 is a small semicircular stone enclave at the edge of the canyon rim. The sandstone slabs of this feature are partially buried and partially upright. Depositional depth is good $20+\mathrm{cm}$.

Lithic artifacts noted on the site include, 32 quartzite reduction flakes, a quartzite retouched flake, a quartzite biface fragment, a quartzite core, and 2 quartzite hammerstone cobbles. There were also the 2 chert projectile point fragments (collected), a chert biface fragment, and 2 chert reduction flakes. There were 5 sandstone mano fragments and 1 sandstone metate fragment.

\section{LA6613:}

The site is located on the east/northeast facing slopes of an unnamed tributary to Welsh Canyon in the canyon wall face, beneath overhangs, along sloping terraces, and along the steep talus slope of the canyon wall. The site elevation is 5000' $(1524 \mathrm{~m})$. Juniper is found on the site with cholla, prickly pear, mixed grasses, low forbs, cottonwood trees, and a large grapevine. The soil is tan silty sand with aeolian and alluvial deposits on part of the site, residual gravels in part, and sandstone outcrops in other parts.

The site has two components. The first component is a prehistoric lithic scatter and habitation site with rock art panels. The historic component consists of trash material and a section of barbed wire fence. The prehistoric site consists of a dense scatter of lithics and groundstone with 2 complete metates recorded, 8 manos and mano fragments. Features on the site include 5 amorphous stains, which might be a shale lens eroding out onto the surface, but the features have no FCR associated with them. Other areas contain large amorphous burned soils, FCR, lithics, and groundstone. These probably represent deflated fire pits. One diagnostic projectile point was recovered; it is a Middle Archaic side notched argillite point.

larger.

One petroglyph is located at the extreme NW position of a NE facing boulder. A large boulder 1-m to the NE creates a passage, which is from 1 to $3 \mathrm{~m}$ wide and $10 \mathrm{~m}$ long. A small pile of rocks appears to have been placed directly below the figure, which has the form of curving a meander with 10 loops. Another petroglyph is a net form pecked into a boulder that is among the jumbled talus blocks at the site.

Lithics found on the site include 71 quartzite reduction flakes, 6 quartzite cores, a quartzite scrapper, a quartzite biface fragment, and a lightly ground quartzite cobble. 
There was also found 3 chert reduction flakes, 2 basalt flakes, an argillite-tested cobble, 3 sandstone metate fragments, and 9 sandstone mano fragments.

The historical component feature of the site consists of 4 pieces of historical artifact material found along transects. The site also has a section of barbed wire fence. The historical material consists of a can, a Ridenous-Baker coffee box (which was found in the crevice between two boulders), an 8-mm Mauser cartridge case, and a metal box.

\section{LA6614:}

The site is located on the east-facing slope of Welsh Canyon. The rim rock outcrop yields to sharply sloped talus, which then meets a lower bedrock outcrop escarpment. The site continues below this escarpment down the slope to the valley floor, where it is intersected by an ephemeral drainage near the road. Vegetation includes juniper and Rhus trilobata, cacti, yucca, rabbit brush, artemisia and mixed grasses. Soils are tan to brown silty sand with boulders, cobbles and pediment gravels intermixed.

The site is a prehistoric lithic procurement area measuring $120 \mathrm{~m} \times 46 \mathrm{~m}$. The site is on a steep slope below the top rim rock outcrop and extends to the canyon floor. The site consists of primarily secondary flakes and a large number of cores. All the lithic material is gray/maroon quartzite, that occurs at this location as a secondary deposit, in cobble sized fragments. The soil on site is shallow allowing low potential for intact buried cultural features. There were 106 quartzite flakes of various stages of reduction counted on the site in addition there were 12 quartzite cores.

\section{LA6615:}

The site is situated on a northeast facing talus slope with a sandstone escarpment and into the floor of Welsh Canyon. It is at an elevation of $4850^{\prime}$ (1478). Vegetation includes juniper, buffalo bush, sage, rabbit brush, blue gramma, yucca, cactus, mixed bunch grasses, and low forbs. The soil is shallow sand with pediment gravels and bedrock outcrops among escarpment and talus boulders.

The site is a lithic procurement area measuring $90 \mathrm{~m} \times 50 \mathrm{~m}$. It appears to be a secondary source for gray quartzite. The numbers of cores and large flakes noted on site in relation to the lack of tools indicate the probable function of the site may have been lithic procurement. The site is situated on a very steep slope and the soil is shallow. There were 68 quartzite reduction flakes counted on the site and 9 quartzite cores.

\section{LA6616:}

The site is located at the edge of an east facing rim rock above the confluence of Welsh Canyon and an unnamed tributary at $4740^{\prime}(1444 \mathrm{~m})$ elevation. Vegetation on the site includes juniper, yucca, prickly pear, cholla, and rabbit brush. Soils are a yellowish-brown, fine-grained silty sand. 
The site is a prehistoric lithic scatter, measuring $80 \mathrm{~m} \times 40 \mathrm{~m}$. It consists of primarily fine grained quartzite flakes in various stages of reduction that are on a shallow layer of silty sand with pediment gravels and bedrock outcrops. There were 48 quartzite reduction flakes counted on the site. There was also a quartzite core and a chert flake counted. Due to the absence of diagnostic artifacts and cultural features combined with the shallow soil on the site there is low potential for this site to yield further information.

\section{LA6617:}

The site is located in an upper tributary canyon to Welsh Canyon, on the southwest side facing easterly at an elevation of $4952^{\prime}(1509 \mathrm{~m})$. Juniper is the dominant plant with other vegetation including grasses and gourds (coyote squash). The soil is a buff to tan sand.

The site contains a small rock shelter measuring $9 \mathrm{~m} \times 6 \mathrm{~m}$. The floor is flat with a partially exposed hearth, which appears to be intact. Scattered FCR down the slope below the shelter contains some flaking debris. The site contained 4 quartzite reduction flakes and 1 chert shatter flake. Because the hearth contains charcoal for $14 \mathrm{C}$ dating and the deposits appear to be intact this site contains information potential for further research, however the site should not be a high priority.

ROCK SHELTER:

Aspect (90 degrees)

Lithics

Hearths

\section{LA6618:}

The site is located on an east-facing slope of a side canyon, of Welsh Canyon at an elevation of 5007' $(1526 \mathrm{~m})$ in rocky area of juniper and grasses. The soil is a brown-grey sandy loam. The site contains 3 rock shelters and a lithic scatter in a site area that measures $70 \mathrm{~m} \times 70 \mathrm{~m}$. The site also contains the lithic scatter; deflated hearths, charred earth, and FCR intermixed on the surface and slightly buried. This material is located on the rim overlooking the 3 rock shelters.

Lithic material found on the site includes 10 argillite reduction flakes, 6 quartzite reduction flakes, 3 chert reduction flakes, 2 hornfels reduction flakes, and 1 basalt reduction flake. There was also a chert biface tool and a chalcedony side notched projectile point, which was collected. Because of intact hearth remains and other intact deposits, and wall remains the site has potential to yield further information on the prehistory of the area.

ROCK SHELTER:

Aspect (310 degrees) Lithics

Grinding Surfaces Hearths

Wall Remnants 


\section{LA6619:}

The site is located on the north-facing slope of the southern wall of Welsh Canyon at the base of the upper sandstone rim rock outcrop. The site extends down the talus slope at an elevation of $4999^{\prime}(1524 \mathrm{~m})$. Juniper is the dominant plant on the site with cholla, prickly pear, Rhus trilobata, snow berry, current, low forbs, and mixed bunch grasses. Soils are tan silty sands with bedrock boulders and pediment gravels.

The site contains a prehistoric rock shelter with groundstone and lithics. It measures $33 \mathrm{~m} \times 12 \mathrm{~m}$. A deep trough-like metate with one edge pecked and a flat slab metate with a lightly smoothed and pecked surface is found in the rock shelter. The lithic debris on site is scarce consisting of 5 quartzite reduction flakes, 1 quartzite flake tool, and a large quartzite cobble with a unifacially retouched edge. There was also 1 quartzite mano, lightly smoothed with 2 battered ends. There was no depositional intact material.

ROCK SHELTER:

Aspect (360 degrees) Permanent Water $2821 \mathrm{~m}$

Grinding Surfaces

Lithics

Groundstone

\section{LA6620:}

The site is located on the west-facing slope of a north/south trending tributary of Welsh Canyon. It is beneath a tall but shallow overhang at the base of the top most rim rock outcrop and adjacent to a shallow ephemeral wash. The site elevation is 4996' (1522 $\mathrm{m})$. Juniper and cholla, prickly pear, Rhus trilobata, low forbs, and mixed bunch grasses grow on the site.

The site contains a prehistoric rock shelter and lithic scatter measuring $15 \mathrm{~m} \times 22$ $\mathrm{m}$. within the rock shelter and down slope. A charcoal stain $30 \times 30 \times 50+\mathrm{cm}$ in depth is located beneath the overhang. Lithic debris found on site includes 6 quartzite reduction flakes, 4 quartzite cores and 3 chert reduction flakes. Due to the depth of soil within the shelter and the presence of charcoal staining this site does have the potential to yield further information on the prehistory of the area.

ROCK SHELTER:

Aspect (270 degrees) Permanent Water $2654 \mathrm{~m}$

Lithics

Groundstone

Hearths

\section{LA6621:}

The site is located on the northeast projecting finger ridge at the confluence of Welsh Canyon and an unnamed tributary at an elevation of $4833^{\prime}(1473 \mathrm{~m})$. The vegetative environment is juniper scrubland with cholla, prickly pear, rabbit brush, blue gramma, 
sunflower, low forbs, and sparse bunch grasses. The main soil is reddish brown silty sand intermixed with pediment gravels.

The site is a prehistoric lithic procurement and reduction area. It measures $180 \mathrm{~m}$ $\times 150 \mathrm{~m}$. The site lies atop and below the terrace, along the alluvial flood plain of the canyon floor. The site consists of a dense scatter of lithics primarily quartzite. The high percentage of cores and large early stage reduction flakes suggests that this site was used as a lithic reduction site, of secondary lithic deposits. Two hearths on the site suggest temporary camping with groundstone suggesting food or plant processing as a secondary site activity. The site has good depositional material $(100 \mathrm{~cm}+)$. An amorphous stain of burned rock with dimensions of $90 \times 140 \mathrm{~cm}$. and another amorphous dark stain with FCR and dimensions of $70 \times 60 \mathrm{~cm}$ are evident on the surface of the site.

Of the lithics found on site 191 were quartzite reduction flakes, and 26 were quartzite cores. There were also 12 chert reduction flakes, 3 limestone reduction flakes, and a chalcedony scrapper. Groundstone found on site included 2 sandstone manos and a sandstone slab metate fragment. The site has potential for depositional material and it could contain information important to understanding the prehistory of the area.

\section{LA6622:}

The site is located near the bottom of a northwest facing talus slope, at the confluence of a unnamed tributary and Welsh Canyon at an elevation of 4808' (1465 m). The vegetative environment is pinon/juniper with other vegetation on the site including yucca, rabbit brush and mixed bunch grasses. The site is in an area of talus boulder outcrops, with pediment gravels intermixed with fine-grained silty sand.

The site is a prehistoric lithic scatter measuring $50 \times 10 \mathrm{~m}$. consisting mainly of a sparse scatter of lithics, primarily quartzite flakes and cores. The lithics lie on a shallow deposit of silty sand with talus boulders and pediment gravels throughout. Activities inferred from the artifacts include lithic reduction and possible procurement of a secondary quartzite deposit. The site is situated adjacent to a $90+\mathrm{cm}$ silty canyon floor alluvial deposition, which could reveal further cultural material although this site was noted only on the shallow and steep slope. There were only 12 quartzite reduction flakes found on site and 1 quartzite core.

\section{LA6623:}

The site is located on the north facing talus slope of the south canyon wall of Welsh Canyon and onto a colluvial plain. Its elevation is 4838' (1475). The site is located in a moderate stand of juniper with lesser amounts of cholla, prickly pear, rabbit brush, blue gramma, scrub oak, low forbs, and mixed bunch grasses. The soil is tan silty sand with quartzite cobbles, talus boulders, and pediment gravels.

The site is a prehistoric lithic procurement area measuring $42 \times 16-\mathrm{m}$. Cultural material on site consists of white quartzite in all stages of the reduction sequence. The 
frequency of primary flakes and large cores suggests an activity of lithic procurement and reduction on site. The site is situated on shallow soil deposits. There were 32 quartzite reduction flakes found on site with 17 quartzite cores.

\section{LA6624:}

The site is located on a sloping mesa top above a narrow unnamed tributary of Welsh Canyon. Its elevation is 5050' (1539 m). The site vegetative environment is juniper to grasslands transition with pinon, mixed grasses, scrub oak, small forbs, cholla, and prickly pear. The soil is brown silty sand.

The site is a prehistoric lithic scatter measuring $32 \times 18-\mathrm{m}$. It is a small but dense lithic scatter, located on a finger mesa. A transect $(24 \times 2 \mathrm{~m})$ was sampled to determine lithic material type and production stages. There were 3 cores and a sandstone mano fragment found. There were no other tools, FCR, or charcoal stain on site. The surface is deflated and armored in tabular sandstone pebbles and cobbles. There were 41 quartzite reduction flakes found on site and there were also 6 chert reduction flakes.

\section{LA6625:}

The site is located around the base of a sandstone cliff overlooking an unnamed tributary of Welsh Canyon at an elevation of 4960' (1511 m). Juniper dominate the site with mixed grasses, small forbs, scrub oak, snakeweed, and sage. The soil is light brown coarse sand.

The site contains a small prehistoric rock shelter with a lithic scatter in an area that measures $16 \times 10 \mathrm{~m}$. The small rock shelter has a maximum height of $1.5 \mathrm{~m}$ at the base of a sandstone cliff. The slope below the shelter is very steep and rocky. No artifacts were found within the shelter, except some possible FCR. The lithic material found on the site includes 8 quartzite reduction flakes, 1 chert flake fragment, and 2 pieces of sandstone FCR. The artifacts appear to have been transported down slope from the shelter. The depth of deposition is unknown.

The site is very small but in conjunction with other sites, could yield data pertinent to the prehistoric settlement patterns in the area.

ROCK SHELTER:

Aspect (90 degrees) Permanent Water $1983 \mathrm{~m}$

Lithics

5LA6626:

The site is located on top of a narrow unnamed mesa between Black Hills and Welsh Canyon at an elevation of 5040' $(1536 \mathrm{~m})$. The vegetative environment is juniper/savanna with scrub oak, mixed grasses, small forbs, buckwheat, prickly pear, pinon, and snakeweed. The mesa top where the site is located is fairly flat to gently rolling. 
Patches of grass and stands of juniper surround gravel filled clearings where the vegetation is sparse. The soil is a light brown sandy loam.

The site is a prehistoric lithic scatter with a possible hearth and it measures $80 x$ $140 \mathrm{~m}$. The surface is presently stable, due to the lag gravel armor in the clearings. There are small pockets of high artifact density within the overall scatter. A possible deflated hearth with groundstone fragments measures $1 \times 1 \mathrm{~m}$. A few milling slab fragments were observed around this hearth and also scattered elsewhere around the site.

The lithic debitage includes 81 quartzite reduction flakes, 4 chert reduction flakes, and 1 quartzite core. There were 3 retouched quartzite flakes, a chert biface, an indurated shale biface, and 4 quartzite core tools. Eight groundstone fragments and 4 basin metate fragments, made of sandstone, were noted.

The artifacts are in a deflated context and additional work at the site is likely not warranted.

\section{LA6627:}

The site is located at the base of a sandstone cliff in a large unnamed tributary to Welsh Canyon at an elevation of 4880' (1487 m). Intermixed juniper and grass dominate the vegetation on the site. The site contains a rock shelter with an interior hearth and lithics; it measures $15 \mathrm{~m} \times 12 \mathrm{~m}$. The hearth is an amorphous charcoal stain with charcoal chunks and scattered pieces of FCR. The feature has been partially eroded but enough remains that a radiocarbon date could be obtained. There is a metate fragment within the rock shelter and a few scattered flakes. A single flake and a sandstone basin metate fragment were found on the slope below the rock shelter. Thirty-six quartzite reduction flakes were found on site with 1 chert biface and 1 quartzite core.

\section{ROCK SHELTER:}

Aspect (220 degrees) Permanent Water $1200 \mathrm{~m}$

Lithics

Groundstone

Hearth

\section{LA6628:}

The site is located on a steep southeast-facing slope at the mouth of a large unnamed tributary to Welsh Canyon. Its elevation is $4780^{\prime}(1457 \mathrm{~m})$. Juniper and grasses are found with mixed grasses, small and large forbs, prickly pear, cholla, and yucca. The soil is light brown sand.

The site is a lithic scatter, measuring $12 \times 14-\mathrm{m}$., on a steep $(12-30 \%)$ southeast facing slope, near an ephemeral drainage.

There were 50 quartzite reduction flakes found on the site and 2 quartzite cores. 


\section{LA6629:}

The site is located on a finger ridge, terrace, and talus slope on the northwest side of an unnamed tributary of Welsh Canyon at an elevation of 5000' (1524). The site is in the zone of pinon/juniper. Other vegetation found on the site include cacti, rabbit brush, mixed grasses, and Rhus trilobata. Soil are extremely fine grained, light tan silty sands, intermixed with pediment gravels, rocks and boulder outcroppings at the surface.

The site extends down the southeast-facing slope of a ridge. It measures $230 \times 140$ $\mathrm{m}$. Cultural material on site consists of a sparse lithics, primarily quartzite. The largest concentration is located on the southeast slope of the site. This site was located on the Welsh Canyon Survey when an unlabeled PVC datum was noted on this ridge top. Because no paper work or site form could be located for this site it was re-recorded. Lithic debitage counted on the site included 71 quartzite reduction flakes, a quartzite core, a limestone reduction flake, and a small sandstone metate fragment. The site lies on shallow soil with no diagnostic artifacts or buried features, therefore; the potential is low that this site will yield further information.

\section{LA6630:}

The site is located on a small bench overlooking the intermittent channel of Welsh Canyon. Its elevation is 4760' (1451 m). Juniper is found on the site with mixed grasses, small forbs, buckwheat, prickly pear, snakeweed, and cholla. The soil is a light to medium brown silty sand.

The site is a lithic scatter measuring $135 \times 80 \mathrm{~m}$. No diagnostic tools, FCR, or charcoal staining, or features of any kind were evident on the surface. Quartzite outcrops and chert nodules are found naturally in the vicinity. The identified lithic debitage includes 20 quartzite reduction flakes, 2 quartzite cores, 10 chert reduction flakes, 3 chert cores, a limestone groundstone fragment, a sandstone groundstone fragment, and a quartzite mano.

The depositional depth is unknown.

\section{Field Season Sites}

\section{LA6740:}

The site consists of a lithic procurement area, measuring 140 meters NS by 85 meters EW. Its elevation is $1494 \mathrm{~m}$ (4900ft) and the site is set in a juniper scrubland vegetative zone. The site area itself consists of a small hill located on a terrace/bench off the main rim of Welsh Canyon. Hundreds of quartzite cores that have been tested and accompanying flake material are found on the surface of the site. All materials are a fine coarse-grained white quartzite. Some cores may have weathered out of the hill but there is little evidence of sub-surface deposits and although the site has only moderate 
disturbance from natural erosion and animal activity, it is not a good candidate for additional research.

\section{LA6741:}

The site consists of a large lithic scatter measuring $320 \mathrm{~m}$ on its EM axis by $140 \mathrm{~m}$ on its N/S axis. Found at an elevation of $1426 \mathrm{~m}\left(4680^{\prime}\right)$, the site is set in a juniper scrubland with juniper, prickly pear, mixed bunch grasses, yucca, cholla, and mountain mahogany growing on the site. The site is a gently sloping bench area, located between the mesas forming Welsh Canyon. It is about .5 kilometer from the drainage in the canyon bottom. The site has two areas of lithic concentration at the base of the first terrace and where the present day two-track road crosses it. Although there are thousands of flakes, the detritus is sparsely scattered across the site area. One concentration of material is found on the flat area just west of the canyon rim. Most material is quartzites in various colors and stages of reduction but chalcedony and a grey/blue chert were noted. No patterned artifacts were found nor were any features obvious on the surface of the site.

\section{LA6742:}

The site is a dense lithic scatter measuring $88 \mathrm{~m} \mathrm{~N} / \mathrm{S}$ by $50 \mathrm{~m} \mathrm{E/W}$. Its elevation is $1439 \mathrm{~m}\left(4720^{\prime}\right)$. The site setting is on a hilltop or bench near the rim of Welsh Canyon in a juniper scrubland that supports juniper, cholla, mixed grasses, prickly pear, yucca, and rhus trilobata. Two dark stains, apparently the result of a fire feature, are found on the site but no chunks of charcoal were evident in these stains. A concentration of chert cores was found around the darker soil and flakes are found in the center of the stain area but the heaviest concentration is found around it. A general flake scatter is found through out the site. Another smaller stain was also noted but it did not contain any artifacts. A small, formed scraper of brown chert was found but not collected. There were also two mano's found, one of rhyolite and the other of quartzite.

The heaviest concentration of lithic materials on the site are green and brown chert while other cherts found on the site were red, grey, and white. Light grey quartzite was also a prominate material. This site might contain subsurface deposits that are worthy of further investigation.

\section{LA6743:}

The site is located in the canyon bottom on a slope of land cut by an arroyo. Vegetation includes juniper trees, grasses, cholla and prickly pear cactus. The site measures $43 \mathrm{~m}$ north-south and $30 \mathrm{~m}$ east-west. A sparse lithic scatter appears on both sides of the arroyo. The artifacts identified include a large flaked chopper and three cores but no other tools. Tested chert cobbles and a series of primary, secondary and tertiary flakes of white quartzite were also found. The site appears to have been heavily eroded by water considering the deep arroyo present and although it could contain subsurface cultural deposits, it is not a high priority for additional research. 


\section{LA6744:}

The site is a rock shelter located on the canyon rim, on a slope under a rocky prominence near the upper end of a side canyon to Welsh Canyon. The rock shelter contains a possible hearth and three sets of tool grooves. It measures $80 \mathrm{~m}$ north-south and $80 \mathrm{~m}$ east-west. Residual soil deposition coming off the knoll and aeolian soils are found in the rock shelter. Vegetation includes juniper, prickly pear and cholla, yucca, and bunch grasses.

One projectile point and two scrapers were found. A large lithic scatter lies among the rocks spreading south and southwest of the mouth of the rock shelter. The majority of the lithic material is brown quartzite with some local chert, argillite, and chalcedony. Few tested cobbles, shatter, and cores were noted. Only a few tertiary flakes were found. From the numbers of heat-cracked stones found in the slope near the rockshelter it is inferred that roasting pit features may be intact in its deposits.

The site also contained a historic component. Historical remains include a gate found inside a natural boulder formation that makes an enclosure, which was determined to be a sheep pen. Axe cut logs wrapped with smooth wire were found inside the enclosure. A datable tobacco can placed the date of the sheep pen at the mid-twentieth century during the ranching period.

\section{LA6745:}

Site 5 LA6745 is a small oval-shaped lithic scatter $14 \times 10-\mathrm{m}$ that lies on the top of a ridge-top finger overlooking Welsh Canyon and a tributary. Its long axis is north to south along the ridge at an elevation of $5110 \mathrm{ft} .(1558 \mathrm{~m})$. Vegetation at the site is a clearing between juniper and prickly pear interspersed with range grasses. Lithic artifacts at the site are grey or white quartzite flakes of ordinary grade ranging in size between $100 \mathrm{~cm}$ long and $10 \mathrm{~mm}$ wide. The total number of surface artifacts found at the site is ten including a quartzite core, four flakes, three pieces of shatter, a retouched chalcedony flake and a chalcedony scraper. The sandy soil at the site appears deflated and it is unlikely to produce additional cultural material. This small scatter probably represents a brief stop for tool manufacture.

\section{LA6746:}

The site is represented by a rectangular quartzite lithic scatter $61 \times 56$ meters. Hundreds of tested quartzite chunks, along with a large number of cores and flakes in all stages of reduction, are found on the site. It covers a wide area, with two dense concentrations. The site is located in a swale of a slope in a juniper scrub forest. The depth of the reddish-brown silt, loam soil was not measured, but seems deep enough to yield subsurface material. Although the site is covered with hundreds of tested cobbles and flakes, a remarkable lack of tools and advanced reduction was noticeable. Site 5LA6746 was used for procurement of lithic material and blank preparation. Data concerning lithic studies, resource use by prehistoric peoples, and transport and technology studies could be gained from this site. 


\section{LA6747:}

The site is located on a knob at the edge of a terrace overlooking the bottom of Welsh Canyon. The surface exhibits a lithic scatter of chert nodules, quartzite flakes, and a single piece of groundstone, possibly siltstone. Of particular interest is a cache containing approximately 40 large cobbles of several varieties of non-local materials. A historic rock wall with incorporated barbed wire and other historic artifacts are also on the site which covers approximately 0.6 acres and the aforementioned cache of rocks may be related to this later component or it could be a product of the prehistoric site use.

A dense concentration of flakes is found near the inner edge of the wall near the cache of cobbles. The southeastern boundary is on a shear 50-ft drop off to the canyon floor below. A modern well and corral are also located below the site 50-m east at the bottom of the canyon. The plant community in the area is typical juniper scrub that contains a substantial amount of yucca at the site. Soils consist of rocky, reddish tan sand approximately $25 \mathrm{~cm}$ deep.

5LA6747 was probably used for raw material storage that would be used for tool production at a later date. The site might yield information on lithic technology and special use locational data.

\section{LA6748:}

The site is found on a hill slope to the west of Welsh Canyon. It is a lithic scatter measuring $65 \mathrm{~m}$ east west by $32-\mathrm{m}$ north-south and it consists primarily of tested chert nodules. The site is situated at $4660 \mathrm{ft}(1402 \mathrm{~m})$ elevation in a juniper-pinon vegetation zone. The soil is dark brown sandy loam about $30 \mathrm{~cm}$ deep. A barbed wire fence runs east west through the center of the site.

Cultural material found at this site consists of approximately 30 flakes, cores, and shattered lithic material. A grab sample was analyzed in the field. It is being eroded by wind and water causing artifacts to gravitate down the steep 60-degree slope on the east. Although the solid deposition is deep, no sub-surface artifacts seem to be readily apparent.

Research potential of this lithic reduction site has been exhausted by the recording process. It does not appear to be eligible for inclusion in the National Register of Historic Places at this time, as it does not meet any qualifying criteria.

\section{LA6749:}

Site 5LA6749 is a northeast facing rock shelter that contains a buried hearth and three lithic artifacts. It is located in a cutbank along the bottom of Welsh Canyon where it is surrounded by riparian vegetation consisting of juniper, cottonwood, grasses, and cholla. The entire site contains about 0.8 acres, which measures $75-m$ north-south by $42-m$ 
east-west. The soil is relatively deep $(1.5 \mathrm{~m})$ when compared to other cultural sites in the area. This is revealed by deposition in the cutbank.

The top $30-\mathrm{cm}$ is described as brown loamy topsoil. Under this layer is about 70 $\mathrm{cm}$ of light brown loam, followed by $20 \mathrm{~cm}$ of pinkish-orange soil interspersed with pink granules. The remainder is slumped and eroded sediment. A buried hearth is eroding at the one-meter level and contains an unspecified type of rock, gray ash, and charcoal. All this is interlaced with black ash. The hearth measures about $50-\mathrm{cm}$ diameter by $50 \mathrm{~cm}$ deep. The only artifacts visible on the surface are two chert flakes and a chunk of quartzite shatter. This location was probably a brief open campsite judging from the cultural remains. The site has been covered by sediment and is now eroding out of the side of the cutbank. It shows moderate disturbance by water erosion and may be affected further by wind and water erosion. In addition, animal activity and general neglect threaten it by allowing the arroyo to erode further. It is likely to produce subsurface cultural material and should be tested.

Site 5LA6749 qualifies for National Register eligibility under criteria D, its research potential. This site is a good candidate for work on the geomorphology of the region.

\section{LA6750:}

The site is an extensive lithic procurement site measuring $180 \mathrm{~m} \mathrm{NIS} \times 90 \mathrm{~m}$ EIW at an elevation of $1462 \mathrm{~m}$ (4798 ft.) It is located in a pinonljuniper environment with yucca, prickly pear, mountain mahogany, and mixed bunch grasses also growing on on the site. The soils are fine-grained sands that vary from red to brown.

The site is located on the West side of a North/South trending ridge and extends east toward two converging drainages, which bisect a small saddle. Hundreds of tested boulders, large primary and secondary flakes, and core remnants of mainly white quartzite are found on the site. Other on-site materials include peach and purple quartzite and a few local chert nodules. Very little deposition was noted and the site is not a good candidate for further work.

\section{LA6751:}

The site is a lithic scatter measuring $70 \mathrm{~m}$ north-south and $68 \mathrm{~m}$ east-west at an elevation of $1433 \mathrm{~m}$. It is bounded to the east by the Welsh Canyon two-track road and the north by a small drainage. Vegetation includes bunch grasses, yucca and mountain mahogany in a vegetative community dominated by juniper. Soils are red to brown sands. The site apparently contains a lithic procurement area that is located on a slope, which rises to a small knoll. The cultural material consists of broken quartzite cobbles and chunks washing down from the north and depositing into the lower elevations of the site. White quartzite outcrops and local chert nodules exist on the site as well as tested boulders, cobbles and flakes. There are no formal tools. 


\section{LA6752:}

The site is a lithic scatter and procurement area measuring $40 \mathrm{~m} \mathrm{~N} / \mathrm{S} \times 32 \mathrm{~m}$ EN at an elevation of $1445 \mathrm{~m}\left(4740^{\prime}\right)$. Located in a juniper scrubland vegetative area the site setting also contains grasses, yucca, prickly pear, and cholla. Soils are reddish in color and fine-grained in texture. They apparently include sands and sandy, clay loams. The site is located on a gentle south facing terrace which ends abruptly on a steep slope where it empties into a drainage. Hundreds of local chert nodules, primary, secondary, and tertiary flakes of the same materials are found on the site. There was a lack of cores on the site. Three utilized flakes were found on the site, but they were made of quartzite rather than the local chert. Deposition of the cultural material was not noted.

\section{LA6753:}

The site is a large lithic scatter and procurement area measuring $125 \mathrm{~m} \mathrm{EN} \times 62.5$

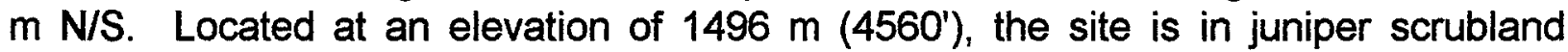
vegetation with yucca, bunch grasses, and prickly pear also growing on the site. Soils are yellow and coarse grained with sandstone cobbles and boulders throughout them. The site is situated on a knoll, above a terrace adjacent to the arroyo. White and peach colored quartzite cores, shatter, and flakes, numbering in the hundreds, are found on the surface of the site. Based on the surface examination it is thought that areas of intact subsurface deposits could be found on this site.

\section{LA6754:}

The site is a large lithic scatter and procurement area that measures $160 \mathrm{~m}$ northsouth by $120 \mathrm{~m}$ east-west. The site elevation is $1595 \mathrm{~m}$ (4860 ft). It is situated in pinonjuniper scrub land with yucca, prickly pear, cholla, rhus tribolata, and bunch grasses predominating at the site. Soil is a red to brown silty sand mixed with rocks.

The site is located at the junction of two tributaries of Welsh Canyon. It extends from a small terrace on the east slope down to the ravine and up onto a small knoll on the west side of the Welsh Canyon. Lithic materials found here consist of hundreds of chert flakes in all stages of reduction and hundreds of tested chert nodules. Chert is outcropping on the site.

\section{LA6755:}

The site consists of a lithic scatter and procurement area measuring $45 \mathrm{~m}$ EIW $x$ $32 \mathrm{~m} \mathrm{NIS}$ at an elevation of $1463 \mathrm{~m}\left(4800^{\prime}\right)$. The site environment is juniper scrubland with prickly pear, cholla, and mixed bunch grasses also growing on the site. Soils are reddishyellow sands.

The site itself consists of 50-100 nodules of all sizes with chert inclusions. The material is of a very poor flaking quality; however, flaking was attempted. The site does not exhibit any areas of buried deposits and additional research would not be productive. 5LA6756: 
The site consists of a lithic scatter and two rock shelters in an area that measures $120 \mathrm{~m} \mathrm{ENW} \times 100 \mathrm{~m} \mathrm{~N} / \mathrm{S}$. Located at an elevation of $1219 \mathrm{~m}\left(4000^{\prime}\right)$, the site is in a juniper scrubland environment with cholla, prickly pear, and grasses also grwoing on it. Soils are light brown sands.

The site is on a tributary peninsula of Welsh Canyon about $75 \mathrm{~m}$ above the drainage where it is situated on top of the peninsula, which drops off $10 \mathrm{~m}$ at the rim rock. The rock shelters are under the sandstone rim rock 20 meters from the bottom of the drainage. Surface artifacts include argillite and quartzite flakes and several quartzite manos. The rock shelters are small but contain possible wall remnants, and rock shelter. One has a possible hearth in it. The aspect of the shelters is northwest. Because of the number of lithic flakes present, the hearth remnants, the walls, and the rock shelters, this site is worthy of additional investigation.

\section{LA6757:}

The site is a small rock shelter with a lithic scatter, in an area measuring $20 \mathrm{~m}$ EIW $\times 15 \mathrm{~m}$ NIS. It is at an elevation of $1524 \mathrm{~m}\left(5000^{\prime}\right)$ in a juniper scrubland vegetative zone with prickly pear, yucca, and mixed bunch grasses also on the site. Soils are light brown silty sands. The rock shelter is near the top of a steep canyon with the lithic scatter eroding out of it and down the slope. No surface evidence of hearth remains was noted in the shelter nor were any wall remnants obvious but the soil depth is estimated at $20-360 \mathrm{~cm}$. The lithic material found includes various quartzites and chert.

The field investigators believe this site will produce intact cultural deposits when test excavated. It is a good candidate for additional research.

\section{LA6758:}

The site is a lithic scatter incorporated with a small east facing rock shelter. Including the lithic scatter near it, the site measures $95 \mathrm{~m}$ in diameter. Elevation is 1505 $\mathrm{m}(4940 \mathrm{ft})$. The environment is juniper scrubland where rhus tribolata, mixed bunch grasses, cholla, and prickly pear predominate within the boundaries. Soil is rocky brown sand with areas of dark stain from weathering shale deposits underneath the sand.

The rock shelter sits under the rim at the top of a canyon with a lithic scatter on the rim as well as below the shelter on a narrow ledge surrounded by boulders. It is almost inaccessible from the bottom of the canyon. Inside the shelter there is a hearth (Feature 2) with a discolored soil stain and charcoal. Lithic material found inside the shelter includes flakes, a scraper, a mano fragment, and a metate fragment. The artifacts were arranged on top of a rock next to the metate, suggesting human intervention of some type. Lithic materials found in the scatter consist of dark gray quartzite, chert, and hornfels. This site is worthy of additional investigation. 


\section{LA6759:}

The site is a lithic scatter measuring $65 \mathrm{~m}$ NIS $\times 53 \mathrm{~m}$ EIW. It is at an elevation of $1518 \mathrm{~m}\left(4980^{\prime}\right)$ in a vegetative zone dominated by juniper scrubland with prickly pear, yucca, cholla, and mixed bunch grasses also on the site. Soils are mainly a light brown sandy loam. The site is located on the canyon rim.

A cultural material scatter is eroding down a slope on the site. It includes quartzite reduction flakes, a chert scraper, a quartzite slab metate, and two shaft straighteners (one of siltstone and one of quartzite). There was also a sandstone mano fragment on the site. This site appears to have potential buried deposits to a depth of $30+$ centimeters. This coupled with the large number of tools suggests it might be a good site to test excavate.

\section{LA6760:}

The site is a lithic procurement area measuring $65 \mathrm{~m}$ north-south by $30 \mathrm{~m}$ east-west located at $4700 \mathrm{ft}$ ( $1433 \mathrm{~m}$ ) elevation. Vegetation surrounding the site is juniper scrubland with mountain mahogany, cholla, prickly pea, yucca and mixed bunch grasses predominating. Soil is composed of brown, sandy loam.

A lithic artifact scatter associated with this site is located on a gentle slope of a small terrace. The artifacts are eroding onto the talus slope below. The raw material found here is gray quartzite, which is weathering out of the slope. Hundreds of the quartzite reduction flakes found here are the result of quarrying activities but this type of site is duplicated at several locations. The lack of good intact buried cultural levels at the site suggests it is not a good candidate for additional work.

\section{LA6761:}

The site is a lithic scatter and procurement area measuring $70 \mathrm{~m}$ NIS $\times 40 \mathrm{~m}$ EIW. It is located at an elevation of $1487 \mathrm{~m}\left(4880^{\prime}\right)$, in a juniper scrubland vegetative zone with yucca, mountain mahogany, and indian paintbrush being the other site vegetation. Soils are light graylbrown sandy loams.

The site is located on a gentle slope above a flat terrace/bench. The source of lithic material found on the site is pink quartzite boulders, which are weathering out of the slope. The lithic material consists of hundreds of flakes in all stages of reduction and core fragments. No features were noted nor did the field investigators find areas with the potential for recovery of buried remains.

\section{LA6762:}

The site is a lithic scatter and reduction area located on the side of Welsh canyon. Its dimensions are $100 \mathrm{~m}$ north-south and $70 \mathrm{~m}$ east-west with an elevation of $1450 \mathrm{~m}$. Vegetation includes prickly pear and cholla cacti, yucca and mixed bunch grasses in a juniper canyon environment. 
The immediate site area is along the top a protuberance of land that overlooks a tributary canyon of Welsh Canyon. The site area is covered with a large scatter of quartzite flakes in all stages of reduction, utilized flakes, and cores. Only quartzite material was identified. No areas of buried deposits were noted by the survey crews.

\section{LA6763:}

The site is a lithic procurement area measuring $180 \mathrm{~m}$ east-west and $85 \mathrm{~m}$ northsouth at an elevation of $1463 \mathrm{~m}$. Vegetation includes yucca, prickly pear and pedio cacti and mixed bunch grasses in a juniper scrub environment. Soils are dominated by light tan sandy loams.

Site 5 LA6763 is located on a long terrace or bench that overlooks a southern tributary to Welsh Canyon. The procurement area has an extensive scatter of quartzite cores and flakes in all stages of reduction. The flakes number in the thousands. Three possible hearths are located on the site as evidenced by dark stains on the soil. One coarse sandstone mano was found and hundreds of chert flakes and cores were included in the lithic materials on the site.

This site contains different material types and evidence of use over an extended period of time (long enough to have produced all the flakes and left the fire remains). If the site is not completely deflated, and eroded, test excavations could produce meaningful information.

\section{LA6764:}

The site is a rock shelter and lithic scatter in an area measuring $200 \mathrm{~m}$ EIW $\times 100 \mathrm{~m}$ NIS. The site elevation is $1414 \mathrm{~m}\left(4640^{\prime}\right)$. It is located in pinon/juniper scrubland with squaw bush, rhus trilobata, prickly pear, cholla, and mixed bunch grasses being the other on site vegetation. Soils are primarily light brown sandy loams.

The site contains a rock shelter located on a grassy bench just above the floor of Welsh Canyon. The lithic scatter extends onto the terrace/bench just above the shelter. The rock shelter measures $21 \mathrm{~m} \times 6 \mathrm{~m}$ and contains a bedrock metate with 6 grinding surfaces. There is a possible rock wall in front of the shelter and there are at least 2 hearths on the flat grassy area east of the rock shelter. The lithic scatter above the rock shelter measures $150 \mathrm{~m}$ EIW $\times 125 \mathrm{~m}$ NIS and contains hundreds of flakes of various quartzites in all stages of reduction. The aspect of the rock shelter is east.

This site is a good candidate for additional research. Intensive recording of the rock shelter, the bedrock metates, and the rock wall should take place and during the research a determination should be made as to whether test excavations would be meaningful. 
5LA6765:

The site is a lithic scatter measuring $355 \mathrm{~m}$ EIW $\times 80 \mathrm{~m}$ NS at an elevation of $1475 \mathrm{~m}$ $\left(4840^{\prime}\right)$. Vegetation on the site is juniper, prickly pear, cholla, and mountain mahogany. The soils are dominated by light brown silty sands.

The site is located in an area of rolling hills on a bench south of Welsh Canyon. The lithic scatter is sparsely dispersed over a very large area. Concentrations of quartzite debitage are found within the site area. Chert nodules, shatter, and flakes are also found on site. This material occurs at roughly the same elevation as other procurement sites on the opposite side of the wash.

\section{LA6766:}

The site is a lithic scatter covering about 1.78 acres at an elevation of $1408 \mathrm{~m}$ $\left(4620^{\prime}\right)$. It is located on a small hill or bench overlooking Welsh Canyon. Vegetation is dominated by juniper with prickly pear, yucca, and cholla also growing on the site. Soils include fine silty sands that range in color from red to grey.

Sparse lithics consisting of 20 quartzite flakes and a single mano were noted on the site surface. No other features were evident and no additional research is warranted for the site.

\section{LA6767:}

The site is a lithic scatter with an open camp measuring $160 \mathrm{~m}$ east-west and $132 \mathrm{~m}$ north-south at an elevation of $1530 \mathrm{~m}$. Vegetation on the site includes prickly pear, yucca and mixed bunch grasses in a juniper scrubland environment. The soils consist of light brown sands.

The site is located on a ridge that extends to the edge of the mesa and down the slope. The site area contains a general scatter of lithic debitage and deflated hearths and among this there are several pockets of lithic concentrations. At least eight soil stains exists on the site that provide evidence for possible hearths and four separate lithic concentrations exist with quartzite and chert predominating. On site collections include a rhyolite pestle, a projectile point, an obsidian biface, and a black chert nodule.

An historic component was also located on the site. Historic debitage included sardine and paint tin cans, a $44 \mathrm{mg}$. shell casing and milled lumber. The historic debitage was scattered within the prehistoric findings. The prehistoric component may be buried in some locations and worthy of additional investigation.

\section{LA6768:}

The site is a small rock shelter and lithic scatter within an area measuring $50 \mathrm{~m}$ NIS $x 40 \mathrm{~m}$ EIW. The site elevation is $1509 \mathrm{~m}$ (4950'). Its setting is in juniper scrubland with cholla and mixed bunch grasses also found on the site. The primary soils are brown, sandy loams. 
The site is located on a gentle slope on a bench along a side canyon of Welsh Canyon. It is just below the mesa top, with an east facing aspect. There are remnants of two hearths inside the shelter. Water erosion through the west side of the shelter is causing cultural debris to wash down stream. A metate fragment was found on the side of this eroded area. The field crews estimated there are hundreds of lithics on this site, which are dominated by quartzite and orthoquartzites. This is a site that will likely yield good information with additional research.

Metate Fragment $14 \mathrm{~cm} \times 13 \mathrm{~cm} \times 4.5 \mathrm{~cm}$

fine grain sandstone--

grinding surface--discoloration around edge suggests breaking by heat, smooth with no pecking.

\section{LA6769:}

The site is a lithic scatter and open camp site measuring $80 \mathrm{~m}$ EIW $\times 85 \mathrm{~m}$ NIS. It is at an elevation of $1524 \mathrm{~m}\left(5000^{\prime}\right)$ in a vegetative community of mainly juniper with rhus trilobata, and mountain mahogany among the other vegetation. The main soil consists of a brown sandy loam.

The site is located on a bench along a side canyon of Welsh Canyon. The lithic material is found on top of the bench, the slopes between and on to several adjacent benches. A prehistoric cultural material midden is located below the second terrace. It contains groundstone tools and hundreds of quartzite, orthoquartzite, and chert flakes. The midden also appears to contain the remains of several roasting pits. Cultural materials may be buried on this site and it may be possible to find them in test excavations.

\section{LA6770:}

The site is a rock shelter and lithic scatter in an area measuring $67 \mathrm{~m}$ NIS $\times 67 \mathrm{~m}$ EIW at an elevation of $1512 \mathrm{~m}\left(4960^{\prime}\right)$. The site is located in a upland juniper environment with scrub oak, rhus trilobata, grape vine, mountain mahogany, skunk bush, prickly pear, cholla, and mixed bunch grasses intermixed through the juniper. The soils are light brown, alluvial sands with some clay.

The site is located at the head of an un-named side canyon, which is a tributary to Welsh Canyon. It is just below a ridge, overlooking the canyon, which has eroded back into the mesa. The site is very complex with a rock shelter and lithic scatter combined with a number of features. The rock shelter measures $8 \mathrm{~m} \times 1.5 \mathrm{~m}$ with a north facing aspect. Inside the shelter there are nine tool grooves ground into the back wall, and a rock wall enclosing a cist. The cist measures $20 \mathrm{~cm} \times 35 \mathrm{~cm}$ in depth. There are charcoal stains in front of the shelter, and there is a rock art panel along the east wall of the shelter. The rock art panel measures $30 \mathrm{~cm} \times 15 \mathrm{~cm}$. The panel is very faint and difficult to record but it is clearly present. It contains zig-zag lines and other unidentifiable meanders and two incised holes. One secondary argillite flake, a quartzite core, and ten sandstone fragments of heat 
cracked stone were noted inside the rock shelter. The deposits might contain buried deposits. It should be test excavated.

The lithic scatter was concentrated around a small knoll southwest of the shelter, where the material is washing down slope to a small basin to the south. The lithic materials on the site are predominately quartzite, othoquartzite, and cherts in all stages of reduction. A mano was found on the west edge of the knoll. Made of a fine grained gray quartzite with striations and pecking, it measures $5 \mathrm{~cm} \times 7.5 \mathrm{~cm} \times 4 \mathrm{~cm}$.

\section{LA6771:}

The site is an open campsite with two components, a prehistoric lithic scatter and

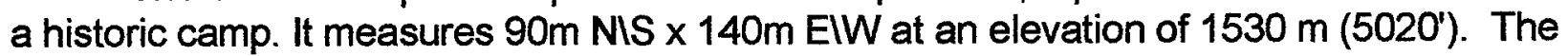
site environment is juniper scrubland with mountain mahogany, grapevine, yucca, prickly pear, cholla, and rhus trilobata also found growing on the site. The soils are light brown rocky sand.

The site location is on a mesa above the southeast ridge of an arm of Welsh Canyon. The prehistoric lithic scatter is sparse with a total of 18 flakes in the surface inventory. These included 6 quartzite flakes, 2 quartzite cores, a quartzite scraper, a fine grained granite mano and an argillite projectile point (collected). The site also contains a soil stain, which is possibly the remains of a hearth.

The historic component contains tin cans, glass, stoneware, ceramic, door knobs, milled lumber, auto windshield glass, a skillet, baking pans, buckets, barrel hoops, and bailing and barbed wire. There is a small intact log corral and the remains of a small milled lumber structure. The site appears to have been used sporadically over time as indicated by the time span of the artifacts found. The articles collected were a whiskey bottle with the neck broken off, a coffee can lid (MORADO COFFEE), a 22-caliber gun clip, and a 44caliber shell casing. The cultural material was photographed extensively and because there is little opportunity for buried remains, the site is not a good candidate for. further work.

\section{LA6772:}

The site is a small lithic scatter measuring $49.5 \mathrm{~m}$ NIS $\times 40 \mathrm{~m}$ EIW. The site elevation is $1494 \mathrm{~m}$ (4900'). It is in juniper scrubland with prickly pear, mountain mahogany, yucca, and mixed bunch grasses also growing on the site. The soil is primarily light brown sands.

The site is located on a ledge and down a steep slope from a ridge overlooking the juncture of two un-named tributaries of Welsh Canyon. It is on a generally rocky surface with bedrock exposure. but there are pockets of soil $15-20 \mathrm{~cm}$ in depth at places. No features were noted but a mano fragment was recorded. The lithic materials found were various quartzites and some green chert in various stages of reduction. There was one gray quartzite core and one tested cobble. The site soils are shallow and all information has been exhausted with its initial recording. 


\section{LA6773:}

The site is a small sparse lithic scatter measuring $20 \mathrm{~m}$ NIS $\times 22 \mathrm{~m}$ EIW. It is at an elevation of $1536 \mathrm{~m}\left(5040^{\prime}\right)$ in a vegetative zone of juniper, mountain mahogany, yucca, prickly pear, and mixed bunch grasses. The soils are primarily light brown sands.

The site is located on a rock slope of a northwest facing ridge on an un-named tributary of Welsh Canyon. Flakes and cores of a variety of materials are washing downslope toward the bottom of the canyon. The predominate material is quartzite in various colors although there was a single tested cobble of chalcedony in the inventory. A total of 24 lithic fragments were counted on the hillside. Because of the shallow deposition and steep slope the site is not a likely place to complete additional research.

\section{LA6774:}

The site is a lithic scatter and procurement area within an area that measures $82 \mathrm{~m}$ east-west and $65 \mathrm{~m}$ north-south at an elevation of $1542 \mathrm{~m}$. Vegetation includes mountain mahogany, yucca, cholla, and mixed bunch grasses in a juniper scrubland environment. The soil consists mainly of extremely rocky yellow sand.

The site is located on a slope at a point on an unnamed tributary of Welsh canyon; a low ridge separates two small drainages on the site. It consists largely of quartzite flakes that are scattered down the point of the ridge. The flakes are almost exclusively the same type of light grayish brown quartzite with a total of approximately 75 flakes in various stages of reduction. No depth was noted in the site deposits.

\section{LA6775:}

The site is a large lithic procurement area and scatter that measures $83 \mathrm{~m}$ east-west and $48 \mathrm{~m}$ north-south at an elevation of $1457 \mathrm{~m}$. The site vegetation includes mountain mahogany, side oats, cholla, and mixed bunch grasses in a juniper scrubland environment. Soils are light brown colluvial sands.

Quartzite is found in the sandstone outcrops on the site and the majority of flakes are white quartzite, presumably from this source. Many quartzite cobbles appear to have been tested for their quality and flakes, in all stages of reduction, are scattered about the site. No buried deposits are apparent on the site.

\section{LA6776:}

The site is a small lithic procurement area with an accompanying scatter of chipped stone detritus. It measures $18 \mathrm{~m}$ NIS $\times 13 \mathrm{~m}$ EIW at an elevation of $1546 \mathrm{~m}\left(4825^{\prime}\right)$. The vegetation is within the pinon/juniper with yucca, prickly pear, mountain mahogany, rue beaux, spider wort and mixed bunch grasses also growing on the site. Soil is light yellow sands with quartzite shatter throughout.

The site is located in an outcrop of quartzite on a bench and slope below O.V. Mesa. It is covered with tested cobbles, battered rocks and flakes in all stages of 
reduction. The quartzite material is gray, fine grained, and low quality. The site is small, and the material is of poor quality, and not a major source of lithic material.

\section{LA6777:}

The site is a lithic procurement area and lithic scatter that measures $50 \mathrm{~m}$ EIW and $95 \mathrm{~m}$ NIS. The site elevation is $1475 \mathrm{~m}$ (4840Ft.), and it is located in an environment of juniper scrubland with prickly pear cactus and mixed bunch grass vegetation. The soil is primarily light brown rocky sand and gravel.

Topography of the site includes a steep terrace located on an unnamed side canyon adjacent to O.V. Mesa. The slope contains small, tested chert nodules and flakes. Apparently the main chert outcrop is located further up the slope to the west. The chert found at this site is of four different types of color - gray, green, red, and brown, but the quality of the chert is not high as it contains inclusions and fractures. A random sample of chert was collected for future source analyses. It is doubtful that test excavation would uncover any intact areas for study.

\section{LA6778:}

The site is a lithic procurement area with its accompanying scatter within an area that measures $102 \mathrm{~m}$ EIW $\times 67 \mathrm{~m}$ NIS. It is at an elevation of $1493 \mathrm{~m}\left(4900^{\prime}\right)$ in a juniper scrubland with mountain mahogany, yucca, cholla, prickly pear, and mixed bunch grass also growing on the site. The soils are primarily light yellow sandy loams.

The site is on a narrow terrace above the canyon floor. The canyon is an un-named tributary of Welsh canyon. The site is located among a large outcrop of quartzite boulders. The quartzite is a light gray, fine grained, good flaking, high quality material. The site is literally covered with thousands of boulder/cores, tested cobbles, and flakes in all stages of reduction. Unfortunately the material is mainly on the surface and little could be learned through excavation.

\section{LA6779:}

The site is a small lithic scatter measuring $13.5 \mathrm{~m} \mathrm{NIS} \times 6.9 \mathrm{~m}$ EIW. At an elevation

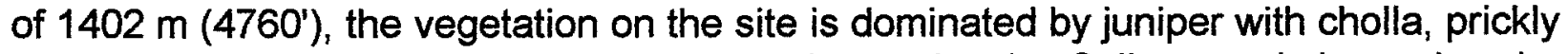
pear, snake bush, and mixed bunch grasses also on the site. Soils are pale brown in color and slightly sandy loams.

The site is located in Welsh Canyon on a finger terrace overlooking an un-named drainage where it is situated on the flat top of the first terrace at the bottom of Welsh Canyon. The site is small and contains a very light scatter of lithics. One core, three shatter flakes, two tertiary flakes, and one primary flake (all of white quartzite) and a tertiary argillite flake were noted on the site. This represents the total number of flakes located on the site. The site is small and on the surface. It is not a good candidate for additional research. 


\section{LA6780:}

The site is a lithic scatter measuring $28 \mathrm{~m}$ from north to south and $25 \mathrm{~m}$ from east to west. It is located at an elevation of $1524 \mathrm{~m}\left(5000^{\prime}\right)$ where it is nestled in a pinon/juniper grove. Yucca, cholla, prickly pear, and mixed bunch grasses also grow on the site. The soils are silty light brown sands.

The site is on the first terrace near the bottom of Welsh Canyon, overlooking a side drainage. It is set on a gentle slope below the sandstone outcrop and a little above the bench. About 50 flakes constitute the entire site complex. These are mainly quartzite, both light gray and gray/brown, with lesser numbers of white and orange chert. The flakes are in all stages of reduction; two cores and one tested cobble were also noted.

\section{LA6781:}

The site is a lithic procurement area with an accompanying scatter of surface debitage. It measures $65 \mathrm{~m}$ NIS $\times 35 \mathrm{~m}$ EIW at an elevation of $1494 \mathrm{~m}\left(4900^{\prime}\right)$. The site is located in a juniper vegetative zone with yucca, bushes, and mixed bunch grasses. The site is located on a terrace that faces northeast into an un-named tributary of Welsh Canyon.

The terrace is literally covered with quartzite boulders and cobbles that make up the cultural material on the site surface. Hundreds of flakes, cores, and tested cobbles in all stages of reduction were noted. The quartzite material ranges in color from white to pink to light and dark grey and although it is poor quality, it was utilized. Additional work on the site might produce information on the quarrying process, but the site has no obvious buried components and little opportunity for recovery of intact deposits.

\section{LA6782:}

The site is a lithic scatter measuring $120 \mathrm{~m}$ NIE $\times 80 \mathrm{~m}$ SIW at an elevation of $1463 \mathrm{~m}\left(4800^{\prime}\right)$. Vegetation on the site is primarily juniper with cholla, yucca, mountain mahogany, prickly pear, and mixed bunch grasses. The soils are light brown sandy loams.

The site is located along the top of a small knoll and down the slope to a ravine, directly above the junction of an un-named side canyon and the main drainage of a tributary to Welsh Canyon. The site exhibits an intense lithic scatter with pockets or concentrations of material. The lithics are exclusively quartzite in either grey or pink colors. The scatter consists of hundreds of flakes and cores in all stages of reduction, but no good buried deposits were noted.

\section{LA6783:}

The site exhibits a large concentration of lithics measuring $200 \mathrm{~m}$ NIW $\times 140 \mathrm{~m}$ EIW. It is at an elevation of $1402 \mathrm{~m}\left(4600^{\prime}\right)$, in juniper scrubland with prickly pear, sage, yucca, and mixed bunch grasses also growing on the site. Soils are red sandy loams. 
The site is on a flat, sandy bench with bedrock either on the surface or very near it because the soil depth is less than $20 \mathrm{~cm}$. The bench is located at the fork of Welsh Canyon, and one of its un-named tributaries and the site covers the entire point around the base where the two canyons meet. A large concentration of lithic materials in all stages of reduction are found on the surface of the site; the predominate material is quartzite in various shades of grey. There are four colors of cherts including white, grey, dark blue/grey, and brown. A single flake of petrified wood that had been heat treated was noted and a biface of red/yellow Jasper that had also been heat treated was recorded. While heat treated flakes are not unusual they are not common in Welsh Canyon. There were also argillite flakes on the site and an obsidian tertiary flake was collected. A projectile point base, made of red chalcedony, was also collected. The site appears to represent more than a single period of use and it is a possible site for further research. The degree to which the site is deflated needs to be explored.

\section{LA6784:}

The site is a lithic scatter/open camp, measuring $75 \mathrm{~m}$ NIS $\times 25 \mathrm{~m}$ EIW at an

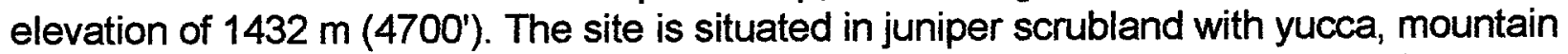
mahogany, three leaf sumac, and mixed bunch grasses also found on it. Soils are grey/brown sandy loams.

The site is on a terrace above a southwest facing slope directly above the Welsh Canyon drainage. Cultural material on the site consists of a flake scatter with four manos and four metate fragments. The site materials are concentrated on the slope where they are eroding into the Welsh Canyon drainage. Between 50 and 100 pieces of debitage are exposed with the groundstone artifacts. A dark soil stain, near the site datum, suggests a former area where habitation took place. Three of the manos and one metate fragment were found within 10 meters of this dark soil area.

The primary lithic flake material found was quartzite in various shades from light grey to grey/brown. The recorded sample included 32 flakes and two cores in various stages of reduction; there were also two white primary chert flakes in the sample. This site has potential for the recovery of buried cultural remains and it should be test excavated to learn if they could be located.

\section{LA6785:}

The site is a lithic scatter measuring $85 \mathrm{~m}$ NIS $\times 75 \mathrm{~m}$ EIW at an elevation of $1445 \mathrm{~m}$ (4740'). The site is in a pinon/juniper vegetation zone with yucca, mountain mahogany, prickly pear, and mixed bunch grasses as the other on site vegetation. The soils are mainly fine reddish sand.

The site is located on a sandy rise between a series of sandstone knobs that appear to be ancient lithified dunes to the northeast of Welsh Canyon. The site is in a side tributary of Welsh Canyon in a hilly area of ancient sand dunes. The present soils are 
eroding from the ancient dunes. The lithic scatter, eroding down slope from this sandy area, consisted of mostly grey quartzite flakes in various stages of reduction. Some white chert shatter and tertiary flakes were also found in the detritus. An obsidian biface was collected.

\section{LA6786:}

The site is a large lithic procurement area measuring $305 \mathrm{~m} \mathrm{NIS} \times 45 \mathrm{~m}$ EIW. It is at an elevation of $1439 \mathrm{~m}\left(4720^{\prime}\right)$ in a vegetative zone dominated by juniper. Prickly pear, yucca, mountain mahogany, gramma grass, thorn bush, and mixed bunch grass also grow on the site. The soil is mainly a light brown, very rocky sand loam.

The site is located on a finger ridge, which extends from 40 degrees east of north at the lower elevation to 220 degrees in the SW at the higher end of the slope. The site nearly extends into Welsh Canyon proper but not quite. It does extend across the two-track road into Welsh Canyon. The unmodified lithic material found on the site is a fine grained high quality quartzite and there are six concentrations of this quartzite in various colors found on the site. These may correspond to areas where it was quarried. One area of heavily eroded slope may have been dug out for the stone material. The quartzite outcrops are found across the site with some tool production and material reduction scattered generally over the entire site.

An area to the northeast of the site contains a mound of redeposited (by machinery) sediments, bearing cultural materials. The origin of this mound is likely from road improvements through the site area. No diagnostic artifacts were observed. Artifact density is estimated to be approximately 50-100 per sq. meter at some places on the site. Some flakes exhibit bipolar fractures. This site is a good candidate for studying the quarrying process in the region. There may be buried remains at the site, but additional research is needed to learn whether this is the case.

\section{LA6787:}

The site is a small lithic reduction area measuring $30 \mathrm{~m} \mathrm{NIS} \times 35 \mathrm{~m}$ EIW. Located at an elevation of $1487 \mathrm{~m}\left(4880^{\prime}\right)$, the site is in juniper scrubland with rue beaux, cholla, prickly pear, gramma and mixed bunch grasses also growing on it. The soils are dominated a light brown rocky sand. The site is located on a small terrace above the plain that makes up the bottom of Welsh Canyon. The terrace trends east toward the drainage and along its northern perimeter there is a small drainage basin, which empties directly into Welsh Canyon. A low ridgeline of hills is immediately south of the site.

The site is classified as a sparse lithic reduction site with 52 quartzite flakes in various stages of manufacture noted on its surface. Because of its close proximity to site 5LA (PC96047) $(80 \mathrm{~m})$ the site may be related to the latter but the site region needs additional surface reconnaissance to learn if it might be related to its neighbors. 


\section{LA6788:}

The site is a large lithic manufacturing area and possible camp site measuring $330 \mathrm{~m}$ NIS $\times 120 \mathrm{~m}$ EIW. It is at an elevation of $1420 \mathrm{~m}\left(4660^{\prime}\right)$ in juniper scrubland with rue beaus, prickly pear, and mixed bunch grasses also on it. The soils are a slightly sandy loam and eroded sandstone bedrock. The site is located west of Welsh Canyon on a long terrace that is bisected by a west to east trending drainage.

The surface of the site is covered with a variety of quartzites and cherts that are dominated by small flakes in all stage of reduction. Cores are small or exhausted but some may have been used as choppers or for other work where a small pointed tool was needed. Other tools include scrapers including well-made plano convex scrapers, bifaces, a possible awl, a mano, and a pestle-like stone. No diagnostic artifacts were recovered. At least one possible hearth was noted on the site.

The lithic materials found are predominately quartzites in various qualities and colors; white quartzites were more numerous than the other colors. Grey, brown and white cherts were also found on the site.

\section{LA6789:}

The site is a lithic scatter and production site measuring $130 \mathrm{~m}$ EIW $\times 70 \mathrm{~m}$ NIS. It is at an elevation of $1445 \mathrm{~m}\left(4740^{\prime}\right)$ in juniper scrubland with prickly pear, cholla, yucca, and mixed bunch grass also on the site. The soils are light brown rocky sands.

The site is located on the side of a hill that slopes toward a two-track road along its southwest side. The cultural material on the site consists of flakes and cores, with very few patterned tools. The material is quartzite with cores and flakes in all stages of reduction. A tested chert cobble and the tip of a projectile point (non-diagnostic) were found on the site. No obvious areas of buried material were noted and the site is not a good candidate for further research.

\section{LA6790:}

The site is a lithic scatter measuring $65 \mathrm{~m} \mathrm{NIS} \times 70 \mathrm{~m}$ EIW at an elevation of $1432 \mathrm{~m}$ $\left(4700^{\prime}\right)$. The site vegetative environment is juniper scrubland with prickly pear, pedro cacti, and mixed bunch grasses as the other on site vegetation. There is no soil the site surface because it is situated on the degraded sandstone caprock and has washed onto the rock talus underneath.

The site is a lithic scatter, which is eroding across the tilted bedrock that slants from east to west and onto the sandstone talus beneath the slope. The lithic materials observed on site were white, grey, and brown quartzite; blue and pink chert. A fragment of rhyolite tuff mano was also found. Less than 100 flakes are on the surface of the site. The proximity of bedrock at the site is such that additional research would not be worthwhile. 
5LA6791:

The site is a historical rock art panel measuring $20 \mathrm{~m} \times 1 \mathrm{~m}$. It is located in Welsh Canyon on a rock face adjacent to the main drainage bottom. The rock slab faces west about 11 meters north of the boundary fence.

The rock art is an older looking circle with two leg-like appendages that appear to have been added to it. Other pecking on the rock includes the historic words JUAN, A. JONIO, COPuuts, CARPIO, 101. The pecking is $55 \mathrm{~cm}$ above the ground level. It is apparently the work of cowboys or sheepherders and common throughout the region.

\section{LA6792:}

The site is a lithic scatter measuring $85 \mathrm{~m}$ north-south and $120 \mathrm{~m}$ east-west with an elevation of $1466 \mathrm{~m}$. On site vegetation includes yucca, prickly pear, and mixed bunch grasses in a vegetative community dominated by juniper. Soils are reddish brown silty sands. The site is located on a slightly sloping terrace directly above Welsh Canyon.

The predominate material identified on the site is quartzite in various hues, qualities and stages of reduction; two white chert flakes were also found. Fragments of two rhyolite tuff manos suggest the processing of plants at the site. This site does not appear to have sufficient depth for buried deposits and it is not worthy of additional research.

\section{LA6793:}

The site is a small lithic scatter measuring $20 \mathrm{~m} \mathrm{NIS} \times 30 \mathrm{~m}$ EIW at an elevation of $1389 \mathrm{~m}\left(4584^{\prime}\right)$. It is located in a pinon/juniper canyon environment with yucca and grass being the only other vegetation on the site. Soils are light brown silty sands with very high clay content. Gypsum deposits are weathering out at the surface. The site lies in a shallow depression on the second bench/terrace of Welsh Canyon at the center of a slight rise. It is near the mouth of a large side canyon, approximately 300 meters from the main Welsh Canyon drainage.

The lithic scatter consists of mostly light grey quartzite material, within an area approximately $6 \mathrm{~m} \times 2 \mathrm{~m}$. Only 19 flakes in various stages of reduction were noted on the surface of the site. The site does not meet any NRHP criteria and its information potential is exhausted by the initial recording.

\section{LA6794:}

The site is a small open campsite and cultural material scatter in an area about 750 square meters that is located on the western periphery of the Red Rocks Ranch compound. It is in the bottom of Red Rocks Canyon at the confluence of an un-named tributary where the main graveled road leads to the ranch. The site lies in a triangle created by the main road and a two-track leading west. The smaller road bisects the site.

Artifacts found at the site include less than 50 chipped stone flakes in various stages of production. The predominate material is quartzite and about $10 \%$ chert. A single 
argillite flake was found. Two of the flakes show use wear. A $5 \times 5 \mathrm{~m}$ concentration of heatcracked reddened sandstone covering a light stain suggest the remains of a hearth.

Although this site is still somewhat intact, it shows heavy impact from flood plain erosion as well as ranching activities. Its location between the two roads and the road maintenance disturbance has further damaged the site. With the road through it, the site will continue to suffer heavy impact.

The vegetation community surrounding the area is primarily juniper scrubland and grasses. It appears that the area including the site had been cleared in the past and planted with range grass. The aeolian and alluvial soil at the site is brown adobe clay mixed with organic material, and appears to be over $30 \mathrm{~cm}$ deep. Due to its location in a moderate to heavy use area and long disturbance history its research potential is extremely limited. Its potential has been exhausted by the recording process.

\section{LA6795:}

This site consists of a moderate density artifact scatter containing tools and groundstone within an area covering 1.12 acres. The site is set in lithified sand dunes and areas of loose sand overlooking Welsh Canyon to the west and a tributary to the north. The site is on the southwestern slope of a terrace on the canyon wall. The residual and colluvial soils are orange sands. Soil depth is $0-35 \mathrm{~cm}$. The site has a predominance of juniper trees, prickly pear, grasses and yucca. Several small water catchments that were holding water when the site was visited are located south of the site.

The site is a moderately disturbed open campsite representing a temporary occupation used for tool manufacturing. Analysis of a sample of the surface artifacts shows a mixture of quartzite and chert flakes in secondary and tertiary stages of production. Three pieces of different mano fragments are made of sandstone. A crude biface of grey argillite-like material may be a non-local material. Another biface fragment is a milky white chalcedony and although it is broken it may be part of a projectile point. A total of over 50 artifacts are estimated on the site. Deposition of cultural materials is unknown but is likely more than $10 \mathrm{~cm}$. The artifacts are concentrated in small pockets of deposition on crossbedded sandstone deposits. This site is likely to yield information concerning prehistoric occupation at this area of Welsh Canyon. It is a site that should be evaluated through test excavation.

\section{LA6796:}

A possible rock structure with a lithic artifact scatter and semi-circular stacked rocks are the main archaeological remains at this site. A small cluster of lithics is present immediately below and west of the rock wall and a hearth lies next to the wall. The sandstone wall runs north-south for about $3.15 \mathrm{~m}$ and it measures $1.5 \mathrm{~m}$ wide but several rocks are scattered down the slope, which may have originally been part of the wall (or perhaps another one). The associated hearth contains heat-altered stone and is roughly 
$40 \times 30 \mathrm{~cm}$. The entire site, which measures $15 \mathrm{~m}$ north-south and $10 \mathrm{~m}$ east-west, is found within on a sloping terrace facing west overlooking Welsh Canyon.

Vegetation at the site includes juniper, mountain mahogany, prickly pear, cholla and yucca in a juniper scrub environment.

Residual and colluvial soils are approximately $30 \mathrm{~cm}$ deep and the soils consist of fine sands that are a rust color.

Cultural material at the site includes a very small scatter of secondary and tertiary quartzite flakes and a very crude biface of pinkish gray chert. A total of eight lithic artifacts were observed on the surface. The derivation of the stone walls on this site is of uncertain origin and as a result the site is worthy of additional investigation.

\section{LA6797:}

A rock shelter and accompanying artifact scatter covers an 8.65 acre site on a cliff edge overlooking the southwest corner of a Welsh Canyon tributary. The sandstone shelter, which measures approximately $160 \mathrm{~m}$ across by an average of $10-12 \mathrm{~m}$ deep, is located in an alcove facing northwest $30 \mathrm{~m}$ above ancient sand dunes and flats. The artifacts spread west across the flats toward Welsh Canyon. The cultural material scatter begins about $100 \mathrm{~m}$ outside the shelter and density increases toward the shelter. The site is heavily eroded and artifacts are washing down a 45 degree angle slope in front of the shelter.

Juniper trees and rhus trilobata grow at the shelter entrance while grasses and prickly pear are found in the flat areas of the site. The surrounding juniper scrub community of plants also includes cholla.

Analysis of a sample of cultural material found in the shelter shows a preference for quartzite and quartz material used for flaking but a small amount of chert and basalt is also present. Two sandstone mano fragments indicate some food processing activities. Over 50 heat altered sandstone pieces mixed with ashy soil throughout the interior of the rock shelter suggest hearths or fire features, although they are no longer intact. Field crews believe the rock shelter may contain intact deposits and produce meaningful information through excavation.

\section{LA6798:}

This rock shelter measures $25 \mathrm{~m}$ long by $3 \mathrm{~m}$ wide along an axis that is oriented northeast/southwest in a cliff face overlooking Welsh Canyon. The entire site measures $27.5 \mathrm{~m}$ north/south by $35 \mathrm{~m}$ east/west, covering about 0.2 acres. The surrounding pinon-juniper scrubland vegetative environment includes grasses, cholla, and yucca. Soils at the site are made of red-brown sand approximately $25 \mathrm{~cm}$ deep at the datum. The site overlooks an ancient sand dune bed. 
The site consists of the rock shelter with a high density lithic scatter eroding onto the slope below it. Ashy fill and heat altered rock is present inside and immediately in front of the rock shelter suggesting it contains additional materials that are still intact. The diversity of artifacts includes mano fragments, hammerstones, a pottery sherd, a triangular side-notched point, and numerous chipped stone flakes. Ash and fire cracked rock suggest considerable roasting or cooking activities occurred at this site.

Over 500 artifacts are exposed on the ground surface at this site. Field analysis of a sample showed a variety of materials including several colors of quartzite and chert that were found in about equal amounts. A small bit of argillite flaking debris was also noted. Flakes in secondary and tertiary production stages were predominate, but several quartzite cores were noted. A reddish quartzite pestle/hammerstone was found in front of the shelter near a mano fragment.

A small whole triangular projectile point was collected from, about $20 \mathrm{~m}$ in front of the shelter. It is a pinkish-white mottled chert that measures $22 \mathrm{~mm}$ long by $12 \mathrm{~mm}$ at its widest point with side notches, an expanding stem and a straight bottom base. The ends of the tangs and a small part of the base are missing from the specimen. The size and style suggests an unknown late Ceramic Period cultural association.

Two small plain ware sherds were collected from directly in front of the shelter. They appear to be body sherds from separate vessels. One is from a bowl, while the other is from a larger object, perhaps a jar. Each was made from a different clay source. One has a reddish color, the other is a whitish material. It appears to be more eroded than the first but both retain cord pattern impressions on the outside and smooth interiors although not highly polished. A notable lack of temper material is noted in the paste, although there may be some very fine sand present. Both pieces have carbonized cores.

Over 100 heat altered sandstone fragments on the site suggests a food processing pit was used here. All artifacts were observed on the surface, but the soil depth and number of observable artifacts suggest a high probability of subsurface cultural material. This site is recommended for test excavation. It is likely to yield information important to the understanding of prehistoric occupation of the PCMS area.

\section{LA6799:}

This 0.55 acre site encloses the partial remains of a circular rock structure; an associated semi-circular wall; remains of two additional rock walls; and an extended lithic artifact scatter. The site extends northeast-southwest $74 \mathrm{~m}$ and east-west $30 \mathrm{~m}$. The site exists in a pinon-juniper vegetation zone at $4720 \mathrm{ft}$. elevation. Native grasses, pincushion cactus, juniper, mountain mahogany, and yucca predominate. The site sits on a point of land on a mesa top above ancient sand dune flats approximately $20 \mathrm{~m}$ below above the floor of Welsh Canyon. Soil is about $5-10 \mathrm{~cm}$ deep and is dominated by reddish brown sandy loams. 
The stone structures are all in good condition although the west side of the circular feature is missing. These remains measure about $3 \mathrm{~m}$ in diameter and it was likely originally room or dwelling area. A second feature is an arc of curved stone wall about $15 \mathrm{~m}$ long that is situated $15 \mathrm{~m}$ east of the circle. This may have been another room or a protecting wall. A lithic concentration lies in the surface between these features. Two additional rock alignments are to the southeast. The first lies $20 \mathrm{~m}$ from the circular feature. It is a wall that is two courses of rocks in width. Another feature is also a rock alignment, is about $7.5 \mathrm{~m}$ to the southeast.

A wide variety of chipped stone artifacts were observed at this site. Field analysis of a representative sample showed a strong preference for quartzite. The assemblage ranged from cores and core fragments through all stages of production to one finished projectile point, which was collected. There seems to be a nearly equal amount of primary, secondary, and tertiary flake debitage. In addition to quartzite, a small amount of chert and argillite was used at this site. A concentration of flakes was found between the circular features although a general scatter exists over the entire site.

The projectile point is made of a dark gray quartzite material. It measures $50 \mathrm{~mm}$ long and $24 \mathrm{~mm}$ at its widest by $4 \mathrm{~mm}$ thick. It appears unfinished on one side, but is deeply side notched $(3 \mathrm{~mm})$ on the finished side. The stem is expanding, the base is flat and one side is almost straight. The other side is slightly convex. The point is whole, with no indication of damage. The edges show use wear. The straight edge may have been retouched at some time, which resulted in the loss of the tang on that side. No other diagnostic artifacts were observed on the surface at the time of the survey.

Site 5LA6799 appears to be the remnants of a prehistoric habitation, where tool production occurred. It is a high quality site with excellent potential for research into problems related to the Ceramic Period in the region.

\section{LA6800:}

This site lies on a mesa above an unnamed tributary east of Welsh Canyon near the edge of a ridge that contains a white quartzite outcrop. The elevation is $4800 \mathrm{ft}$. The quartzite outcrop was used as a source to obtain raw material for tool manufacture and it is the most important feature on the site.

The pinon-juniper vegetation zone around the site is augmented by mountain mahogany, yucca and grasses within the site area itself. The soil surrounding the quartzite outcrop is tan, sandy loam, about $5 \mathrm{~cm}$ deep.

The lithic scatter covers about 300 square meters and it measures $20 \mathrm{~m}$ north-south by $15 \mathrm{~m}$ east-west. A sample analysis of the material showed about equal amounts of secondary and tertiary flakes, and shatter. There was a general paucity of primary flakes 
on the ground surface. This may indicate that larger flakes were reduced to blanks at the site before transport. There are approximately 50 flakes total at the site. No diagnostic artifacts were found at the time of this visit. The research potential at this site is limited. The deposition is shallow and subsurface deposits are unlikely, However, the remaining artifacts may provide some research data about quarry technology and raw material reduction.

\section{LA6801:}

This open campsite, on a slope above Welsh Canyon, contains a lithic scatter that is oriented generally southwest between a two-track road and a small drainage. It measures about $75 \mathrm{~m} \times 65 \mathrm{~m}$ in an area of about 1.2 acres. The site is in a pinon-juniper vegetative community at $4820 \mathrm{ft}$. elevation. Predominant plants include juniper, yucca, pinon, prickly pear, cholla, and grasses. Soils are at least $10 \mathrm{~cm}$ deep and are organic/tan sandy silts.

The site is located on an open slope bounded by two drainages. The total assemblage is approximately 75 quartzite and chert flakes. A quartzite mano was noted near the center of the site where it is near the datum. Two bifacial cutting tools and an end scraper were also noted on the site. Lithic concentrations are clustered almost in a straight line down the slope through the middle the site. A field analysis of about $10 \%$ of the assemblage revealed both chert and quartzite flakes in all stages of reduction, however no cores were noted.

Activities inferred from cultural remains at 5LA801 indicate food processing and tool manufacture from materials carried in from other locations. Sub-surface deposits seem unlikely, as the soil is shallow at this location. The site could yield information important to prehistoric lifeways in the area but it is not a good choice for test excavations.

\section{LA6802:}

This small rock shelter is located on the slope of the south wall of an upper branch to Red Rocks Canyon. It faces northwest overlooking an erosional drainage along the canyon floor. Vegetation on the site is predominately rhus tribolata and grasses. The surrounding area is a mixture of riparian and desert scrub vegetation. Soils in the alcove are a blend of grey sand and gravel of undetermined depth.

The shallow alcove at $4960 \mathrm{ft}$. elevation measures $6.6 \mathrm{~m}$ northeast by $2.3 \mathrm{~m}$ southwest for a total of about $15 \mathrm{sq}$. $\mathrm{m}$. It contains fire-cracked rock and charcoal. An associated light stain was too indistinct to be measurable, but may indicate the presence of a hearth. Dense vegetation on the slope in front of the shelter probably obscures more material. An extremely large packrat midden inside the shelter covers some of the space and it may obscure cultural items. 
Only one artifact was found at this site--a quartzite projectile point. It is triangular shaped with side notches and a concave base. Due to the lack of good soil deposition, excavations in this sheltered area might not be productive.

\section{LA6803:}

Hundreds of tested quartzite cobbles and primary flakes found at this site indicate it served as a small procurement and primary lithic reduction area. It measures $36 \mathrm{~m}$ northwest-south by $24 \mathrm{~m}$ north-south. The site elevation is $5000 \mathrm{ft}$ where it is situated in a juniper scrub environmental zone. Juniper, rhus triboa, yucca, grama, and prickly pear predominate. The soil consists of light brown sandy loam about $10 \mathrm{~cm}$ deep. The site is on the flat headlands of a tributary southwest off Welsh Canyon that is just east of a promontory locally known as Lookout Point.

All cultural material found here is quartzite. Some is taken from bedrock exposed within the site boundaries. Other quartzite was apparently imported but that is not a certainty. A grab sample of cultural material showed primary and secondary reduction flakes. Total numbers of artifacts are estimated in the hundreds but no diagnostic pieces were noted, nor did field crews find any buried cultural material.

\section{LA6804:}

This small $37 \mathrm{~m}$ by $10 \mathrm{~m}$ lithic scatter lies on the valley floor at the confluence of a branch tributary of Red Rocks Canyon, about $400 \mathrm{~m}$ south of Red Rocks Ranch. Elevation is $4840 \mathrm{ft}$ and the site lies on the southern slope beneath a bluff. Vegetation along this flood plain environment includes range grasses, a few sparse junipers, rabbitbush, prickly pear, and cholla. Soils are deep at the drainage and are as deep as $15 \mathrm{~cm}$ at the site. They consist of light yellow sandy loams. The site is in fair condition as the artifacts are eroding slowly downslope into the arroyo.

About 25 percent of the lithic artifacts were field analyzed from a total of about 200 artifacts. All are made of quartzite material, appearing in mostly secondary and tertiary production stages. One tool, a burin, is included in the assemblage. This lithic and tool production site could provide limited research information about settlement and subsistence patterns in the area.

\section{LA6805:}

The site is a small rockshelter habitation site measuring $13.5 \mathrm{~m}$ north-south by 11 $m$ east-west. It is located in a juniper/canyon environment with rhus tribolata and grasses being the dominant vegetation. The soils are dark brown sandy loams with a depth of 20 $\mathrm{cm}$ in the back of the shelter.

The site is located on a west facing bench of an unnamed side canyon of Red Rocks Canyon. The rock shelter has a hearth in the back containing charcoal, which may be datable. There are rock alignments inside the shelter, which appear to be wall remnants. There were 10 flakes total counted inside the shelter - five dark brown quartzite 
tertiary flakes, 1 argillite secondary flake, one tan quartzite tertiary flake, one mottled banded tertiary flake, one mottled gray chert biface, one light gray banded chert tertiary flake, and one gray quartzite primary flake. No lithics were diagnostic and none were collected. The site has been disturbed by water running through the center during rain, roof fall and animal burrowing.

An area of bedrock at the south end of the site may have been used as a grinding surface but this is difficult to establish as the surface is extremely exfoliated. There is a possibility that petroglyphs are also present in this area, but again, the condition of the rock surface is very poor. This site is worth additional investigation.

\section{LA6806:}

The site is a rock shelter and lithic scatter in an area measuring $75 \mathrm{~m} \mathrm{ENX} 45 \mathrm{~m}$ $\mathrm{N} / \mathrm{S}$. At an elevation of $1450 \mathrm{~m}\left(4760^{\prime}\right)$, the site is located in a pinon/juniper environment with squaw bush, skunk bush, sunflower, prickly pear, bladder warts and pedio cacti also on the site. The soils are a red sandy residual loam.

The main feature on the site is a rock shelter located on a bench in an un-named side canyon of Welsh canyon, directly above the wash. It is situated in an area of ancient aeolian dune, and the soil is bright red residual sand. The shelter has a southwest facing aspect. Although it is identified as a rock shelter, it is not a good one because there are no overhangs or crawl spaces. The rocks actually serve more as a windbreak rather than an overhang. There are two hearths located up near the base of the bluffs and lithic materials are eroding down the slope toward the wash.

The lithic material consists of quartzite. A total of about 100 flakes were noted on the site; these contain seven tertiary flakes, an exhausted core, and one reworked chert biface. A quartzite mano was also found on the site. The sheltered area between the rocks on this site appears to contain buried remains and good potential for excavation in the sandy soils.

\section{LA6807:}

The site is a lithic scatter and open camp measuring $40 \mathrm{~m}$ EIW $\times 50 \mathrm{~m}$ NIS at an elevation of $1456 \mathrm{~m}\left(4780^{\prime}\right)$. The site is in a juniper scrubland with pinon, yucca, prickly pear, and mixed bunch

grasses also growing on the site. Soils are light brown sandy aeolian deposits mixed with gravels and at least $10 \mathrm{~cm}$ of depth.

The site is located on the top of mesa finger ridge, off of an un-named tributary of Welsh Canyon. The cultural remains on the site are lithics in an open camp setting. The evaluated sample, which was extrapolated from hundreds of flakes, is almost exclusively a very high quality mottled orange and white chert. The site is definitely a tool production area. A large exceptionally well-made biface was found on the west side of the site, but 
there were no diagnostic artifacts found and nothing was collected. If the chert found on this site is local then we have not discovered its source in the region. There appears to be too much for it to be a trade item or from some distant source. The site is worth additional research, if only to try to learn the origin of the chipped stone material.

\section{LA6808:}

The site is a small rock shelter/windbreak measuring $69 \mathrm{~m}$ NIS $\times 42 \mathrm{~m}$ EIW. It is at an elevation of $1444 \mathrm{~m}\left(4740^{\prime}\right)$, in a vegetative zone that is juniper scrubland with squaw bush, prickly pear, cholla, yucca and mixed bunch grass. Soils are light brown sandy loams.

The site is a very small rock shelter, more of a windbreak type setting, in an area approximately $36 \mathrm{~m}$ long with a southeast facing aspect. Lithic materials are eroding down the slope toward the wash. Above the rock shelter and directly behind it there is a small grassy depression with a large soil stain and lithics throughout. This dark area appears to be more than a normal hearth and may be a roasting pit area. Behind the soil stained area is another line of rock boulders that could have also served as a windbreak. The lithic materials include hundreds of flakes and cores in various stages of reduction. The predominate material is quartzite in either a light grey or dark grey color, but there are also examples of white chert, jasper, mottled dark grey chert, and grey/green chert. All the materials appear to be local in origin. No diagnostic tools were found on the site. This site should be evaluated for future research.

\section{LA6809:}

The lithic scatter at this site runs east-west $90 \mathrm{~m}$ by north-south $35 \mathrm{~m}$. within an area of .78 acres. It is on a peninsula-like terrace at $4554 \mathrm{ft}$. elevation overlooking and crossing an UN-named drainage that empties into Welsh Canyon from the northeast. Vegetation on the site includes yucca, gramma grass, juniper, prickly pear, cholla, rhus, and young cottonwoods. This wetter community is at the bottom of a drainage where it is surrounded by juniper scrubland on the higher levels. Soils are mostly water borne gravel, mixed with brown sand and clay for a depth of at least $10 \mathrm{~cm}$. A stone and juniper drift fence borders the drainage.

Hundreds of chipped stone flakes cover the site with one dense concentration near the center of the top of the ridge-shaped peninsula including abundant quartzite, with lesser amounts of chert, chalcedony, and a few basalt flakes. A sample analysis suggests mostly tertiary flakes indicating the site is an area where the final stages of tools production and modification took place. Two cores, a utilized flake, and a biface were found in the assemblage. A segment of a fossil bone, identified as Pal-6, was collected on the site.

Site 5LA6809 is a surface scatter that is slowly eroding down the bank of the drainage that runs through it. There may be some cultural material under the surface that was covered by bank overflow during flood periods. 


\section{LA6810:}

This site is a large lithic scatter that lies on a terrace in a clearing between two drainages overlooking an unnamed tributary of Welsh Canyon. It covers $125 \mathrm{~m}$ east-west by $60 \mathrm{~m}$ north-south for a total of 1.85 acres at $4760 \mathrm{ft}$ elevation. The surrounding vegetative community is a mixture of pinon-juniper with mountain mahogany, yucca, prickly pear, cholla and grasses. A few cottonwood trees are interspersed. Soil is up to $10 \mathrm{~cm}$ deep and consists mainly of red, sandy loams.

The chipped stone artifacts that make up this site are primarily quartzite flakes in all stages of production. A very small amount of chert is also present. Quartzite cores, and some shatter was noted and at least one quartzite flake tool had evidence of use wear. This location was probably used as a tool production and maintenance site, based on the type and amount of materials in the assemblage. This site may yield additional data that would lead to a better understanding of the life ways of prehistoric inhabitants in the PCMS region.

\section{LA6811:}

This site is another large lithic scatter similar to others found nearby in the Welsh Canyon complex, It covers an area of 2.16 acres and measures $125 \mathrm{~m}$ NIS $\times 70 \mathrm{~m}$ EIW at $4660 \mathrm{ft}$. elevation. The site is located on the slope of a small hill overlooking Welsh Canyon to the west. Yucca, juniper, prickly pear, mountain mahogany, and grasses predominate within the juniper vegetative community at the site. Two small washes passing through the edges of the site ultimately join a larger drainage to the east.

Artifacts are dispersed randomly over the ground surface of the site, but more dense concentrations were noted at four locations. The assemblage includes quartzite flakes and tested cobbles. Among the flakes, primary are most numerous. A small amount of chert shatter and chipped stone debris is present. The site was likely used for stone tool manufacture and although this site could yield information concerning tool production from raw material, it is duplicated by many others with better deposition and greater opportunity for study.

\section{LA6812:}

Site 5LA6812 is a small lithic and artifact scatter located near a large sandstone outcrop that is situated on a slope overlooking an unnamed tributary that drains into Welsh Canyon. Other nearby sites are probably all interrelated to with this one.

The site covers a small area $35 \mathrm{~m}$ by $15 \mathrm{~m}$ running north-south between the base of a cliff and a $6 \mathrm{mt}$ drop off that continues down the terrace slope. Soils are very shallow, occurring only where there are clumps of vegetation. Most of the site is on bedrock and the only soils are sparse sandy loams that are less than $5 \mathrm{~cm}$ deep. The juniper scrubland community supports a few juniper bushes and rhus tribolata, with the usual prickly pear, yucca, and cholla. 
Heat-cracked, reddened sandstone cobbles scattered throughout the site suggest deflated hearths but any stain, ash, or charcoal has been washed away from the bedrock by erosion. Several sandstone spheres measuring up to $5 \mathrm{~cm}$ diameter are scattered throughout the site but they are not readily identifiable as cultural artifacts. Nonetheless other nearby sites do not contain these particular sandstone spheres and they may have been collected at this site for an unknown reason. Site 5 LA6812 is a scenic, and interesting site, but probably does not meet National Register qualifications at present because it does not have any buried deposits. Further investigation might yield more data concerning settlement and subsistence patterns but the site is not a high priority.

\section{LA6813:}

The large lithic scatter represented at this site covers an area $98 \mathrm{~m}$ east-west by $63 \mathrm{~m}$ north-south and contains 1.53 acres. It is located at $5160 \mathrm{ft}$ elevation on an unnamed tributary east of Weish Canyon. Artifacts are eroding from two southeast facing rock shelters that are situated under the canyon rim.

Vegetation at the site contains a riparian community at the drainage bottom while the more typical juniper scrub continues upslope to the rock shelter. Artifacts are eroding down slope from the rock shelters, and across a shallow drainage to the south. The site continues south across the PCMS boundary fence a short distance, about $5 \mathrm{~m}$. Two areas of artifact density are apparent in the surface exposures.

The lithic assemblage includes a range of local lithic material fashioned into several types of tools and manufacturing debitage. Field analysis of a representative sample showed a high percentage of secondary and tertiary flakes. The preferred material was quartzite, with some chert also utilized. A small amount of basalt and siltstone was observed. The total number of artifacts is estimated to be in the thousands. Utilized flakes are common. Other tools include a quartzite knife blade, several choppers, and additional unifaces and bifaces. There is a notable lack of cores found at this location.

The shelters hold no cultural material on the interior floor surfaces, but deposition is deep, probably at least $30 \mathrm{~cm}$ that may contain subsurface cultural material. Large rodent middens and roof fall probably obscure some of the cultural deposits.

\section{LA6814: (Red Rocks)}

The site includes a rock shelter/alcove with a rock art panel inside and an accompanying lithic scatter down the slope in front of it. The entire site, which covers an area approximately $25 \mathrm{~m}$ north-south by $18 \mathrm{~m}$ east-west, is located on a south-facing slope of an unnamed east-west tributary of Red Rock Canyon. The soils are gray-brown sandy silts that range to about $10 \mathrm{~cm}$ deep. Some grasses are growing in the shelter and there is prickly pear and juniper growing down the slope in front of the shelter. The surrounding area is a juniper scrubland community. 
The rock shelter measures $7 \mathrm{~m}$ across the back and $2.5 \mathrm{~m}$ at the opening. A rock wall containing an historic fence post stretches across the face of the overhang about 2 or 3 meters in front of the shelter. The rock art pictograph panel features four distinct elements. The figures appear to be quadrupeds with exaggerated long legs. The images are on a sandstone base created with black paint, which may be charcoal based. The entire panel measures $60 \mathrm{~cm}$ long by $38 \mathrm{~cm}$ high and faces southeast at 82 degrees. No cultural artifacts were found inside the shelter.

The lithic scatter, found directly in front of the alcove, consists of quartzite and chert flakes in all stages of production. No diagnostic artifacts were found and no collections were made.

This site could yield important information on prehistoric cultures in the area. It is eligible for National Register nomination under criteria $D$, research potential.

\section{LA6815: (Red Rocks)}

The site includes a rock shelter and lithic scatter measuring $80 \mathrm{~m}$ east-west by 57 $\mathrm{m}$ north-south. The site is situated within a side canyon to Red Rocks Canyon in a mixed pinon-juniper and riparian habitat. Rhus tribolata, cholla, and mixed bunch grasses are the dominant vegetation on the site. The site elevation is $1463 \mathrm{~m}$ (4828').

The rock shelter has an associated lithic scatter that extends down to an arroyo on a 2 percent slope. The lithics are a moderately dense scatter of chipped stone debris along the flood plain of a branch of Red Rocks Canyon. Several small rock overhangs are located along the edge of the scatter and evidence for habitation (bedrock metate, lithics) was identified in the largest overhang. Tools observed at the site include a stemmed projectile point that appears to be reworked; a basalt uniface, a quartzite biface, and a couple of utilized flakes. The site has relatively dense vegetation and surface visibility was restricted.

The southern boundary of the site is defined by a wash and a large vertebrate femur (possibly bison) was observed $65 \mathrm{~cm}$ below the ground surface. No artifacts were observed in this cut bank. The site is on a terrace that has two meters or more deposition, and it is possible that the site is multi-component and/or has $50 \mathrm{~cm}$ plus of deposition on it. Site 5LA6814, described above, is located roughly $40 \mathrm{~m}$ from the eastern boundary of this site.

There were a total of 75 lithic artifacts counted on the site. Of the random sample taken there were 11 gray quartzite tertiary flakes, 6 gray quartzite secondary flakes, 7 reddish quartzite shatters, 3 reddish-white chert tertiary flakes, a secondary obsidian flake, a basalt tertiary flake, 2 gray quartzite utilized flakes, a basalt uniface, a crude banded red and white quartzite biface, and one stemmed jasper projectile point (reworked) which was collected. 
5LA6815 meets qualification for eligibility in the National Register of Historic Places, under criteria D. Further research is recommended.

\section{LA6816: (Red Rocks)}

This lithic scatter measures $104 \mathrm{~m}$ east-west $\times 26 \mathrm{~m}$ north-south at an elevation of $1569 \mathrm{~m}$ (4920'). The vegetation includes pinon-juniper with cholla, prickly pear, yucca, rye grass, and mixed bunch grasses. Soils are light-brown silty sand.

The site, directly adjacent to the drainage/wash at the bottom of Red Rocks Canyon, is situated on the north bank of the drainage and within view of the Red Rocks ranch house. The site contains a very dense concentration of lithics with quartzite in various colors and stages of reduction being almost the exclusive material type. There was one primary flake of pink chert in our extrapolated sample of hundreds of flakes.

The site may have intact buried deposits and it would probably produce meaningful information through excavation. It meets National Register criteria and it should be useful in providing further information on the prehistory of the area.

\section{LA6817: (Red Rocks)}

The site is a lithic scatter measuring $58 \mathrm{~m}$ north-south by $42 \mathrm{~m}$ east-west at an elevation of $1506 \mathrm{~m}$ (4940 ft). It is located in pinon-juniper vegetative zone with thyme, prickly pear, cholla, yucca, and mixed bunch grasses also growing on the site. Soils are light brown sandy clays. The site is located on the top of the ridges above Red Rock Canyon just west of Red Rocks Ranch road. It consists of a very low density scatter of lithics.

A recent (less than 5 years) excavation is located on the site. This disturbance is rectangular and 1 by $3 \mathrm{~m}$ in dimensions. The contents of the excavation are in a linear pile with larger rocks separated into a separate pile. These observations are consistent with an archaeological test excavation that was not back-filled, but no known research has been reported for this site. An isolated side scraper was found to the south of the site.

The site area has the highest density of flakes observed in across the uplands in this quarter section. The total number of lithics on the site consists of: two reddish brown quartzite tertiary flakes, a basalt core fragment, a basalt primary flake, a quartz primary flake, a reddish brown quartzite utilized flake (secondary flake) a dark gray quartzite tertiary flake, a basalt tertiary flake (utilized). This site does not warrant additional research.

\section{LA6818:}

The site contains a rock shelter and lithic scatter within an area measuring $50 \mathrm{~m}$ southeast by $40 \mathrm{~m}$ northwest. The site elevation is $1509 \mathrm{~m}$ ( $4980 \mathrm{ft}$ ). Vegetation on the site is juniper with mountain mahogany, cholla, yucca, prickly pear and mixed bunch grasses. Soils are a light brown sandy loam intermixed with sandstone cobbles. 
The site is located on a terrace that slopes down toward a drainage in an unnamed side canyon of Welsh Canyon. The utilized rock shelter faces southeast above a north-south drainage and a light lithic scatter extends down the steep grassy slope toward the drainage bottom. The shelter is shallow, but there is a well-developed sandstone ledge in front of it with a lithic concentration. Located just off the site on the east and west sides are areas of soft dirt suggesting the locations of possible middens.

The lithic sample is an extrapolation of approximately $50 \%$ of the total surface lithics. The predominate material is quartzite in all stages of reduction. There were also small numbers of chert retouched flakes and a tertiary basalt flake. Test excavations at the site might produce intact cultural deposits in the areas along the front of the rock shelter.

\section{LA6819:}

The site is a small lithic procurement area measuring $11 \mathrm{~m}$ north-south by $25 \mathrm{~m}$ east-west at an elevation of $1524 \mathrm{~m}$ (5000 ft). Its environmental setting is pinon-juniper with mountain mahogany, cholla, prickly pear, and mixed bunch grasses as the other on-site vegetation. Soils are dominated by light brown sandy loams.

The site is located on a small knoll (hill) that is situated on a terrace/bench overlooking the bottom of an unnamed side canyon to Welsh Canyon. The lithics include many chert nodules and tested cobbles, which are weathering out of the site. A very sparse flake scatter is washing down the slope. Two fire-cracked rock concentrations suggest a possible campsite. Of the total number of lithics counted on site 14 were chert flakes, 8 chert cores, one chert shatter, one tested chert cobble, and one quartzite primary flake.

The site is shallow and probably does not contain intact cultural remains. Because of the paucity of lithic materials the site is not recommended for any additional research. It information potential has been exhausted through the initial recording.

\section{LA6820:}

This 10,080 square meter lithic scatter measures $140 \mathrm{~m}$ north-south by $72 \mathrm{~m}$ eastwest over an area encompassing 2.49 acres. It is located on a hilltop and slope overlooking Welsh Canyon from the east. On-site vegetation consists of juniper, yucca, tuff grass, bunch grasses and desert daisy in a typical juniper scrubland setting. Soils consist of light brown sandy loams approximately $10 \mathrm{~cm}$ deep. The artifact assemblage is made up of quartzite and chert lithic material, in all phases of tool production, but no formal tools were recognized. A coarse quartzite gastrolith appeared to have been knapped, or tested. The total number of artifacts is in the thousands.

The site is characterized as a generally undisturbed lithic procurement area, with raw material reduction performed on-site. This production site could yield important data concerning prehistoric quarries, material use and lithic technology. No good intact areas for the recovery of subsurface cultural remains were evident and the site would have to be 
more carefully evaluated before implementing any controlled excavation or site sampling strategy.

\section{LA6821:}

The site is a lithic scatter measuring $70 \mathrm{~m}$ east-west by $30 \mathrm{~m}$ north-south at an elevation of $4947 \mathrm{ft}$. The site vegetation is juniper with cholla, yucca, prickly pear and mixed bunch grasses. Soils are rocky brownish-gray sandy loams.

This area is on a gently sloping terrace/bench of a southwest to northeast trending arm of Welsh Canyon. The site is located between 5LA6819, which is approximately 75 $\mathrm{m}$ above and $8 \mathrm{~m}$ east; and $5 \mathrm{~L} \mu 6820$ which is located approximately $35 \mathrm{~m}$ west-southwest, on the edge of the terrace/bench. The site consists of many cobbles and shatter from poor quality chert and quartzite flakes in the primary and secondary stages. A random sample was extrapolated from hundreds of flakes but there were no diagnostic tools found and no collection was taken. The site is deflated and has no subsurface potential for containing subsurface artifacts.

\section{LA6822:}

The site is a lithic scatter measuring $30 \mathrm{~m}$ east-west by $45 \mathrm{~m}$ north-south at 5410 feet elevation. Vegetation is juniper with prickly pear, cholla, yucca, and bunch grasses. The predominant soil is a rock brown sandy loam.

The site is located on a hillside between two terraces within a north-south trending unnamed tributary of Welsh Canyon. It is approximately $30-45 \mathrm{~m}$ from the top of the first elevated terrace down a 20 degree slope to the drainage. Mostly chert flakes in green, blue and red in all stages of reduction and a little quartzite are found on the surface of the site. There do not appear to be areas where excavations would uncover intact cultural remains.

\section{LA6823:}

The site is a lithic scatter measuring $38 \mathrm{~m}$ east-west by 20 meters north-south. Its site elevation is 4840 feet. Vegetation is dominated by juniper with yucca, prickly pear, sage, forbs and mixed bunch grasses also growing on the site. The soil is a light brown sandy loam. The site is located on a gently slope on the second terrace above Welsh Canyon.

Cultural materials on the site consist of a quartzite scatter of lithics in all stages of reduction. No formal tools, no diagnostic artifacts were noted and no collections were made. The site is not a good candidate for further research.

\section{LA6824:}

The site is a small lithic scatter measuring 25 m east-west by $20 \mathrm{~m}$ north-south that is located at 4744 feet in elevation. It is set in pinon /juniper with yucca, cholla, prickly pear, thyme, and mixed bunch grass also growing on the site. The primary soils are light 
brown silty sands. The site is located on the top of a bench close to a drop-off above the drainage. The site is adjacent to an unnamed wash in the bottom of an unnamed tributary of Welsh Canyon.

Cultural material on the site consists of approximately 30 lithic fragments in a small cluster. The predominate material was quartzite ( 26 flakes) in all stages of reduction. No diagnostic artifacts were identified and no site collection was made. The rock shelter at site 5 LA6837 is located immediately across the wash from this site. No additional work is recommended for the site.

\section{LA6825:}

This site includes a rock shelter $(50 \mathrm{~m}$ by $55 \mathrm{~m})$ and lithic scatter that covers approximately one-half acre. It is situated at $4680 \mathrm{ft}$ elevation to the north of a tributary off the west side of Welsh Canyon. The site is on a steep slope surrounded by juniper bushes, rhus tribolata and bunch grasses. Soils are about $10 \mathrm{~cm}$ deep and predominantly red sandy loams. The site has moderate disturbance from water run off over the caprock; this water is washing through the rock shelter. It also has had moderate disturbance by animal burrowing activity--possibly badgers. Back dirt from these holes contains charcoal, indicating the possibility of subsurface cultural deposits.

The site faces southeast at a point about $50 \mathrm{ft}$ above the canyon floor. Two hearths occur near the rock face near the back of the shelter. Field analysis of 16 artifacts represents all the exposed surface materials. The flakes are in all stages of production. Four are a bluish chert and the remainder is quartzite. Two quartzite cores and a biface tool are present in the assemblage. Although only surface artifacts were observed, approximately $50 \mathrm{~cm}$ of deposition is estimated and the presence of subsurface cultural material is highly likely.

Site 5LA6825 meets the standards for inclusion on the National Register. It is likely to yield information important to better understand settlement and subsistence patterns in the area of PCMS and the southeastern Colorado region.

\section{LA6826:}

The site includes a rock shelter that is located on the north side of a tributary canyon east of Welsh Canyon. The entire site measures $65 \mathrm{~m}$ north-south by $45 \mathrm{~m}$ eastwest for a total of 0.7 acres. It is at $4800 \mathrm{ft}(1463 \mathrm{~m})$ elevation. Vegetation on the site is juniper, bunch grasses, prickly pear, and cholla, in a general area of juniper scrub. The soils are sandy and slightly silty with a depth of about $30 \mathrm{~cm}$. The site has moderate disturbance from animal activity, probably badger holes, but it is otherwise in excellent condition.

The main part of the site, the rock shelter, is just below the rim rock in front of a sandstone face. A charcoal stain and disturbed area lies directly in front of the shelter and measures about 30 by $20 \mathrm{~m}$. Artifacts include two mano fragments (quartzite and sandstone), a variety of quartzite flakes, and a chert core. A corner notched argillite 
projectile point was collected. This rock shelter was undoubtedly used as a habitation site. Based on the size and style of the projectile point, this activity may have taken place sometime in the Late Archaic, between 1000 B.C. and A. D. 200 (Loendorf, et al. 1996). The site is a good candidate for additional research.

\section{LA6827:}

This primary feature at the site is rock shelter that is well-protected from the prevailing winds. Located on the slope of a bench near the bottom of an unnamed side drainage to Welsh Canyon, the site measures $85 \mathrm{~m}$ east-west by $35 \mathrm{~m}$ north-south, covering 0.5 acres. It faces south at $4700 \mathrm{ft}$ elevation in a juniper/grassland vegetation zone where Rhus tribolata, juniper, prickly pear, cholla, mixed bunch grasses, and yucca are growing. The sandy loam soil is red, and about $10 \mathrm{~cm}$ deep. The main part of the site is on bedrock, which causes the artifacts to gravitate down the slope during heavy rains, and the site is heavily disturbed by wind and water erosion.

Cultural remains at the site include an assemblage of undiagnostic artifacts in the form of chert and quartzite flakes in various states of reduction, chert cores, plus one mano. About 150 high quality pieces of lithic material are exposed on the site near the rock shelter. Diagnostic artifacts might be found at the site, but it is not a good candidate for subsurface investigations.

\section{LA6828:}

The site is a small lithic scatter that measures $20 \mathrm{~m}$ east to west by $20 \mathrm{~m}$ north to south. It is situated in a lush pinon-juniper forest with lesser stands of yucca, prickly pear, and mixed varieties of bunch grasses. The dominant soils are reddish brown silty sands. The cultural materials at the site are located on a small terrace above the bottom of a small unnamed tributary to Welsh Canyon. Eight quartzite flakes were noted on its surface. No formal tools were found and no features were noted.

The site is small. It does not contain evidence for buried subsurface cultural remains nor any areas where their recovery is likely. No additional research is recommended.

\section{LA6829:}

The site is a small, isolated lithic scatter that measures $1 / \mathrm{m}$ east-west by $10 \mathrm{~m}$ northsouth. The vegetative setting is juniper scrubland with juniper bunch grasses, prickly pear, and cholla predominant at the site. The predominant soil is silty sand. It is located north of Welsh Canyon near the head of a drainage that empties into the canyon.

Cultural artifacts include a low-density lithic scatter with a total of 14 pieces visible on the ground surface. These were field analyzed resulting in a majority of tertiary flakes. None of these was reworked. Three sandstone manos were also noted. All of the flakes are quartzite except for three, which are chert. One quartzite core fragment was noted. 
The site is probably a brief camping site where tools were made for quick use. As no subsurface deposits are likely at this location, its research potential has been exhausted by recording.

\section{LA6830:}

The site is a lithic scatter that measures 120 m east-west by $110 \mathrm{~m}$ south-south. Located at an elevation of $4760 \mathrm{ft}$, the site is set in pinon-juniper with prickly pear, cholla, and mixed bunch grasses. The soils are mainly light brown sandy loams.

The site is located on a ridge in the bottom of Welsh Canyon. A large scatter of lithic artifacts with several very dense concentration of flakes that appear to be knapping stations were recorded at the site. Both of these features are located on the margins of exposed sandstone bedrock and each has more that 100 small flakes of various material types such as grey, yellow, tan and white quartzite; white, tan, brown, reddish, and white chert; basalt, and argillite. Much of the site is located outside the interior boundary fence for the Pinon Canyon Maneuver site. One of the concentrations consists of the 100 small flakes, plus 15-20 other flakes along the outside of the boundary fence. Quartzite and chert flakes in all stages of reduction number in the hundreds across the surface of the site.

This site may have some areas where subsurface test excavations would produce intact cultural remains. Further work needs to be done to try to locate such areas.

\section{LA6831:}

The site is a lithic scatter located at $1408 \mathrm{~m}$ elevation in a local environment of pinon-juniper with yucca, prickly pear, cholla, cottonwood, and mixed bunch grasses. Soils are predominantly red and sandy. The site is located on a small grassy knoll that is set on sandstone bedrock in an area of ancient lithified dunes. It is near the bottom of an unnamed tributary of Welsh Canyon.

Cultural material consists of a small scatter of lithics in a pocket of soil that is found along the cross-bedded sandstone bedrock. No diagnostic artifacts were identified but more than 40 lithic artifacts were observed at the site. Several small water catchements in sandstone bedrock that were holding water when the site was visited are located roughly $10 \mathrm{~m}$ from the eastern edge of the site. A quartzite biface was observed and ten quartzite tertiary flakes are bifacial thinning flakes. The predominant lithic material on this site is quartzite in various stages of reduction. Because of the paucity of artifacts and lack of deposition to yield subsurface cultural material, the research potential of the site is exhausted by recording.

\section{LA6832:}

The site is a historic structure with its accompanying artifact scatter. It measures $38 \mathrm{~m}$ north-south by $26 \mathrm{~m}$ east-west at $1414 \mathrm{~m}$ elevation. The vegetation is pinon-juniper 
with cholla, yucca, prickly pear, and mixed bunch grasses also growing on the site. Soils are light brown silty sand.

The site is located on a terrace between two drainages in an unnamed tributary of Welsh Canyon. The historical component consists of three standing posts with a pile of stones against the most northeasterly post. The site appears to be the remnants of a historic Euro-American homestead and artifact scatter. This site probably dates to the late 19 th or early 20 th century. The preliminary dating of the site was made by considering the styles

and apparent age of ceramic sherds and a sewing machine found on the site. No additional research is warranted.

\section{LA6833:}

The site is a lithic scatter/open camp located on a sandstone terrace/bench above the first terrace in Welsh Canyon. It is bounded on two sides by drainages. The artifacts consist of predominately quartzite flakes, but one complete mano and three mano fragments were also observed. White quartzite nodules that appear to have been naturally deposited are scattered throughout the site area and flakes of this material that appear to be cultural in origin suggest this location was a source area for this material. A cluster of grey quartzite flakes with core fragments appears to represent the place where the core was reduced. Little deposition exists on the site area and most artifacts are resting on exposed sandstone bedrock.

A random surface sample was extrapolated from a total of $75+$ artifacts on the site. The predominate material was white quartzite with 40 flakes in various stages of reduction; there were basalt flakes, two primary gray chert flakes and one piece of shattered chert among the sample. A grey quartzite shaft straightener, a coarse-grained quartzite mano, and a sandstone mano fragment were identified in the sample. The site does not exhibit any areas where subsurface investigations are likely to produce remains.

\section{LA6834:}

The main feature at the site is a rock shelter that is associated with a lithic scatter. Located at an elevation of $1394 \mathrm{~m}$, the site is in juniper and pinon with the normal understory of vegetation. Soils are predominantly light brown silty sands. The rock shelter is situated just off the first terrace edge in the bottom of Welsh Canyon. The ceiling of the rock shelter appears to have collapsed into the formerly occupied space. A relatively dense scatter of lithic detritus is eroding down the slope in front of the shelter while grey ashy fill and heat cracked rocks are present in the shelter, itself.

No patterned artifacts were recovered, but the detritus includes quartzite flakes in various stages of reduction. Of the 35 analyzed, there were 5 chert flakes, a utilized basalt flake, and an argillite flake. The remainder was quartzite. The site would be difficult to 
excavate because the roof-fall is obstructing any access. It is not a good candidate for more research.

\section{LA6835:}

The site is a small lithic scatter measuring 45 east-west and 40 north-south. It is located at an elevation of $1450 \mathrm{~m}$ in pinon/juniper with cholla, prickly pear, yucca and mixed bunch grass comprising the remaining vegetation. The main soil is reddish brown silty sand.

Site materials are exposed along the top of a ridge near the edge of a drainage in an unnamed side canyon of Welsh Canyon. A dense concentration of lithics $(12 \mathrm{~m} \times 18 \mathrm{~m})$ within a large and much more diffuse scatter of flakes is found on the site. An unusually high proportion of the artifacts observed consisted of poor quality chert in a variety of colors. A poorly made, small triangular corner notched point was collected from the site. The lithic concentration is about $50 \%$ quartzite and $50 \%$ chert in various stages of reduction. The total number of artifacts on the site is estimated at approximately 75 . No further work is recommended.

\section{LA6836:}

The site is a very small lithic scatter measuring $10 \mathrm{~m}$ north-south and $5 \mathrm{~m}$ east-west with an elevation of $1457 \mathrm{~m}$. Vegetation includes cholla and prickly pear, yucca and mixed bunch grasses in a pinon/juniper. The soil is light gray-brown silty sand.

It is located on a terrace/bench in Welsh Canyon. Cultural materials consist of a small cluster of quartzite flakes probably from the reduction of a single core because the material is all the same. The total number of quartzite flakes was 62 flakes in all stages of reduction. There is no depth to any of the remains and the site is not recommended for additional research.

\section{LA6837:}

This small rock shelter and associated lithic scatter measures $10 \mathrm{~m}$ east-west by $8 \mathrm{~m}$ north-south. The south-facing site is located beneath a ridge on the slope of an unnamed tributary of Welsh Canyon. It is at $4800 \mathrm{ft}(1463 \mathrm{~m})$ elevation in a pinon-juniper biotic zone. Vegetation on the site includes juniper, cholla, grasses, prickly pear, and some pinon pine. The soil, approximately $15 \mathrm{~cm}$ deep at the datum near the face of the rock shelter, is composed of light brown silty sand. The rock shelter and cultural material at this site have had moderate disturbance and are being weathered slowly down the slope.

The rock shelter is a shallow rock overhang. The associated artifacts are in front, and on the slope below. A series of rocks are located in front of the shelter, but there is no evidence of stacking or other modification present. A small amount of heat altered stone and ashy fill is in the shelter. A single cord impressed ceramic sherd was collected from inside the shelter. Some deposition may be present inside, but the floor area is limited. 
It measures roughly $3 \mathrm{~m}$ by $1 \mathrm{~m}$. A small bifacially thinned chert flake that appeared to be a projectile point preform was observed but not collected.

A representative sample of artifacts was field analyzed at the site and of they include chert and quartzite flakes, quartzite cores, and quartzite and chert shatter. Quartzite was the preferred material. The majority of the flakes were in the tertiary phase of production, followed by secondary, and primary flakes. Three quartzite uniface flakes were also noted at the site. There are approximately 25 pieces of heat altered sandstone present in the rock shelter suggesting use for a fire feature.

Although small in size, this site could yield important information concerning the prehistory of the Pinon Canyon area. Subsurface deposits could be present that would have research potential. It is recommended for testing to determine its eligibility for inclusion in the National Register of Historic Places.

\section{LA6838:}

The site is historical consisting of a depression bounded on one side by $8 \mathrm{ft}$ of stone wall remains. The footings indicate an $8 \mathrm{ft} \times 12 \mathrm{ft}$ structure once stood here. A small trash scatter lies just south of the location. The entire site measures $120 \mathrm{~m}$ north-south by $70 \mathrm{~m}$ east-west for a total of 2.08 acres.

The site is located on a gentle slope of a small valley east of a Welsh Canyon tributary. Vegetation is primarily juniper grassland with juniper bushes, cholla, bunch grasses, prickly pear, buffalo gourds, and sage predominating at the site. The soil is light brown adobe clay.

Two eight foot wooden posts remain upright northwest of the structure. They are set $18 \mathrm{~m}$ apart but their function is unknown. An $8 \times 8 \mathrm{~m}$ square corral lies $50 \mathrm{~m}$ to the south but the footings are all that remain of the structure. Virtually all building material has been removed from the site, apparently scavenged for other buildings in the region. The small $10 \times 10 \mathrm{~m}$ artifact scatter contains a variety of historic trash. Glass fragments include the base of a green medicine bottle, green window glass, two separate containers made of manganese glass, and over 30 fragments of milk glass. Six pieces of hand painted porcelain were probably the same decorated artifact. In addition to glass and ceramic ware, a .30-.30 Winchester cartridge and a $2 \mathrm{ft}$ diameter galvanized metal tube were identified. The sandstone wall remnant $8 \mathrm{ft}$ long by $1.5 \mathrm{ft}$ wide stands at the northwest corner of the structure foundation. The remnants of this historical habitation represent a homestead typical of those found on the Pinon Canyon Maneuver Site between the 1880's and 1920's and the presence of manganese glass on the grounds supports these dates. Additional work is not recommended.

\section{LA6839:}

This small lithic scatter is located on a bench in the bottom of Welsh Canyon at the southwest edge of a gentle slope toward a drainage. It measures $16 \mathrm{~m}$ east-west by $10 \mathrm{~m}$ 
north-south at $4760 \mathrm{ft}(1450 \mathrm{~m})$ elevation. Juniper, bunch grasses, prickly pear, cholla, mountain mahogany, and yucca grow on the site, which is located in a primarily juniper scrub biotic zone. Light brown sandy, clayish loam reaches a depth of over $20 \mathrm{~cm}$ at the datum on the east side of the site.

The small scatter of cultural material is composed of greenish and red chert flakes. A sample analyzed in the field resulted in a majority of tertiary flakes, followed by about half as many secondary flakes. Primary flakes are very few in number. One chert core was observed. No tools, diagnostic artifacts, or features were noted. No eroding artifacts were seen from the surface of the site, but due to the depth of the soil buried deposits might be present. This site could contain buried deposits but additional investigation is needed to learn if there are areas where they might be present. With the absence of features and diagnostic tools, the site should not have a high priority.

\section{LA6840:}

This 1000 sq. $m$ lithic scatter is situated on a terrace atop a hill at the base of a ridge that rises to rim rock. A small drainage is located around the site on the north, east, and south while the west side rises sharply to rim rock. The site is in a tributary of Welsh Canyon at $4820 \mathrm{ft}(1469 \mathrm{~m})$ elevation. Juniper, cholla, prickly pear, and bunch grasses are the predominant plants on the site. The soil consists of sandy brown loam mixed with small rocks. A datum was placed west of the center of the site, where the deposition is over 15 $\mathrm{cm}$. There has been light disturbance here due to wind and water erosion that has caused the cultural material to slowly erode downhill, but the site is generally in good condition.

Artifacts consist of lithic debitage that was analyzed in the field and learned to contain chert and quartzite material that was used to produce primary, secondary, and tertiary flakes. The majority of the assemblage is tertiary quartzite flakes. A few quartzite and chert cores were also noted. No diagnostic artifacts or features were found on this site. The site may contain intact deposits that could teach us about lithic technology. However, the absence of any evidence for fire features and the lack of diagnostic tools indicates it is not a likely candidate for research.

\section{LA6841:}

The site is located on the talus slope near the bottom of Welsh Canyon; it measures $60 \mathrm{~m}$ north-south and $100 \mathrm{~m}$ east-west at an elevation of $1463 \mathrm{~m}$. The talus slope meets at the junction of two small side canyons bound on the northeast, east, and southeast by a drainage. Vegetation includes juniper, cholla, prickly pear, and native grasses. Erosion from wind and water is moderate and there is some disturbance from animal activity.

The site consists of a lithic scatter of chert and quartzite flakes in all stages of reduction. A sandstone mano fragment was also identified. At least 100 flakes, several cores, a mano and utilized flake suggest lithic production and possible habitation. No features were noted and no areas where buried remains might be located were evident. 


\section{LA6842:}

The rock shelter and its accompanying lithic scatter are located on a steep slope of an unnamed side tributary of Welsh Canyon at $4800 \mathrm{ft}$ elevation. The entire site measures $90 \mathrm{~m}$ east-west by $44.5 \mathrm{~m}$ north-south for a total of approximately one acre. A juniper forest surrounds the area. Vegetation consists of juniper, mixed bunch grasses, cholla, yucca, and prickly pear predominates. A datum placed at the mouth of the shelter showed a soil depth of a little over $10 \mathrm{~cm}$ consisting of light brown sandy residual loam. The site has suffered a moderate amount of disturbance from natural erosion.

The south facing rock shelter contains cultural material, but no features or diagnostic artifacts on the ground surface. The recorded lithic assemblage consisted of flakes, some cores, three bifacial tools, and a mano fragment. The field analysis showed a preference for a dark brown quartzite material to produce primary and tertiary flakes in the process of tool making. The bifaces, which appear to have been used as scraper tools, were made of chert, quartzite, and argillite.

Soil within the rock shelter could yield additional artifacts that could help to identify the prehistoric culture that may have lived in this rock shelter. Data relevant to the research design for the prehistory of PCMS could be obtained by testing at this site.

\section{LA6843:}

This small lithic scatter is located on a terrace on the east side of Welsh Canyon about in the center of the slope between the floor of the canyon and rim rock. The elevation is $4740 \mathrm{ft}$, which is in an area of juniper scrubland. The site measures $24 \mathrm{~m}$ north-south by $15 \mathrm{~m}$ east west. Vegetation at the site included juniper, rhus tribolata, yucca, prickly pear, cholla, broom snake

weed, bunch grasses, and range forbs. The light yellow, sandy loam soil is $20 \mathrm{~cm}$ deep. A datum was placed near the center of the eastern boundary.

The artifacts are scattered across the surface of the site with no concentrations. The total assemblage of 14 flakes showed the exclusive use of quartzite for lithic reduction. Primary, secondary, and tertiary stages were observed. One chert core was also present. No diagnostic artifacts, tools, or features were noted. The site served as a brief stop for tool manufacture by a prehistoric culture.

This site offers limited research potential, which is probably exhausted by the recording process. It is not recommended for eligibility to the NRHP at this time.

\section{LA6844:}

This circular-shaped lithic scatter measures 40 m diameter. It is located on a bench on the east side of Welsh Canyon at $500 \mathrm{ft}$ elevation in juniper, grasses, prickly pear, yucca, and cholla. Light brown silty sand ranges up to $20 \mathrm{~cm}$ at various locations. There has been some light disturbance to the site from non-cultural processes of wind and water erosion causing weathering and transportation of artifacts down slope. 
A relatively dense scatter of lithic artifacts, consisting of over 75 items is found at the site. These include quartzite and chert flakes, cores, and shatter. A single utilized flake plus a shaft straightener were also on the site. Lithic analysis conducted in the field on a sample showed a majority of the artifacts are flakes in the tertiary stage of production with a lesser amount of secondary stage flakes. This site was apparently a tool manufacturing area used by an unknown prehistoric culture that inhabited the region. No diagnostic artifacts or features were seen at the site.

There is a possibility for subsurface deposits that could contain cultural data, but the absence of fire features and the lack of diagnostic artifacts make the site a poor candidate for immediate research.

\section{LA6845:}

This site is another small lithic scatter that is so routinely found in this area of Welsh Canyon. It measures $29 \mathrm{~m}$ east-west by $12 \mathrm{~m}$ north-south for a total of $348 \mathrm{sq} . \mathrm{m}$. It is at $5236 \mathrm{ft}$ elevation where it is situated on the top of a bench near an unnamed side drainage of Welsh Canyon. Yucca, prickly pear, grasses, juniper, and cholla predominate at the site. A datum was placed near the center of the site where there is approximately $20 \mathrm{~cm}$ of light brown, silty, sandy soil.

Cultural materials consist of a small amount of chert and quartzite lithic debitage. Forty-one pieces including primary, secondary, and tertiary reduction stage flakes, shatter, and cores were noted. In addition a uniface tool and two utilized flakes were observed. No diagnostic tools or features were evident. This site was probably used for tool manufacture. Due to the presence of tools it may also have been a habitation for a short period of time.

The site could contain hidden cultural remains in the $20 \mathrm{~cm}$ of deposition, but the absence of fire features and diagnostic artifacts makes it a poor candidate for immediate research. This site, as well as others in its vicinity should be monitored to learn if any cultural materials erode into view and if so, the potential for recovery of intact remains should be evaluated.

\section{LA6846:}

This site is a small scatter of cultural material that measures $25 \mathrm{~m}$ north to south by $8 \mathrm{~m}$ east to west. It is situated on a bench east of Welsh Canyon at $1493 \mathrm{ft}$ elevation where it is surrounded by a pinon-juniper forest with cholla, yucca, and grasses as the understory. Light disturbance has occurred in the area from natural erosional factors. The soils consist of light brown silty sand, about $20 \mathrm{~cm}$ deep. Thirteen quartzite and chert flakes and three chert cores make up the artifact assemblage at 5LA6846. The flakes are in primary, secondary, and tertiary stages of reduction and occur in equal numbers. 
The site is probably a brief stop for limited tool production. There is a chance that subsurface artifact exist due to the amount of deposition. Sheet wash action at the site could cover and uncover the artifacts during heavy rains that occur seasonally in the Pinon Canyon area. However, research potential is limited based on the surface finds.

\section{LA6847:}

This small lithic artifact scatter measures $32 \mathrm{~m}$ north-south by $20 \mathrm{~m}$ east-west for a total of $640 \mathrm{sq}$. $\mathrm{m}$. It is located at the base of a drainage slope on the east side of Welsh Canyon in pinon-juniper vegetation with grasses, cholla, and prickly pear also growing on the site. Silty light brown sandy soil is approximately $10 \mathrm{~cm}$ deep at the datum.

Artifacts found on the surface consist of quartzite debitage, including two utilized flakes and a uniface. The site appears to have little deposition. Most of the artifacts are scattered on exposed colluvial sediments. All 16 artifacts were field analyzed; the only material used was quartzite, and most of the flakes were classed as tertiary stage. In addition to the flakes, two cores were noted. This was probably a small tool manufacturing station used briefly by an unknown prehistoric culture. No diagnostics or features were present.

\section{LA6848:}

The site is a large lithic procurement area and an accompanying scatter of chipped stone debitage. It measures $115 \mathrm{~m}$ north to south by $110 \mathrm{~m}$ east to west and it is located in the usual juniper forest with cholla and prickly pear in the understory. Soils are light brown sandy clay. The site covers the entire end of a point above an unnamed side drainage to Welsh Canyon.

A large outcrop of high quality, blood-red chert is found in natural deposits on the site. Thousands of flakes and cores in all stages of reduction are scattered across the surface of the site. Although the site is large and it exhibits a good example of a chert source, there are no buried deposits. Additional research is not warranted.

\section{LA6849:}

The site is a lithic scatter situated along the sloping side of Welsh Canyon at an elevation of $5009 \mathrm{ft}$ ( $1518 \mathrm{~m}$ ). Juniper, cholla, milkweed, prickly pear, and bunch grasses are growing on the site. The site soils are light brown sandy clays and residual loams. Artifacts noted on the surface include 15 chert cores, 25 primary chert flakes, 15 secondary chert flakes, 12 tertiary chert flakes, and 8 tested chert cobbles. A single fragment of a sandstone mano was also noted on the site.

No diagnostic artifacts were recovered from the site. No areas with apparent buried cultural remains were noted by the investigators and the site is not considered a good candidate for additional research. 


\section{LA6850:}

This sparse lithic artifact scatter which measures $40 \mathrm{~m}$ north-south by $30 \mathrm{~m}$ eastwest is situated on the top of a terrace at the rim of a tributary drainage east of Welsh Canyon. A datum was installed just west of the site center where the light brown silty sand has a deposition of over $10 \mathrm{~cm}$. Vegetation on site is juniper, cholla, yucca, prickly pear, and various grasses.

The lithic scatter consists of 13 flakes of brown and white quartzite. One argillite and one petrified wood flake were also observed. About half of the artifacts (6) were tertiary quartzite flakes while the remainder were in primary and secondary stages of reduction. The argillite flake had been utilized. The research potential at this site has been exhausted by the recording process and no further recommendations are warranted.

\section{LA6851:}

This $70 \mathrm{~m}$ by $65 \mathrm{~m}$ lithic scatter is located on the top terrace at $5300 \mathrm{ft}$ elevation above a large unnamed tributary on the east side of Welsh Canyon. The site covers about 1.1 acres in a canyon rim setting of pinon-juniper vegetation. Predominant plants at the site are juniper, pinon, cholla and grasses. The silty, light brown sand is $15 \mathrm{~cm}$ deep at the datum, which was placed toward the north end of the site.

The scatter of lithic cultural material is made up of more than 65 quartzite flakes in all stages of reduction. A lesser number of chert flakes were also noted. In a field analysis of a sample of the artifacts the field crew determined that about 20 percent of the quartzite flakes were tertiary pressure flakes and about half were primary flakes. The remainder was chert secondary or tertiary flakes. No diagnostic cultural material or features were found. Apparently the site was used as a tool production site by an unidentified prehistoric culture.

Due to the soil deposition, there could be buried artifacts at this site. However the absence of fire features and diagnostic tools means the site is not a likely candidate for further research.

\section{LA6852:}

A large lithic scatter that covers 1.4 acres makes the major part of this site that is situated at the corners of several sections and therefore difficult to record in terms of legal location. A brass cap marks the corner of the sections at the site. It is on a terrace at 5300 $\mathrm{ft}$ elevation north to northeast of Welsh Canyon. The vegetation on and around the site is

pinon, juniper, grasses, prickly pear, yucca, and cholla. A datum was placed just outside the eastern site boundary, where the light brown silty sandy soil is more than $20 \mathrm{~cm}$ deep. The site has been lightly disturbed by natural erosional factors.

More than 140 lithic artifacts are present on the ground surface but neither archaeological features nor formal tools were observed among the assemblage. Field analysis of a representative sample indicated that about equal numbers of primary and 
secondary quartzite flakes are in the assemblage, while tertiary quartzite flakes predominated. Lesser amounts of chert flakes in all three reduction stages were noted. This lithic scatter may contain important information, but with no fire features and the absence of dated artifacts, it is difficult to place in any context.

\section{LA6853:}

The site is a lithic procurement area that covers $2800 \mathrm{sq} . \mathrm{m}$ and measures $70 \mathrm{~m}$ north-south by $40 \mathrm{~m}$ east-west. It is located on the east side of a canyon slope above Welsh Canyon in the Black Hills area in a juniper and pinon vegetation area. A yellowish to brown sandy loam soil measures slightly over $15 \mathrm{~cm}$ deep at the datum, which was placed in the north end of the site. The ground surface is undisturbed.

Cultural material consists of a relatively dense scatter of flakes that are almost exclusively gray quartzite. The artifacts are along the edge of a bench below the top of Welsh Canyon. The similarity of the lithic material and the range of flake types present, (primary, secondary, tertiary, shatter, and cores) suggests that the location is a lithic procurement area. There appears to be little if any deposition of cultural deposits. No diagnostic artifacts or archaeological features were noted. A field analysis of the lithic material shows a majority of the flakes were in the secondary stage of reduction. Over 75 pieces were observed on the ground surface of the site. The site is duplicated at many other locations and the absence of fire features at this location suggests it is not a site worthy of additional research.

\section{LA6854:}

The site is located near the canyon rim in a dense juniper and pinon forest. The site measures $6 \mathrm{~m}$ north-south and $8 \mathrm{~m}$ east-west at an elevation of $1554 \mathrm{~m}$. Cultural material consists of a small cluster of lithics in a very localized area that appear to have little or no deposition. Flakes are predominately gray quartzite material and are found in various stages of reduction. The debitage includes three utilized flakes, no diagnostic lithics were identified. The total quantity of artifacts observed at the site was 15 artifacts. Additional research is not recommended.

\section{LA6855:}

This very small lithic scatter measures $6 \mathrm{~m}$ north-south by $8 \mathrm{~m}$ east-west at an elevation of $5100 \mathrm{ft}$. It is on the rim of a tributary to Welsh Canyon where it is within a juniper-pinon vegetative zone. Artifacts are resting on bed rock, however, the silty, light brown sandy soil in about $10 \mathrm{~cm}$ deep at the datum which is placed near the southern edge of the site. It has been lightly disturbed by wind and water erosion.

The site materials consist of a small cluster of culturally modified lithic material in a very localized area. There seems to be little or no deposition where most of the artifacts occur. The total number of surface artifacts (15) was analyzed in the field. This showed mostly quartzite material had been used, resulting in flakes mostly in secondary and tertiary stages of reduction. There is also quartzite and argillite shatter present. Two of 
the quartzite flakes show use wear. This site is probably a tool manufacturing station used only briefly. The research potential of this site has been exhausted by recording, and no further recommendations are made at this time.

\section{LA6856:}

This historic campsite is set in a pinon-juniper scrub forest, near the edge of the rim of a small tributary off the north end of Welsh canyon. It measures $56 \mathrm{~m}$ east-west by 50 $\mathrm{m}$ north-south at an elevation of $5220 \mathrm{ft}$. The sandy loam soil is $10 \mathrm{~cm}$ deep at the site datum and the locale is in fair condition, suffering from erosional factors and animal disturbance. The artifacts are broken and scattered throughout the site area, and are eroding down slope when they occur in drainage areas.

The cultural remains at the site include two campfire hearths, recorded as Features 1 and 2. Other items include broken green, amethyst, purple, and clear bottle glass. One neck and shoulder fragment shows a stopper type lip. Several glazed white stoneware fragments appeared to come from one undecorated and unmarked cup. One of these pieces was a handle segment, and another was the handle attachment from the side of the cup. A whole slightly green beverage bottle was collected for temporal identification. Several stove fragments were found in and near the hearths. These appeared to come from the top portion of a wood stove, which could have been used as a griddle, grille, or cooking surface on top of the coals from the campfire. One of these cast iron pieces, a corner, was embossed with the script figure " 8 ". One piece was a fragment of a fire box door. The remaining piece was the top rim that held the surface lids in place. No further manufacturer data was found on these fragments.

The two hearths were found within about $1.5 \mathrm{~m}$ of each other in the center of the site near the eastern boundary. The larger of the two measured about $2 \mathrm{~m}$ in diameter and contained large sandstone rocks surrounding it. The center contained smaller heat cracked rock, charcoal, ash, and one of the stove parts. The other campfire measures about $1 \mathrm{~m}$ in diameter, and also contains ash, charcoal, and fire-cracked rock. Interesting artifacts found and recorded on the site were five diagnostic tobacco tins. Among them are one-pin hinged tobacco cans with lids attached, and a curved slip-on top tobacco can with lid still attached. The latter has a match-striking platform on the bottom. The curved structure was made to slip comfortably into a pocket. All the cans measure approximately $11 \times 7.5 \times 2.5 \mathrm{~cm}$. Undiagnostic items in the scatter are several pieces of bailing wire, and the bail handle from a bucket, a tin can bottom with no markings, and a lard bucket. $A$ piece of milled lumber, probably the fragment of a small stake, was found near the site, but appeared to be not associated and may have been introduced at a later time.

This site represents an open camp consistent with line camps or sheepherder camps associated with ranching activities in the Pinon Canyon area. Due to the absence of small corrals, it was most likely identified with cattle ranching. The site could date from the 1880 s to pre-World War I, due to the presence of purple glass fragments. 
It is unlikely that this site can yield much additional information concerning ranching activities in the area. Most of its research potential has been exhausted by the recording process.

\section{LA6857:}

This site is an extensive lithic scatter measuring 130 by $65 \mathrm{~m}$; it is situated at 5240 $\mathrm{ft}$ on a terrace in the bottom of an eastern tributary at the head of Welsh Canyon. Juniper, cholla, prickly pear, and native grasses predominate at the site while the soils are about $10 \mathrm{~cm}$ deep at the site datum and consist of light brown silty sand. The terrace surface is bedrock that is eroding and decomposing. The artifacts on the surface have weathered and are partially buried. At least two water catchments are located in the drainage east of the site and both had standing water at the time of the visit.

Cultural materials include an assemblage of over 50 quartzite and chert flakes scattered over an extensive area. A quartzite uniface was also noted. Analysis of a representative sample was conducted in the field and no collections were taken. The debitage is in primary, secondary, and tertiary stages of reduction. No other tools or cultural features were observed. This is most certainly a lithic reduction site and perhaps a living area as well. The site does not contain fire features and it is not a likely location for productive excavation.

\section{LA6858:}

This large lithic artifact scatter is located at $5300 \mathrm{ft}$ elevation on an eastern slope of a large unnamed tributary canyon off the north end of Welsh Canyon. It measures 140 $\mathrm{m}$ east-west by $80 \mathrm{~m}$ north-south, covering 2.8 acres. Vegetation on the site includes juniper, cholla, prickly pear, and bunch grasses while the soils are light brown, silty sands that measure a little over $10 \mathrm{~cm}$ deep. The setting has had light disturbance resulting in erosional displacement of the artifacts.

The site is situated on a drainage on the top of a terrace. Cultural material consists of 39 flakes of quartzite and chert. The majority of the flakes in both materials are in the tertiary stage of reduction and some are tiny pressure flakes. Primary and secondary flakes are also present. One quartzite core was noted. It is likely that artifacts have washed down slope due to its location on the edge of the drainage. This site has been adequately recorded by New Mexico State University field crews.

\section{LA6859:}

This small rock shelter overlooks a large unnamed tributary east of Welsh Canyon. It is on a south-facing slope below a point, overlooking the valley floor at an elevation of $5300 \mathrm{ft}$. Vegetation at the site is juniper, cholla, grasses, prickly pear, pinon, and rhus trilobata in order of predominance. Light brown, silty sand is $20 \mathrm{~cm}$ deep. Minor disturbance has occurred at the site as rock fall is present inside the shelter, and artifacts are weathered and eroding down slope. 
Four chert and quartzite flake artifacts were found outside the shelter, down the slope. None were found inside. Some of the rock fall has been used to build a $3.5 \mathrm{~m}$ wall along the west side to enclose the shelter. An ancient juniper branch lies on the floor inside. Subsurface deposits could be present in the deposition of the shelter floor that may contain important information concerning the prehistory of the area. It is a good candidate for investigation through test excavation.

\section{LA6860:}

This site is composed of two south-facing rock shelters connected by a short length of sandstone rock face. It is located on an unnamed side drainage of Welsh Canyon on a slope above a small bench at $5200 \mathrm{ft}$ elevation. The entire site including both shelters, and the connecting cliff face measures 92 m east-west by 20 north-south, for a total of 0.45 acres. Vegetation at the site includes juniper, bee weed, grasses, cholla, prickly pear, and rhus trilobata. Juniper-pinon scrub surrounds the nearby canyon lands. Soils range up to $20 \mathrm{~cm}$ deep and are dominated by light brown, silty sand. Slight disturbance at the site is caused by animal burrows disturbing the fill and there has been some erosion due to wind and water.

The two rock shelters are located within roughly $15 \mathrm{~m}$ of each other and a relatively high density of artifacts is scattered down the slope below the shelters. A rodent burrow near the center of the larger shelter appears to have exposed a portion of a hearth. This shelter appears to have $30 \mathrm{~cm}$ or more of deposition in the interior. The other shelter also appears to have soil deposition in the interior. Ashy fill and heat altered stone are scattered down the slope below both shelters. A small bench, below the shelters, exhibits artifacts but it is unclear if they were deposited by slope wash or are associated with another activity area. No evidence for bedrock metates was found, and no type of ground stone was located despite careful examination.

One shelter measures about $30 \mathrm{~m}$ wide east-west and is about $17 \mathrm{~m}$ deep at its widest point, which is near the center. Both ends are terminated by piles of boulders in front of the cliff face. The east end is about $8 \mathrm{~m}$ wide, and the west about $2 \mathrm{~m}$ wide. Height at the tallest point is approximately $4.5 \mathrm{~m}$. Two hearths, Features 1 and 2 are toward its east end. Heat cracked rock is present on the surface and flaking debitage is scattered over the floor of the shelter. A natural barrier of large boulders protects the interior and other walls of smaller rocks are collapsed on each end.

The other shelter measures about $28 \mathrm{~m}$ east west by $10 \mathrm{~m}$ deep at its widest point. It is about $4 \mathrm{~m}$ high. Large boulders obscure the interior, and no artifacts or features are found on the surface of the interior of the shelter, but they are scattered outside and down slope in front.

Field examination of the cultural material on this site indicates the use of quartzite and chert material reduced to primary, secondary, and tertiary debitage. Over 100 flakes were noted in the site boundaries. A representative sample indicates that quartzite was 
used most often, and the majority of the flakes are in a tertiary stage, closely followed by secondary flakes. Primary flakes are also present, but in lesser quantities. Chert flakes were mostly in secondary form, but all stages are present. Both quartzite and chert shatter were noted. One fine-grained basalt utilized flake was noted and a second utilized flake was made of quartzite. Several pieces of bone were found. Four of these appeared burned while another fragment, speculated to be a bird bone, and was not burned. No temporally diagnostic artifacts were visible on the surface and no collections were made.

These two rock shelters were most certainly used as habitation sites for at least some period of time. During occupation, they were used for tool manufacture and food processing, probably in the form of roasting. This site offers an excellent source of resource information on the prehistoric cultures that inhabited the Pinon Canyon area. Subsurface deposits are likely to exist, based on the deposition of the soil and the small sample that was extracted from the rodent burrow. It should be tested and possibly excavated later, based on those results.

\section{LA6861:}

This site is a rock shelter with very few associated artifacts. There is a great amount of deposition in the bottom of the shelter, which may account for the lack of artifacts on the surface. There are additional smaller shelters in the rock face directly north that also have no artifacts. In between the shelters are two bedrock metates, which add to the possibility of deposition at these sites.

\section{LA6862:}

This rock shelter and lithic artifact scatter is situated at the base of a short cliff with a steep slope extending downhill in front. The site measures $46 \mathrm{~m}$ east-west by $15 \mathrm{~m}$ north-south at $5200 \mathrm{ft}$ elevation. The vegetation on the site is juniper, cholla, prickly pear, and grasses. The primarily aeolian and residual deposition is composed on light brown, silty sand about $15 \mathrm{~cm}$ deep. The site has been moderately disturbed by wind and water erosion.

The site consists of a shallow rock overhang with an associated low-density lithic scatter. The slope below the shelter has extensive deposits of ash and heat altered stone. Feature 1 is a shallow basin-shaped metate that is ground into a large sandstone block apparently tilted on its side since it was used. Feature 2 is an oval ring of sandstone rocks, against a large boulder, that probably were part of a structure. Feature 3 is a small cavity in the sand stone overhang of the shelter. A ground sandstone slab was found resting in this hole. The slab was covering a cavity in the sandstone and it may have been used to close a storage area. The ground stone slab and soil samples were collected from the cavity for further analysis.

A large triangular, side-notched projectile point was collected from in front of the east side of the site, near the southern border. The point measures $33 \mathrm{~mm}$ long by $11 \mathrm{~mm}$ wide at its shoulder by $3 \mathrm{~mm}$ thick. It has side notches, which make the stem $7 \mathrm{~mm}$ wide. The base is convex. The sides of the point are straight. The point is crudely made, having 
rough edges, and off-center point. The style is consistent with the Late Archaic period as defined for the Pinon Canyon region (Loendorf et al. 1996).

This site is likely to yield important research data through testing and excavation. It is recommended for eligibility for inclusion in the National Register of Historic Places.

\section{LA6863:}

This rock shelter and associated lithic artifact scatter is located at $5280 \mathrm{ft}$ elevation on a cliff slope near the north end of Welsh Canyon. The south-southeast facing site measures $16.5 \mathrm{~m}$ east-west by $8 \mathrm{~m}$ north-south. It is set in an area of juniper scrub vegetation. Soils consist of light tan sand ranging between 0 and $10 \mathrm{~cm}$ deep. The site is undisturbed.

The site consists of a shallow rock overhang with a line of sandstone rocks that appear to have been stacked along the front of the shelter. Artifact density was very low throughout the site. and the interior of the shelter does not appear to have much deposition, probably only about $10 \mathrm{~cm}$ at its deepest. In contrast to other rock shelters in the area 5LA6863 lacks ash and heat- altered stone deposits on the slope below. In-field artifact analysis of all 16 flakes found on the surface of the site showed 13 secondary and tertiary quartzite flakes. A Two pieces of quartzite shatter and one angular piece of chert rounded out the assemblage. The site was probably used for a short-term habitation and tool manufacture stop. It may yield important information for research, but it is not a high priority site.

\section{LA6864:}

This site, a source for procurement of lithic materials, is located on the slope of a terrace near the north end of Welsh Canyon. It measures 50 east-west by $30 \mathrm{~m}$ northsouth at $4800 \mathrm{ft}$ elevation. Vegetation at the site is juniper, mixed bunch grasses, prickly pear, rhus trilobata, and mountain mahogany in order of predominance. Ten $\mathrm{cm}$ of light brown sandy-clay loam cover some areas of the site Weathering has caused light disturbance causing artifacts and native material to erode from the fill.

The site consists of a scatter of chert nodules, shatter and flake debitage. Chert nodules appear to be eroding out of the slope and they were apparently reduced where they occurred. The reddish brown chert has numerous inclusion and fracture planes. Consequently, much of the material at the site is shatter. A sample of the raw material was collected. Analysis conducted in the field revealed over 50 artifacts. The majority is shattered chert fragments; however, primary, secondary, and tertiary, flakes were also noted. Several cores, and core fragments were also left at the site. A tested chert gastrolith was noted among the debris.

\section{LA6865:}

This historic rock art panel is located on a sandstone boulder north of a drainage near the head of an unnamed side canyon to Welsh Canyon. It is in a pinon-juniper zone at $4940 \mathrm{ft}$ elevation where juniper and mountain mahogany predominate. Soil at the base 
of the panel consists of dark brown sandy loam about $20 \mathrm{~cm}$ deep. There has been no vandalism at the site and natural erosion has caused only light disturbance to the incised figures.

The $44 \mathrm{~cm}$ by $20 \mathrm{~cm}$ panel faces southwest at an angle of 202 degrees about 101 $\mathrm{cm}$ above ground level. It has been incised on a sandstone boulder. Identifiable elements are the letters " $\mathrm{X}$ ", "B", "O", and the number "30". There is no patina or lichen covering the carvings. The makings on this panel was probably made by people associated with ranches that operated in PCMS beginning prior to the 1880 s until the arrival of the military in 1982 but no further data is available for this site at the present time.

\section{LA6866:}

This site is a rock shelter and lithic artifact scatter found at the base of a cliff above a 30 degree slope at an elevation of $5280 \mathrm{ft}$. The east-facing shelter and site measures $30 \mathrm{~m}$ east-west by $12 \mathrm{~m}$ north-south. The site is surrounded by pinon and juniper. Soil consists of light brown silty sand about $30 \mathrm{~cm}$ deep.

The site consists of a large rock shelter that is below the rim of unnamed side drainage to Welsh Canyon. A relatively low density lithic scatter was observed on the slope below the shelter. Two projectile point preforms were found in the western portion of the site. One is nearly complete and was collected, but both appear to be small triangular shaped, suggesting the site dates to the late prehistoric period. A sandstone mano was noted. A possible wall made of sandstone chunks, once stacked, was noted inside the shelter. It measures 0.6 by $2.5 \mathrm{~m}$. Ashy fill and fire-crack rock is scattered down the slope in front of the shelter. The site is moderately disturbed by wind and water erosion, and has suffered damage from animal activity.

Lithic analysis conducted on the total assemblage of 34 artifacts indicates chert and quartzite in about equal quantities. Flakes in primary, secondary, and tertiary production stages; shatter; two cores; the preform projectile points; and a quartzite biface were present. This site reflects use as a habitation and from tool manufacture.

\section{LA6867:}

This site is another of the many lithic artifact scatters that occur in the Pinon Canyon Maneuver Site. It is located on a point overlooking Welsh Canyon Valley to the southwest at an elevation of $5260 \mathrm{ft}$. The scatter measures $30 \mathrm{~m}$ north-south and $25 \mathrm{~m}$ east-west in a juniper and mountain mahogany vegetation zone. The soils are light tan residual sandyclay loams, about $10 \mathrm{~cm}$ deep.

The site consists of a very light scatter of lithic debitage with many of the flakes on exposed sandstone bedrock. Little or no deposition appears to be present. A historic tin can was also found on the site. An analysis of the total quantity (12) artifacts showed use of chert and quartzite material to produce tools leaving a debitage of primary, tertiary and secondary flakes as well as shatter from both types of material. One chert core fragment 
was noted. Not much other information is available by observation of the ground surface. This site has limited research potential, which has been exhausted by the recording process.

\section{LA6868:}

This site is a scatter of lithic artifacts that measures $15 \mathrm{~m}$ north-south by $5 \mathrm{~m}$ eastwest. It is located on a terrace at a point that overlooks Welsh Canyon about $100 \mathrm{ft}$ below. Its elevation is $5160 \mathrm{ft}$ where it is set in a pinon-juniper forest that has juniper, cholla and mountain mahogany at the immediate site. The light tan sandy clay loam is $10 \mathrm{~cm}$ deep.

This is a very small scatter of lithics that are on a small bench between two unnamed drainages. Little or no deposition exists on the site area. The artifact assemblage consists of eight primary, secondary and tertiary flakes. All but one is made from quartzite material. One core and a piece of shatter were noted.

It offers very little research potential.

\section{LA6869:}

This small sandstone rock shelter, under the cap rock just below the canyon rim, overlooks a large un-named tributary east of Welsh Canyon. It measures $4 \mathrm{~m}$ east-west with a southern exposure. and $3 \mathrm{~m}$ deep by $7 \mathrm{~m}$ high at the entrance. A large bush nearly fills the interior space. Vegetation on the site is composed of juniper, cholla and bunch grasses. Residual deposited sandstone covers the floor of the site is a depth of about 10 $\mathrm{cm}$.

No artifacts were found in the shelter, but hearth remains are located in the center of the floor. This hearth is defined by a circular depression containing fire cracked rock (FCR), flakes and chunks of charcoal. The rock shelter is enclosed by a small wall of boulders that cross most of the opening starting from the west, past the center. To the northwest of this rock shelter there is another alcove that contains no artifacts or features, but a small fragment of metal was found there. This may indicate that some of the activity at the site is historic in age.

\section{LA6870:}

The site is a small lithic scatter measuring $30 \mathrm{~m}$ north-south by $30 \mathrm{~m}$ east-west that is located on a large terrace overlooking a south trending terrace of a small unnamed tributary east of Welsh Canyon at $5260 \mathrm{ft}(1603 \mathrm{~m})$ elevation. The site is set in a pinonjuniper vegetation zone with a predominance of juniper, pinon, yucca, grasses, prickly pear, and cholla at the site. Soils are slightly silty light brown sands.

Cultural material found at the site includes a small assemblage of 14 chert and quartzite flakes. These were analyzed in the field and learned to contain primary, secondary, and tertiary stages of reduction. No tools or culture features were observed. 
5LA6871:

The lithic artifact scatter at this location measures $75 \mathrm{~m}$ east-west by $60 \mathrm{~m}$ northsouth at $4300 \mathrm{ft}$ elevation. It is situated on a terrace on the east side of an unnamed tributary near the head of Welsh Canyon. The vegetation is a pinon-juniper plant community with pinon, juniper, grasses prickly pear, and yucca predominating at the site. Light brown silty sand soil is $30 \mathrm{~cm}$ deep at the site datum placed near the northern boundary. The site has experienced light disturbance due to natural weathering. Artifacts have probably washed down slope slightly.

Over 100 artifacts are estimated on the ground surface of the site. Analysis of a representative sample showed almost exclusive use of chert material with primary, secondary, and tertiary flakes were made from both gray and blue-green chert. A basalt biface was also noted. Based on the use of only one type of material available at this location, it is classed as a lithic procurement area.

\section{LA6872:}

This $40 \mathrm{~m}$ by $40 \mathrm{~m}$ lithic artifact scatter is located beneath cap rock on a bluff overlooking an unnamed tributary near the head of Welsh Canyon. The elevation is 5150 ft. Juniper, pinon, cholla prickly pear, grasses and yucca are the major plants on the site. Soil is light brown silty sand about over $20 \mathrm{~cm}$ deep. The site has been lightly disturbed by wind and water erosion and artifacts have been weathered and possibly moved by noncultural processes.

Artifacts associated with this site include flakes in tertiary, secondary, and primary reduction stages in that order of preference. The material is predominately chert.

\section{LA6873:}

This small site contains a sparse collection of lithic artifacts that are located on a terrace adjacent to the bottom of an unnamed tributary near the mouth of Welsh Canyon. The site measures $45 \mathrm{~m}$ east-west by $25 \mathrm{~m}$ north-south. Its elevation is $4690 \mathrm{ft}$. Plants at the site are juniper, grasses, yucca, and prickly pear and soils are $15 \mathrm{~cm}$ deep and consist of light brown silty sand. The site has been lightly disturbed from weather and down slope movement of artifacts.

The site exhibits various materials such as chert, basalt, argillite, and quartzite. The flakes are concentrated in an area about two meters in diameter. An argillite utilized flake tool was noted in this concentration. This site represents one of the numerous small tool production-lithic reduction sites found in Welsh Canyon.

\section{LA6874:}

This site is an extensive lithic scatter, roughly circular, located near the head of Welsh Canyon. It measures 115 by $110 \mathrm{~m}$ and covers an area of 3.13 acres. The site is situated on a terrace on the east side of an unnamed tributary. Juniper, grasses, prickly 
pear, yucca, and cholla plants predominate the site within a surrounding community of pinon-juniper scrub. Reddish, light brown

silty sand is $10 \mathrm{~cm}$ deep at the site datum. The artifacts have been partially buried by noncultural processes.

The wide area of cultural material contains a high proportion of fine-grained material. Most of the artifacts are flakes and cores, but one quartzite projectile point base was noted, but not collected, as it had no diagnostic attributes. Several bifacially reduced flakes were also noted. The site continues an extended distance on a terrace above the main tributary to Welsh Canyon and into a small side drainage bordering the site on the southeast. There was water standing in the side drainage at midsummer, the time of the visit.

The material used was mostly dark grey quartzite and various shades of chert. Analysis conducted in the field showed the majority of the flakes were in the tertiary reduction stage. There is a scarcity of tools at this site and no features were observed. Some of the artifacts are partially buried. Subsurface artifacts might also be present.

\section{LA6875:}

The site is a complex of three small rock shelters and an associated lithic artifact scatter that occurs along the base of the same rock face. The entire site measures $17 \mathrm{~m}$ north south by $12 \mathrm{~m}$ east-west. All the rock shelters face northwest. They are located below a cliff above a $\mathbf{4 0}$ degree slope that extends down to a drainage in a tributary of Welsh Canyon. The vegetation community is pinon-juniper with juniper, prickly pear, yucca, cholla, grasses, cane-like stalk grass, moss, and Rhus trilobata predominate at the site. Soils are light brown silty sands. Deposition varies from bedrock to $50 \mathrm{~cm}$ deep. The site is moderately disturbed from wind and water erosion.

Two of the rock shelters have little or no deposition on the interior and consequently, no artifacts were observed inside them. One rock shelter, however, has 50 $\mathrm{cm}$ or more of deposition and buried deposits are very likely. A corner-notched basalt projectile point was collected from fill that appears to have eroded from the rock shelters. The site is covered by comparatively dense vegetation and surface visibility at the time of the survey was poor. In addition to the collected projectile point, there was an argillite secondary flake, quartzite flakes, and shatter. It seems likely this site was used for living space and tool manufacture some time during the Late Archaic Period.

\section{LA5876:}

This site is a large lithic scatter that is clearly associated with two small rock shelters. The site complex is located on a terrace near the rim near the head of a side canyon to Welsh Canyon. It measures $120 \mathrm{~m}$ north-south by $90 \mathrm{~m}$ east-west. Predominate plants at the site are pinon and juniper bushes, mountain mahogany, and cholla. The soil is yellow brown sand about $10 \mathrm{~cm}$ deep. The site is in good condition, not having been disturbed. 
The site consists of a dispersed scatter of lithic artifacts that are mostly on sandstone bedrock. Little or no deposition exists in most of the site area except in the rock shelters, which have between 10 and $15 \mathrm{~cm}$ of deposition. Flakes were observed on the surface around the shelters and they are likely from the fill within them. A biface fragment that probably is part of a large corner-notched projectile point was collected from near the center of the site. Old rebar and pin flags were found in front of the shelters suggest that this site had been previously recorded, however we were unable to learn who was responsible for this work.

The cultural assemblage, analyzed in the field, showed a preference for quartzite material and tertiary flakes. Primary and secondary flakes were present with some shatter. Lesser amounts of chert debitage in the form of secondary and tertiary flakes, along with a small amount of shatter were also present. This site has medium potential for recovery of intact deposits. Testing should be conducted to determine its integrity.

\section{LA6877:}

This lithic scatter is found on a ridge at the top of a small cliff east of the head of a side drainage to Welsh Canyon. It is at $5300 \mathrm{ft}$ elevation and measures $30 \mathrm{~m}$ northwestsoutheast by $25 \mathrm{~m}$ northeast-southwest. Pinon-juniper vegetation surrounds the site. Ten $\mathrm{cm}$ of light brown silty sand is found in parts of the site, which has been lightly disturbed by wind and water erosion. It has also been disturbed by animal activity.

The site consists of a sparse scatter of lithic artifacts on exposed sandstone bedrock. A piece of PVC pipe set between three rocks found at the edge of the site suggests it may have been recorded previously, although no numbers or other identification was attached and we were not able to identify the field crew who left this datum.

A total of 19 lithic artifacts were on the ground surface. Analysis showed all but two of these were quartzite and the remainder was chert. Tertiary stage reduction flakes are most common (11) followed by secondary and primary. One piece of quartzite shatter and a quartzite uniface was noted but no diagnostic remains or features were observed. This site has limited research potential, which has been exhausted by the recording process.

\section{LA6878:}

This site is a large lithic scatter found at $5300 \mathrm{ft}$ elevation at the head of a major, but unnamed, drainage just east of the head of Welsh Canyon. It measures $500 \mathrm{~m}$ northsouth by 250 m east-west, covering over 30 acres. It is in an area of pinon-juniper scrub forest where the soil deposition, light brown sandy loam, ranges from 10 to $20 \mathrm{~cm}$. The site is not disturbed except where the two-track road was constructed through its north end. Pinon-juniper vegetation has grown up around some of the scattered artifacts. 
The site consists of a large scatter of artifacts that are located on the edge and in the bottom of the drainage. Several locations with higher artifact density were observed and five partial bifaces were found in close proximity to each other in one of these concentrations. Ten $\mathrm{cm}$ or more of deposition is present in some areas and buried cultural material may occur. Over 350 lithic artifacts are estimated for the site but no diagnostic artifacts or features were noted at the time of the visit.

The lithic analysis showed use of quartzite, chert, and basalt material. Tertiary quartzite flakes constitute the majority, followed by quartzite secondary and primary flakes. Quartzite and chert shatter and cores were present. A quartzite uniface was noted. Considering its size, number $c i$ artifacts, types of material, and likelihood of subsurface deposits, 5 LA6878 may be eligible for nomination to National Register of Historic Places. Additional investigation needs to be completed to learn if there are any areas with intact subsurface deposits.

\section{LA6879:}

Approximately 30 tested chert cobbles within a 60 by $35 \mathrm{~m}$ area suggest lithic procurement was the primary activity at this site. It is situated on the south-facing slope of a tributary to Welsh Canyon. Vegetation at the site consists of juniper, pinon, cholla, and mountain mahogany predominately. The soil consists of a light brown sandy loam approximately $10 \mathrm{~cm}$ deep.

A random sample analysis of the lithic material indicates chert and quartzite flakes primary and tertiary flakes and a larger portion of chert shatter. No tools or diagnostic artifacts were found but the site was apparently used by an unknown prehistoric culture to obtain raw materials for further reduction away from the site.

A fragment of fossilized bone was collected at this site. The unidentified fossilized bone measures $35 \mathrm{~mm}$ by $25 \mathrm{~mm}$ by $20 \mathrm{~mm}$ and assigned paleontology \# 5 .

\section{LA6880:}

This lithic scatter measures $85 \mathrm{~m}$ east-west by $50 \mathrm{~m}$ north- south where it is situated on a terrace in the bottom of Welsh Canyon. It covers 1.26 acres. Soils are composed of light brown silty sands. There has been light disturbance at the site from natural erosional forces.

The site consists of a moderate density of lithic artifacts scattered on a small terrace in the bottom of Welsh Canyon. A chalcedony projectile point base that appears to represent a corner-notched Archaic artifact was found on the site. A biface fragment made of the same material was also seen at the site. The remainder of the assemblage consisted of over 50 lithic artifacts, many of which are tertiary quartzite flakes. Other quartzite and chert flakes were observed in about equal numbers. Quartzite and chert shatter was also noted. The site does not have evidence of fire features and even though there may be some buried deposits, it is not a high priority site. 


\section{LA6881:}

This lithic scatter at $5320 \mathrm{ft}$ is located near the edge of a ridge overlooking a tributary on the east side of Welsh Canyon. It measures $50 \mathrm{~m}$ north-south by $30 \mathrm{ft}$ eastwest. Juniper, grasses, prickly pear, yucca, and cholla are the predominant vegetation at the site. The soil is brown silty sand up to $30 \mathrm{~cm}$ deep. The site is relatively undisturbed, but the artifacts appear weathered and may have been transported down slope by erosion.

The cultural assemblage consists of a lithic scatter; there are 26 artifacts in all. The flakes are made of brown quartzite exclusively and they are in all stages of reduction. One biface was noted, along with one pressure flake, and a piece of shatter. No diagnostic material or features were noted. This was a tool-making site used for a brief period of time in prehistory. The research potential at 5LA6881 limited, and is exhausted by the recording process.

\section{LA6882:}

This small lithic scatter covers approximately $385 \mathrm{sq} . \mathrm{m}$ and is located on a nearly flat, west facing slope of a terrace overlooking Welsh Canyon. A two-track road bisects the site

Soils at this location are light brown and silty sand in a pinon-juniper vegetative community. Within the site juniper predominates, with an under story of cholla, yucca, prickly pear and range grasses.

The site consists of a small scatter of lithics that appear to have been exposed by a blade cut for the two-track road. Flakes were observed only in the disturbed fill of the road, and the remainder of the site could have up to $20 \mathrm{~cm}$ of deposition. Although only surface material was observed, the artifacts at the site are weathered and the road has impacted some. A total of eight flakes were analyzed in the field. One of the eight flakes is a secondary basalt flake and the remainder is quartzite.

\section{LA6883:}

This site represents a dense lithic scatter that measures $30 \mathrm{~m}$ north-south by $16 \mathrm{~m}$ east-west. It is located on a bench above an un-named tributary east of Welsh Canyon at $5050 \mathrm{ft}$. elevation in a pinon-juniper setting. Soils are about $30 \mathrm{~cm}$ deep and are light brown, silty and sandy.

The site consists of a high-density artifact scatter that occurs immediately next to an isolated sandstone outcrop, but no other modifications were noted on the outcrop. The top of the outcrop provides an excellent view of the surrounding area and Welsh Canyon to the west. Over 100 artifacts occur on the ground surface of the site. The site has undergone only light disturbances by wind and water erosion, but the artifacts show weathering and they may have been transported by natural processes. No diagnostic pieces were located and no collections were made. Due to the extent of up to $30 \mathrm{~cm}$ of 
possible culture deposits, subsurface material can be expected. Exploratory test excavations may be in order for this site.

\section{LA6884:}

The site is a 0.58 acre lithic scatter measuring $55 \mathrm{~m}$ north-south by $57 \mathrm{~m}$ east-west. It is situated on a low terrace approximately $1200 \mathrm{ft}$ west of an un-named tributary that leads to Welsh Canyon. It is near the bottom of the drainage in a pinon-juniper vegetative zone. Juniper, yucca, native grasses, and cholla predominate at the site. Soils contain sandy loams, and are estimated at about $20 \mathrm{~cm}$ depth. From the surface, the site appears to be undisturbed.

The cultural assemblage consists of 16 chert and quartzite flakes; 4 pieces of chert shatter; a quartzite core; and a chert core fragment. A small chert projectile point was collected and returned to the lab for further analysis. The flakes were in primary, secondary, and tertiary stages of reduction. Many of the artifacts are resting on exposed sandstone bedrock and little deposition is present in the site area. Small chert nodules are scattered throughout this area and this material was utilized for tool manufacture. A small water catchment that contained water when the site was visited is present in the drainage below the site. A shallow rock shelter with no evidence for habitation is present on the cliff on the eastern site boundary.

The collected projectile point is made of mottled grey and white chert, in poor condition. It is missing the distal portion of the tip, and both lateral portions of the base. The remaining portion of the base has a straight bottom. The sides of the body are slightly convex. It measures $1 \mathrm{~cm}$ at its widest point, which is at the shoulder. It is $2 \mathrm{~mm}$ thick. Without the tip the projectile point measures $19 \mathrm{~mm}$ in length.

\section{LA6885:}

This lithic scatter measures $45 \mathrm{~m}$ east-west by $40 \mathrm{~m}$ north-south for a total of 1800 sq. $m$; it is at $4960 \mathrm{ft}$ elevation in a mixed pinon-juniper grassland. The soils are reddish brown clays that have a depth of about $10 \mathrm{~cm}$ deep at the datum. The site does not exhibit many disturbances.

The site is located on the top and sides of a small ridge in Welsh Canyon. One hundred or more chert nodules were observed at the site that range in color from light reddish brown to light purple with a very small number of light green fragments. Some of the material is highly vitreous, but all the nodules are irregular and have numerous inclusions and flaws. Most of the chert consists of angular fragments and many are broken through non-cultural activities but there are chert flakes that are clearly reduced in tool manufacture with platforms and scarring on the dorsal surfaces. A sample of chert nodules was collected. Material that appears to have derived from this source was observed at other in the area. 
No diagnostic tools or features were noted. 5LA6885 was a lithic material procurement site used by an unidentified prehistoric population. This site could yield information important to research on lithic material site locations and material culture technology but with the absence of fire features and the lack of diagnostic tools, it is not a good candidate for additional research.

\section{LA6886:}

The site is a small relatively dense scatter of lithic artifacts that measures $20 \mathrm{~m}$ east-west by $15 \mathrm{~m}$ north-south. It is located at $4920 \mathrm{ft}$ elevation at the edge of a small bench in Welsh Canyon. Vegetation on the site is juniper, cholla, yucca, prickly pear, and mountain mahogany. The soils consist of $15 \mathrm{~cm}$ of light brown sandy loams. A small drainage lies near the drainage may have caused some erosion, but generally the site is undisturbed.

Two utilized quartzite flakes and a small sandstone mano fragment were observed at the site. This scatter is located to the northeast of 5LA6885, a lithic procurement site and chert from that source appears to be present on this site. At least $20 \mathrm{~cm}$ of deposition exists in the site area, which may indicate presence of buried deposits. Other artifacts present include quartzite flakes and shatter, and chert flakes, cores, and shatter. The majority of both quartzite and chert flakes are tertiary and secondary types. This could indicate tools are being manufactured here after primary reduction has already taken place elsewhere. This site is probably a tool manufacturing location with a habitation site as well, however, no features or diagnostic items were observed on the surface.

The likelihood of subsurface deposits is strong at this site and testing is recommended to determine its research potential.

\section{LA6887:}

This site is a lithic procurement site near 5 LA6885, which is also a source of chert nodules. The material is eroding out of limestone deposits on the edge of a small side drainage to Welsh canyon. Site 5LA6887 measures $46 \mathrm{~m}$ north-south by $27 \mathrm{~m}$ east west. It is located on a terrace at $4980 \mathrm{ft}$ elevation, between two drainages that are to the north and on the south of the site. Both drainages empty into Welsh Canyon. The vegetation on the site includes juniper, cholla, yucca, mountain mahogany, and pinon. Soils are dark brown loams. The site has not been disturbed.

The chert material in the form of nodules found at this site is very similar in appearance to that found at 5LA6885, except that no light purple was observed. Most of the chert at this source is mottled reddish brown in color. Some of the material is highly vitreous, but all of it is irregular and has numerous inclusions and flaws. Most of the chert material consists of angular fragments. A representative sample was collected.

Over 50 pieces of cultural material was observed on the ground surface and a representative analyzed sample showed most of it was chert shatter, but flaked chert was 
present in primary, secondary, and tertiary stages of reduction. Some chert cores were also noted. This is a lithic procurement and tool-manufacturing site.

Although it is important to learn the sources of these raw materials there is little else that can be done at this site. It lacks fire features and diagnostic artifacts.

\section{LA6888:}

This lithic procurement site is located on a terrace in the bottom of an unnamed tributary of Welsh Canyon. It measures $75 \mathrm{~m}$ northeast-southwest by $55 \mathrm{~m}$ northwest by southeast and covers 1.02 acres. Its elevation is $4900 \mathrm{ft}$. The $30 \mathrm{~cm}$ deep soil is light brown silty sand with a good mix of pebbles. Juniper, yucca, grasses and prickly pear are the main plants on the site.

This site is located at one of a series of limestone outcrops containing chert nodules that occurs on small ridges in Welsh Canyon. This chert source contains more whiter and light green nodules than nearby chert outcrops, but all these sources have a roughly similar range of variation in appearance. A chert sample was collected. Most of the material at the site consists of shattered nodules, but some breakage appears to have resulted from cultural activities. Unmistakable flakes have been produced and remain at the site. Isolated chert fragments are scattered in the deposits between 5LA6885, 5LA6887, and 5LA6889. A single quartzite flake was also noted on 5LA6889.

This is a good example of the chert procurement sites found in Welsh Canyon. It could yield information, especially concerning lithic source locations and production technology. .

\section{LA6889: (Red Rocks)}

This is a scatter of cultural material found near a spring in the bottom of Red Rocks Canyon. It covers about 1.5 acres at an elevation of $4880 \mathrm{ft}$. Juniper bushes, cholla, and grasses are found at the site. Thirty $\mathrm{cm}$ of brown silty sand and red sand with pebbles was located at the datum just west of the site center. There has been slight disturbance from erosion that has also weathered the artifacts. Water has transported some of the artifacts down slope somewhat. The site is located next to a small spring that was flowing when the site was visited.

The site consists of a relatively dense scatter of cultural material on a small terrace. A small biface fragment was collected that is probably a projectile point preform. Two unusual manos with ground edges were noted at the site. One of these was collected because of its unusual double-beveled edges on both long axes of the tool. A small number of historic artifacts included glass, rim-fire cartridge, and metal artifacts are scattered on the site. No other diagnostic or features were observed.

Over fifty artifacts were estimated at 5LA6889. Analysis of a representative sample of 36 separate pieces showed use of quartzite, chert, and chalcedony lithic material. The 
two manos are of basalt and quartzite. A majority of the flaked material is quartzite in the tertiary stage of reduction. Quartzite shatter and a core were also observed. Estimated depth of deposition at the site is at least one meter, or more. This multiple component site served as a prehistoric habitation, tool manufacture, and food processing site. A historical component is not temporally defined, but is probably related to ranching activities in the area because the Red Rocks Ranch is nearby.

This site is eligible for nomination to the National Register of Historic Places under criterion D. Testing of the site for excavation potential is recommended.

\section{LA6934:}

This site consists of a very dispersed and sparse scatter of cultural material. Very little deposition appears to be present and the majority of the cultural material occurs in exposed sandstone bedrock. Small nodules of chert occurring in mottled white, light green and red are scattered throughout the site area. Some of the larger fragments of this material have been worked. A small fragment of a water-worn quartzite cobble that appears to have been part of a mano was noted. It is located high up one of the main side canyons to Welsh Canyon in an area of juniper and mixed grasses.

This site could probably yield very little research information due to little or no deposition that would hold buried deposits. The data potential has been exhausted by the recording process.

\section{LA6935:}

This lithic procurement site is one located in a series of limestone outcrops containing chert nodules. The outcrops occur on ridges along the edge of a bench on the side of Welsh Canyon near its mouth. This small site measures $27 \mathrm{~m}$ by $12 \mathrm{~m}$ and it is found at an elevation of $5000 \mathrm{ft}$. The plant community is pinon-juniper and the soils are light brown silty sands.

The chert found at this source is very low-grade material. It is reddish brown to tan with some grey and light purple in color. A sample was collected for analysis. A representative sample was analyzed and found to contain cores, shatter, primary, and secondary flakes. Isolated chert nodules are scattered in the deposits between the series of chert sources in this region of the canyon. Sites 5LA6885, 5LA6887, 5LA6888, 5LA6935, and 5LA6936 have the highest densities of chert in the area.

The site is a good example of the chert procurement sites found in Welsh Canyon. Unfortunately there is little more that can be learned from it without fire features or diagnostic artifacts. 


\section{LA6936:}

This lithic procurement site is another located the series of limestone outcrops that contain cryptocrystalline silicates. These outcrops occur on ridges along the north east edge of Welsh Canyon near its mouth. This small site measures 75 m east-west by $45 \mathrm{~m}$ north-south. It is at an elevation of $4890 \mathrm{ft}$. The main soil is reddish light brown silty sand.

Small fragments of chert are scattered throughout most of the west side of the canyon in the area of these chert sources. Some of the ones at 5LA6936 are highly vitreous, but all the material has numerous inclusion and flaws. A sample of the chert was collected. A quartzite flake with edge retouch was observed at this site. The chert at all of the sources consists largely of shattered fragments, which may be the result of cultural activities.

This is a good example of the chert procurement sites found in Welsh Canyon. It could yield a great deal of research information, especially concerning lithic source locations and production technology but the absence of fire features and diagnostic artifacts make it a poor candidate for additional work. With new methods for sourcing lithic raw materials, this area should be included.

\section{LA6937:}

The site consists of a cultural material scatter located on a south trending slope between two drainages. Site dimensions measure $55 \mathrm{~m}$ east to west and $20 \mathrm{~m}$ north to south. The soil character is a slightly silty reddish-brown sand that erodes by alluvial, residual and colluvial forces. Vegetation on the site includes juniper, bunch grass, prickly pear, yucca and cholla. Located in a pinon-juniper desert scrub environment.

Rock shelters under the rim to the north produced no cultural material. However, the artifacts, located below the rock shelters, seem to be eroding out from under fill that has been deposited from upslope. A concentration of fire cracked rock (FCR), measures about $.75 \mathrm{~m}$ in diameter and is located about $10 \mathrm{~cm}$ below the surface. The FCR, accompanying flakes and a mano fragment are eroding from the bank along the drainage to the east. Deposition on the highest point of the site is about $60 \mathrm{~cm}$.

A sample of lithic material, approximately $50 \%$ of the total surface quantity, was noted to contain quartzite material in primary, secondary and tertiary production stages. One of the primary quartzite flakes has edge wear. Chert material in primary and tertiary stages of production was also identified.

\section{LA6938:}

The site consists of three rock shelters and an accompanying lithic and cultural material scatter. The scatter extends from the bench below the rock shelters down the slope into Welsh Canyon. The site is located on red sandstone bedrock, finely eroded by wind and water. Vegetation on the site includes pinon, juniper, cholla and mountain mahogany. 
A large corner notched projectile point was recovered at the site and at least 6 manos were noted. Heat cracked stones, charred earth, and other evidence of fires suggest a good possibility for recovering charcoal at this site. One of the rock shelters has a potential wall in front of it that measures about $3.6 \mathrm{~m}$ in length.

The presence of patterned artifacts and fire features, plus the potential for excavation make this an important site. It is recommended for test excavation.

\section{LA6939:}

The site is a rock shelter and lithic scatter located in an ancient sand dune bed at the bottom of Welsh Canyon. The site dimensions are $60 \mathrm{~m}$ north-south and $20 \mathrm{~m}$ eastwest and it is at an elevation of $1414 \mathrm{~m}$. Vegetation includes juniper, grasses, cholla and pinon in a residual and colluvial depositional environment.

The rock shelters consist of three rock overhangs that are located to the north of the site but no evidence for human use has been found in the area. A total of 18 lithics were observed at the site, mainly tertiary flakes, of a variety of materials that include quartzite, chalcedony, and chert. However, substantial buried deposits may be present. A flake was found $70 \mathrm{~cm}$ below the ground surface in the drainage on the edge of the site, along a small terrace that consists of at least $3 \mathrm{~m}$ of deposition. This site is a potential candidate for additional research. In the original assessment of this site, it was not recommended for further work, but the deeply buried cultural remains should be investigated to learn if they represent an intact cultural horizon. If so, test excavations should be undertaken into the terrace to learn the extent and nature of the cultural remains.

\section{LA6940:}

The site consists of a rock shelter with a small lithic scatter in its vicinity. Junipers are growing in front of the shelter and the surface visibility is poor on the slope in front of the shelter. A pin flag was used to test the deposits in the shelter and at least $50 \mathrm{~cm}$ of deposition is present. The site measures $30 \mathrm{~m}$ north-south and $30 \mathrm{~m}$ east-west at an elevation of $1463 \mathrm{~m}$. The site is at the base of a small cliff and there is a small bench in front of the shelter with Welsh Canyon directly below. Vegetation includes juniper, cottonwood, and various grasses in a canyon bottom riparian setting.

A total of 6 artifacts were observed at the site - 5 quartzite and 1 chert flakes in various stages of reduction. Activities inferred from the site include habitation and tool manufacture. The dense vegetation and grasses around the rock shelter prohibited intensive investigation of the area. Presumably more lithics are present.

This site is a good candidate for additional research. Test excavations would probably reveal intact subsurface cultural levels that can be dated. It should be protected and preserved. 


\section{LA6941:}

The site is a lithic scatter with an associated rock shelter located in an ancient sand dune area at the bottom of Welsh Canyon. The rock shelter lacks a good overhang and it appears devoid of artifacts but there is a large lithic scatter surrounding it. Site dimensions measure $35 \mathrm{~m}$ by $60 \mathrm{~m}$; it is at an elevation of $1434 \mathrm{~m}$. Vegetation includes juniper, grasses, prickly pear and cholla and the soils are reddish brown silty sands.

Artifacts at the site include primary, secondary and tertiary flakes and one mano fragment. Lithic material is predominately quartzite but a small number of chert primary flakes were also identified. That the material occurs in many stages of reduction, including tested cobbles, suggests that this site was a lithic reduction area.

\section{LA6942:}

The site is located on a south-facing terrace slope that descends onto the floor of Welsh Canyon. It is composed of a 55 by $20 \mathrm{~m}$ lithic and cultural material scatter found between two small drainages. Rock shelters occur under the rim rock to the north. These shelters produced no cultural material, but artifacts seem to be eroding from fill in these areas that is eroding down slope.

Dominant vegetation found on the site includes juniper, bunch grasses prickly pear, yucca and cholla. Soils average about $50 \mathrm{~cm}$ deep and are slight silty, reddish-brown sands.

A concentration of fire-cracked rock, an accompanying stain, flakes and a mano fragment are eroding from the cut bank along the drainage to the east. This occurrence, identified as Feature 1 on the site map, is about $10 \mathrm{~cm}$ under the surface and measures about $75 \mathrm{~cm}$ in diameter. Deposition on the highest part of the site is about $60 \mathrm{~cm}$ deep. Subsurface material is highly likely.

There is an excellent potential that the site will yield information important to the prehistoric record. Therefore it is considered eligible for inclusion in the National Record of Historic Places. Testing should be considered to learn the integrity of the subsurface remains at the site.

\section{LA6943:}

The site contains a rock shelter with an accompanying lithic scatter located on the first bench above the bottom of Welsh Canyon. Juniper, yucca, and prickly pear are the dominant vegetation in reddish brown loamy soils. Some of the artifacts are on the exposed bedrock but others are in areas of deposition including those in the rock shelter, which may be buried as deep as $50 \mathrm{~cm}$.

The artifacts include a variety of flakes in several material types and all stages of manufacture. No diagnostic artifacts were recovered, but they are likely in the deposits. 
Mano fragments attest to grinding activities at the site. Darker, ashy soil suggests fire features at this site.

The site has considerable potential for recovery of intact cultural materials that are in levels that can be assigned an age. It is worthy of preservation, protection, and test excavation.

\section{LA6944:}

The site consists of two rock shelters located on opposite sides of an isolated sandstone outcrop and an associated lithic scatter. Site dimensions measure approximately 90 meters north to south and 55 meters east to west. The site extends down a slope to a small terrace above a tributary drainage in Welsh Canyon. Soils reddishbrown silty sands with a depth of approximately 20 centimeters. Vegetation includes juniper, native grasses, yucca, prickly pear, and pinon in a pinon-juniper desert scrub environment.

Shelter 1 has a west facing aspect with 15 centimeters of deposition. It measures 2.5 meters in height and 2 meters in depth. A small lithic scatter is present below the rock shelter. These lithics are concentrated around several boulders that may have been used as a windbreak. Shelter 1 has a semicircular wall with two vertical slabs that encloses the space below the rock overhang.

Shelter 2 faces north and has over 40 centimeters of deposition. This shelter measures approximately 4 meters in height and 2 meters in depth. Lithics are scattered on the slope below shelter 2 and were also observed on a sandstone bench to the east of shelter 2.

Two small rock overhangs that lack evidence for habitation are present in the rock above the lithics on the sandstone bench. Shelter 1 and 2 were included as a single site because surface lithics were observed on top of the ridge that separates the two rock shelters suggesting a common use and the rock shelters are located in close proximity of each other. Some historic drift fence is found between the sandstone outcrop of shelters 1 and 2 and the main part of the ridge. The rock wall is constructed of sandstone and measures $4.7 \mathrm{~m}$ in length by $3.2 \mathrm{~m}$ in width and $0.5 \mathrm{~m}$ in height.

A representative sample of artifacts identified at the site indicates a variety of quartzite and chert. The materials were found in various stages of production: primary, secondary, tertiary flakes, as well as many cores and shatter. A small crude biface that appears to be a projectile point preform of white chert material was also identified. The biface appears to have been discarded, however, due to step fracturing and not completed as a formal tool. Six manos of tan and grey quartzite were noted. Three con-joinable fragments of sandstone that appear to be part of a metate were also found at the site. 
The site exhibits moderate disturbance by wind erosion, water erosion, and animal activity. It has not been vandalized. Because of the quantity of materials available for research and considering the depth of deposit in the shelters, this site is recommended for test excavations.

\section{LA6945:}

The site consists of a cultural material scatter approximately 30 meters by 35 meters. It is located below the rim rock on a slope overlooking a small drainage in Welsh Canyon. The slope consists of slightly silty light brown sand that erodes from residual and colluvial deposition. Vegetation consists of juniper, yucca, bunch grasses and cholla located in a desert scrub environment.

A highly concentrated scatter of artifacts occurs on a small bench. Total quantity of artifacts observed at the site (34) consists of a variety of quartzites, cherts, and one milky white chalcedony. The materials express varying levels of production: primary, secondary and tertiary flakes as well as some shatter. Two mano fragments of tan quartzite were found at the site. The artifacts predominately occur in a roughly $8 \mathrm{~m} \times 8 \mathrm{~m}$ area.

\section{LA6946:}

The site consists of a cultural material scatter 19 meters east to west and 38 meters north to south. Located on a south-southwest trending finger terrace, the site slopes down at a 5 degree slope toward Welsh Canyon. The soil is made of reddish brown sand and erodes by both residual and colluvial deposition. The maximum depth of soil deposition measures 20 centimeters. Vegetation on the site includes juniper, prickly pear, bunch grasses, and cholla.

Over 100 lithics were noted at the site. A representative sample shows that white and pink quartzite tertiary flakes comprised most of the detritus. However, tan and purple quartzite in both the primary and secondary stages of production were observed as well. The tip of a biface (possibly a projectile point fragment) was found but not collected.

\section{LA6947:}

The site is located on a south-southwest trending terrace that slopes gently toward Welsh Canyon. The site consists of a lithic scatter downslope and a possible hearth in an area $17 \mathrm{~m}$ by $65 \mathrm{~m}$. Soil on the site has a depth of 25 centimeters that includes residual and colluvial deposition. Vegetation includes juniper, bunch grasses, prickly pear, and cholla.

A grab sample of lithic flakes observed indicates that lithic reduction may have taken place at this site. Chert, white quartzite, and dark grey quartzite materials were identified. Primary and tertiary flakes were found in these materials. Also, one white chalcedony flake in the tertiary stage of production and one chert core were located. A small cluster of fire cracked rock found indicates the possibility of a hearth on the site. 
Sandstone material measuring 0.50 meters by 0.50 meters is located in the lower portion of the site boundary.

\section{LA6948:}

The site consists of a circular series of rocks with site dimensions of $5 \mathrm{~m} \times 5 \mathrm{~m}$. The stacked rock structure is located on top of an isolated sandstone outcrop above a small terrace adjacent to the bottom of Welsh Canyon. Vegetation on the site includes juniper and native grasses. Soil depth measures 10 centimeters within the feature. Animal activity, wind and water have heavily disturbed the site.

The site is located immediately north of cultural material scatter 5LA6783 and the two sites may be associated. A single quartzite flake that was within the rock structure was the only artifact observed on top of the outcrop. Roughly 10 stones are scattered in the area of the structure. These stones may be displaced from the structure.

\section{LA6949:}

The site consists of a sparse lithic scatter that measures 24 meters east to west and 30 meters north and south. The site rests on the gentle slope of a large terrace overlooking the east bank of Welsh Canyon. Light brown silty sand makes up the terrain that has been deposited by aeolian, residual, and colluvial forces. Wind and water erosion has moderately disturbed the site. Vegetation on the site consists of juniper, prickly pear, native grasses, yucca, and cholla with the surrounding association of pinon-juniper desert scrub. Soil depth at the site measures 30 centimeters. No cultural features were noted on the surface associated with the artifacts.

The total quantity of artifacts at the site equals twenty-five. Grey chert comprises 16 of the lithic flakes. Secondary and tertiary flakes were found and one utilized flake was identified. The other artifacts were flaked from grey quartzite. Both secondary and tertiary flakes were found.

\section{LA6950:}

The site is a small lithic scatter 40 meters east to west and 40 meters north to south. The site setting slopes off the north side of a tributary and is located between a main drainage and a smaller side drainage. Elevation of the site measures 1,463 meters. Soil at the site consists of a reddish-brown silty loam that measures $30 \mathrm{~cm}$ in depth. Because the site is located on a slope between two drainages, a high amount of alluvial deposition has taken place and this may have buried some of the artifacts associated with the site. Vegetation on the site includes juniper, grasses, rhus trilobata, yucca, and prickly pear.

A sample of artifacts was observed. Dark grey quartzite primary, secondary, and tertiary flakes and one quartzite core were observed as well as one flake of white quartzite. Also, one chert core and tertiary chert flakes were identified. 


\section{LA6951:}

The lithic scatter consists of a relatively dense number of artifacts located on a southern trending slope that erodes into Welsh Canyon. The site measures 45 meters north to south, and 18 meters east to west. A concentration of artifacts occurs 6 meters northwest of the datum, additional artifacts are scattered downslope. Vegetation is dominated by juniper; however, bunch grass, sage, prickly pear, and cholla appear within the site boundaries at an elevation of 1,408 meters. Soil depth at datum measures $10 \mathrm{~cm}$. The soil is a reddish brown silty sand with a surrounding environment that displays both residual and colluvial deposition.

Over 45 artifacts were located at the site. A representative sample suggests an unusually high proportion of fine-grained quartzite tertiary flakes. Quartzite flakes in other various stages of production were observed as well as secondary and tertiary chert flakes. Also, a material believed to be tan siltstone was identified. This artifact fragment was ground and shaped, possibly into a pendant.

\section{LA6952:}

The site consists of a relatively dense scatter of cultural material on a slope along a side drainage of Welsh Canyon. The location is directly above a terrace that exists along the drainage. A light, reddish-brown silty sand covers the ground at an elevation of 1,448 meters. The site measures 20 meters north and south and 15 meters east and west. With a total area of 300 meters and a total quantity of artifacts numbering 16 the site is rather small. However, the site is one of a series of similar lithic scatters along the north side of this drainage off Welsh Canyon. Isolated flakes are scattered throughout the north side of the drainage between these sites and the sites, therefore represent a dense concentrations of activity in the overall setting.

Vegetation on the site includes juniper, prickly pear, cholla, native grasses, and sunflowers. The soil depth is approximately $20 \mathrm{~cm}$ at the datum. Because the site is on a slope that leads to a drainage, high colluvial and aeolian deposition exists.

Cultural materials include tan and grey quartzite, grey limestone, and both red and brown chert. Quartzite primary, secondary and tertiary flakes, limestone tertiary flakes, and chert shatter flakes were noted. One shell fragment believed to be freshwater shell was also identified. A mano of tan quartzite and a mano fragment of grey quartzite complete the quantity of artifacts observed.

\section{LA6953:}

The site is a lithic scatter and an adjoining rock overhang that shows signs of habitation. The lithic scatter is positioned between two drainages, bound on the east side by Welsh Canyon and on the south side by a tributary of Welsh Canyon. Most of the lithics occur on sandstone bedrock, but flakes are also present on a small terrace along the drainage bottom. Sandstone bedrock exposed at the surface makes up the foundation of the site, which is approximately 1.98 acres in size. The shelter below the overhang is 
10 meters wide and has a southerly aspect, thereby facing the tributary. A hearth is located in the vicinity of the shelter, which leads to the conclusion that the shelter was used. There are two concentrations of cultural material each approximately 20 meters by 40 meters in diameter. One concentration is located on the terrace directly in front of the shelter. The second concentration is located 70 meters east of the shelter near the intersection of Welsh Canyon and the tributary.

Vegetation is dominated by juniper; however, bunch grass, cholla, as well as prickly pear appear within the site boundaries. Soils are made of red-brown sandstone approximately $30 \mathrm{~cm}$ at the datum. Density of vegetation occurs mainly at the place where the two streams intersect. This area is also heavily eroded with increased water flow.

Over 40 artifacts were observed on the ground surface. Field analysis of a representative sample of artifacts at the site revealed quartzite, chert, and sandstone. Grey and white quartzite was found in primary, secondary, and tertiary stages of production as well as some cores. To a lesser extend red and grey tertiary chert flakes and some shatter was found. Also, near the hearth, at least 50 heat altered sandstone fragments were located. Ashy fill and heat altered stone are scattered down the slope below the rock shelter at the site. 